\title{
Past, Present and Future of Partial Extraction Therapies
}

\author{
PhD Thesis
}

\author{
DR. HOWARD GLUCKMAN \\ SUPERVISOR: PROF. KATALIN NAGY, DDS, PhD \\ UNIVERSITY OF SZEGED, FACULTY OF DENTISTRY, DEPARTMENT OF ORAL \\ SURGERY
}

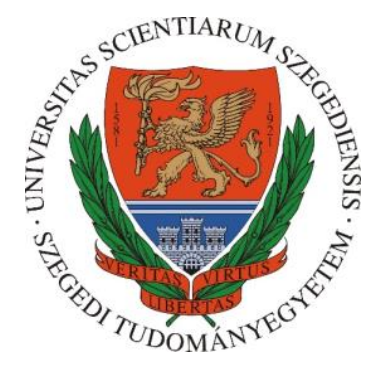

University of Szeged, Hungary 


\section{TABLE OF CONTENTS}

LIST OF PUBLICATIONS PROVIDING THE BASIS OF THE THESIS ….......................................... 4

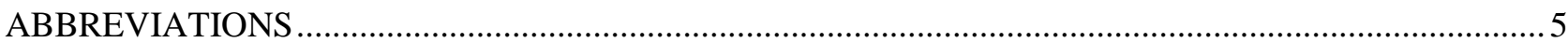

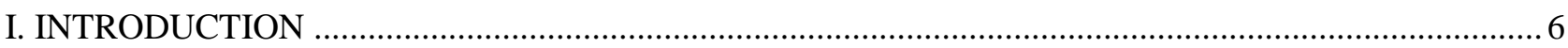

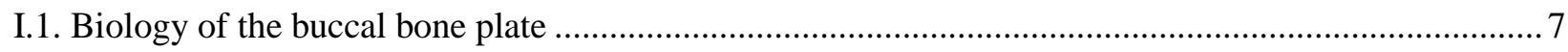

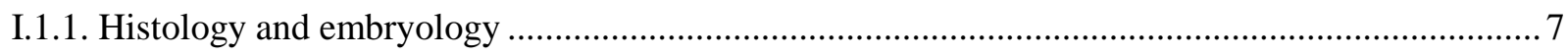

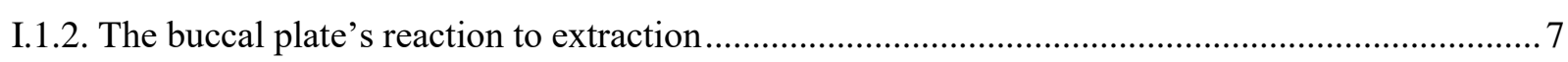

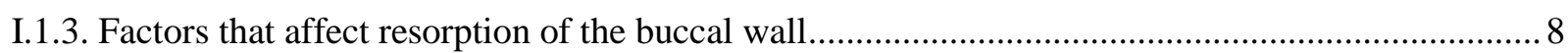

I.2. Problems associated with the collapse of the buccal plate................................................................... 9

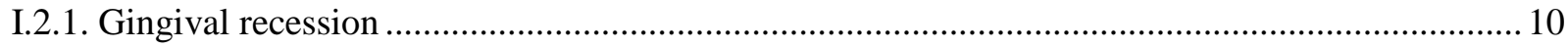

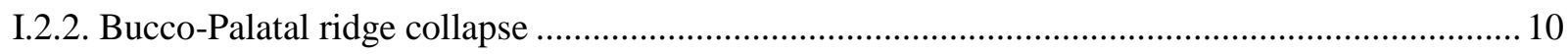

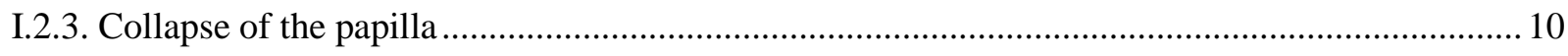

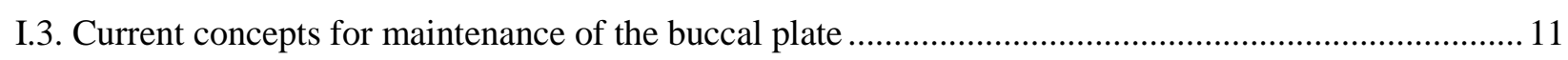

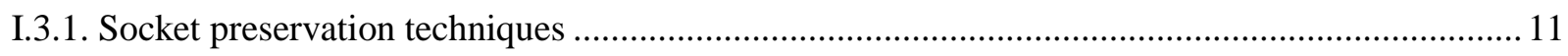

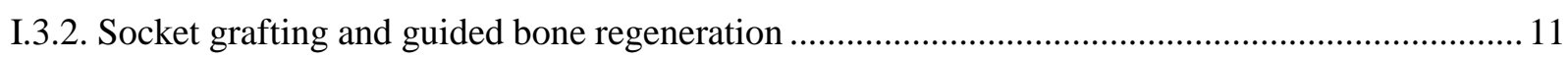

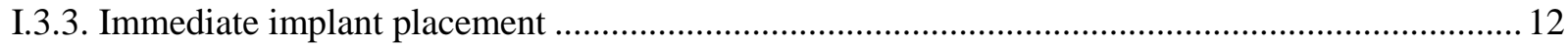

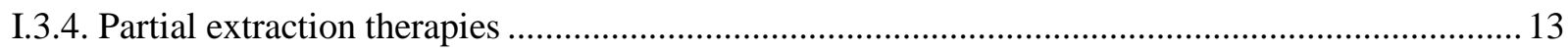

II. STATEMENT OF THE PROBLEM, HYPOTHESIS AND OBJECTIVES …....................................... 14

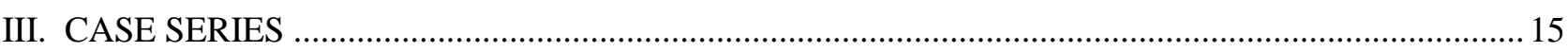

III.1. A retrospective evaluation of 128 socket-shield cases in the esthetic zone and posterior sites: Partial extraction therapy with up to 4 years follow-up. ............................................................................... 15

III.2. The pontic-shield: partial extraction therapy for ridge preservation and pontic site development. ... 18

IV. CASE REPORTS

IV.1. Human Histologic Evidence of New Bone Formation and Osseointegration Between Root Dentin

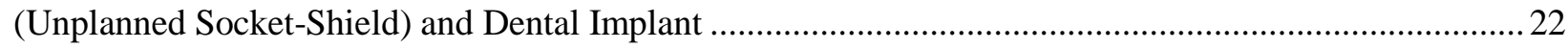

IV.2. The socket-shield technique to support the buccofacial tissues at immediate implant placement.....24

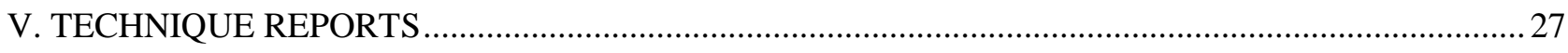

V.1. Prosthetic management of implants placed with the socket-shield technique..................................2 27

V.2. Partial Extraction Therapies (PET) Part 1: Maintaining Alveolar Ridge Contour at Pontic and

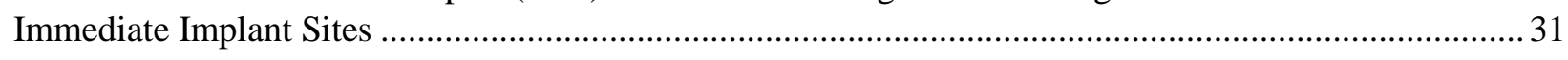

V.3. Partial Extraction Therapies (PET) Part 2: Procedures and Technical Aspects ................................. 34

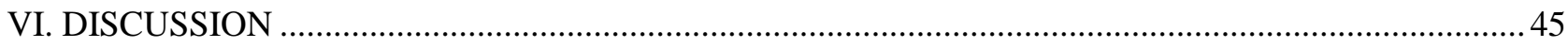

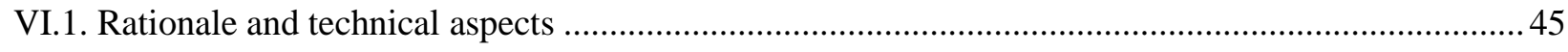

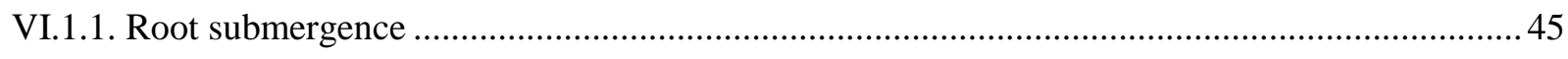

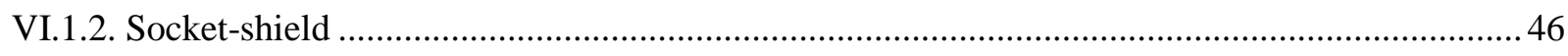

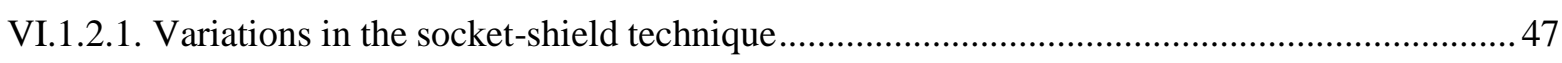

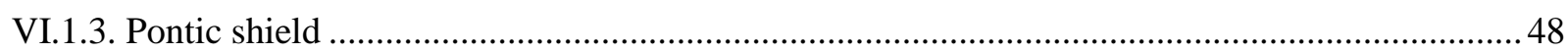

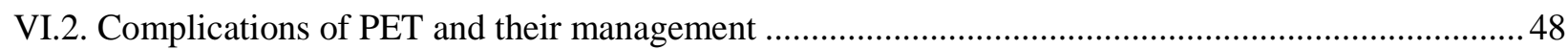


VI.3. Prosthetic considerations 51

VI.4. Perspectives and the future of partial extraction techniques .......................................................52

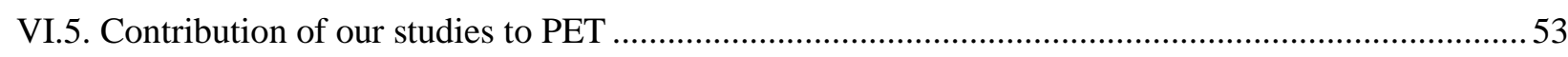

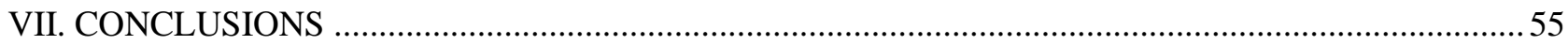

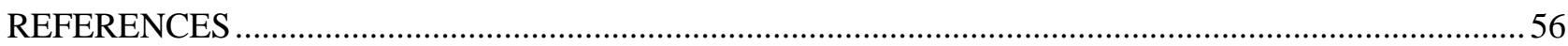

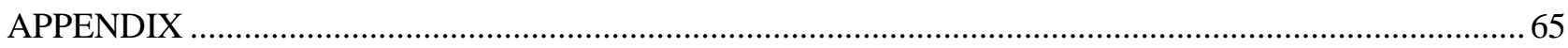




\section{CASE SERIES}

Gluckman H, Salama M, Du Toit J. A retrospective evaluation of 128 socket-shield cases in the esthetic zone and posterior sites: Partial extraction therapy with up to 4 years follow-up. Clin Implant Dent Relat Res. 2018 Apr;20(2):122-129.

Gluckman H, Du Toit J, Salama M. The pontic-shield: partial extraction therapy for ridge preservation and pontic site development. Int J Periodontics Restorative Dent. 2016 MayJun;36(3):417-23.

\section{CASE REPORTS}

Schwimer C, Pette GA, Gluckman H, Salama M, Du Toit J. Human Histologic Evidence of New Bone Formation and Osseointegration Between Root Dentin (Unplanned Socket-Shield) and Dental Implant: Case Report. Int J Oral Maxillofac Implants. 2018 Jan/Feb;33(1):e19e23.

Gluckman H, Du Toit J, Salama M. The socket-shield technique to support the buccofacial tissues at immediate implant placement. International Dentistry African Edition 2015;5(3):614.

\section{TECHNIQUE REPORTS}

Gluckman H, Nagy K, Du Toit J. Prosthetic management of implants placed with the socketshield technique. J Prosthet Dent. 2018 Dec 13.

Gluckman H, Salama M, Du Toit J. Partial Extraction Therapies (PET) Part 1: Maintaining Alveolar Ridge Contour at Pontic and Immediate Implant Sites. Int J Periodontics Restorative Dent. 2016 Sep-Oct;36(5):681-7.

Gluckman H, Salama M, Du Toit J. Partial Extraction Therapies (PET) Part 2: Procedures and Technical Aspects. Int J Periodontics Restorative Dent. 2017 May/Jun;37(3):377-385.

Summed Impact Factor: 17.959

Number of Independent Citations: 13 


\section{ABBREVIATIONS}

CBCT - Cone beam computer tomography

CTG - Connective tissue graft

GBR - Guided bone regeneration

ISQ - Implant Stability Quotient

PET - Partial extraction therapy

PRF - Platelet-rich fibrin

PS - Pontic shield

RCT - Randomized clinical trial

RS - Root submergence

SS - Socket shield 


\section{INTRODUCTION}

Tooth loss has always been a challenge in dentistry due to the physiological alterations that occurs to the bone structure following extraction (1). When replacing missing teeth with implant-supported restorations, the timing of implant placement is crucial to maintain adequate tissue volume and aesthetic results (2). Since most post-extraction dimensional changes take place between 3-6 months, delayed protocols for implant placement result in bucco-palatal collapse of the alveolar bone as well as gingival recession (3).

Immediate implant placement has been a mainstay of treatment for many years and has shown excellent long and medium term survival, comparable with delayed implant placement approaches (4-9). However, despite the advantages of one single surgical procedure, shorter treatment duration and higher patient acceptance, immediate implant placement per se does not counteract the natural bone remodelling process, hence it cannot prevent the collapse of the buccal bone (10-14). In a long-term study with 10 years of follow-up, immediate implants placed in the aesthetic zone with concomitant guided bone regeneration (GBR) presented average reduction of the facial wall of $1.6 \mathrm{~mm} ; 24 \%$ of the implants had a missing facial bone wall (12). Similarly, a study from Cosyn and coworkers (13) reported mid-facial recession above $1 \mathrm{~mm}$ in $47 \%$ of the patients 5 years after immediate implant placement with bone grafting in the anterior maxilla. These complications have led to the relegation of immediate implant placement to specific cases, thus limiting the long-term predictability of this treatment protocol.

Using a conservative approach, partial extraction therapies (PET) have revolutionised Implant Dentistry by preventing post-extraction resorption of the alveolar bone, particularly in cosmetically challenging areas (15). The support for the buccofacial tissues provided by PET has brought a new dimension to immediate implant placement. Since PET promotes maintenance of adequate three dimensional bone volume, the risk for marginal recession and cosmetic complications in general is reduced, thus promoting optimal long-term aesthetic and functional results for immediate implants (16).

This introduction session provides a comprehensive understanding of the principles behind PET before critically reviewing the current state of evidence and their clinical applications. In the following sections, we discuss the biological foundation and background that led to the development of PET, including the biology of the buccal bone, the consequences associated with resorption of the buccal plate and the current available options to deal with this problem. 


\section{I.1. Biology of the buccal bone plate}

\section{I.1.1. Histology and embryology}

The maxilla and the mandible are composed by specific anatomical structures with different embryologic origins, including the basal bone and the alveolar process. The basal bone constitutes the body of both mandible and maxilla. It is formed concomitantly with the skeleton through intramembranous osteogenesis (17).

The alveolar process contains the tooth alveolus, and it is formed by osteoblasts from the dental follicle following tooth eruption (17). In the alveolar process, the bundle bone constitutes the inner socket lining and the bone crest. Its formation occurs concomitantly to the formation of the root and the cementum, as it provides attachment for the periodontal ligament. The bundle bone is considered part of the periodontal structure, as it contains numerous openings to provide attachment for periodontal Sharpey's fibres (sometimes referred to as Cribriform plate), connecting the periodontal ligament to the cancellous bone through neurovascular bundles. Physiologically, the bundle bone is a tooth-dependant structure, composed by compact fibres arranged in thin parallel lamellae (18). Human studies have reported that $90 \%$ of sites in the anterior maxilla present facial wall thickness $\leq$ $1 \mathrm{~mm}$; in almost half of those sites the thickness is $\leq 0.5 \mathrm{~mm}$ (19-24). Thin buccal walls are mainly composed by bundle bone, thus they tend to resorb following removal of the tooth (19).

\section{I.1.2. The buccal plate's reaction to extraction}

The extraction of a tooth sets off a cascade of biological reactions involving soft and hard tissues. Human studies have described the sequence of events that take place following removal of the tooth, initiating with the formation of a blood clot in the socket $(1,20)$. By the first week, granulation tissue slowly replaces the blood clot. Deposition of bone minerals starts from the second week and increases gradually. From 2-4 weeks, granulation tissue containing new vascular structures, erythrocytes and inflammatory cells and a provisional matrix made up of mesenchymal cells, vessels and collagen fibres constitute the majority of the tissues in the socket. After 6-8 weeks, immature woven bone fills the marginal parts of socket, which is gradually replaced by mature bone over a period of approximately 24 weeks (21).

Findings from animal studies showed that disruption of the blood supply from the periodontal ligament to the bundle bone following tooth extraction induces physiological changes, leading to osteoclastic activity and gradual resorption of the buccal bundle bone $(22,23)$. 
Post-extraction dimensional changes in the alveolar process have been reported since the sixties (24, 25). Since then, numerous clinical trials have measured the alveolar bone loss resulting from tooth removal, and the topic has been explored in depth in three systematic reviews $(3,18,26)$. Altogether, findings from these reviews show that the majority of changes occur in the first 3-6 months, and horizontal reduction is more pronounced than the vertical component. Loss of alveolar width ranged from 2.6 to $4.5 \mathrm{~mm}$ (29-63\%), while loss of alveolar height ranged from 0.4 to $3.9 \mathrm{~mm}$ (11-22\%) $(3,18,30)$. In a later clinical study, Chappuis et al. reported median vertical bone loss of $7.5 \mathrm{~mm}$ in sites with thin bone phenotype following tooth extraction (19). Lingual or palatal horizontal bone resorption has been reported to reach $30 \%$, while buccal bone loss was reported as $56 \%$ in the same study (27). Lingual and palatal walls tend to present limited resorption as compared to the buccal wall, probably due to their increased thickness (22).

\section{I.1.3. Factors that affect resorption of the buccal wall}

The rate and extent of buccal bone resorption can be affected by different factors, such as buccal plate thickness, implant position and gingival biotype (28-30). Buccal bone thickness has been linked to alveolar ridge alterations after immediate implant placement $(29,31,32)$. An experimental study in dogs evaluated bone loss after immediate implant placement and reported marked changes in buccal and lingual walls, with greater resorption rate for thin buccal walls (9). Those findings were confirmed in human studies, where thick buccal walls presented less bone resorption after immediate implant placement $(19,29,33)$.

A study from our group revealed that the buccal bone crest was thin $(<1 \mathrm{~mm})$ in $83 \%$ of all anterior maxillary teeth included. At the mid-root point, $92 \%$ of those teeth had thin buccal bone (24). This suggests that the majority of patients who undergo extraction of an anterior tooth is at high risk of having a buccal wall collapse, which can become a challenge when planning implant-supported restorations $(20,21,38)$.

Implant position is another critical factor affecting resorption of the buccal plate. Irrespective of the implant system, optimal 3D positioning in the aesthetic zone is crucial to prevent buccal bone loss $(30,34)$. Higher gingival recession has been observed when non-submerged implants were placed 1 $\mathrm{mm}$ away from the buccal wall, as compared to those that had a $2.3 \mathrm{~mm}$ distance to the buccal bone. In this study, 6 out of 8 implants placed in a more buccal direction presented poor cosmetic results (35). Immediate implants placed more buccally presented three times more gingival recession as compared to those placed in a more lingual. 
In order to decrease the risk of collapse of the buccal wall and consequent aesthetic complications, current recommendations for immediate implants include a more palatal position of the implant and a $2 \mathrm{~mm}$ horizontal gap between the shoulder and the buccal wall $(36,37)$.

Bone loss following tooth removal is also influenced by gingival biotype. Thick gingival tissues present more favourable immune response and wound healing in both periodontal and implant surgeries, due to increased blood supply, collagen and extracellular matrix content $(30,38,39)$ $(35,42,43)$. Thin gingival biotypes present a compromised response to inflammatory and traumatic events, such as tooth extraction, undergoing more pronounced remodelling and bone resorption as compared to thick biotypes $(30,40)$. In an animal model, a flapless implant approach associated with a gingival graft was not able to counteract the increased bone loss in areas with thin buccal plates (41).

A prospective human study assessed the influence of gingival thickness on alveolar bone stability around dental implants. The results indicate that thin gingival biotypes presented buccal bone loss up to $1.45 \mathrm{~mm}$ in the first year, while thick biotypes only lost $0.2 \mathrm{~mm}$ (42). Altogether, there is enough evidence to support thin gingival biotype as a risk factor for buccal bone loss.

\section{I.2. Problems associated with the collapse of the buccal plate}

The long-term functional success of implants is well documented. The current challenge is the longterm aesthetic stability of implant-supported restorations, which depends on the stability of the periimplant soft and hard tissues (43).

Thin buccal plates typically respond to trauma from tooth extraction with extensive physiological changes that can lead to unwanted cosmetic and functional complications (44). During tooth removal, thin buccal walls can crack, further complicating ridge remodelling. Surgical trauma during extraction can increase the risk for ridge deformities, hence atraumatic extraction is crucial to minimize damage to the buccal wall (45). In a clinical study, $45 \%$ of the sites (total of 53 teeth) presented complications at the buccal wall after atraumatic tooth removal, described as partial loss of buccal plate $(4 \%)$, fracture of the buccal plate (9\%), dehiscence $(28 \%)$, and complete loss of the buccal plate (4\%) (46). Thus, surgical trauma can be another risk factor for post-extraction ridge remodelling, even when atraumatic techniques are employed. Even the most well-succeeded atraumatic extractions still result in socket remodelling (19). 


\section{I.2.1. Gingival recession}

Gingival recession is one of the most prevalent aesthetic complications of immediate implants in the anterior areas $(13,30,32,35)$. It has been estimated that $9-41 \%$ of immediate implants develop buccal recession over $1 \mathrm{~mm}$ after 1-3 years (4). In some instances, particularly if the implant is adjacent to natural teeth, buccal bone deficiencies can be concealed by the presence of thick soft periimplant tissues (19). In other situations, in the absence of buccal bone, thin gingival tissues can look grey due to their transparent nature, revealing the underlying metal implant surface. Thin gingival phenotypes that lack the support from the buccal wall are at high risk of developing recession (44). This serious aesthetic complications can compromise the outcomes of an otherwise well-integrated implant, especially in patients with high aesthetic demands (31).

\section{I.2.2. Bucco-Palatal ridge collapse}

A few weeks following tooth extraction, there is a rapid decrease in the height of the buccal wall resulting from the physiological changes in the bundle bone. The resorption process continues in a second phase, where alveolar bone remodelling occurs in the outer surface of the alveolar bone, leading to horizontal and vertical collapse (47). The highest rate of resorption occurs in the first six months post-extraction (two-thirds) and continues throughout life at an average rate of $0.5-1 \%$ per year (17). It has been estimated that the total loss of bone volume of the edentulous ridge can range from $40-60 \%$ over the first $2-3$ years $(48,49)$, with more pronounced collapse in the horizontal direction (29-63\%) as compared to the vertical direction (11-22\%) (26). This irreversible and continuous atrophic process can limit the amount of bone available and change the architecture of the ridge, thus making tooth replacement with implants more challenging (50).

\section{I.2.3. Collapse of the papilla}

There is an interdependence between the interproximal tissues and the architecture of the underlying bone at natural teeth and at implant-supported restorations $(50,51)$. Thus, depth, height and width of peri-implant papillae depends on the presence of buccal and interproximal bone support (52).

The remodelling and resorptive changes that take place in the buccal plate after tooth extraction typically leads to loss of crestal bone in the interproximal area $(22,27,30)$, which can result in decreased papillary height (53). The lack of adequate soft tissue fill in the proximal area is usually perceived as a black triangle below the contact point; it constitutes not only a significant cosmetic 
challenge in the anterior areas, but can also have consequences on speech and food impaction (54). The minimum thickness of the buccal bone around implants has been recommended to be 2-4 $\mathrm{mm}$ in order to prevent gingival recession and crestal bone loss (51, 55). Many techniques have been developed with the aim of regenerating the interdental tissues, however, the unpredictability of the outcomes suggest that prevention is still the best strategy (56).

\section{I.3. Current concepts for maintenance of the buccal plate}

\section{I.3.1. Socket preservation techniques}

Since ridge volume is essential for implant-supported restorations and pontic sites, a lot of effort has been put into limiting post-extraction bone loss through alveolar ridge preservation (57). The rationale behind socket preservation techniques is to stabilize the blood clot, promote bone formation and ultimately prevent the volume loss of the alveolar ridge (58).

Several treatment strategies aimed at maintaining the alveolar bone after tooth extraction have been evaluated, including socket grafting (59-61), augmentation of the buccal wall $(62,63)$ and immediate implant placement (64-67).

\section{I.3.2. Socket grafting and guided bone regeneration}

A multitude of biomaterials have been described in the literature for socket preservation and augmentation, including bioactive agents, bone grafts (alloplasts, allografts and xenografts), resorbable and non-resorbable membranes, autologous bone and blood-derived materials such as platelet-rich fibrin (PRF) (68-70).

The rationale for the use of bone substitutes in fresh sockets is that the graft functions as a scaffold to stabilize the coagulum and stimulate mineralization of the clot (21). Allografts consist of mineralised or demineralised freeze-dried bone (DFDBA or FDBA, respectively) extracted from human donors while xenografts are extracted from other species (71). The most used xenograft is deproteinised bovine bone mineral (DBBM) (72). Alloplasts are inert synthetic grafts, such as hydroxyapatite, calcium sulphate, tricalcium phosphate and glass polymers (73).

The use of barrier membranes was introduced to extraction sockets in order to promote the proliferation of osteoblastic cells through exclusion of fibroblast and epithelial cells, and to create space for bone filling by preventing entrance of soft tissues into the wound, according to the principles of guided tissue regeneration (74). 
It is reported both in the systematic review from Vittorini Ortegas et al (70) and in Vignoletti et al. (75) that ridge preservation techniques present an average loss in horizontal width of 1.83 and 1.99 $\mathrm{mm}$, respectively, when compared with natural socket healing.

In a more recent systematic review, MacBeth and co-workers reported a standardized mean difference between alveolar ridge preservation and natural healing following tooth extraction was $0.7 \mathrm{~mm}$ for vertical bone loss. For horizontal bone loss, there was high variation and the difference between the two protocols was not statistically significant. When different techniques were compared (GBR, socket grafting and socket seal), there was no evidence to indicate which one presents superior results (76).

Thus, despite the fact that socket preservation techniques present better outcomes than natural socket healing, they are not able to prevent ridge collapse nor maintain the three-dimensional volume of the alveolar ridge following tooth extraction, irrespective of technique and material. Due to the limited results, further grafting is often needed, making it a costly and lengthy treatment option $(15,77)$.

\section{I.3.3. Immediate implant placement}

Despite the initial impression that immediate implants could reduce bone resorption (67), experimental $(49,75,78-80)$ and clinical studies $(27,81)$ have not been able to support this hypothesis.

An animal study from Araujo et al. suggested that a large gap ( 2 or more mm) between the buccal bone and the immediate implant has a more positive effect on the maintenance of the buccal wall (22). Those findings were supported by other studies $(33,82)$ demonstrating that placement of implants close to the buccal wall leads to increased bone loss. However, even the presence of an adequate jumping gap does not seem to avoid changes in the buccal plate. Using cone beam computer tomography, two clinical studies reported vertical bone loss in the buccal wall one year after loading of immediate implants $(83,84)$.

The combination of guided-bone regeneration with immediate implants can have beneficial effects. In a randomised clinical trial, immediate implants without grafting presented horizontal loss of $48 \%$ after 4 years, while bone loss for the groups with grafting was $16 \%$ (35).

Even though the understanding of the factors that influence immediate implant placement have evolved over the years, it has been estimated that $9-41 \%$ of all immediate implants develop buccal marginal recession over $1 \mathrm{~mm}$ after 1 to 3 years (85). Albeit immediate implants have the potential 
to provide a suitable treatment solution, they lack the biological support for the preservation of the bucco-facial tissues when not associated with PET.

Although different strategies for ridge preservation and immediate implant placement have decreased the alveolar dimensional changes, none of the above mentioned techniques has been able to predictably prevent resorption of the buccal wall following tooth extraction $(43,86)$.

\section{I.3.4. Partial extraction therapies}

Partial extraction therapies (PET) include a group of interventions that rely on the maintenance of the dental root or part thereof to prevent the collapse of the buccal bone wall, thus facilitating implant therapy. The initial concept for PET was introduced in the 1950s, when root retention was evaluated as an option to preserve ridge volume in edentulous patients (87).

The biological rationale for PET is the maintenance of the root with its periodontal ligament, which provides blood supply to the bundle bone, keeping it vital. Consequently, bone remodelling is minimised, ridge architecture and bone volume are preserved (58). In other words, by keeping at least part of the tooth root, the biological cascade of events that lead to bone remodelling following tooth extraction is not triggered. Thus, PET techniques are aimed primarily at preserving the bundle bone. In order to achieve stable functional and aesthetic results in the anterior area over the long-term, it has been suggested that the buccal plate should have a minimum thickness of $2 \mathrm{~mm}(88)$, which is far from clinical reality, considering that 80 to $90 \%$ of anterior teeth have a buccal plate below $1 \mathrm{~mm}$, as evaluated through CBCT $(19,31,89)$.

In times when the mere survival of an implant is no longer the only treatment goal, but a long-term success in terms of aesthetics, function and healthy hard and soft tissues, minimising irreversible ridge collapse should become an integral part of the treatment plan. Using the patient's own tooth as part of the treatment protocol is a more conservative option, which requires less biomaterials and provides high survival rates (90). The healing time is not extended when PET is used in conjunction with immediate implants and it can be applied to teeth with endodontic and/or apical pathology (16). Hence, PET is a valuable adjunct when dealing with thin buccal walls, thin gingival phenotypes and multiple adjacent implant sites, with potential benefits for immediate, immediate-delayed and delayed implant placement, as well as for traditional restorative approaches at pontic sites (90). The concept of PET includes three different techniques: root submergence, pontic-shield and socketshield (58). Each technique will be discussed in detail in the following chapters. 


\section{STATEMENT OF THE PROBLEM, HYPOTHESIS AND OBJECTIVES}

\section{Statement of the problem}

The buccal bone wall is mainly composed of bundle bone, being a tooth-dependant structure. Following tooth loss, the buccal bone collapses, leading to irreversible horizontal and vertical alveolar bone loss, which usually results in functional and aesthetic complications, including decreased ridge volume, collapse on the interdental papilla and gingival recession. Current available treatment options are not able to prevent alveolar ridge collapse nor recreate the volume of bone lost.

\section{Hypothesis}

The preservation of a natural tooth root or part thereof provides an effective and predictable approach to circumvent post-extraction dimensional changes that result in the resorption of the alveolar bone at immediate implant sites and pontic sites, due to the maintenance of vital bundle bone and periodontal ligament apparatus in the facial aspect of the tooth.

\section{Objectives}

The overall objective of the studies included in this thesis was to provide proof of concept for PETs in terms of clinical application and long-term results, including implant survival, reproducibility, efficacy and safety of this approach through case series, case reports and technique reports. 


\section{CASE SERIES}

\section{III.1. A retrospective evaluation of 128 socket-shield cases in the esthetic zone and posterior sites: Partial extraction therapy with up to 4 years follow-up. ${ }^{1}$}

Tooth loss results in irreversible reduction in the volume and height of the alveolar bone, leading to devastating changes that can compromise implant placement and prosthetic replacement. Ridge preservation techniques have not been able to prevent the dimensional changes resulting from tooth extraction. Retention of part of a natural tooth is a conservative approach, which maintains the vitality of the periodontal ligament attached to the root fragment, limiting the resorption of the bundle bone $(15,58)$.

The objective of this case series was to evaluate the survival of immediate implants placed in conjunction with the socket shield technique in large cohort of patients, who were followed up for 14 years.

\section{Material and Methods}

This retrospective study included patients from a private practice who had been subjected to the socket shield approach concomitant with immediate implant placement.

The inclusion criteria were:

- Previous implant placement with the socket shield technique

- Minimum of 12 months from provisional or definitive restoration

- Clinical exam, periapical radiograph and clinical photograph were the minimum requirements for follow-up

- All treatment failures and complications were included.

The exclusion criteria included implants that did not have a restoration after 12 months and patients who were unable to attend recall session.

Upon recall, all patients signed an informed consent agreeing to participate in the study. The primary outcome variable was implant survival and the secondary outcome variables were implant failure,

\footnotetext{
${ }^{1}$ Gluckman H, Salama M, Du Toit J. A retrospective evaluation of 128 socket-shield cases in the esthetic zone and posterior sites: Partial extraction therapy with up to 4 years follow-up. Clin Implant Dent Relat Res. 2018 Apr;20(2):122-129.
} 
peri-implant mucositis, peri-implantitis and other complications. The data was compiled on Excel files and presented as percentage prevalence.

\section{Results}

In total, 128 patients met the inclusion criteria and were evaluated during a recall session, with maximum follow-up time of 4 years (Figure 1).

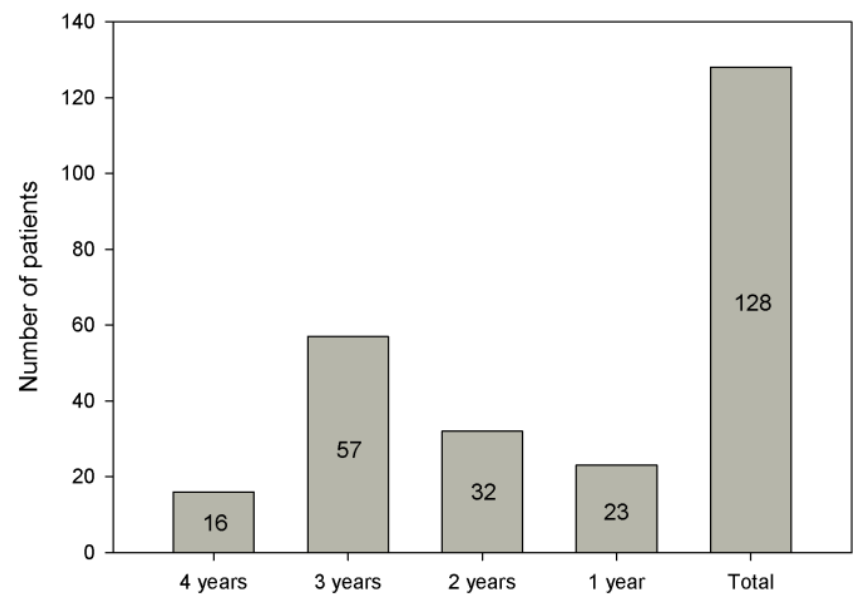

Figure 1. Number of patients followed-up per years of follow-up.

Patient age range was $24-71$, with average age of 39. In relation to gender, 70 implants were placed in females and 58 in males. Regarding location, maxillary incisors were

The most frequent site (64\%), followed by premolars $(22 \%)$ and canines (14\%, Figure 2). The majority of sites were located in the maxilla (89.9\%), with only $10.1 \%$ of sites in the mandible.

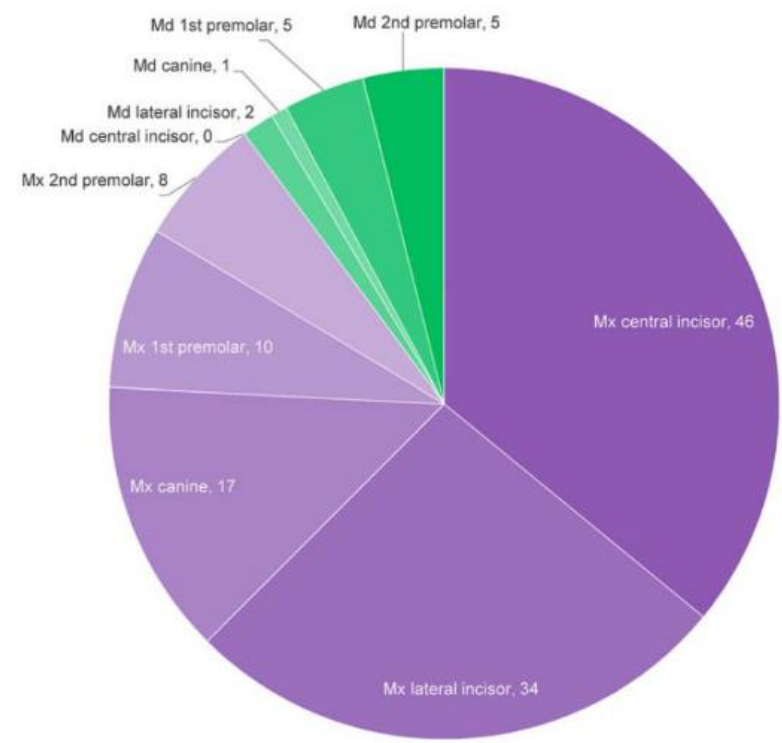

Figure 2. Distribution of socket-shield cases according to site and location. 
In total, $19.5 \%$ sites presented complications ( $\mathrm{n}=25$, Table 1$)$. From those, five implants failed during initial osseointegration and had to be removed and replaced in two cases. In these five early failures, three shields were still intact.

Sixteen socket-shields became exposed, from which twelve were internal (towards the crown) and four were external (facing the oral cavity). Internal exposures were simply followed-up or treated through a reduction of the exposed fragment. The external exposures were treated through reduction of the exposed fragment and in two of the four cases, a connective tissue graft was applied to improve soft tissue healing.

Infection was present in three socket-shields, which were removed. In two of those cases, the implants were also removed. One shield migrated and was kept in place without further complications. From the 128 implants, 123 survived (96.1\% survival rate).

Table 1. List of complications and treatment approach for each. Exp/I: internal exposition; Exp/E: external exposition; Inf: infection; IF: implant failure; Migr: migration.

\begin{tabular}{|c|c|c|c|c|c|c|c|}
\hline Patient & Tooth & $\operatorname{Exp} / \mathbf{I}$ & $\mathbf{E x p} / \mathbf{E}$ & Inf & IF & Migr & Management \\
\hline 1 & 21 & & & & 1 & & SS intact, implant replaced, osseointegrated, restored \\
\hline 2 & 11 & 1 & & & & & SS reduced, soft tissue healed, restored \\
\hline 3 & 21 & 1 & & & & & No treatment, no additional complications \\
\hline 4 & 33 & & 1 & & & & Reduced, CTG, soft tissue healed, restored \\
\hline 5 & 21 & & & 1 & & & SS removed, implant decontaminated, GBR, restored \\
\hline 6 & 13 & & & & 1 & & implant replaced, restored, shield intact \\
\hline 7 & 12,11 & & 2 & & & & SS reduced, soft tissue healed, midfacial recession \\
\hline 8 & 12 & 1 & & & & & SS reduced, restored \\
\hline 9 & 21 & & 1 & & & & SS reduced, CTG, soft tissue healed, restored \\
\hline 10 & 12 & & & 1 & 1 & & $\begin{array}{l}\text { SS \& implant removed, healed, new implant \& GBR, } \\
\text { restored }\end{array}$ \\
\hline 11 & 11 & & & 1 & 1 & & SS \& implant removed, ridge preservation graft, FPD \\
\hline 12 & 21 & 1 & & & & & No treatment, no additional complications \\
\hline 13 & 11 & 1 & & & & & SS reduced, restored \\
\hline 14 & 11 & 1 & & & & & No treatment, no additional complications \\
\hline 15 & 21 & 1 & & & & & No treatment, no additional complications \\
\hline 16 & 21 & 1 & & & & & No treatment, no additional complications \\
\hline 17 & 23 & 1 & & & & & No treatment, no additional complications \\
\hline 18 & 22 & & & & 1 & & Implant removed, RPD \\
\hline 19 & 11,21 & 2 & & & & 1 & No treatment, no additional complications \\
\hline 20 & 34 & 1 & & & & & SS reduced, soft tissue healed, restored \\
\hline Totals & & 12 & 4 & 3 & 5 & 1 & 22 sites in total, 14 managed and 8 monitored \\
\hline
\end{tabular}




\section{Conclusions}

This is the first case series of PET including over 100 patients. The use the patient's own dental structures with the socket-shield technique seem to be effective in terms of implant survival after up to 4 years follow-up. The implant survival and complication rates observed were comparable to conventional immediate and delayed placement. The socket shield is a sensitive technique and controlled clinical trials are required to further explore this approach.

\section{III.2. The pontic-shield: partial extraction therapy for ridge preservation and pontic site development. ${ }^{2}$}

It has been demonstrated that up to $56 \%$ of the alveolar ridge can be resorbed following tooth extraction (22). Partial extraction therapies seem to limit post-extraction dimensional changes in the alveolar bone by maintaining the vitality of the bundle bone and the periodontal ligament (16). Several early studies on root submergence reported preservation of the alveolar ridge under full dentures and fixed prostheses (91). However, this technique is not indicated in the presence of endodontic apical pathology. This study presents a modification of the socket-shield technique, which can be used in the presence of apical infection, called the pontic-shield. This study demonstrates that a modification of the socket-shield technique can successfully develop pontic sites and preserve the ridge.

\section{Material and Methods}

Ten systemically healthy patients in need of implant placement were included in the study, with a total of 14 pontic sites. Smokers and teeth with apical pathology were included as well. The extraction sockets were filled with an augmentation material (xenograft) and sites were left to heal for at least three months, after which an interim fixed partial denture (FPD) was fabricated with moderate pressure at the pontic areas over the following 3 months. The final restorations were placed after the sockets had fully healed with no evidence of shield exposure. Patients were followed-up after 12 and 18 months.

\footnotetext{
${ }^{2}$ Gluckman H, Du Toit J, Salama M. The pontic-shield: partial extraction therapy for ridge preservation and pontic site development. Int J Periodontics Restorative Dent. 2016 May-Jun;36(3):417-23.
} 


\section{The pontic shield technique}

The same clinician performed all the surgical procedures. The first step was the standardized preparation of a socket-shield. The tooth was decoronated under local anaesthesia and the remaining root was sectioned in the mesio-distal direction, using a long shank bur, in order to preserve the buccal half of the root intact. The extraction of the palatal root fragment was performed with care after the insertion of Periotomes and severing of the palatal periodontal ligament (with the apical pathology, if present). The buccal fragment was then reduced to $1 \mathrm{~mm}$ above the alveolar bone and carefully thinned to become concave using a long shank, round, large diamond bur. The apex of the socket was curetted for removal of apical infection. Using a sharp probe, immobility of the shield was confirmed.

The sockets were grafted with a xenograft and closed with a buccal flap advancement (in five sites), with a Zucchelli connective tissue graft (CTG) in two sites, with a cytoplast membrane in one site and using a socket-seal approach in three sites. Initially, three sites were managed without closure.

\section{Results}

Through subjective observation of the occlusal and facial aspects of the pontic sites, ridge preservation was achieved in all 14 cases after 12 and 18 months recall. Complication was observed in one patient, where 3 pontic-shields were exposed due to the lack of adequate soft tissue closure during surgery. These sites were treated with an advanced buccal flap, which led to successful closure and healing. For all other patients, healing was uneventful for the duration of the study (Table 2).

Table 2. Methodology and outcomes for the pontic-shields ( $n=14,10$ patients).

\begin{tabular}{|c|c|c|c|c|c|}
\hline $\begin{array}{l}\text { Patients } \\
\text { (no.) }\end{array}$ & $\begin{array}{c}\text { Socket- } \\
\text { shield(s) (no.) }\end{array}$ & $\begin{array}{c}\text { Socket-closure } \\
\text { technique }\end{array}$ & Healing & Complications & $\begin{array}{c}\text { Further treatment } \\
\text { needed }\end{array}$ \\
\hline 4 & 5 & Buccal flap advancement & Complete & - & - \\
\hline 1 & 3 & No flap closure & $\begin{array}{l}\text { Incomplete healing in } \\
\text { all } 3 \text { sockets }\end{array}$ & $\begin{array}{l}\text { Exposure of } \\
\text { the shield }\end{array}$ & $\begin{array}{l}\text { Exposure of the shields } \\
\text { requiring surgical closure }\end{array}$ \\
\hline 1 & 1 & $\begin{array}{l}\text { Placement of cytoplast } \\
\text { membrane }\end{array}$ & $\begin{array}{l}\text { Complete with wider } \\
\text { band of attached gingiva }\end{array}$ & - & - \\
\hline 2 & 3 & Socket-seal technique & $\begin{array}{l}\text { Complete healing, } \\
\text { took longer }\end{array}$ & - & - \\
\hline 2 & 2 & $\begin{array}{l}\text { Zuchelli free gingival } \\
\text { graft closure with buccal } \\
\text { and palatal pouch }\end{array}$ & $\begin{array}{l}\text { Complete healing with } \\
\text { excellent soft tissue } \\
\text { contours }\end{array}$ & - & - \\
\hline
\end{tabular}



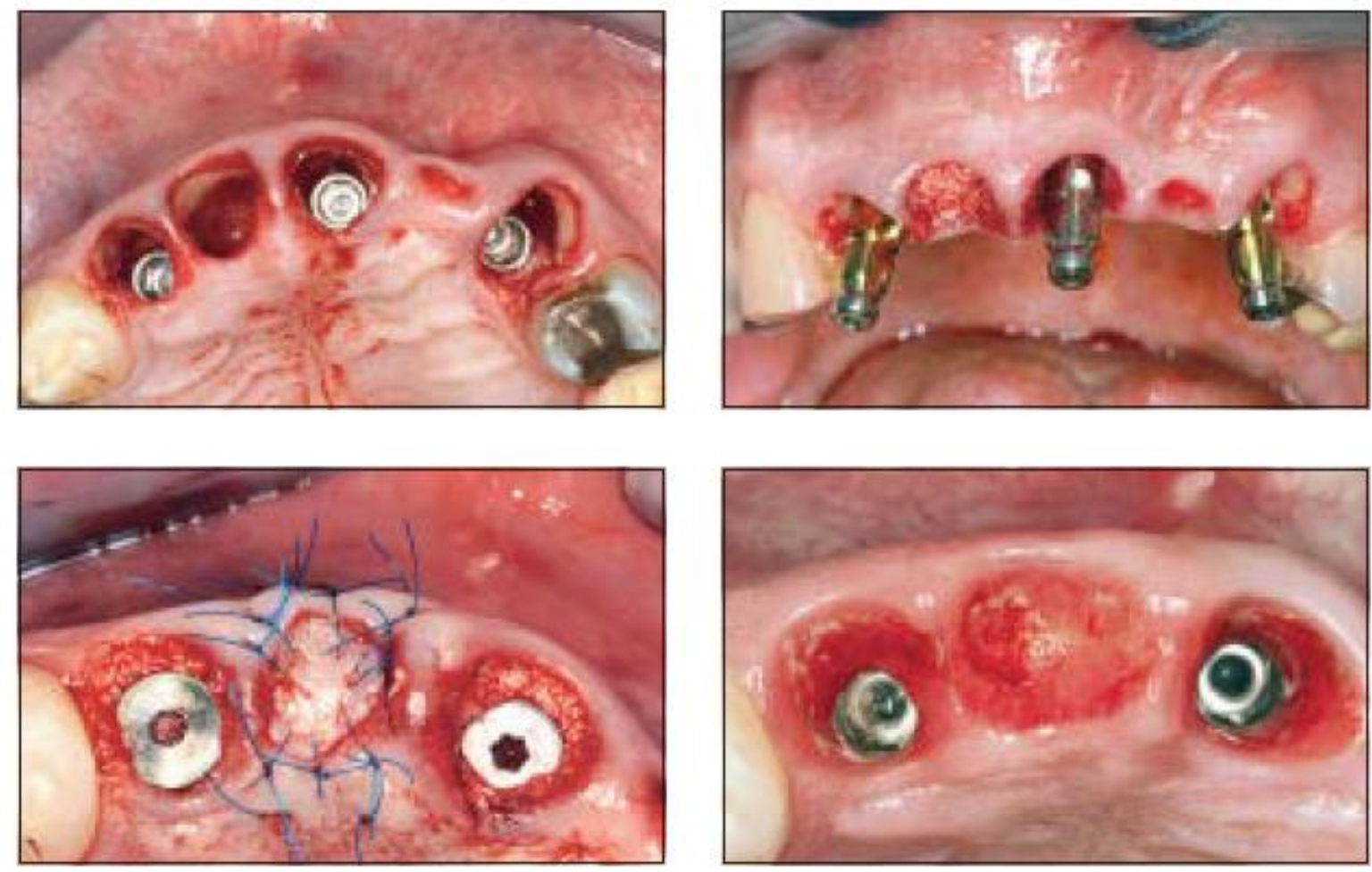

Figure 3. Case 1 - Top left: socket-shields at sites 12,11, 21, and 23, with immediate implants inserted at 12,21, and 23. At site 11, socket-shield with grafting and soft tissue closure followed by preparation of the site as pontic shield. Top right: immediate grafting of post-extraction socket at site 11 with xenograft. Bottom left: connective tissue graft at site 11. Bottom right: 90 days of healing with additional 90 days of pressure at pontic site to create adequate soft tissue frame for final prosthesis. Note the total absence of buccopalatal collapse at site 11.
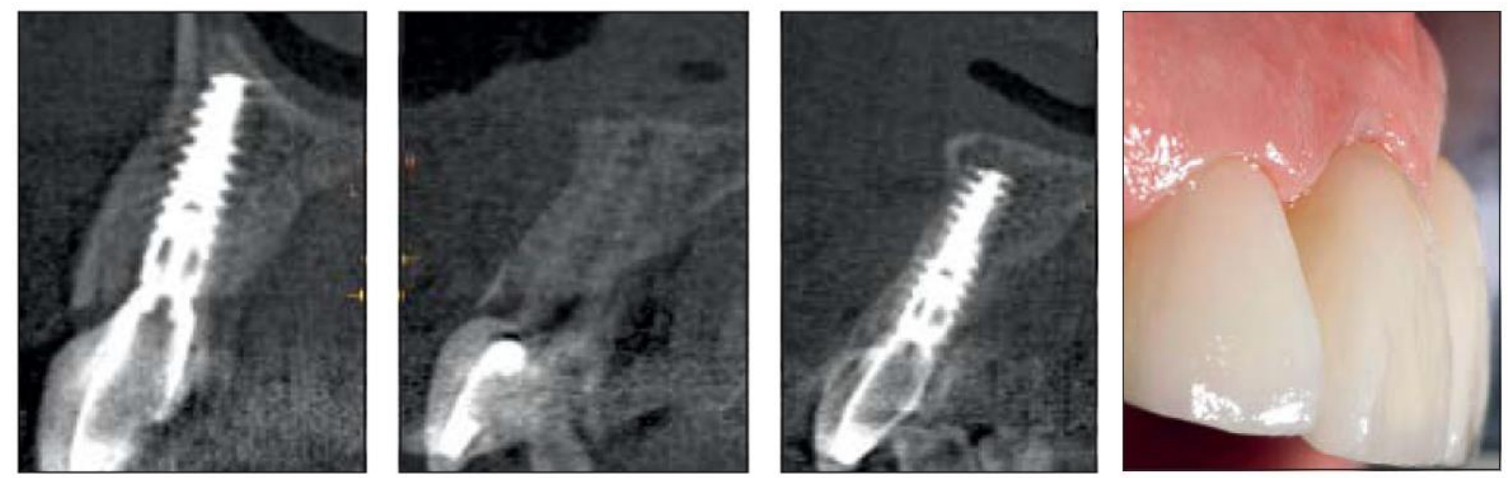

Figure 4. Case 1 - Post-operative CBCT and clinical view after 18 months. 

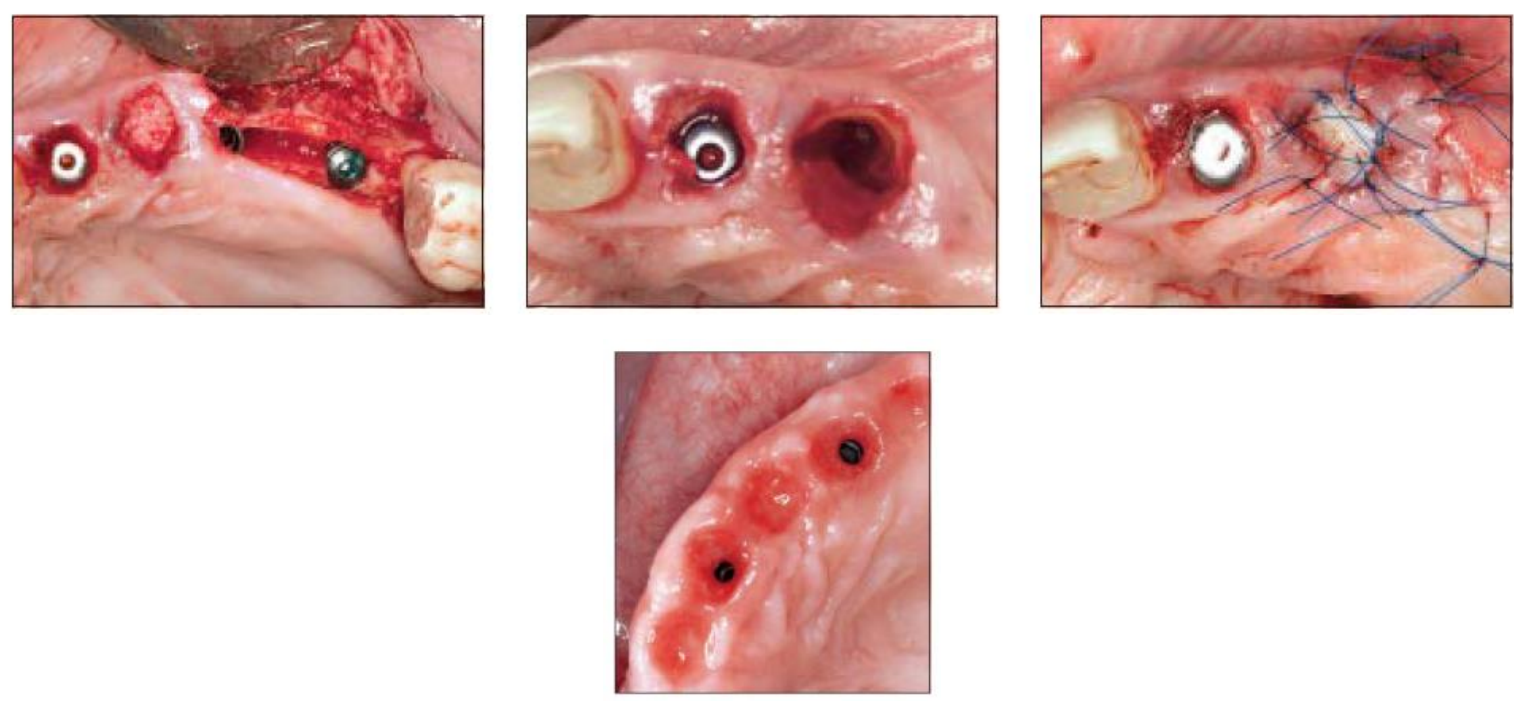

Figure 5. Case 3 - Top Left: Xenograft placed within socket 23 (with sinus augmentation and ridgesplit at 24 to 26). Top middle: 21 was planned for root submergence, 22 was immediate implant with socket-shield, and pontic shield at 23 site. Top right: Final closure of the pontic-shield surgery with connective tissue graft. Bottom: Six-month follow-up. Note the absence of ridge collapse.

\section{Conclusions}

This case series suggests that the pontic-shield, a partial extraction technique resulting from a modification of the socket-shield technique, can be a suitable approach for the preservation of the alveolar ridge at pontic sites. Further research is required to validate this technique in clinical practice. 


\section{CASE REPORTS}

\section{IV.1. Human Histologic Evidence of New Bone Formation and Osseointegration Between Root Dentin (Unplanned Socket-Shield) and Dental Implant ${ }^{3}$}

The socket-shield technique has evolved markedly since its first introduction in 2010 and has becoming more widely accepted as a ridge preservation approach at immediate implant sites (58). It is hypothesized that the retained root fragment maintains the vitality of the bundle bone and the periodontal apparatus, which limits the destruction of Sharpey's fibres, preventing the collapse of the alveolar bone (92).

While animal studies have provided evidence on the histological results obtained with this technique, for ethical reasons, human histological evidence is not available $(93,94)$. Hence, there is uncertainty concerning the type and composition of the tissues that form following the socket-shield technique. This study presents the first histological evidence on the formation of bone between the root dentin and the implant surface in a patient.

\section{Case report}

During a routine periodontal check-up, a systemically healthy female patient, 45 years of age, had a history of immediate implant placement and reported discomfort around the implant crown, located at the left side, at maxillary first premolar. The dental history included loss of the left maxillary premolar two years earlier, immediate implant placement, submerged healing, implant exposure and cementation of the definitive crown. Upon clinical examination, a deep pocket was present in the mid buccal aspect of the implant, with bleeding on probing. On a periapical radiograph, a foreign object was noticed in the mesial aspect of the implant and diagnosed as a root fragment.
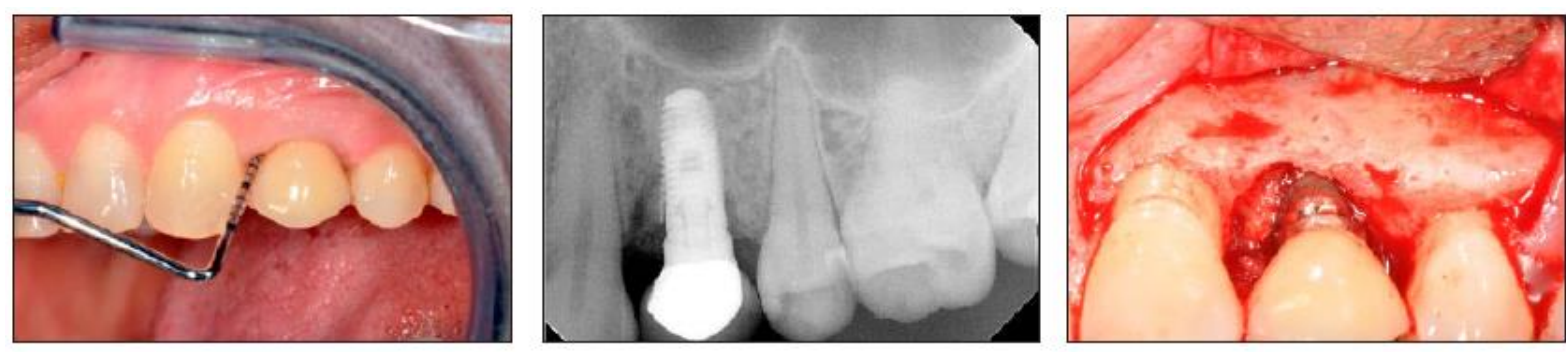

Figure 6. Initial presentation showing periodontal probing, periapical radiograph and clinical view following elevation of the flap.

\footnotetext{
${ }^{3}$ Schwimer C, Pette GA, Gluckman H, Salama M, Du Toit J. Human Histologic Evidence of New Bone Formation and Osseointegration Between Root Dentin (Unplanned Socket-Shield) and Dental Implant: Case Report. Int J Oral Maxillofac Implants. 2018 Jan/Feb;33(1): e19-e23.
} 
The treatment selected included removal of the shield and placement of another implant. After local anaesthesia and flap elevation, a lateral window was prepared, through which the implant and the adhered root fragment was removed and prepared for histological analysis. The socket received an allograft combined with recombinant human platelet-derived growth factor-BB, which was covered with a titanium-reinforced membrane and a collagen membrane before flap closure. Three months later, another implant was placed and later restored.
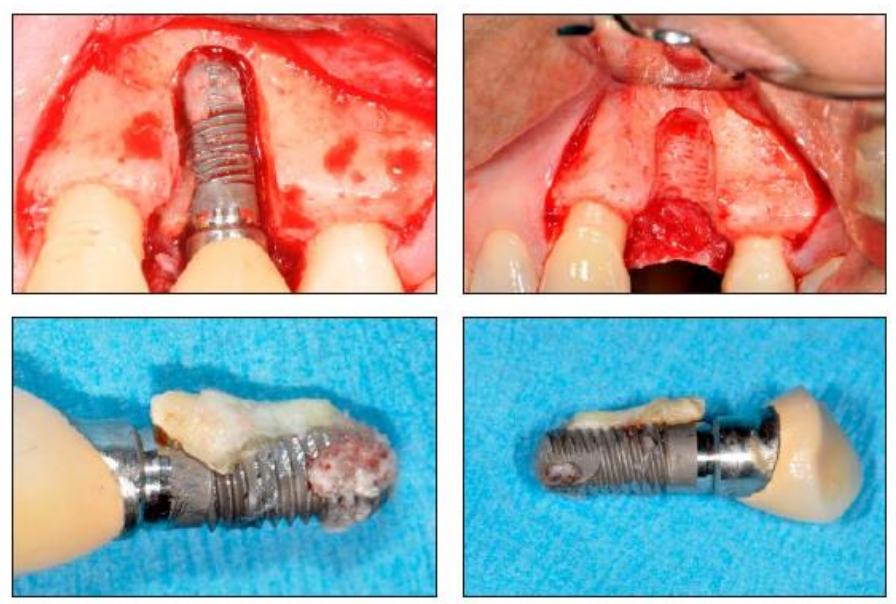

Figure 7. Surgical removal of the implant and the root fragment.

\section{Histological results}

The fragment was confirmed as being part of a dental root, with dentinal tubules and outer cement. The tissue observed between the implant threads was vital bone with osteocytes and vacuoles containing remnants of dentin fragments, which were most probably dislodged during insertion of the implant. Fibrovascular tissues were not apparent between bone and dentin or implant. Under polarized light, the bone tissue between the threads presented mineralization with concentric lamellae, characterizing mature bone.
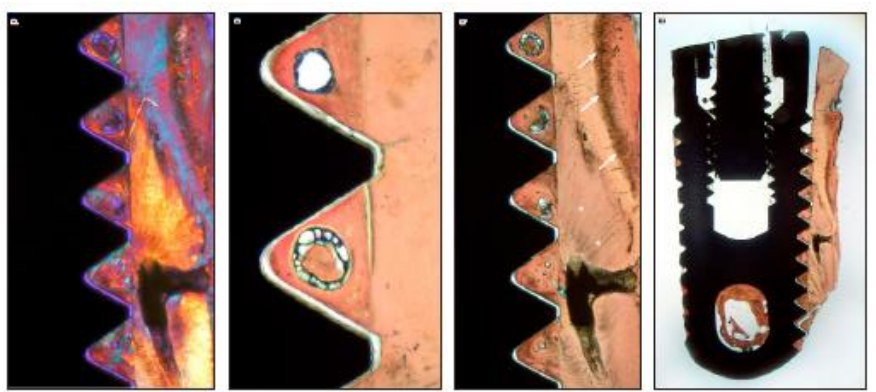

Figure 8. Histological analysis showing vital bone between implant threads 


\section{Conclusion}

This case report of an unplanned socket-shield at an immediate implant site suggests that the space between dentin, bone and implant surface can be occupied by bone tissue, which is the ideal outcome for the long-term success of dental implants.

\section{IV.2. The socket-shield technique to support the buccofacial tissues at immediate implant placement $^{4}$}

Tooth loss and the inevitable subsequent alveolar bone loss is a challenge for restorative dentistry (85). Traditional ridge preservation techniques have shown limited results so far, besides presenting longer treatment time, increased morbidity and cost. Hence, PET such as the socket-shield technique offers a promising conservative approach, where part of the patient's own tooth is used to maintain the dimensions of the alveolar ridge. This case report supports the hypothesis that a prepared root fragment can function as shield to limit the collapse of the buccal bone wall at immediate implant sites.

\section{Case report}

A healthy, non-smoking, adult male, 43 years of age, presented with a ferrule-less central maxillary incisor (tooth 21). The tooth had endodontic treatment with a failing post-core crown. Immediate implant placement was planned concomitant with socket-shield preparation. After local anaesthesia, the crown was removed, and the root was sectioned in a mesio-distally with a long-shank resection bur. With the help of periotomes, the periodontal ligament was severed in the palatal area, after which the palatal fragment was carefully removed. The buccal section of the root was reduced coronally to $1 \mathrm{~mm}$ above the crest, and thinned into a concave contour using a long-shank round diamond bur. The socket's palatal wall and the apex were curetted to remove potentially infected tissue and the immobility of the shield was confirmed using a sharp probe. The osteotomy for a 4 x $13 \mathrm{~mm}$ internal conical connection implant was prepared and the implant was inserted palatal to the socket shield with the help of a surgical guide.

A xenograft was placed in the jump gap. The implant received a provisional crown (ISQ over 70) with an S-shape emergence profile, in order to provide adequate space for soft tissue growth between the crown and the shield.

\footnotetext{
${ }^{4}$ Gluckman H, Du Toit J, Salama M. The socket-shield technique to support the buccofacial tissues at immediate implant placement. International Dentistry African Edition 2015;5(3):6-14.
} 

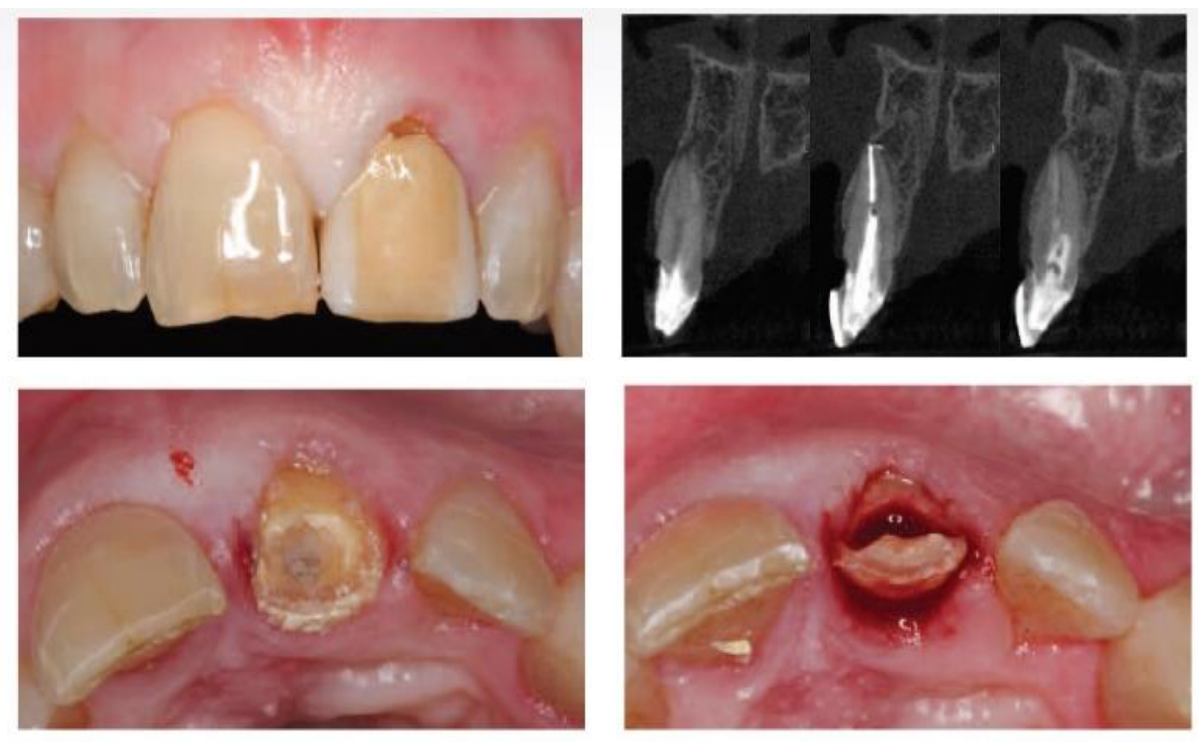

Figure 9. Top: clinical and CBCT preoperative view, tooth 21. Bottom: lack of ferrule and mesiodistal sectioning of the root.
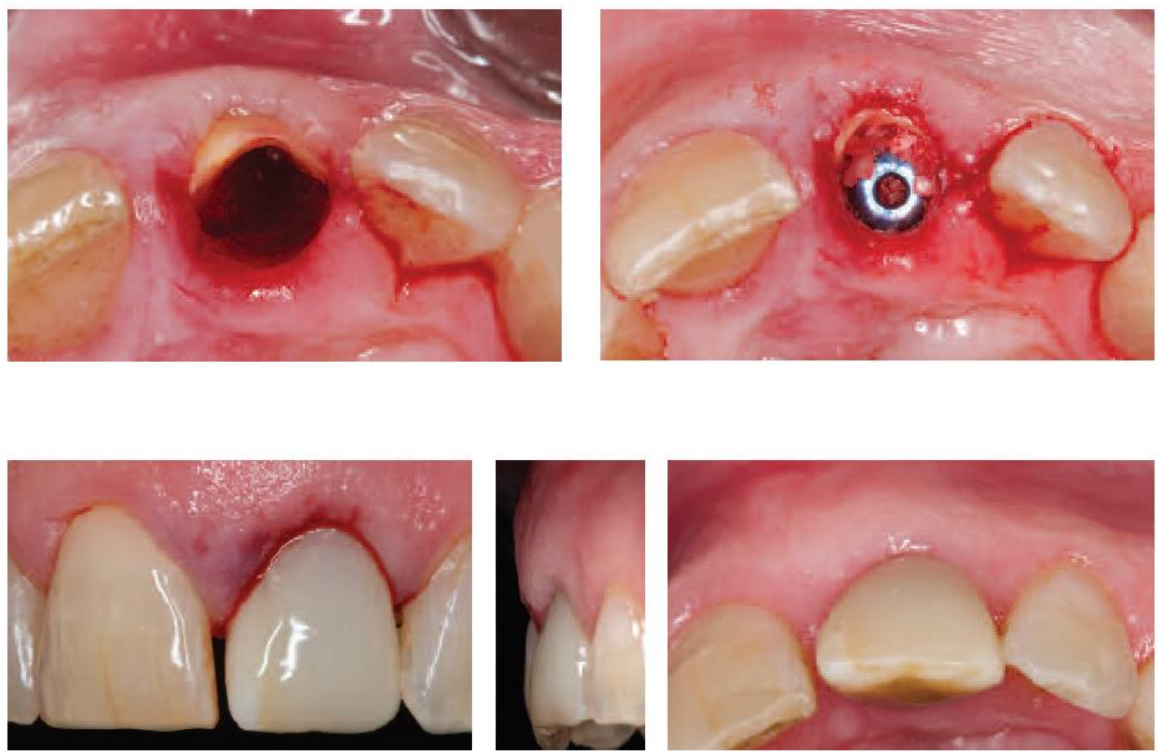

Figure 10. Top: the prepared socket-shield, followed by implant placement and grafting of jump gap. Bottom left: provisional trial. Bottom middle: 1 week follow-up. Bottom right: 1- month followup. 

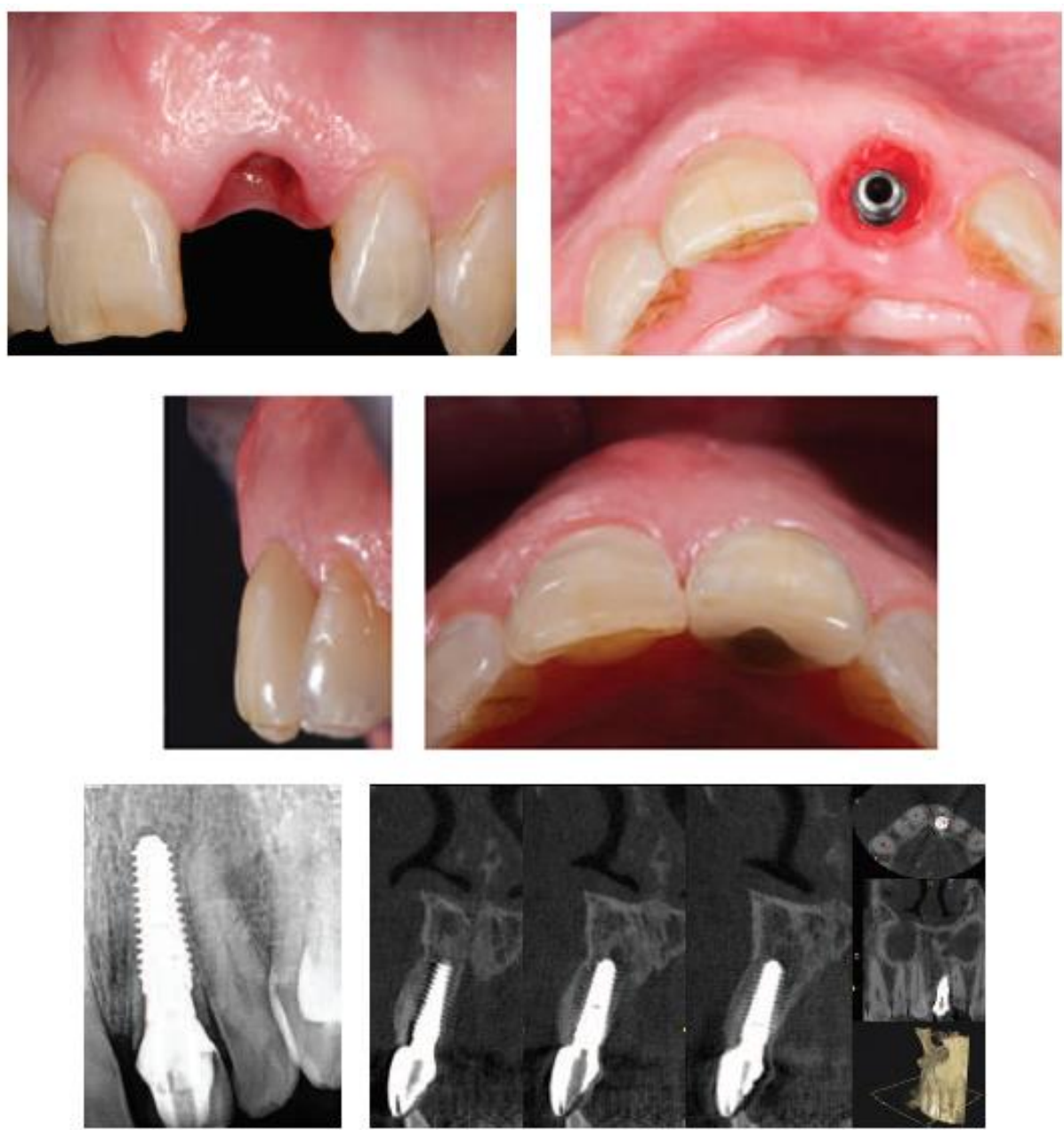

Figure 11. Top: 3 month follow-up. Middle: final restoration in place. Bottom: periapical radiograph and CBCT at 1-year follow-up.

\section{Results}

Healing was uneventful and the implant was successfully osseointegrated and presented optimal cosmetic results after 1-year follow-up, with soft tissues comparable to the neighbouring natural central incisor. The patient had no complications. The final CBCT showed thick facial tissues at the implant site. The socket shield provided optimal support for the buccofacial tissues, preventing ridge collapse.

\section{Conclusion}

Management of post-extraction ridge alterations is a common challenge in restorative dentistry. The socket-shield constitutes a promising solution for the prevention of post-extraction alveolar loss and this study reports the stability of the outcome after a year. Additional research is necessary before this technique can be routinely used in clinical practice. 


\section{TECHNIQUE REPORTS}

\section{V.1. Prosthetic management of implants placed with the socket-shield technique ${ }^{5}$}

Early attempts to preserve edentulous ridges were performed in the 60es through root submergence, characterising the initial foundation for PET (24).

Since alveolar bone reduction is inevitable after tooth removal, the most reliable way to prevent bone resorption is to prevent tooth loss (95). The idea of keeping the root of a condemned tooth originated as a potential solution for the problems encountered with alveolar ridge collapse in full dentures wearers. The rationale behind this approach is the maintenance of vital bundle bone through retention of the root, providing better soft and hard tissue architecture and papilla preservation in pontic and immediate implant sites (16).

The finding that $9.4 \%$ of the 128 cases of socket-shield followed up for up to 4 years presented exposure of the shield highlighted the importance of prosthetic management for this technique (90). Internal exposure means that part of the shield penetrated the soft tissues facing the crown and the abutment, which in many cases resulted in inflammatory changes. This complication requires treatment, since peri-implant soft tissues must remain healthy without inflammation or ulcerations.

Immediate implant placement combined with the socket shield technique is an advanced procedure, as such, it is recommended that a comprehensive planning of the prosthetic outcomes is carried out together with the general planning. Use of digital smile design or similar software or trial restorations are imperative for successful results.

\section{Technique}

During preparation of the socket shield, contrary to previous guidelines, our group suggests that the height of the shield must be at crestal level and not above it. We also suggest the preparation of an internal bevelled chamfer, which allows accommodation of an S-shaped emergency profile for the crown, creating adequate prosthetic space. Regarding interim restorations, they are indicated only when the implant has high primary stability (> 70 ISQ). If the primary stability is not adequate ( $<60$ ISQ), a customized transgingival abutment should be used in order to mimic the intended emergence profile. In the transgingival component, a narrow S-shape is recommended to ensure enough space for the soft tissues. When placing the prosthetic component, which is intended to seal the socket,

\footnotetext{
${ }^{5}$ Gluckman H, Nagy K, Du Toit J. Prosthetic management of implants placed with the socket-shield technique. J Prosthet Dent. 2018 Dec 13.
} 
there should be minimal or no blanching of the facial gingiva. The interim crown should not have contacts in excursive movements and maximum intercuspation. If a custom abutment is used, there should be no contact with the subsequent provisional prosthetic component. A post-operative radiograph is crucial this stage.

The importance of the S-shape at the connecting abutment for both interim and permanent restorations cannot be underestimated. It should be as narrow as possible as it emerges, to allow for adequate space for soft tissue growth, followed by a wider curve. This design prevents excessive pressure on the coronal part of the shield, which can facilitate exposure.

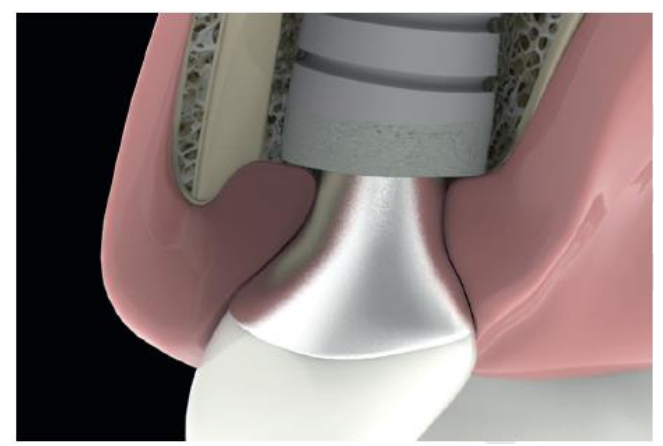

Figure 12. Illustration of the socket-shield with the internal bevelled chamfer. The transgingival prosthetic component presents the S-shape contour to create adequate space for the soft tissues.

The use of customized impression techniques, whether digital or analogue, is essential to duplicate the subgingival portion of the crown or the custom abutment. Failure to follow this may lead to increased pressure on the shield, which can lead to an internal exposure due to the thinning of the overlying gingiva by the final crown.
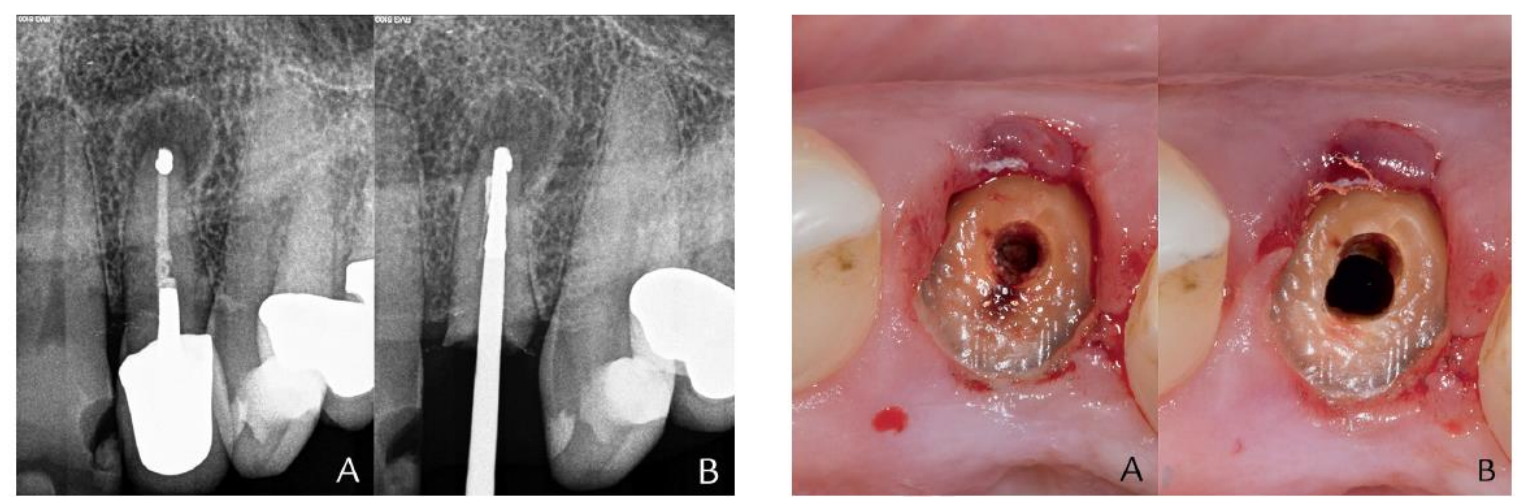

Figure 13. Periapical radiographs, A- preoperative view, B- decoronated tooth with long-shank rotating instrument inserted to root length. Clinical images: A- occlusal view of decoronated tooth, B- root canal widened with diamond bur. 


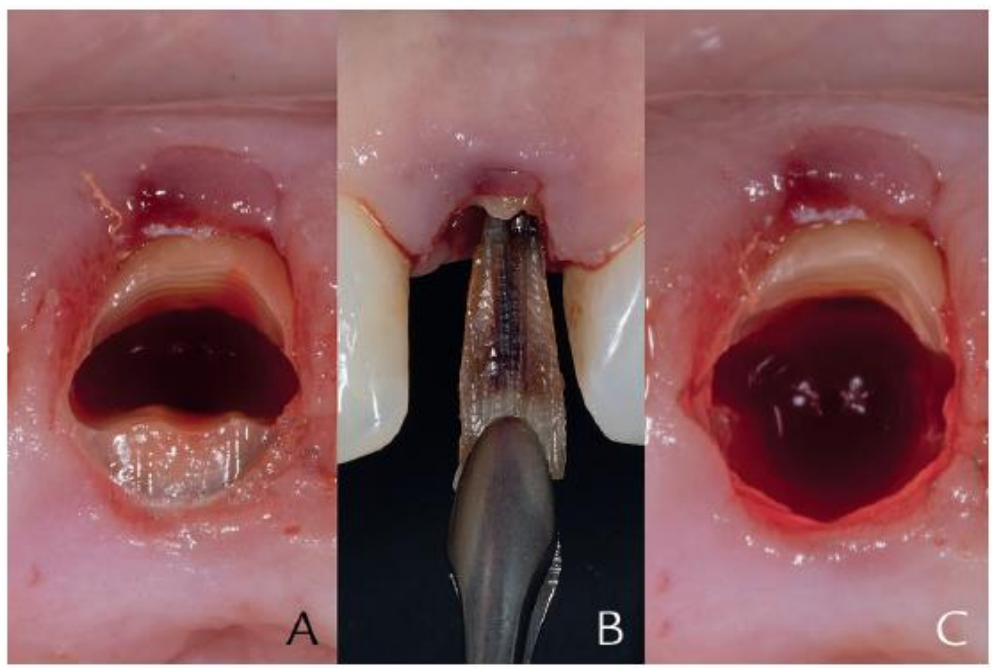

Figure 14. A - Sectioning of the root, B- removal of palatal fragment, C- occlusal view after removal of palatal portion.
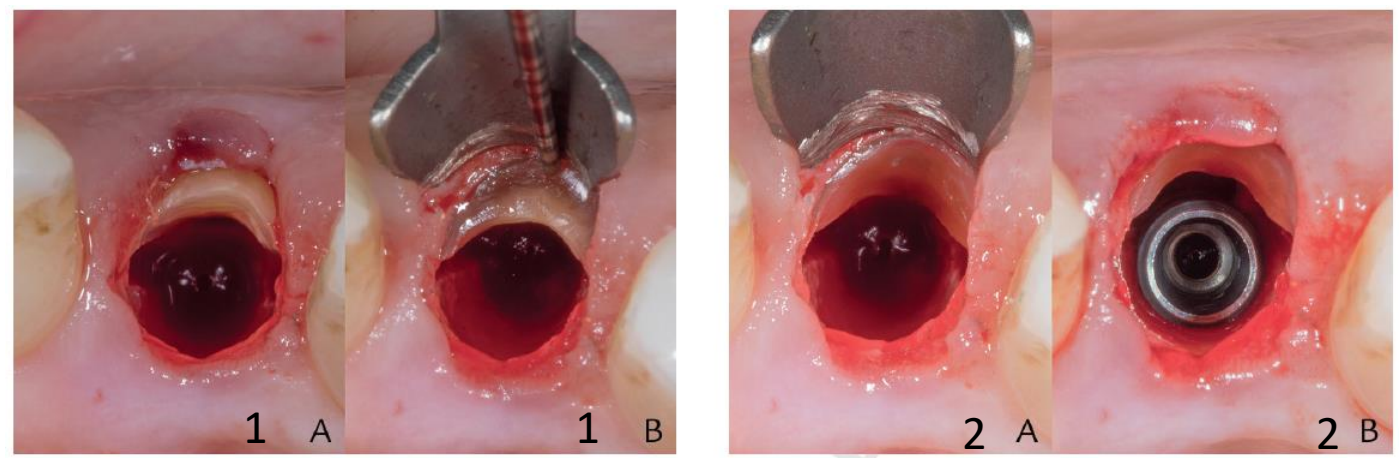

Figure 15. 1A- Removal of root canal content and rinsing of the socket. 1B- Socket shield reduced to bone level with gingival protection. 2A- Beveled chamfer created. 2B- immediate implant placed palatal to the shield.

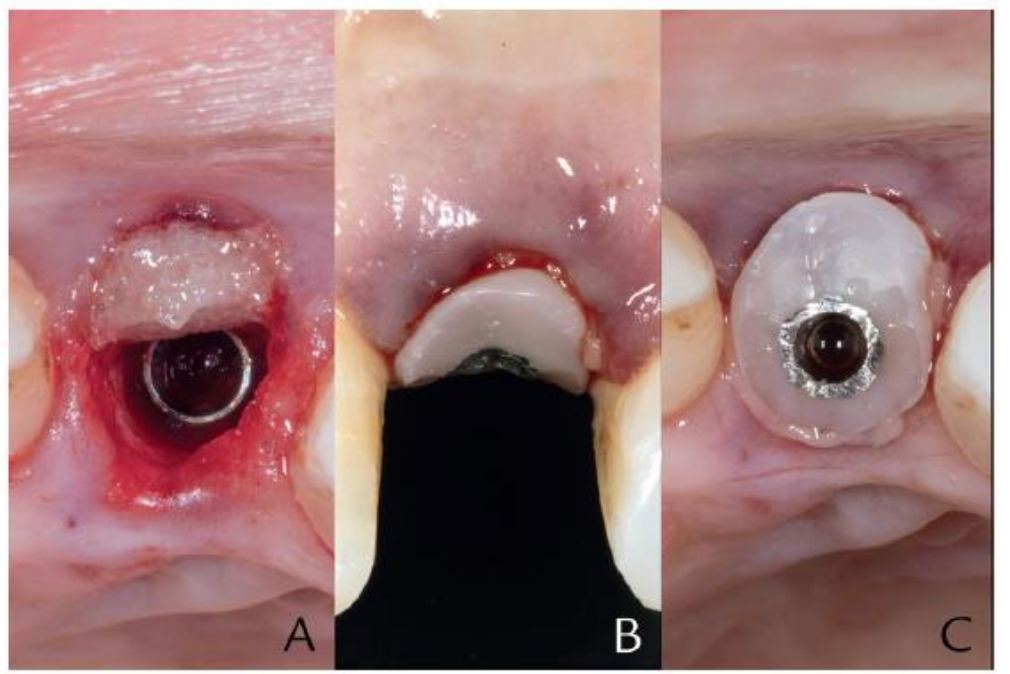

Figure 16. A- Grafting of jump gap. B and C-customized healing abutment with platelet rich fibrin underneath. 

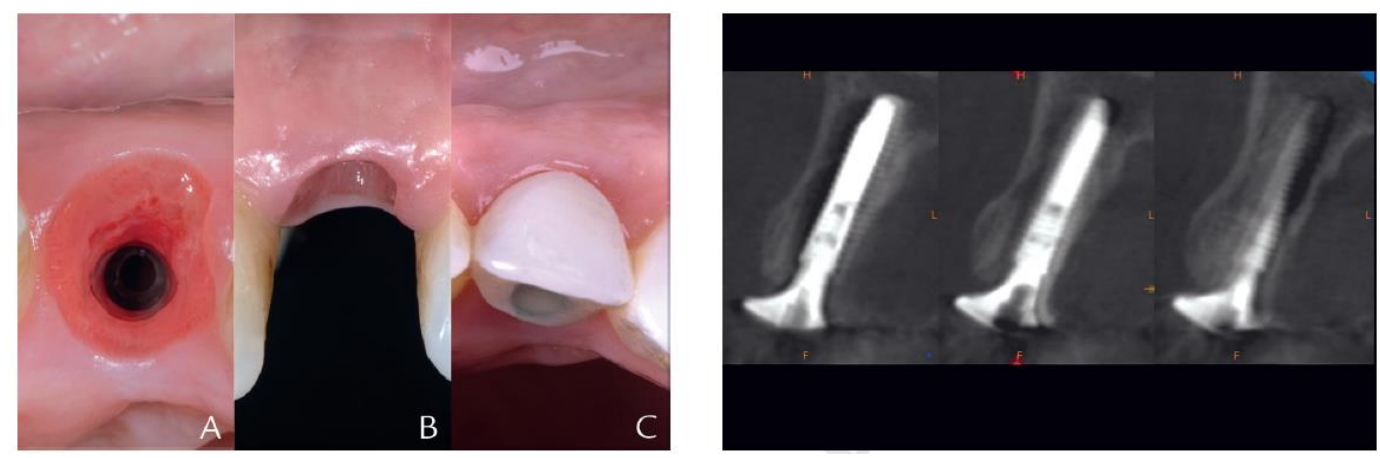

Figure 17. Three-month follow-up and definitive crown. Postoperative CBCT just before final restoration.

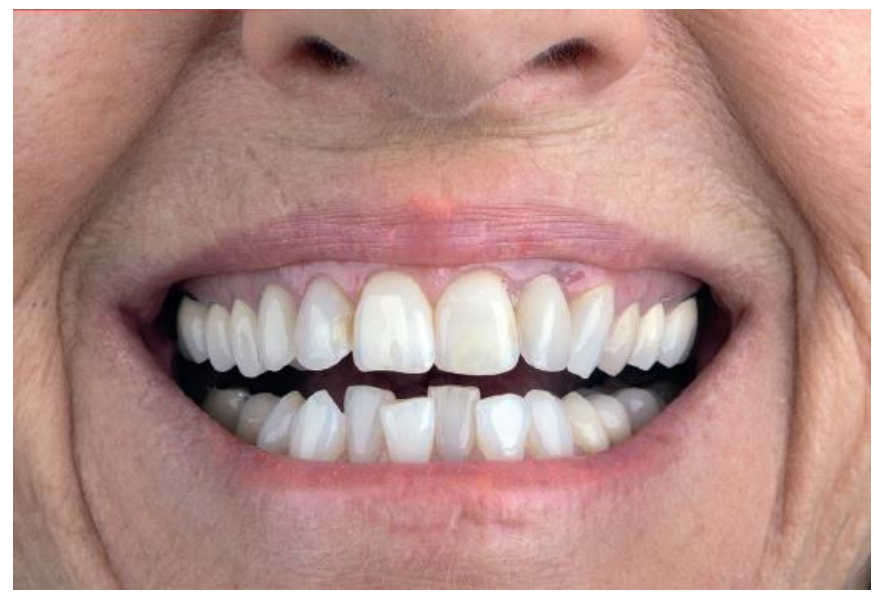

Figure 18. Final result.

\section{Conclusion}

The socket-shield technique has evolved based on results from an ever-increasing number of publications on PET. In order to further improve this technique, it is crucial to minimize the development of complications. Internal exposures, a common complication for the socket-shield, can be nearly avoided through a reduction of the height of the shield in its coronal portion. In order to optimize long-term results, the prosthetic management of the site is also imperative and needs to include a customized transgingival healing abutment prepared in an S-shape, in order to allow for maximal infill of the coronal soft tissue around the interim and definitive restoration. When these steps are followed, the rate of complication decreases substantially, thus increasing the efficacy of the socket shield technique. 


\section{V.2. Partial Extraction Therapies (PET) Part 1: Maintaining Alveolar Ridge Contour at Pontic and Immediate Implant Sites ${ }^{6}$}

Resorption of the alveolar bone following tooth extraction is a well-documented process in the literature, resulting from the loss of the bundle bone $(3,18,22,26)$. Surgical augmentation is often a necessity in edentulous sites, however, both ridge preservation approaches and augmentation procedures cannot prevent ridge collapse (12). PET present a pre-collapse approach through the partial or total retention of the dental root. This study presents a review of PET, as well a classification and guidelines for their clinical application.

\section{PET classification}

PET include root submergence, socket-shield and pontic-shield techniques, each with its own guidelines and indications. While root submergence has been explored for nearly 70 years, the socketand pontic-shield concepts were only introduced a couple of years ago.

The combination of the three different modalities of PET is a possibility, providing additional treatment options in terms of implant placement strategy and restoration design.
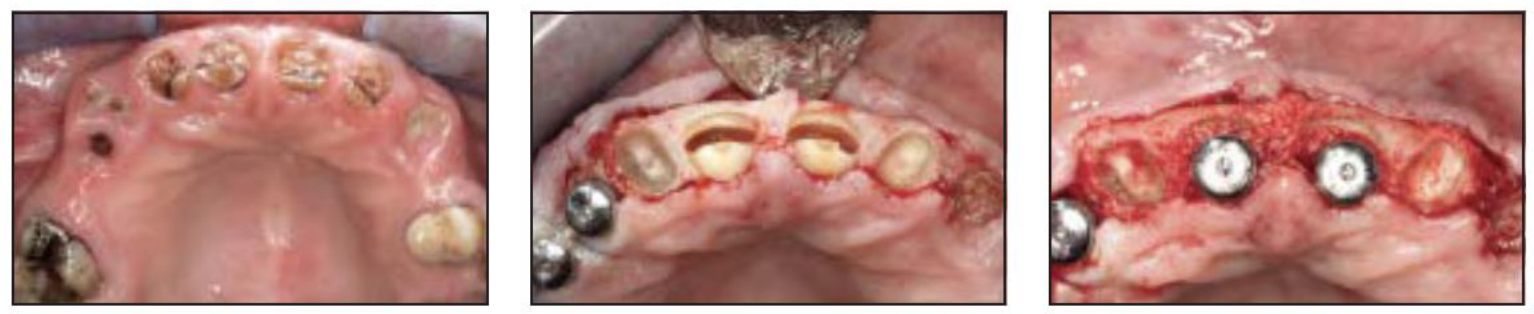

Figure 19. Case 1 - Patient with rampant caries subjected to root submergence of maxillary lateral incisors and socket-shield at central incisors combined with immediate implant placement.

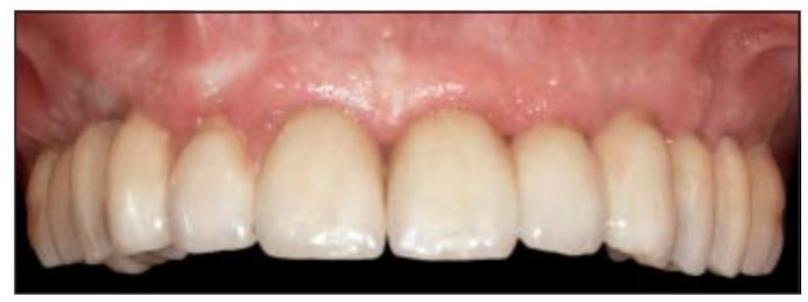

Figure 20. Case 1 - one- year follow-up.

\footnotetext{
${ }^{6}$ Gluckman H, Salama M, Du Toit J. Partial Extraction Therapies (PET) Part 1: Maintaining Alveolar Ridge Contour at Pontic and Immediate Implant Sites. Int J Periodontics Restorative Dent. 2016 SepOct;36(5):681-7.
} 

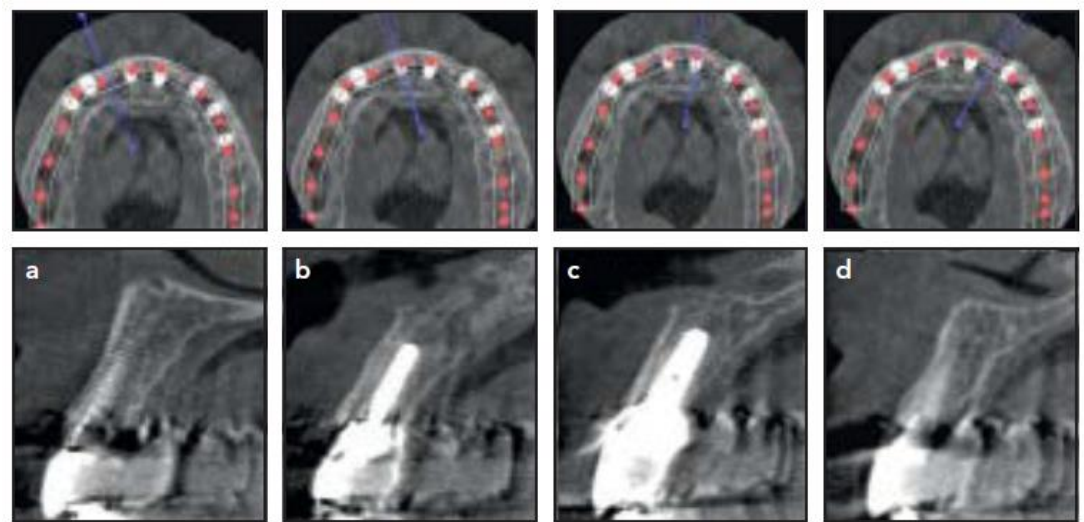

Figure 21. Case 1 - Post-operative CBCT at 1-year follow-up.
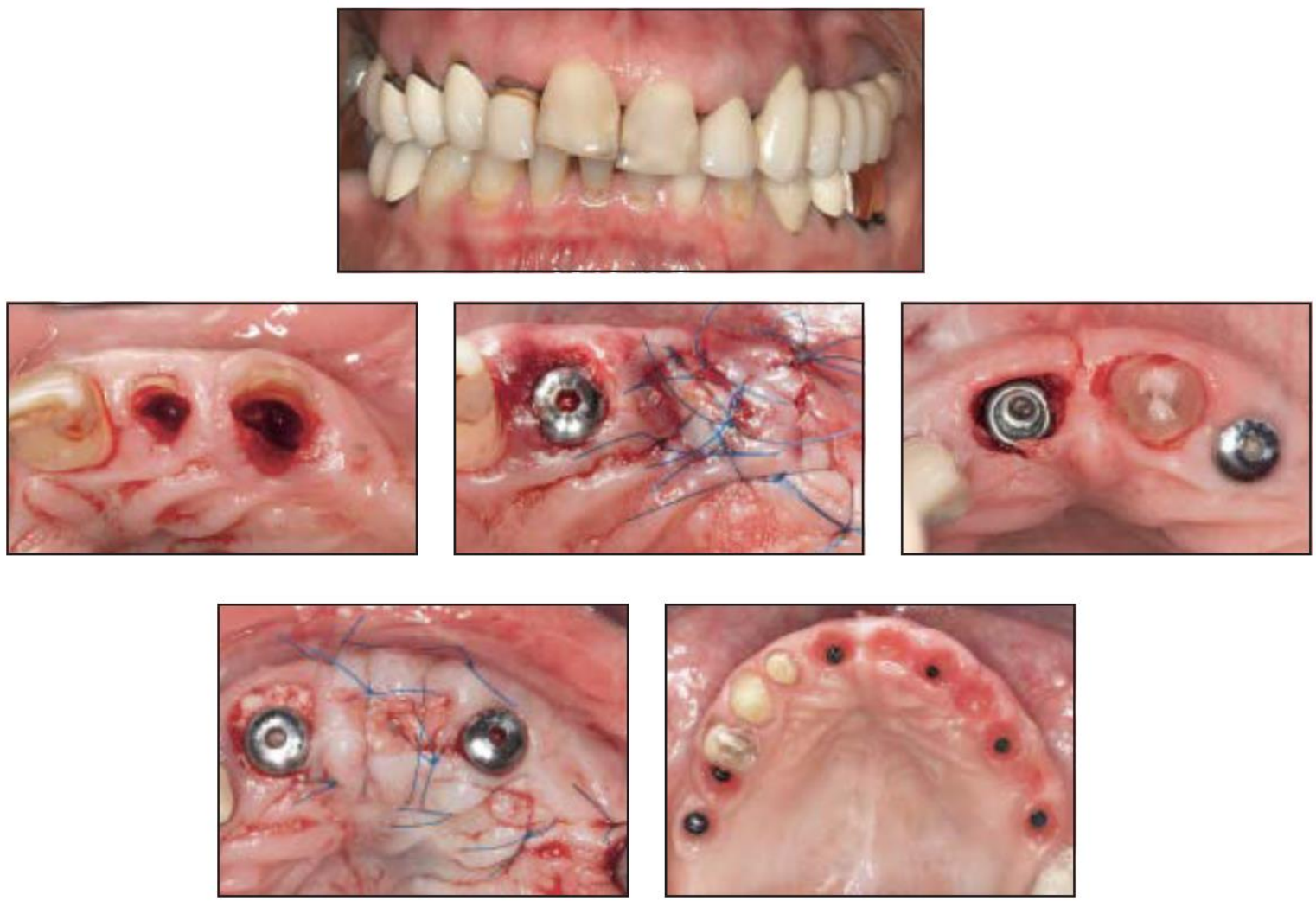

Figure 22. Case 2. Top: pre-operative clinical view. Middle: At stage 1, socket-shield technique carried out at left lateral incisor (left). Pontic shield carried out at the maxillary left canine, healing abutment fixed in place at the left lateral incisor, and connective tissue graft closure of at maxillary left canine (middle). At stage 2, immediate implant placement at right central incisor (right) and root submergence at the left central incisor.
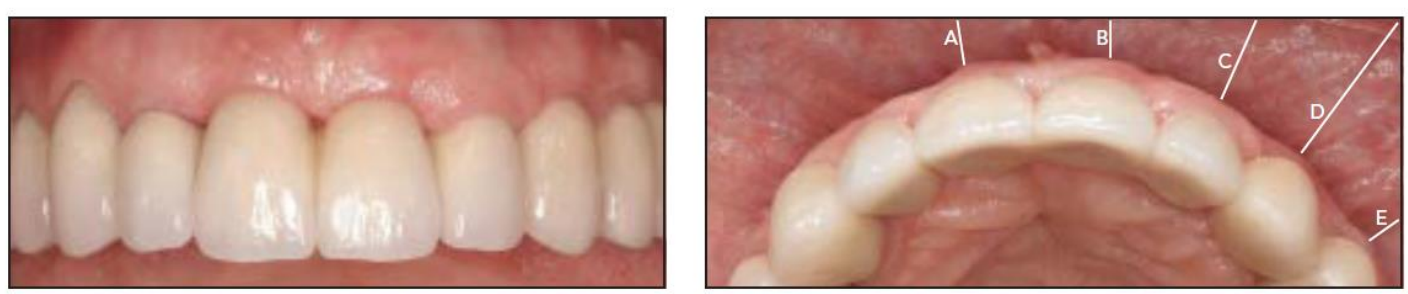

Figure 23. Case 2. Final result at one-year recall. 

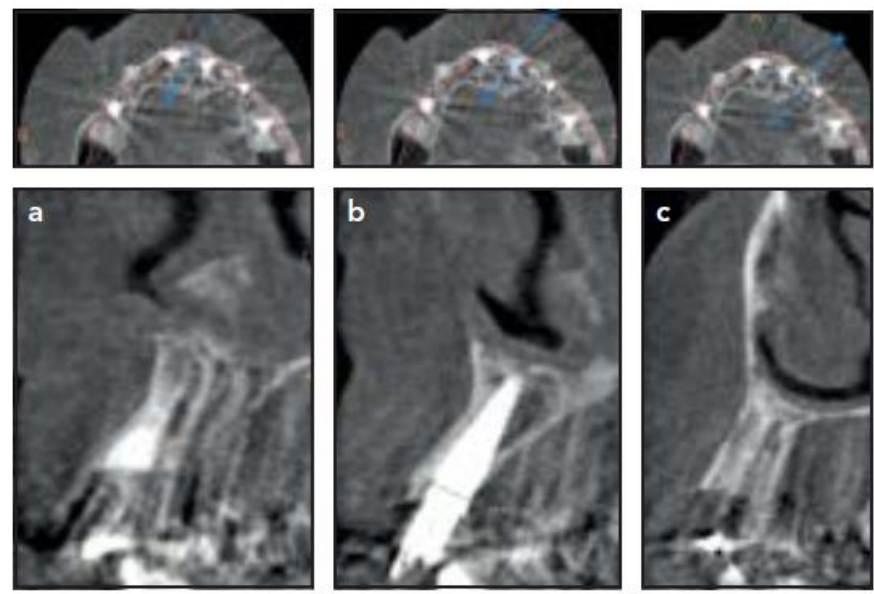

Figure 24. Case 2. Post-operative CBCT at one- year recall.

The first step, common to all PET is the decoronation of a tooth indicated for extraction. In the root submergence technique, the entire root is retained below the alveolar bone and covered by the soft tissues. For the socket- and pontic-shield, the root is sectioned in the mesio-distal direction, the palatal fragment is carefully extracted, and the buccal fragment is reduced below bone level and prepared as a concave, chamfered structure. For the socket-shield, the jump gap is grafted, followed by osteotomy preparation and implant placement. Lastly, for the pontic-shield, the socket is grafted and sealed, which usually includes a soft tissue graft. An overview on the three PET modalities and their indications is provided in Table 1.

\begin{tabular}{|c|c|}
\hline PET & Clinical situation(s) indicated \\
\hline $\begin{array}{l}\text { Root } \\
\text { submergence }\end{array}$ & $\begin{array}{l}\text { Unrestorable tooth crown or tooth indicated for extraction } \\
\text { Absence of apical pathology } \\
\text { Healthy amputated pulp or endodontic therapy completed } \\
\text { Intention to preserve the alveolar ridge } \\
\text { Planned removable full or partial prosthesis } \\
\text { Planned pontic site beneath fixed prosthesis } \\
\text { Cantilever pontic site as an alternative to two adjacent implants } \\
\text { Actively growing young patient planned for implant } \\
\text { treatment later } \\
\text { Ridge preservation in conjunction with other PET }\end{array}$ \\
\hline Socket-shield & $\begin{array}{l}\text { Unrestorable tooth crown or tooth indicated for extraction } \\
\text { Tooth root with or without apical pathology } \\
\text { Intention to preserve the alveolar ridge, specifically to } \\
\text { prevent buccopalatal collapse } \\
\text { Immediate implant placement } \\
\text { Ridge preservation in conjunction with other PET }\end{array}$ \\
\hline Pontic shield & $\begin{array}{l}\text { Unrestorable tooth crown or tooth indicated for extraction } \\
\text { Tooth root with or without apical pathology } \\
\text { Intention to preserve the alveolar ridge } \\
\text { Planned pontic site(s) beneath fixed prosthesis } \\
\text { Cantilever pontic site as an alternative to two adjacent implants } \\
\text { Ridge preservation in conjunction with other PET }\end{array}$ \\
\hline $\begin{array}{l}\text { Proximal } \\
\text { socket-shield }\end{array}$ & $\begin{array}{l}\text { Unrestorable tooth crown or tooth indicated for extraction } \\
\text { Tooth root with or without apical pathology } \\
\text { Intention to preserve interdental papillae } \\
\text { Planned immediate implant placement sites of two or } \\
\text { more adjacent implants } \\
\text { Papillae preservation in conjunction with other PET }\end{array}$ \\
\hline
\end{tabular}

Table 3. Partial extraction therapies (PET) and their indications. 

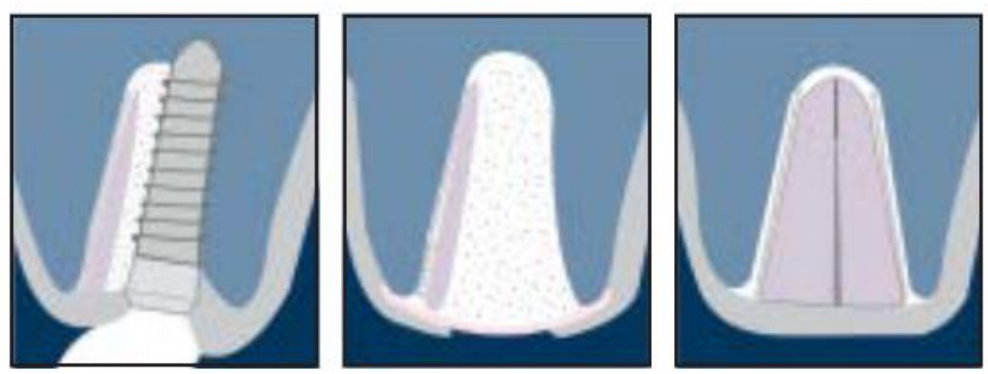

Figure 25. Illustration of the three types of partial extraction therapies (PETs): socket-shield (left), pontic shield (middle), and root submergence (right).
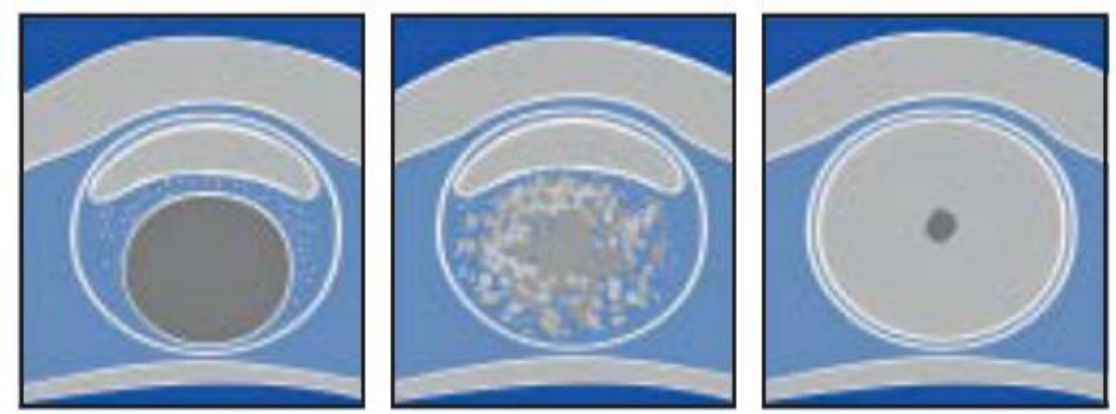

Figure 26. Illustration of the three types of partial extraction therapies (PETs), horizontal crosssection midway through the sockets of PET: socket-shield (left), pontic shield (middle), and root submergence (right).

\section{Conclusions}

When a tooth is indicated for extraction, PET offer a more conservative approach for ridge preservation through the retention of the entire root or part of it. These strategies can enhance pontic sites and preservation interdental and labial soft and hard tissues when combined with immediate or delayed implant placement. Despite the progress resulting from the ever-increasing number of studies on PET in the literature, the authors agree that more robust studies are needed.

\section{V.3. Partial Extraction Therapies (PET) Part 2: Procedures and Technical Aspects ${ }^{7}$}

As a healthy periodontium is essential for the long-term maintenance of a tooth, so are peri-implant tissues crucial for maintenance of dental implants. With tooth extraction, the alveolar bone loses up to half of its volume, constituting one of the biggest challenges in restorative and implant dentistry.

\footnotetext{
${ }^{7}$ Gluckman H, Salama M, Du Toit J. Partial Extraction Therapies (PET) Part 2: Procedures and Technical Aspects. Int J Periodontics Restorative Dent. 2017 May/Jun;37(3):377-385.
} 
PETs emerged as an alternative to avoid or prevent this loss, based on the hypothesis that maintenance of a tooth root or part of it preserves the periodontal apparatus, which maintains the vitality of the bundle bone, thus avoiding major bone resorption post-extraction (92).

Root submergence was the first PET, introduced in the 1950s, as a treatment strategy to maintain the volume of the alveolar ridge under full dentures. Later, the approach was further explored in pontic sites for fixed partial prosthesis and implant restorations. The concept evolved to test the retention of the buccal aspect in association with implant placement (socket-shield technique) and since then, more studies have been published to confirm the efficacy of PET (16). The aim of this study is to suggest the standardization of the technical aspects of PET, in order to increase their reproducibility and increase the quality of future studies on the topic.
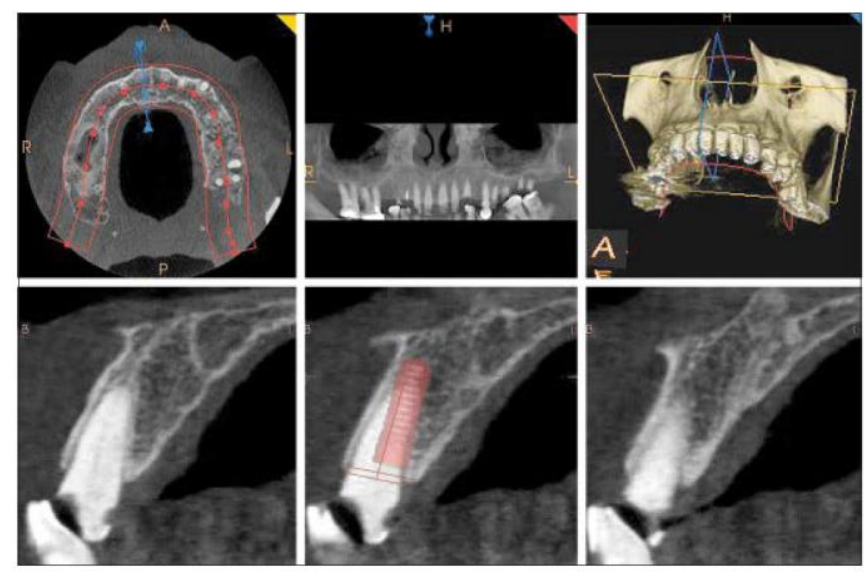

Figure 27. Planning of PET in the maxilla using CBCT. Presence of apical pathology, root dimensions and orientation of the ridge are observed.
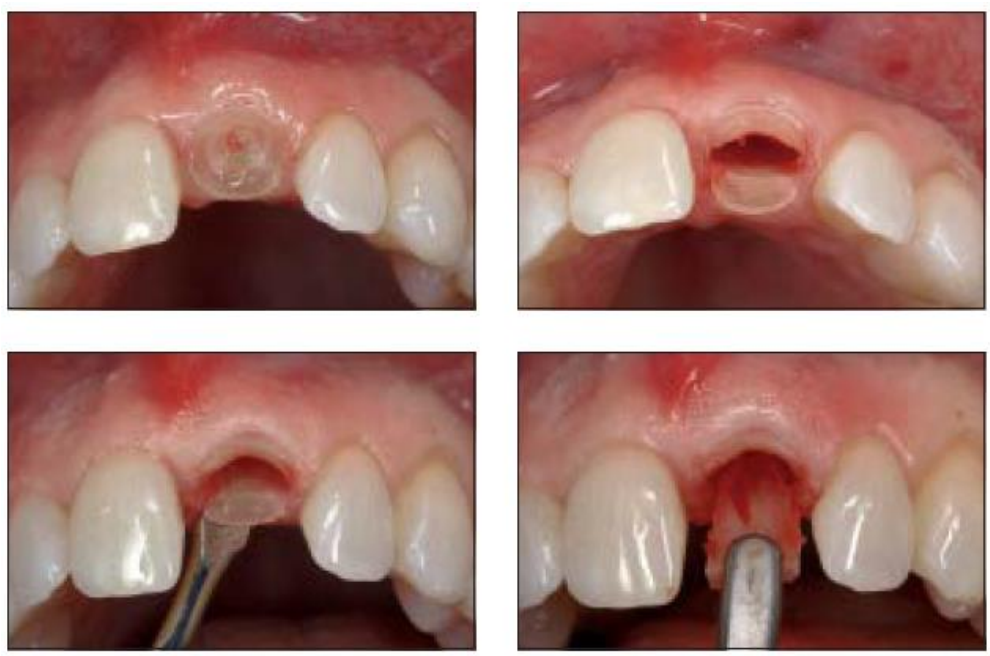

Figure 28. Sequence of decoronation, sectioning of the root, elevation of palatal portion and extraction using microforceps. 

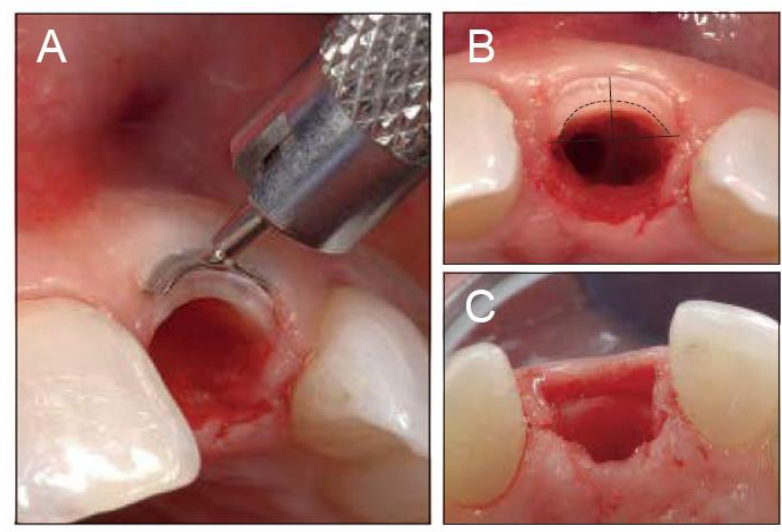

Figure 29. $A$ : reduction of the shield with gingival protector. $B$ : shield reduced midway from the root canal to the root's surface and prepared osteotomy palatal to the socket-shield. $C$ : final socket shield, $1 \mathrm{~mm}$ above the bone crest.

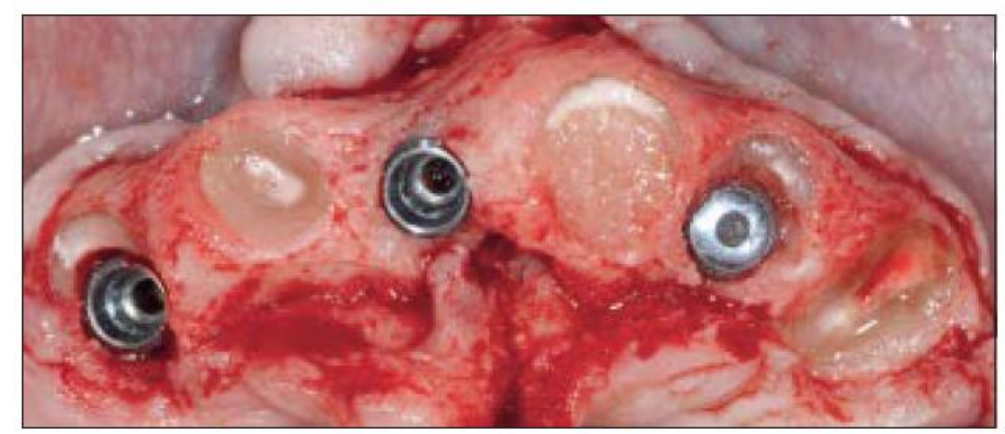

Figure 30. Multiple PET: maxillary left central incisor prepared as pontic shield, socket grafted with xenograft. Note the socket-shield at left lateral incisor allows for grafting of the buccal gap, while the right canine does not.

\section{Socket shield preparation}

The socket-shield technique can be used in vital, non-vital or endodontically-treated teeth indicated for extraction followed by immediate implant placement. It is typically used in anterior areas and can be applied to Ferrule-less and/or caries affected teeth; root caries can be present, as long as it does not affect the shield portion of the root (58). An intact buccal bone wall, absence of infra-bony periodontal defects and a stable and immobile shield after preparation are fundamental requirements for this technique (15).

The contra-indications for the socket shield technique include active periodontitis at the tooth, tooth mobility, shield mobility, partial and total loss of the buccal bone, periodontal disease with vertical bone loss and external root resorption involving the buccal aspect below the bone crest (15). Small curved roots often present at posterior teeth, mandibular anterior teeth and teeth with extremely long roots can be very challenging to be prepared for the socket shield. 
PET requires meticulous planning before surgery, including clinical examination and CBCT scans to allow the three positioning of the tooth and root in the socket. Apical pathology, potential bone defects such as dehiscence and fenestration, length and width of the root must be observed in the CBCT together will all other significant aspects for immediate implant placement. This includes among other distance to adjacent structures, limits of the alveolar ridge and soft tissue volume. A surgical guide prepared from the 3D analysis or a conventional analog guide based on an anatomical wax-up is also required. The CBCT should be taken with a lip retractor or cotton wool roll under the lips to enable visualization of the gingival margin.
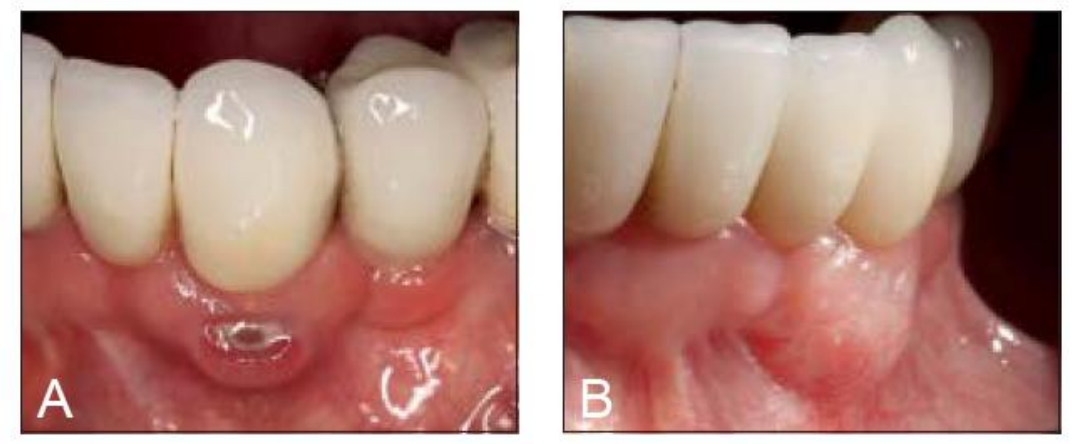

Figure 31. $A$ - Overextended socket shield led to soft tissue perforation. $B$-reduction of the shield allowed for healing and closure.

\section{The socket-shield technique: recommended steps}

1. The root length is measured from the visible gingival level on the CBCT to the root apex.

2. After local anaesthesia, the crown is sectioned from the remaining root structure with a highspeed bur at $1 \mathrm{~mm}$ above the crest to get access to the root canal space. Care must be taken to avoid damage to the soft tissues.

3. If there is no post, jump to section A below. If there is a post present in the root canal, it should be carefully removed with a fast hand piece and a rapid cutting diamond or root resection bur. The cut should not extend around the post; it should rather be limited to the palatal portion of the root to avoid damage to the buccal portion, which will be retained for the shield. The post should be loosened with a slow sweeping motion in the apical direction on the palatal side, until it can be removed. Shield preparation can continue according to the following steps.

\section{A. Measuring the depth}

1. If no material is present in the root canal, an endodontic file is placed to the measured apex to confirm the length of the root from the gingival margin, which will act as the reference point. 
2. If a previous root canal treatment has been completed, the root canal must be widened and the material removed with a number 1 Gates Glidden bur, followed by an X-ray to confirm the length of the root from the gingival margin. If the tooth has not been subjected to endodontic treatment, the root canal must be widened with a number 1 Gates Glidden bur, after which an x-ray determines the length of the root from the gingival margin.

3. The root length is confirmed, and the root canal is widened using increasing sizes of Gates Glidden burs.

4. The length is marked in a long shank root resection bur, which is used to drill to depth straight down the root canal.

5. The depth is confirmed on X-ray to ensure that the apex was reached without left or right deviations. This is important to avoid perforation of the apex or adjacent teeth.

B. Sectioning the root

6. Once depth has been confirmed, the root is sectioned from mesial to distal in a sweeping motion, from apex to coronal. It is critical to keep in mind that, because the root is tapered, the sweeps should be much narrower at the apex as compared to the coronal section.

7. The root is sectioned from the mesial line angle to the distal line angle. It can encroach on the interproximal space, especially if there is an adjacent implant or if it is planned in the future.

8. Once the root is correctly split, an elevator, periotome, or $\mathrm{x}$-tool is placed on the palatal portion of the root to begin mobilising the palatal root portion. The fragment is carefully dislodged buccally towards the space created by the resection bur and removed with a microforceps. It is important to keep finger rest on the buccal gingiva to provide support for the buccal root fragment. This will provide tactile feedback, so the operator can feel any movement in the buccal portion while the palatal portion is being elevated. Movement of the buccal portion indicates that the buccal and palatal fragments are not completely separated. The buccal fragment, its periodontal ligament and the buccal bone crest should not be instrumented.

\section{Apical root preparation}

9. After removal of the palatal portion, it is essential to make sure that the apical portion of the root as well as the root canal contents have been removed. This can be achieved by utilising a long shank round diamond (blue or green diamond). The round diamond is placed at the apex and painted upward, away from the bone, thus thinning the apical portion and removing any remains of the apex. 
10. The area is rinsed with saline solution; granulomatous tissues and apical pathology should be carefully removed from the apex under high magnification and light. When in doubt, the use of a large round bur at slow speed can help ensure removal of the debris. A laser can also be useful to remove stubborn tissue tags from the bone. It is crucial to remove possible sources of infection, including root canal filling material and granulation tissue. An antibiotic rinse, such as metronidazole $500 \mathrm{mg}$ per $100 \mathrm{ml}$, can be used to irrigate the socket.

\section{Coronal root preparation.}

11. Coronal root preparation is one of the most difficult parts; it can lead to complications if not done correctly.

12. The first step is the reduction of the root to the bone level. In his proof of concept article, Hurzeler and coworkers suggested that the root should be left at least $1 \mathrm{~mm}$ above the buccal bone crest (92). However, in the retrospective study from our group, it was found that reduction of the shield to bone level leads to far less complications resulting from internal and external shield exposure. It is imperative to protect the buccal gingiva from the diamond bur, otherwise it can thin it up and lead to an external shield exposure or gingival recession. The shield is further prepared with a long shank bur to become slightly thinner and concave, according to the buccal aspect of the alveolus. The final thickness of the shield should be approximately half of the width from the root canal to the buccal surface of the root.

13. Following shield reduction to bone level, a chamfer is created on the coronal portion, as described by our group (96). This $2 \mathrm{~mm}$ chamfer will create space between the emerging crown and the socket shield. Failure to do this increases the risk of internal shield exposure.

14. Finally, the shield is smoothed off and all sharp edges are removed using a red or yellow long shank diamond bur. The shield must be tested for mobility with a probe. A periapical radiograph can be taken allow for visualisation of the shield.

\section{E. Implant placement}

15. The completion of the shield preparation precedes implant placement. The implant is placed in the correct 3D position, which is planned and executed as if there was no shield present.

16. There are a few important factors that need to be taken into consideration. The implant should be kept as far away from the shield as possible to allow soft tissue to cover the shield. Having the shield up against the implant may have several unwanted sequelae, including internal shield exposure, shield mobility and migration. 
17. In order to create space, the implant should be as narrow as possible, but as wide as necessary to replace the tooth.

18. The implant should also be placed as far palatally as possible to increase the jump gap between the implant and the shield. The palatal position, however, should be within the prosthetic envelope of the crown that will be fitted to the implant.

19. The vertical position of the implant is critical. It is essential to place the implant about $0,5-1 \mathrm{~mm}$ above the apical margin of the $2 \mathrm{~mm}$ chamfer that was previously created in the shield. This will help create space between the shield and the neck of the implant, thus reducing the risk of internal exposure of the implant.

F. Management of the jump gap

20. There is no current data on whether the jump gap should be filled for not. Some groups fill the gap with either xenograft or allograft, while others leave it empty. Both approaches have presented successful results and, until comparative studies are performed, there can be no claim of superiority.

21. Our current approach is that wide jump gaps should filled with highly resorbable calcium phosphosilicate (Novabone). Because the resorption takes places within short time, if calcified tissue is present on the CBCT follow-ups over the long term, it is likely to be bone. Xenografts and allografts do not resorb that easily, thus they can function as a filler with soft tissue encapsulation.

\section{G. Management of the gingival seal}

22. The implant and the bone graft need to be sealed off from the oral cavity. This can be done in one of two ways, either through a custom abutment or a provisional crown.

23. Placement of a provisional crown depends on good initial primary stability of $35 \mathrm{Ncm}$ or higher, as well as an ISQ level of over 75. If these levels are not present, a custom abutment must be placed instead. If there is large apical pathology, no implant can be placed, since it leads to destruction of the apical bone, which is needed for initial primary stability. Under these circumstances, a Glocker approach is recommended. This approach consists of a delayed implant placement, where synthetic bone and a membrane are placed over the shield and the implant is only placed 6 months later, once the bone has healed.

24. It is essential that one of these provisional procedures is carried out, as maintenance of the form and shape of the tissue is key to achieve an outstanding soft tissue profile on long-term. 
Placement of a standard abutment can lead to collapse of the soft tissue, which will need the crown to recreate the profile. During fabrication of the crown, the technician would have no idea on the position of the shield, hence he could inadvertently over build it, leading to thinning off the gingiva overlying the shield and potential shield exposure. A crown with slightly more pressure may lead to orthodontic movement of the shield or its loosening and potential removal.

Instruments and materials needed for the socket shield technique:

1. Long shank bur (root resection)

2. Extra-large round diamond head bur (reduction of the inner aspect of shield into a concavity)

3. End-cutting diamond head bur (reduction of the coronal aspect of shield)

4. Gingival protector

5. Irrigated surgical motor

6. Contra-angled surgical fast hand piece

7. Microperiotomes (atraumatic extraction)

8. Micro forceps (atraumatic extraction).

\section{Pontic shield preparation}

The ideal pontic restoration at an edentulous site requires optimal ridge volume and gingival architecture, which provide harmony between pontic and alveolar ridge, resulting in good aesthetic outcomes (97). Edentulous sites often require surgical interventions to prevent further bone loss and/or augment the collapsed tissues (12).

In 2015, the socket shield was combined with bone grafting to preserve the alveolar bone at pontic sites. Gluckman et al. gave this PET the name "pontic shield"; it combines the preparation of a socket shield with a bone grafting material in cases where root submergence is contra-indicated. Thus, as with the other PETs, the principle is the conservation of vital tooth structure to minimise collapse of the alveolar ridge at pontic sites, thus facilitating aesthetic prosthetic restorations $(16,58)$.

The decision about submergence of the whole root or part thereof (pontic shield) is based on the status of the root and the site. The pontic shield is indicated at pontic sites beneath fixed or removable partial dentures (tooth or implant supported), where root submergence is contra-indicated due to the presence of vertical fracture, apical pathology, failure of the endodontic treatment. Furthermore, if during decoronation of the tooth the pulp is hyperaemic with intense bleeding, shows no bleeding spot or is necrotic, the pontic shield is recommend instead root submergence (15). This approach is 
technically more challenging than root submergence and the cost is increased. It combines the socket shield preparation technique, as described in a previous section, with the use of bone grafting materials.

The initial steps are therefore identical to the socket shield technique, including planning and 3D imaging evaluation. The shield must not be excessively thin in order to preserve its stability and avoid flexure. It is crucial to remove the apical part of the root in the presence of apical infection. Following atraumatic removal of the palatal fragment, curettage of the palatal aspect of the socket and rinse with saline, a bone grafting material is inserted into the socket according to established grafting guidelines. The material should not be densely packed with pressure and the socket shield must not be disturbed. After filling of the socket, complete closure must be achieved with adequate sutures to seal the surgical area. It is the author's experience that aiding closure with a membrane, a rotated pedicle flap or a connective tissue graft can improve healing and avoid complications. The addition of a connective tissue graft presented the best outcomes. A provisional restoration can have light contact with the pontic site during the first 3 months, after which pressure can be gradually increased.

Instruments and materials needed for the pontic shield technique:

1. Long shank bur (root resection)

2. Extra-large round diamond head bur (reduction of the inner aspect of shield into a concavity)

3. End-cutting diamond head bur (reduction of the coronal aspect of shield)

4. Gingival protector

5. Irrigated surgical motor

6. Contra-angled surgical fast hand piece

7. Microperiotomes (atraumatic extraction)

8. Micro forceps (atraumatic extraction)

9. Socket grafting instruments: plugger, particulate graft spoon, crucible

10. SM 69 blade (or other suitable microblade, mandatory for split thickness dissection of facial and palatal pouches to tuck connective tissue graft into)

3. $6 / 0$ nylon sutures.

\section{Root submergence preparation}

The concept of root submergence evolved based on the positive outcomes of accidental retention of fractured roots during extraction (95). The pulp remains vital in the amputated root due to the blood 
supply coming from the apex and the collateral circulation coming from the inner surface of the lap covering the coronal part (98). An early study from Helsham presented a survey of 2.000 patients who were referred for extraction of retained roots; the authors reported that only a small percentage of those patients had symptoms (99).

The potential of root submergence to provide maximum preservation of hard and soft tissues at pontic sites make it a good treatment option. Achieving optimal interdental papillae height can be especially difficult between adjacent implants, thus, keeping the root in a pontic site between implants can result in maintenance of optimal ridge contour and volume and soft-tissue profile, improving short and long-term aesthetic results (91). It can also be an option for planned fixed or removable prosthesis (full or partial). Root submergence can be used to maintain the alveolar bone in young patients while they are actively growing, until the time when implants can be placed. This technique is indicated for infection-free vital or endodontically treated teeth; non-vital teeth and the presence of apical pathology require an alternative PET approach, as discussed in the next section on the pontic shield. Vertical root fractures are a contra-indication to root submergence.

This technique does not require 3D imaging, periapical radiographs can provide enough information for planning this treatment. The technique involves decoronation of a tooth with a diamond bur under copious irrigation; the amputated root must be at least $2-3 \mathrm{~mm}$ below the adjacent bone with the tooth margins at bone level, in order to avoid perforation of the gingiva. As for all PET, the use of a gingival protector can help avoid damage to the soft tissues during surgery. The coronal portion of the root should be hollowed in order to imitate the format of an ovate pontic, sharp edges must be bevelled.

Closure of the soft tissue is an essential aspect of this approach to ensure healing by primary intention. In the 2007 study by Salama et al., who suggested root submergence associated with implantsupported prosthesis, the authors did not advocate soft tissue closure (91). Nevertheless, according to our study group's experience, the absence of soft tissue closure leads to exposed roots, which is not ideal.

There are a few options that can be used to achieve primary closure. A coronally advanced flap can be use in a full arch case; however, this is not the best solution for a single tooth. A free gingival graft can be placed on top of the amputated root to facilitate closure of the soft tissues at single tooth sites (100); another option is the rotated palatal flap (101). For multiple sites, periostal release can be required for closure of the flaps. No pressure should be applied to the soft tissues at the pontic site in the first three months post-surgery (58).

Instruments and materials needed for the root submergence technique: 


\section{Irrigated surgical motor}

2. Contra-angled surgical fast hand piece

3. Extra-large round diamond head bur (reduction of coronal aspect of the root into a concavity)

4. SM 69 blade (or other suitable microblade, mandatory for split thickness dissection of facial and palatal pouches to tuck connective tissue graft into)

5. 6/0 or $7 / 0$ nylon or Proline sutures

\section{Conclusions}

Maintenance of a natural tooth root or part hereof can be the best therapy to prevent post-extraction ridge collapse. PET offer promising treatment approaches and are likely to contribute to a paradigm shift regarding management of tooth extraction sites. Instead of extraction and augmentation, prevention of bone loss in first place is becoming a possibility with PET. The successful application of PET requires a high degree of knowledge and clinical experience. The literature on PET is expanding and this study further contributes to the development of these techniques. 


\section{DISCUSSION}

\section{VI.1. Rationale and technical aspects}

\section{VI.1.1. Root submergence}

Early attempts to preserve edentulous ridges were performed in the 60ties through root submergence, characterising the initial foundation for PET (24). Since alveolar bone reduction is inevitable after tooth removal, the most reliable way to prevent bone resorption is to prevent tooth loss (95). The idea of keeping the root of a condemned tooth originated as a potential solution for the problems encountered with alveolar ridge collapse in full dentures wearers (87). Thus, root submergence was introduced as a treatment strategy to maintain the volume of the alveolar ridge, providing increased retention for dentures. The rationale behind this approach is the maintenance of vital bundle bone through retention of the root, providing better soft and hard tissue architecture and papilla preservation in pontic and edentulous sites (58).

The concept evolved based on the positive outcomes of accidental retention of fractured roots during extraction. An early study from Helsham presented a survey of 2.000 patients who were referred for extraction of retained roots; the authors reported that only a small percentage of those patients had symptoms. Histological analysis was performed in sixty of the retained roots, vital pulp was observed in forty-six of them (99). In another study from Herd (1973), 228 unintentionally retained root fragments in 171 individuals were evaluated. The author found vital pulps and absence of inflammation in 163 of them (102).

Root submergence have also been reported as an alternative treatment for idiopathic root resorption (103) and for cervical fracture of immature permanent teeth in young patients (104). High clinical success (over 90\%) has been reported for root submergence of anterior permanent teeth in young patients over a 2-year follow (105).

The success rate of root submergence is much higher for pontic sites, since the pressure in these sites is much lower when compared to the pressure under full dentures. Hence, this is a promising treatment strategy to help maintain the alveolar ridge in patients who need tooth replacement in larger areas.

This technique was initially introduced as a potential solution for periodontal reattachment and ridge preservation under full dentures. More recent studies indicate that this technique can help preserve interdental papilla height and ridge contour in pontic areas between implants or prosthetic abutments. However, the literature presents high variation in success rates, from around 50 to $100 \%$. Lack of 
standardization, different success criteria and data collection methods leads are some of the limitation factors. Further clinical studies are required to validate the long-term viability of this conservative ridge preservation treatment.

\section{VI.1.2. Socket-shield}

The fact that the currently used socket preservation techniques can only limit alveolar ridge resorption to a certain degree led to the search for alternative options (92). Understanding that the majority of patients have very thin buccal walls in the anterior areas, that extraction per se can be a traumatic event to such thin plates, and that destruction of the periodontal ligament post-extraction causes an irreversible loss of blood supply to the bundle bone has provided a foundation for the development of PET, using the tooth itself to offset loss of alveolar bone $(15,58,90,92)$.

The history of PET started almost 60 years ago, with the first attempts to maintain alveolar bone volume through root submergence (24). Clinical, radiographic and histologic analysis were able to confirm formation of cementum and bone around the root as well as on the coronal part of the root (106-108).

Early attempts of implant placement in contact with root fragments were reported in a few publications. Experimental studies were able to show formation of cementum and/or periodontal ligament at implants placed in contact with pieces of root tips (109-111). In 2009, a case report presented implant placement in direct contact with ankylosed roots in five patients, with almost four years follow-up. All implants survived, the only complication was self-limiting dentin resorption on one of the fragments (112). In 2010, Hurzeler and coworkers published an animal study together with one case report using a similar approach to keep part of the root in contact with immediate implants. The authors called it the socket shield technique and provided the first scientific foundations for PET (92).

The socket shield technique involves preparation of the root of a condemned tooth in such way that part thereof is maintained in the socket (usually the facial part) with its periodontal attachment, including periodontal ligament, vascular elements, cementum and bundle bone (16, 92). This approach is intended to be used in combination with immediate implant placement. The aim is to keep a vital shield, free of complications, which will provide support for the buccal bone, thus avoiding the physiological changes that result in alveolar ridge changes. The end-goal is to preserve the three-dimensional volume of the alveolar ridge to provide optimal functional and aesthetic results for the implant restoration. 


\section{VI.1.2.1. Variations in the socket-shield technique}

The original socket shield technique described by Hurzeler and his working group in 2010 and 2017 employs osteotomy drills in the palatal aspect of the root, after which remaining fragments are removed, leaving only the buccal portion $(92,113)$. The height of the shield is reduced to $1 \mathrm{~mm}$ above bone level and the authors apply enamel matrix derivative to the shield before proceeding with implant placement; no grafting is used.

In 2014, a variation of the socket shield called root membrane was suggested by Siormpas and colleagues, which is in fact very similar to Hurzeler's technique. The authors start the drilling sequence after tooth decoronation using osteotomy drills in the palatal aspect of the root; after preparation only the buccal fragment of the root remains in situ $1 \mathrm{~mm}$ above bone crest. No grafting materials are used (114). In a recent study from the same group (115), the authors changed the technique to include sectioning of the root in the mesio distal aspect and atraumatic extraction of the palatal fragment.

In 2015, our goup was the first to include careful separation of buccal and palatal aspects of the root when preparing the socket shield, providing a more atraumatic version of the original approach, aimed at minimising dentin fracture, mobility of the shield and general surgical trauma (16). While Hurzeler et al. and Mitsias et al. $(92,116,117)$ reported the use of implant drills to prepare the socket shield, our study group uses high-speed drills. The reason for the change in technique was due to a number of factors. Firstly, the use of implant osteotomy drills quickly becomes a very expensive exercise, as the drills are rapidly blunted after a single use when drilling through the dense root structure. Secondly, the drills tend to cause massive vibration and chatter as one starts to enlarge the osteotomy through the root, thus causing loosening of the shield from the bone, which may lead to shield failure and subsequent bone and loss and infection. Thirdly, the implant drill will naturally take the path of least resistance, which is directly down the root canal. This in itself is problematic, as most often the implant position is more palatal (31), leading the osteotomy to be in the incorrect three dimensional position. Direct drilling through the root canal may also lead to perforation of the buccal plate in class 2, 3, 4 and 5 tooth positioned.

Initially, the socket shield was kept $1 \mathrm{~mm}$ above the bone crest; the rationale for this is the stabilization of the supracrestal periodontal fibres and hence prevention of the collapse of the supracrestal soft tissues. However, our group was the first to change it to bone level to avoid complications associated with the exposure of the shield and to recommend a chamfer in the coronal $2 \mathrm{~mm}$ of the shield to provide adequate prosthetic space (96). Later, Han et al. also reported the use of the socket shield at bone level (74). Another change made by Gluckman's group is the use of a bone substitute to fill the 
jumping gap between the implant and the shield, based on results from immediate implant studies showing decreased bone loss and better histological results when a bone substitute is used at immediate implant sites $(35,118)$. This step can be omitted in the absence of space $(90)$.

The use of proximal socket shields was presented in two case reports as an attempt to preserve the interproximal papillae $(119,120)$. Both studies presented positive outcomes with regards to the maintenance of papillae and the scalloped gingival architecture at immediate implants sites.

Lastly, another research group published a case report on the so called root $\mathrm{T}$ belt, which was later applied in an experimental study by the same group (121). In this technique, drilling is performed through the centre of the root in order to create a chamber for the implant, which is completely surrounded by root dentin. The immediate implant should pass the apex of the root by $3 \mathrm{~mm}$. This creates a belt-like protection to prevent displacement of the implant. From the above-mentioned alternatives for the socket shield, the root $\mathrm{T}$ belt presents the poorest results and the authors concluded that a thick root structure (over $2 \mathrm{~mm}$ ) is detrimental to maintenance of the crestal bone (121). It may be inferred that the presence of dentine walls around an immediate implant obstructs the entrance of mesenchymal and pluripotent cells, which is detrimental to the osseointegration process. Currently, there is a lack of studies comparing the different variations of the original socket shield technique.

\section{VI.1.3. Pontic shield}

The pontic shield is a new technique created by Gluckman et al. to circumvent the contra-indications of the root submergence technique (97). This technique is still in its infancy regarding scientific evidence, hence additional research is warranted to validate its application in clinical practice.

\section{VI.2. Complications of PET and their management}

In the report of 128 socket shield cases, our group presented a comprehensive description of the most frequent complications associated with the socket shield technique and their treatment options (90). The most frequent complication was exposure of the shield, present in $12.5 \%$ of the sites. The majority of the exposures were internal $(9.4 \%)$, i.e. the coronal part of the shield perforated the gingiva towards the restoration. The remaining sites had external exposures $(3.1 \%)$ towards the oral cavity. Internal exposures are usually evident during removal of provisional restorations. Exposures are typically caused by excessive height of the shield or by sharp edges that can perforate the gingiva (90). The treatment recommended by our study group included raising a micro-flap to reduce the height of the shield to bone levels and smoothing of eventual sharp edges with a high-speed diamond 
bur. In all instances, a small connective tissue graft can greatly assist with closure. One case of shield migration was also presented in this study, which did not require any treatment (90).

Initially, our group suggested that the socket-shield should stay $1 \mathrm{~mm}$ above bone level as an attempt to preserve the periodontal fibres $(15,58)$. However, we have changed the protocol to reduce the shield to bone level and include preparation of a chamfer in its most coronal part, in order to provide $2-3 \mathrm{~mm}$ of prosthetic space between the margin of the subgingival crown and the shield, allowing for adequate space for soft tissue (96). Those changes led to an almost complete elimination of complications related to exposure of the shield.

Infection of the socket shield is another possible complication, it was reported in 3 out of 128 cases in our study (90). In one site, the shield had to be removed and the implant was kept in place after decontamination and GBR procedures. In the other two cases of infection, both implant and shield were removed. In one of them, another implant was placed, together with standard GBR techniques after healing and resulted in successful osseointegration. In the other patient, a ridge preservation approach was chosen with socket grafting and later restored with a fixed partial prosthesis. In fact, the two major reasons for the complications observed in this study from our group was that the shields were too short and/or too thin. The reduction of the shield width was attempted to increase the space between the shied and the implant in order to reduce the internal shield exposure. However, thinning of the shield led to flexion and loosening. Keeping the shield around 1,5-2mm thick has eliminated this problem completely and the addition of the chamfer for the prosthetic space has reduced the number of internal exposures dramatically (96).

The last complication encountered by our group was implant failure in 5 cases out of the $128(3 \%)$. Those implants were removed and the areas were managed; in three cases, the shields were not infected. Two sites received new implants, one site was simply converted into a pontic-shield after implant removal, and in the last two implant failures, shields and implants were removed and the area was restored through conventional prosthetic solutions. Infected and mobile shield must always be removed according to the author's experience. In most of the cases, the reason for the implant failure was the early load from the provisional and inadequate primary stability of the implant.

A recent retrospective study from Siormpas et al. reported a total of 8 complications out of 250 immediate implants placed in combination with the root membrane technique, with up to 10 years follow-up. Five of the complications consisted of infection of the root fragment, two consisted of implant mobility (lack of osseointegration) and one was peri-implantitis. The complications resulted in implant loss in five of the eight cases. Even though the incidence of complications was low, it can be speculated if it would have been even lower if the root fragments had been prepared at bone level, as opposed to $1 \mathrm{~mm}$ higher than the bone crest, as reported by the authors (115). 
Overall, the prevalence of complications in the clinical studies evaluating socket shield is not high. In a recent study, none of the fifteen patients included presented complications (122). Han et al. did not report biological complications for the forty sites included; one patient presented a prosthetic complication 2 months after implant surgery (loose abutment) (123). Complications were also absent in the ten sites included in the study by Bäumer et al. after 5 years follow-up (132).

Siormpas et al. reported one single complication out of 40 sites ( $2 \%$ of the cases), a self-limiting root resorption that did not affect implant survival. However, as observed in the clinical photos and in the histological images, the authors prepared the socket shield above bone level and did not include internal exposure in the complications. Thus, the reported prevalence of complications needs to be interpreted with caution (114).

As for every surgical procedure, the socket shield has risk for complications. Our group has gained significant insight into the occurrence of complications after the study with $20 \%$ complication rate and up to 4 years recall. Only a small percentage of those required removal of the shield and major rehabilitation of the implant site. The majority ( $16 \%$ out of $20 \%$ ) were retrievable and could have been avoided through the modification of the technique. Our experience with the change in the original protocol shows a drastic reduction in the number of complications.

The same complications mentioned for the socket shield can be expected for pontic shield sites. In the only currently available publication, exposure of three out of ten shields was present as a result of lack of soft tissue closure; the sites were successfully treated through resection of the exposed sections above the crestal bone (97).

In the literature, perforation of gingival tissues, cyst formation, root resorption and periapical pathology have been reported as potential complications associated with root submergence; the frequency of complications is higher when the submergence sites are subjected to occlusal forces $(124,125)$. In the study by Garver et al., forty-five roots were submerged and subjected to occlusal forces under overdentures. After two years, $18 \%$ of the submerged roots required endodontic treatment (126).

Perforation of the soft tissues can be prevented by keeping the height of the remaining root slightly lower than the crestal bone and by avoiding sharp edges through bevelling. Necrosis of the dental pulp and infection seem to be a rare complications, which can require endodontic treatment (91). If the root over erupts spontaneously, it can be reprepared and resubmerged (15).

Using part of the tooth itself to keep the volume of the alveolar ridge is a conservative and costeffective approach in clinical practice. More studies are necessary to further confirm the long-term biological compatibility and complication associated with PET. 


\section{VI.3. Prosthetic considerations}

The finding that $9.4 \%$ of the 128 cases of socket-shield followed up for up to 4 years presented exposure of the shield highlighted the importance of prosthetic management for this technique. Internal exposure means that part of the shield penetrated the soft tissues facing the crown and the abutment, which in many cases resulted in inflammatory changes. This complication requires treatment, as highlighted in the section on complications associated with PET, since peri-implant soft tissues must remain healthy without inflammation or ulcerations (96).

Immediate implant placement combined with the socket shield technique is an advanced procedure, as such, it is recommended that a comprehensive planning of the prosthetic outcomes is carried out together with the general planning. Use of digital smile design or similar software or trial restorations are imperative for successful results (96).

During preparation of the socket shield, contrary to previous guidelines, our group suggests that the height of the shield must be at crestal level and not above it. We also suggest the preparation of an internal bevelled chamfer, which allows accommodation of an S-shaped emergency profile for the crown, creating adequate prosthetic space. Regarding interim restorations, they are indicated only when the implant has high primary stability ( $>70$ ISQ). If the primary stability is not adequate ( $<60$ ISQ), a customized transgingival abutment should be used in order to mimic the intended emergence profile. In the transgingival component, a narrow S-shape is recommended to ensure enough space for the soft tissues. When placing the prosthetic component, which is intended to seal the socket, there should be minimal or no blanching of the facial gingiva. The interim crown should not have contacts in excursive movements and maximum intercuspation. If a custom abutment is used, there should be no contact with the subsequent provisional prosthetic component. A post-operative radiograph is crucial this stage.

The importance of the S-shape at the connecting abutment for both interim and permanent restorations cannot be underestimated. It should be as narrow as possible as it emerges, to allow for adequate space for soft tissue growth, followed by a wider curve. This design prevents excessive pressure on the coronal part of the shield, which can facilitate exposure (96). The use of customized impression techniques, whether digital or analogue, is essential to duplicate the subgingival portion of the crown or the custom abutment. Failure to follow this may lead to increased pressure on the shield, which can lead to an internal exposure due to the thinning of the overlying gingiva by the final crown. 


\section{VI.4. Perspectives and the future of partial extraction techniques}

Despite all the advancements in dental research, tooth loss due to disease and trauma remains a burden worldwide. The discovery of the osseointegration and biocompatible properties of titanium changed the course of tooth replacement, resulting in a major shift in traditional restorative dentistry (127).

As life expectancy increases, so does the need for oral health care and tooth replacement, creating an ever-increasing demand for implants. In the first two decades of implant dentistry, survival was the ultimate treatment goal for implant-supported restorations. The increase in aesthetic expectations by patients and dentists has driven the search for more reliable, predictable, conservative and costeffective restorative cosmetic outcomes (128).

Placement of immediate implants into extraction sockets have brought new perspectives, significantly reducing treatment duration, however, this treatment option does not prevent the inevitable loss of alveolar bone resulting from tooth extraction $(27,67,81)$. Loss of hard and soft tissues post tooth removal remains one the biggest challenges in aesthetic areas. The currently available ridge preservation techniques present limited results when it comes to preventing bone loss and rebuilding bone volume. PET have emerged as a conservative and preventive approach to counteract bone collapse by keeping part of the tooth in its alveolus. Clinicians worldwide are starting to use PET in clinical practice, as seen by the ever-increasing number of studies in the literature. From a biological perspective, long-term studies with up to 10 years follow-up have provided evidence on the safety of these techniques. However, because science makes slow progress, there are still knowledge gaps that require well-planned, controlled clinical studies with larger sample sizes. Our study group has been actively engaged in the production of scientific foundation to create evidence-based practices for PET. With seven publications in this field, two ongoing studies (a multicentre study and a split-mouth design study), we intend to explore every aspect of PET and bridge the gap between clinical decision making and research evidence.

In the literature on PET, few studies have measured volumetric bone changes, which is the ultimate way to measure ridge collapse. Ideally, bone loss analysis should be combined with aesthetic parameters. The use of bone substitutes to graft the gap between the immediate implant and the socket shield is a topic that needs further exploration, as well as the outcomes associated with variations in the socket-shield technique. Ideally, RCT should be employed to explore the influence of different types of bone grafting materials as compared to no grafting. The same principle can be used investigate the effect of variations in the preparation of socket-shields proposed by different study 
groups. The influence of different macro and micro design features of dental implants when used in fresh extraction sockets in combination with the socket shield is also a subject that requires attention in future investigations.

Ethical concerns might hinder the development of randomized clinical trials in some instances. Leaving extraction sockets to heal naturally would be the ideal control group in some studies; however, the amount of evidence on the inevitable ridge collapse that follows tooth extraction makes it ethically unacceptable in clinical studies involving aesthetic areas. Comparison of PET to other ridge preservation techniques in vivo can also become a challenge for the recruitment of participants for clinical studies, considering the far superior aesthetic outcomes observed in areas subjected to PET. Randomization aids in reducing bias in clinical studies, in order to allow for differentiating the effects from treatment itself and the effects of bias. When randomization is not possible for practical and/or ethical reasons, well-designed studies with large sample sizes should be performed.

Due to the advanced surgical skills required for the execution of the socket shield and the pontic shield, these techniques have been used mainly in anterior sites in the maxilla. Because preservation of bone volume is also advantageous in other areas, it can be expected that these approaches would be further developed for use in posterior sites.

\section{VI.5. Contribution of our studies to PET}

Over the last four years, our group published a total of seven scientific publications on PET- the ones that give the basis of this thesis.

The retrospective study on the 128 cases (90) provided a learning curve, as we changed our technique to become more standardized and to decrease the prevalence of complications after encountering a high prevalence of complications. As a result, the occurrence of internal and external exposure of socket-shields presented a marked reduction, as observed in our clinical practice.

We are currently developing two new studies on PET, a multi-centre study on implant survival and the prevalence of complications for the socket-shield technique, and a randomized clinical trial to evaluate a new implant design for immediate implants placed concomitantly with the socket-shield. Despite the relatively weak scientific evidence associated with uncontrolled case series and case reports, especially related to the lack of a comparison group, the sample size of the case series including 128 cases and the mid-term follow-up gives credibility to our results. Through our case series, we were able to expand our knowledge on the socket-shield technique. During the evaluation of PET, the use of comparison groups using other ridge preservation techniques or GBR might result 
in alveolar ridge collapse, which can raise ethical constraints. Hence, our case series can be considered as a source of clinical knowledge on PET, as it provided new insights on implant survival and on the prevalence of complications associated with the socket shield technique.

Despite the smaller sample size and the lack of objective evaluation of the alveolar ridge, the case series including 14 cases also contributes with initial data on the pontic-shield, considering that this was the first case series on this technique (97).

From the two case reports published by our group $(16,129)$, the most recent (129) should receive particular attention due to the histological results confirming the presence of mature bone tissue between the implant and an unplanned socket-shield, around the implant and between its threads. These findings provide the first histological evidence on the nature of the tissues formed around a socket-shield in humans.

The last group of publications from our group include three technique reports, aiming at standardizing the clinical steps for each of the PET techniques and for the prosthetic restoration of immediate implants combined with the socket-shield $(15,58,96)$. These studies provide a solid step-by-step approach to minimize bias in future studies and to guide clinicians and researchers when executing PET.

The publications from our study group have greatly contributed to the current understanding of PET and have led to important clinical changes to increase the predictability, efficacy and overall success of PET. In terms of contribution to society, our studies suggest that the use of the patient's own dental tissues is a safe, reliable and less invasive option to prevent the deleterious bone loss that follows tooth loss.

Among PET techniques, the socket shield has been the most extensively studied by our group and in the literature in general. Root submergence was extensively studies as a support for removable dentures, however, very few studies have evaluated its use in pontic sites. The pontic-shield is a brand-new technique invented by our group and requires even more consolidation from scientific studies. Altogether, despite the rise in the amount of publications on the topic, there is still a lack of robust controlled trials and our group hopes to keep contributing to the growth of PET as a tool in the clinical management of extraction sockets. 


\section{CONCLUSIONS}

The bundle bone is a tooth-dependent structure, which is crucial for the preservation of bone volume in the alveolar ridge. Tooth loss leads to irreversible collapse of the buccal plate, potentially leading to vertical and horizontal bone loss, gingival recession and collapse of the papilla. Currently used techniques for socket maintenance are limited in terms of preventing alveolar bone loss post tooth extraction. Partial extraction therapies (PET) including socket shield, pontic shield and root submergence techniques offer a promising solution to prevent ridge collapse using the tooth itself or part thereof. The literature on PET has expanded significantly since the introduction of the concept in 2010. Even though a few clinical trials have been published and long-term results are available to confirm the safety and the efficacy of the socket shield technique, the majority of the studies are casereports, highlighting the need for stronger scientific evidence for the clinical performance of PET in relation to other ridge preservation techniques. PET are conservative options that offer great potential in the prevention of alveolar bone collapse post tooth extraction. The socket shield technique has been the mostly explored in the literature and most studies show optimal aesthetic and functional outcomes for immediate implant placement. The major drawback for PET seems to be the advanced surgical techniques involved. Our study group has explored different aspects of PET and will continue to do so in the future. Currently, a multi-center study and a clinical study evaluating the effect of implant design on the socket shield technique are being conducted. The use of PET holds promise in terms of maintenance of three dimensional ridge volume, aesthetics, safety and reliability. Altogether, PET are effective preventive strategies to maintain bone volume in extraction sockets and should therefore become an integral part of implant dentistry and restorative dentistry. 


\section{REFERENCES}

1. Trombelli L, Farina R, Marzola A, Bozzi L, Liljenberg B, Lindhe J. Modeling and remodeling of human extraction sockets. J Clin Periodontol. 2008;35(7):630-9.

2. Sculean A, Chappuis V, Cosgarea R. Coverage of mucosal recessions at dental implants. Periodontol 2000. 2017;73(1):134-40.

3. Ten Heggeler JM, Slot DE, Van der Weijden GA. Effect of socket preservation therapies following tooth extraction in non-molar regions in humans: a systematic review. Clin Oral Implants Res. 2011;22(8):779-88.

4. Chen ST, Buser D. Clinical and esthetic outcomes of implants placed in postextraction sites. Int J Oral Maxillofac Implants. 2009;24 Suppl:186-217.

5. Felice P, Soardi E, Piattelli M, Pistilli R, Jacotti M, Esposito M. Immediate non-occlusal loading of immediate post-extractive versus delayed placement of single implants in preserved sockets of the anterior maxilla: 4-month post-loading results from a pragmatic multicentre randomised controlled trial. Eur J Oral Implantol. 2011;4(4):329-44.

6. Raes F, Cosyn J, Crommelinck E, Coessens P, De Bruyn H. Immediate and conventional single implant treatment in the anterior maxilla: 1-year results of a case series on hard and soft tissue response and aesthetics. J Clin Periodontol. 2011;38(4):385-94.

7. Kinaia BM, Shah M, Neely AL, Goodis HE. Crestal bone level changes around immediately placed implants: a systematic review and meta-analyses with at least 12 months' follow-up after functional loading. J Periodontol. 2014;85(11):1537-48.

8. Mangano C, Raes F, Lenzi C, Eccellente T, Ortolani M, Luongo G, et al. Immediate Loading of Single Implants: A 2-Year Prospective Multicenter Study. Int J Periodontics Restorative Dent. 2017;37(1):69-78.

9. Araujo MG, Wennstrom JL, Lindhe J. Modeling of the buccal and lingual bone walls of fresh extraction sites following implant installation. Clin Oral Implants Res. 2006;17(6):606-14.

10. Araujo MG, Sukekava F, Wennstrom JL, Lindhe J. Ridge alterations following implant placement in fresh extraction sockets: an experimental study in the dog. J Clin Periodontol. 2005;32(6):645-52.

11. Botticelli D, Persson LG, Lindhe J, Berglundh T. Bone tissue formation adjacent to implants placed in fresh extraction sockets: an experimental study in dogs. Clin Oral Implants Res. 2006;17(4):351-8.

12. Kuchler U, Chappuis V, Gruber R, Lang NP, Salvi GE. Immediate implant placement with simultaneous guided bone regeneration in the esthetic zone: 10-year clinical and radiographic outcomes. Clin Oral Implants Res. 2016;27(2):253-7.

13. Cosyn J, Eghbali A, Hermans A, Vervaeke S, De Bruyn H, Cleymaet R. A 5-year prospective study on single immediate implants in the aesthetic zone. J Clin Periodontol. 2016;43(8):702-9. 
14. Tonetti MS, Cortellini P, Graziani F, Cairo F, Lang NP, Abundo R, et al. Immediate versus delayed implant placement after anterior single tooth extraction: the timing randomized controlled clinical trial. J Clin Periodontol. 2017;44(2):215-24.

15. Gluckman H, Salama M, Du Toit J. Partial Extraction Therapies (PET) Part 2: Procedures and Technical Aspects. Int J Periodontics Restorative Dent. 2017;37(3):377-85.

16. Gluckman H, du Toit J, Salama M. The socket-shield technique to support the buccofacial tissues at immediate implant placement. Int Dent Afr Ed. 2015;5(3):6-14.

17. Pagni G, Pellegrini G, Giannobile WV, Rasperini G. Postextraction alveolar ridge preservation: biological basis and treatments. Int J Dent. 2012;2012:151030.

18. Van der Weijden F, Dell'Acqua F, Slot DE. Alveolar bone dimensional changes of postextraction sockets in humans: a systematic review. J Clin Periodontol. 2009;36(12):1048-58.

19. Chappuis V, Engel O, Reyes M, Shahim K, Nolte LP, Buser D. Ridge alterations postextraction in the esthetic zone: a 3D analysis with CBCT. J Dent Res. 2013;92(12 Suppl):195S-201S.

20. Evian CI, Rosenberg ES, Coslet JG, Corn H. The osteogenic activity of bone removed from healing extraction sockets in humans. J Periodontol. 1982;53(2):81-5.

21. Farina R. Wound healing of extraction sockets. Endod Top. 2011;25(1):16-43.

22. Araujo MG, Lindhe J. Dimensional ridge alterations following tooth extraction. An experimental study in the dog. J Clin Periodontol. 2005;32(2):212-8.

23. Cardaropoli G, Araujo M, Lindhe J. Dynamics of bone tissue formation in tooth extraction sites. An experimental study in dogs. J Clin Periodontol. 2003;30(9):809-18.

24. Amler MH, Johnson PL, Salman I. Histological and histochemical investigation of human alveolar socket healing in undisturbed extraction wounds. J Am Dent Assoc. 1960;61:32-44.

25. Carlsson GE, Bergman B, Hedegard B. Changes in contour of the maxillary alveolar process under immediate dentures. A longitudinal clinical and x-ray cephalometric study covering 5 years. Acta Odontol Scand. 1967;25(1):45-75.

26. Tan WL, Wong TL, Wong MC, Lang NP. A systematic review of post-extractional alveolar hard and soft tissue dimensional changes in humans. Clin Oral Implants Res. 2012;23 Suppl 5:1-21.

27. Botticelli D, Berglundh T, Lindhe J. Hard-tissue alterations following immediate implant placement in extraction sites. J Clin Periodontol. 2004;31(10):820-8.

28. Misawa M, Lindhe J, Araujo MG. The alveolar process following single-tooth extraction: a study of maxillary incisor and premolar sites in man. Clin Oral Implants Res. 2016;27(7):884-9.

29. Ferrus J, Cecchinato D, Pjetursson EB, Lang NP, Sanz M, Lindhe J. Factors influencing ridge alterations following immediate implant placement into extraction sockets. Clin Oral Implants Res. 2010;21(1):22-9.

30. Evans CD, Chen ST. Esthetic outcomes of immediate implant placements. Clin Oral Implants Res. 2008;19(1):73-80. 
31. Gluckman H, Pontes CC, Du Toit J. Radial plane tooth position and bone wall dimensions in the anterior maxilla: A CBCT classification for immediate implant placement. J Prosthet Dent. 2018;120(1):50-6.

32. Kan JY, Rungcharassaeng K, Umezu K, Kois JC. Dimensions of peri-implant mucosa: an evaluation of maxillary anterior single implants in humans. J Periodontol. 2003;74(4):557-62.

33. Tomasi C, Sanz M, Cecchinato D, Pjetursson B, Ferrus J, Lang NP, et al. Bone dimensional variations at implants placed in fresh extraction sockets: a multilevel multivariate analysis. Clin Oral Implants Res. 2010;21(1):30-6.

34. Buser D, Martin W, Belser UC. Optimizing esthetics for implant restorations in the anterior maxilla: anatomic and surgical considerations. Int J Oral Maxillofac Implants. 2004;19 Suppl:43-61.

35. Chen ST, Darby IB, Reynolds EC. A prospective clinical study of non-submerged immediate implants: clinical outcomes and esthetic results. Clin Oral Implants Res. 2007;18(5):552-62.

36. Buser D, Chappuis V, Belser UC, Chen S. Implant placement post extraction in esthetic single tooth sites: when immediate, when early, when late? Periodontol 2000. 2017;73(1):84-102.

37. Covani U, Cornelini R, Calvo-Guirado JL, Tonelli P, Barone A. Bone remodeling around implants placed in fresh extraction sockets. Int J Periodontics Restorative Dent. 2010;30(6):601-7.

38. Kao RT, Fagan MC, Conte GJ. Thick vs. thin gingival biotypes: a key determinant in treatment planning for dental implants. J Calif Dent Assoc. 2008;36(3):193-8.

39. Hwang D, Wang HL. Flap thickness as a predictor of root coverage: a systematic review. J Periodontol. 2006;77(10):1625-34.

40. Romeo E, Lops D, Amorfini L, Chiapasco M, Ghisolfi M, Vogel G. Clinical and radiographic evaluation of small-diameter $(3.3-\mathrm{mm})$ implants followed for 1-7 years: a longitudinal study. Clin Oral Implants Res. 2006;17(2):139-48.

41. Maia LP, Reino DM, Muglia VA, Almeida AL, Nanci A, Wazen RM, et al. Influence of periodontal tissue thickness on buccal plate remodelling on immediate implants with xenograft. J Clin Periodontol. 2015;42(6):590-8.

42. Linkevicius T, Apse P, Grybauskas S, Puisys A. The influence of soft tissue thickness on crestal bone changes around implants: a 1-year prospective controlled clinical trial. Int J Oral Maxillofac Implants. 2009;24(4):712-9.

43. Chappuis V, Engel O, Shahim K, Reyes M, Katsaros C, Buser D. Soft Tissue Alterations in Esthetic Postextraction Sites: A 3-Dimensional Analysis. J Dent Res. 2015;94(9 Suppl):187S-93S.

44. Chappuis V, Araujo MG, Buser D. Clinical relevance of dimensional bone and soft tissue alterations post-extraction in esthetic sites. Periodontol 2000. 2017;73(1):73-83.

45. Merheb J, Quirynen M, Teughels W. Critical buccal bone dimensions along implants. Periodontol 2000. 2014;66(1):97-105.

46. Leblebicioglu B, Hegde R, Yildiz VO, Tatakis DN. Immediate effects of tooth extraction on ridge integrity and dimensions. Clin Oral Investig. 2015;19(8):1777-84. 
47. Garetto LP, Chen J, Parr JA, Roberts WE. Remodeling dynamics of bone supporting rigidly fixed titanium implants: a histomorphometric comparison in four species including humans. Implant Dent. 1995;4(4):235-43.

48. Schropp L, Wenzel A, Kostopoulos L, Karring T. Bone healing and soft tissue contour changes following single-tooth extraction: a clinical and radiographic 12-month prospective study. Int J Periodontics Restorative Dent. 2003;23(4):313-23.

49. Araujo MG, Lindhe J. Ridge alterations following tooth extraction with and without flap elevation: an experimental study in the dog. Clin Oral Implants Res. 2009;20(6):545-9.

50. Seibert JS, Salama H. Alveolar ridge preservation and reconstruction. Periodontol 2000. 1996;11:69-84.

51. Grunder U, Gracis S, Capelli M. Influence of the 3-D bone-to-implant relationship on esthetics. Int J Periodontics Restorative Dent. 2005;25(2):113-9.

52. Salama H, Salama MA, Garber D, Adar P. The interproximal height of bone: a guidepost to predictable aesthetic strategies and soft tissue contours in anterior tooth replacement. Pract Periodontics Aesthet Dent. 1998;10(9):1131-41; quiz 42.

53. Hermann JS, Buser D, Schenk RK, Schoolfield JD, Cochran DL. Biologic Width around oneand two-piece titanium implants. Clin Oral Implants Res. 2001;12(6):559-71.

54. Zetu L, Wang HL. Management of inter-dental/inter-implant papilla. J Clin Periodontol. 2005;32(7):831-9.

55. Spray JR, Black CG, Morris HF, Ochi S. The influence of bone thickness on facial marginal bone response: stage 1 placement through stage 2 uncovering. Ann Periodontol. 2000;5(1):119-28.

56. Chow YC, Wang HL. Factors and techniques influencing peri-implant papillae. Implant Dent. 2010;19(3):208-19.

57. Araujo MG, da Silva JCC, de Mendonca AF, Lindhe J. Ridge alterations following grafting of fresh extraction sockets in man. A randomized clinical trial. Clin Oral Implants Res. 2015;26(4):407-12.

58. Gluckman H, Salama M, Du Toit J. Partial Extraction Therapies (PET) Part 1: Maintaining Alveolar Ridge Contour at Pontic and Immediate Implant Sites. Int J Periodontics Restorative Dent. 2016;36(5):681-7.

59. Dies F, Etienne D, Abboud NB, Ouhayoun JP. Bone regeneration in extraction sites after immediate placement of an e-PTFE membrane with or without a biomaterial. A report on 12 consecutive cases. Clin Oral Implants Res. 1996;7(3):277-85.

60. Becker BE, Becker W, Ricci A, Geurs N. A prospective clinical trial of endosseous screwshaped implants placed at the time of tooth extraction without augmentation. J Periodontol. 1998;69(8):920-6.

61. Artzi Z, Tal H, Dayan D. Porous bovine bone mineral in healing of human extraction sockets: 2. Histochemical observations at 9 months. J Periodontol. 2001;72(2):152-9. 
62. Lazzara RJ. Immediate implant placement into extraction sites: surgical and restorative advantages. Int J Periodontics Restorative Dent. 1989;9(5):332-43.

63. Becker W, Becker BE, Caffesse R. A comparison of demineralized freeze-dried bone and autologous bone to induce bone formation in human extraction sockets. J Periodontol. 1994;65(12):1128-33.

64. Schulte W, Kleineikenscheidt H, Lindner K, Schareyka R. [The Tubingen immediate implant in clinical studies]. Dtsch Zahnarztl Z. 1978;33(5):348-59.

65. Dahlin C, Sennerby L, Lekholm U, Linde A, Nyman S. Generation of new bone around titanium implants using a membrane technique: an experimental study in rabbits. Int $\mathrm{J}$ Oral Maxillofac Implants. 1989;4(1):19-25.

66. Ross SE, Strauss T, Crossetti HW, Gargiulo AW. The immediate placement of an endosseous implant into an extraction wound: a clinical case report using the RosTR System. Int J Periodontics Restorative Dent. 1989;9(1):34-41.

67. Barzilay I. Rotational accuracy of implant components for single-tooth, root-form implants. Dent Implantol Update. 1991;2(1):5-7.

68. Freitas RM, Spin-Neto R, Marcantonio Junior E, Pereira LA, Wikesjo UM, Susin C. Alveolar ridge and maxillary sinus augmentation using rhBMP-2: a systematic review. Clin Implant Dent Relat Res. 2015;17 Suppl 1:e192-201.

69. Dohan Ehrenfest DM, Del Corso M, Diss A, Mouhyi J, Charrier JB. Three-dimensional architecture and cell composition of a Choukroun's platelet-rich fibrin clot and membrane. J Periodontol. 2010;81(4):546-55.

70. Vittorini Orgeas G, Clementini M, De Risi V, de Sanctis M. Surgical techniques for alveolar socket preservation: a systematic review. Int J Oral Maxillofac Implants. 2013;28(4):1049-61.

71. Shapoff CA, Bowers GM, Levy B, Mellonig JT, Yukna RA. The effect of particle size on the osteogenic activity of composite grafts of allogeneic freeze-dried bone and autogenous marrow. $\mathrm{J}$ Periodontol. 1980;51(11):625-30.

72. Eskow AJ, Mealey BL. Evaluation of healing following tooth extraction with ridge preservation using cortical versus cancellous freeze-dried bone allograft. J Periodontol. 2014;85(4):514-24.

73. Froum S, Orlowski W. Ridge preservation utilizing an alloplast prior to implant placement-clinical and histological case reports. Pract Periodontics Aesthet Dent. 2000;12(4):393-402; quiz 4.

74. Lekovic V, Kenney EB, Weinlaender M, Han T, Klokkevold P, Nedic M, et al. A bone regenerative approach to alveolar ridge maintenance following tooth extraction. Report of 10 cases. J Periodontol. 1997;68(6):563-70.

75. Vignoletti F, Johansson C, Albrektsson T, De Sanctis M, San Roman F, Sanz M. Early healing of implants placed into fresh extraction sockets: an experimental study in the beagle dog. De novo bone formation. J Clin Periodontol. 2009;36(3):265-77. 
76. MacBeth N, Trullenque-Eriksson A, Donos N, Mardas N. Hard and soft tissue changes following alveolar ridge preservation: a systematic review. Clin Oral Implants Res. 2017;28(8):9821004.

77. Esposito M, Grusovin MG, Felice P, Karatzopoulos G, Worthington HV, Coulthard P. Interventions for replacing missing teeth: horizontal and vertical bone augmentation techniques for dental implant treatment. Cochrane Database Syst Rev. 2009(4):CD003607.

78. Barzilay I, Graser GN, Iranpour B, Natiella JR, Proskin HM. Immediate implantation of pure titanium implants into extraction sockets of Macaca fascicularis. Part II: Histologic observations. Int J Oral Maxillofac Implants. 1996;11(4):489-97.

79. Barzilay I, Graser GN, Iranpour B, Proskin HM. Immediate implantation of pure titanium implants into extraction sockets of Macaca fascicularis. Part I: Clinical and radiographic assessment. Int J Oral Maxillofac Implants. 1996;11(3):299-310.

80. Alharbi HM, Babay N, Alzoman H, Basudan S, Anil S, Jansen JA. Bone morphology changes around two types of bone-level implants installed in fresh extraction sockets--a histomorphometric study in Beagle dogs. Clin Oral Implants Res. 2015;26(9):1106-12.

81. Paolantonio M, Dolci M, Scarano A, d'Archivio D, di Placido G, Tumini V, et al. Immediate implantation in fresh extraction sockets. A controlled clinical and histological study in man. J Periodontol. 2001;72(11):1560-71.

82. Sanz M, Cecchinato D, Ferrus J, Pjetursson EB, Lang NP, Lindhe J. A prospective, randomized-controlled clinical trial to evaluate bone preservation using implants with different geometry placed into extraction sockets in the maxilla. Clin Oral Implants Res. 2010;21(1):13-21.

83. Vera C, De Kok IJ, Reinhold D, Limpiphipatanakorn P, Yap AK, Tyndall D, et al. Evaluation of buccal alveolar bone dimension of maxillary anterior and premolar teeth: a cone beam computed tomography investigation. Int J Oral Maxillofac Implants. 2012;27(6):1514-9.

84. Roe P, Kan JY, Rungcharassaeng K, Caruso JM, Zimmerman G, Mesquida J. Horizontal and vertical dimensional changes of peri-implant facial bone following immediate placement and provisionalization of maxillary anterior single implants: a 1-year cone beam computed tomography study. Int J Oral Maxillofac Implants. 2012;27(2):393-400.

85. Chen ST, Buser D. Esthetic outcomes following immediate and early implant placement in the anterior maxilla--a systematic review. Int J Oral Maxillofac Implants. 2014;29 Suppl:186-215.

86. Avila-Ortiz G, Elangovan S, Kramer KW, Blanchette D, Dawson DV. Effect of alveolar ridge preservation after tooth extraction: a systematic review and meta-analysis. $J$ Dent Res. 2014;93(10):950-8.

87. Miller PA. Complete Dentures Supported by Natural Teeth. Tex Dent J. 1965;83:4-8.

88. Qahash M, Susin C, Polimeni G, Hall J, Wikesjo UM. Bone healing dynamics at buccal periimplant sites. Clin Oral Implants Res. 2008;19(2):166-72.

89. El Nahass H, S NN. Analysis of the dimensions of the labial bone wall in the anterior maxilla: a cone-beam computed tomography study. Clin Oral Implants Res. 2015;26(4):e57-e61. 
90. Gluckman H, Salama M, Du Toit J. A retrospective evaluation of 128 socket-shield cases in the esthetic zone and posterior sites: Partial extraction therapy with up to 4 years follow-up. Clin Implant Dent Relat Res. 2018;20(2):122-9.

91. Salama M, Ishikawa T, Salama H, Funato A, Garber D. Advantages of the root submergence technique for pontic site development in esthetic implant therapy. Int J Periodontics Restorative Dent. 2007;27(6):521-7.

92. Hurzeler MB, Zuhr O, Schupbach P, Rebele SF, Emmanouilidis N, Fickl S. The socket-shield technique: a proof-of-principle report. J Clin Periodontol. 2010;37(9):855-62.

93. Baumer D, Zuhr O, Rebele S, Schneider D, Schupbach P, Hurzeler M. The socket-shield technique: first histological, clinical, and volumetrical observations after separation of the buccal tooth segment - a pilot study. Clin Implant Dent Relat Res. 2015;17(1):71-82.

94. Calvo-Guirado JL, Troiano M, Lopez-Lopez PJ, Ramirez-Fernandez MP, de Val J, Marin JMG, et al. Different configuration of socket shield technique in peri-implant bone preservation: An experimental study in dog mandible. Ann Anat. 2016;208:109-15.

95. Casey DM, Lauciello FR. A review of the submerged-root concept. J Prosthet Dent. 1980;43(2):128-32.

96. Gluckman H, Nagy K, Du Toit J. Prosthetic management of implants placed with the socketshield technique. J Prosthet Dent. 2018.

97. Gluckman H, Du Toit J, Salama M. The Pontic-Shield: Partial Extraction Therapy for Ridge Preservation and Pontic Site Development. Int J Periodontics Restorative Dent. 2016;36(3):417-23.

98. Guyer SE. Selectively retained vital roots for partial support of overdentures: a patient report. J Prosthet Dent. 1975;33(3):258-63.

99. Helsham R. Some observations on the subject of roots of teeth retained in the jaws as a result of incomplete exodontia. Austral Dent J. 1960;5(2):70-7.

100. Lambert PM, Skerl RF, Campana HA. Free autogenous graft coverage of vital retained roots. J Prosthet Dent. 1983;50(5):611-7.

101. Nemcovsky CE, Serfaty V. Alveolar ridge preservation following extraction of maxillary anterior teeth. Report on 23 consecutive cases. J Periodontol. 1996;67(4):390-5.

102. Herd JR. The retained tooth root. Aust Dent J. 1973;18(3):125-31.

103. Yu VS, Messer HH, Tan KB. Multiple idiopathic cervical resorption: case report and discussion of management options. Int Endod J. 2011;44(1):77-85.

104. Keceli TI, Kutlu B, Gungor HC. Preserving alveolar bone growth following cervical root fracture: a case report. J Can Dent Assoc. 2013;79:d158.

105. Rodd HD, Davidson LE, Livesey S, Cooke ME. Survival of intentionally retained permanent incisor roots following crown root fractures in children. Dent Traumatol. 2002;18(2):92-7.

106. O'Neal RB, Gound T, Levin MP, del Rio CE. Submergence of roots for alveolar bone preservation. I. Endodontically treated roots. Oral Surg Oral Med Oral Pathol. 1978;45(5):803-10. 
107. Malmgren B, Cvek M, Lundberg M, Frykholm A. Surgical treatment of ankylosed and infrapositioned reimplanted incisors in adolescents. Scand J Dent Res. 1984;92(5):391-9.

108. Andersson L, Emami-Kristiansen Z, Hogstrom J. Single-tooth implant treatment in the anterior region of the maxilla for treatment of tooth loss after trauma: a retrospective clinical and interview study. Dent Traumatol. 2003;19(3):126-31.

109. Buser D, Warrer K, Karring T. Formation of a periodontal ligament around titanium implants. J Periodontol. 1990;61(9):597-601.

110. Warrer K, Karring T, Gotfredsen K. Periodontal ligament formation around different types of dental titanium implants. I. The self-tapping screw type implant system. J Periodontol. 1993;64(1):29-34.

111. Jahangiri L, Hessamfar R, Ricci JL. Partial generation of periodontal ligament on endosseous dental implants in dogs. Clin Oral Implants Res. 2005;16(4):396-401.

112. Davarpanah M, Szmukler-Moncler S. Unconventional implant treatment: I. Implant placement in contact with ankylosed root fragments. A series of five case reports. Clin Oral Implants Res. 2009;20(8):851-6.

113. Saeidi Pour R, Zuhr O, Hurzeler M, Prandtner O, Rafael CF, Edelhoff D, et al. Clinical Benefits of the Immediate Implant Socket Shield Technique. J Esthet Restor Dent. 2017;29(2):93101.

114. Siormpas KD, Mitsias ME, Kontsiotou-Siormpa E, Garber D, Kotsakis GA. Immediate implant placement in the esthetic zone utilizing the "root-membrane" technique: clinical results up to 5 years postloading. Int J Oral Maxillofac Implants. 2014;29(6):1397-405.

115. Siormpas KD, Mitsias ME, Kotsakis GA, Tawil I, Pikos MA, Mangano FG. The Root Membrane Technique: A Retrospective Clinical Study With Up to 10 Years of Follow-Up. Implant Dent. 2018;27(5):564-74.

116. Mitsias ME, Siormpas KD, Kontsiotou-Siormpa E, Prasad H, Garber D, Kotsakis GA. A Step-by-Step Description of PDL-Mediated Ridge Preservation for Immediate Implant Rehabilitation in the Esthetic Region. Int J Periodontics Restorative Dent. 2015;35(6):835-41.

117. Mitsias ME, Siormpas KD, Kotsakis GA, Ganz SD, Mangano C, Iezzi G. The Root Membrane Technique: Human Histologic Evidence after Five Years of Function. Biomed Res Int. 2017;2017:7269467.

118. Januario AL, Duarte WR, Barriviera M, Mesti JC, Araujo MG, Lindhe J. Dimension of the facial bone wall in the anterior maxilla: a cone-beam computed tomography study. Clin Oral Implants Res. 2011;22(10):1168-71.

119. Cherel F, Etienne D. Papilla preservation between two implants: a modified socket-shield technique to maintain the scalloped anatomy? A case report. Quintessence Int. 2014;45(1):23-30.

120. Kan JY, Rungcharassaeng K. Proximal socket shield for interimplant papilla preservation in the esthetic zone. Int J Periodontics Restorative Dent. 2013;33(1):e24-31.

121. Calvo-Guirado JL, Benitez-Garcia JA, Mate Sanchez de Val JE, Perez-Albacete Martinez C, Gehrke SA, Delgado-Ruiz R, et al. Socket-shield technique: the influence of the length of the 
remaining buccal segment of healthy tooth structure on peri-implant bone and socket preservation. A study in dogs. Ann Anat. 2019;221:84-92.

122. Hinze M, Janousch R, Goldhahn S, Schlee M. Volumetric alterations around single-tooth implants using the socket-shield technique: preliminary results of a prospective case series. Int $\mathrm{J}$ Esthet Dent. 2018;13(2):146-70.

123. Han CH, Park KB, Mangano FG. The Modified Socket Shield Technique. J Craniofac Surg. 2018;29(8):2247-54.

124. von Wowern N, Winther S. Submergence of roots for alveolar ridge preservation. A failure (4-year follow-up study). Int J Oral Surg. 1981;10(4):247-50.

125. Bowers GM, Chadroff B, Carnevale R, Mellonig J, Corio R, Emerson J, et al. Histologic evaluation of new attachment apparatus formation in humans. Part I. J Periodontol. 1989;60(12):66474.

126. Garver DG, Fenster RK. Vital root retention in humans: a final report. J Prosthet Dent. 1980;43(4):368-73.

127. Branemark R, Branemark PI, Rydevik B, Myers RR. Osseointegration in skeletal reconstruction and rehabilitation: a review. J Rehabil Res Dev. 2001;38(2):175-81.

128. Bartold PM, Ivanovski S, Darby I. Implants for the aged patient: biological, clinical and sociological considerations. Periodontol 2000. 2016;72(1):120-34.

129. Schwimer C, Pette GA, Gluckman H, Salama M, Du Toit J. Human Histologic Evidence of New Bone Formation and Osseointegration Between Root Dentin (Unplanned Socket-Shield) and Dental Implant: Case Report. Int J Oral Maxillofac Implants. 2018;33(1):e19-e23. 
APPENDIX 


\title{
A retrospective evaluation of 128 socket-shield cases in the esthetic zone and posterior sites: Partial extraction therapy with up to 4 years follow-up
}

\author{
Howard Gluckman BDS, MChD (OMP) ${ }^{1}$ | Maurice Salama DDS² | \\ Jonathan Du Toit BChD, MSc ${ }^{3}$
}

${ }^{1}$ The Implant and Aesthetic Academy, Cape Town, South Africa

${ }^{2}$ Medical College of Georgia, University of Pennsylvania, Philadelphia, Augusta, Georgia

${ }^{3}$ Department of Periodontics and Oral Medicine, School of Dentistry, Faculty of Health Sciences, University of Pretoria, South Africa

\section{Correspondence}

Howard Gluckman, The Implant and Aesthetic Academy, Cape Town, South Africa.

Email: docg@mweb.co.za

\begin{abstract}
Objectives: Tooth loss results in an inevitable alveolar ridge reduction. This has established a cautionary approach to extract, wait, augment, and insert the implant, in lieu of immediate placement. However, saving the tooth or part of it whenever possible is more conservative and supports the vital periodontal tissue buccofacial to an implant. The purpose of this cases series was to report on implant survival using this technique in a large cohort of patients at mid-term follow-up.

Materials and Methods: A private practice patient database was searched for all patients having received socket-shield treatment in conjunction with immediate implant placement. Of the results returned, 128 met the inclusion criteria of $\geq 12$ months from date of restoration, or failing prior to definitive restoration. These patients were recalled for evaluation of the restored implants up to 4 years post-treatment.
\end{abstract}

Results: Seventy immediate implants with socket-shields were placed in female patients and 58 in males, age range 24-71 (mean 39 years). The distribution of sites treated were: maxillary incisors (64\%), premolars (22\%), canines (14\%); maxilla (89.9\%), mandible (10.1\%). 123/128 implants osseointegrated and survived 1-4 years following restoration (survival rate $96.1 \%$ ). A combined complication rate of 25/128 implants occurred (19.5\%). Five implants failed to osseointegrate and were removed. The remaining 20 complications were all managed or observed without management, with implants surviving at mid-term follow-up.

Conclusions: Notwithstanding technique sensitivity and the need for randomized control studies, this case series demonstrates that the socket-shield performs competitively when compared to implant survival rates in both conventional immediate and delayed implant placement.

\section{KEYWORDS}

dental implant, implant dentistry, partial extraction therapy, socket-shield technique

\section{1 | INTRODUCTION}

It has previously been discussed in detail that tissue loss following extraction is a certainty. ${ }^{1-3}$ Single tooth loss, multiple tooth loss, and especially complete removal of the dentition can be devastating for a patient. When multiple teeth or the entire dentition is lost, the alveolar ridge changes discussed here are multiplied. ${ }^{4}$ The osseointegration of a dental implant and its subsequent restoration are milestones in a patient's treatment, and yet are not endpoint of treatment. The volume, health, and esthetics of the supporting tissues need to maintain stability over the long-term. ${ }^{5}$ Yet, implant dentistry has evolved in both acknowledging and managing this inevitable dilemma. The clinician typically may employ some form of augmentation procedure. The focus on treatment goals has also shifted from merely implant survival to treatment success. ${ }^{6,7}$ These include optimal esthetic results, healthy periimplant tissues, restoration of function, and the long-term maintenance of these. There has also been a considerable shift toward less invasive, more conservative treatment in patients. None better stated than "the 


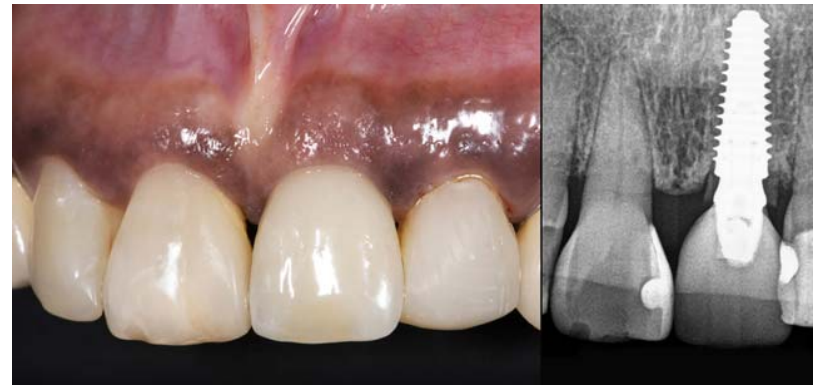

FIGURE 1 Four-year follow-up of a restored immediate implant and socket-shield at tooth site 21

dental profession recognizes that an artifact is of less biological value than the original healthy tissue." ${ }^{8}$ The theme of a recent implant dentistry symposium was "Key Factors for Long-term Success." The necessity for augmentation was addressed and emphasized two further dilemmas-longevity of treatment in patients, and the importance of maintenance during their lifetime. ${ }^{9,10}$ It is questionable whether current treatments can be guaranteed to survive several decades in a patient, especially without maintenance, and these treatments may well need revisions to manage outcomes such as tissue resorption.

A better alternative is required that retains part of the patient's tooth/teeth wherever possible, that provides the clinician with treatment options even later in the patient's life, is more conservative, and requires less or no commercial materials. Such alternatives must be explored and developed to advance dental implant treatment for patients. To reinforce this, data is needed to explore these alternatives, to support their efficacy as well as their safety, and their clinical performance long-term, while ever improving and refining their methodologies. Partial extraction therapies, specifically the socket-shield, encompass all these aforementioned concepts. Hereafter these authors report a 128 socket-shield case series, following up the restored implants in conjunction with this tissue preservation technique, evaluating clinical performance at 1-4 years, including all complications and how they were managed.

\section{I MATERIALS AND METHODS}

This study was observed in full accordance with the World Medical Association Declaration of Helsinki. This study was undertaken with the understanding and written consent of each participant and according to the above-mentioned principles. The patient cohort was derived from a database search at a private practice of all patients who had socket-shield with immediate implant placement. The selection criteria stipulated:

\section{1 | Inclusion}

- All patients who previously had socket-shield treatment

- All patients with minimum mid-term follow-up ( $\geq 12$ months)

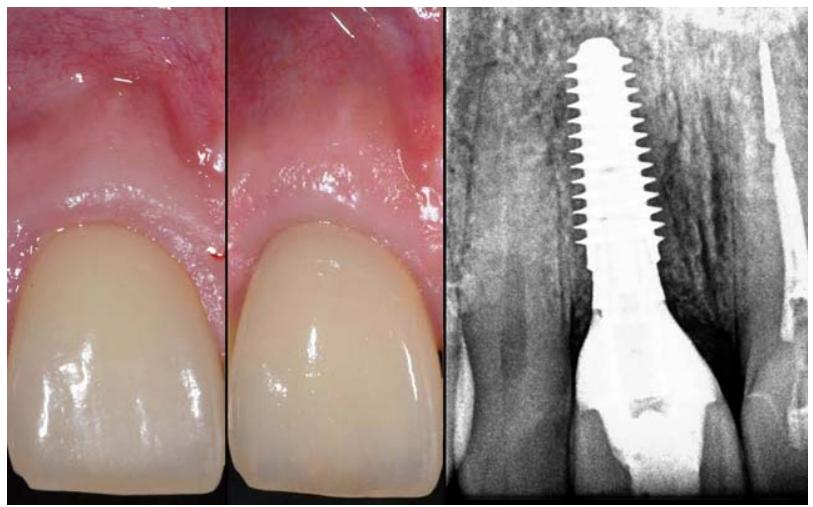

FIGURE 2 Preoperative view of site 11 (left panel), original crown, coronal fracture. Postoperative view (middle panel), screwretained metal-ceramic crown with periapical radiograph (right panel) at 2-year follow-up

- All mid-term follow-up demonstrable by a clinical examination and minimum of a periapical view radiograph and a clinical photograph

- Follow-up start date defined as day of restoration (provisional or definitive)

- All treatment failures (at placement, during osseointegration, during provisionalization, or post definitive restoration)

- All complications (at placement, during osseointegration, during provisionalization, or post definitive restoration)

\section{2 | Exclusion}

- Implants not loaded by a restoration (provisional or definitive) $>12$ months

- Patients unable to return for follow-up evaluation despite $>12$ months elapsed post-restoration

Patients with restored implants at a socket-shield without previous follow-up, or able to present for an additional longer-term follow-up visit, were invited to return for a recall evaluation. All implants evaluated in this study were internal, morse-taper, conical connection implants only (AnyRidge, MegaGen; Ankylos, Dentsply; NobelReplace, Nobel Biocare) as per these authors' standard protocol for socket-shield treatment. At follow-up, a minimum of a periapical radiograph and clinical photograph of the restored implant were taken (Figures 1-3). These together with a clinical examination of the implant and restoration evaluated the treatment by:

\section{3 | Primary outcome measure}

- Implant survival

\subsection{Secondary outcome measures}

- Implant failure

- Signs of peri-implant mucositis 

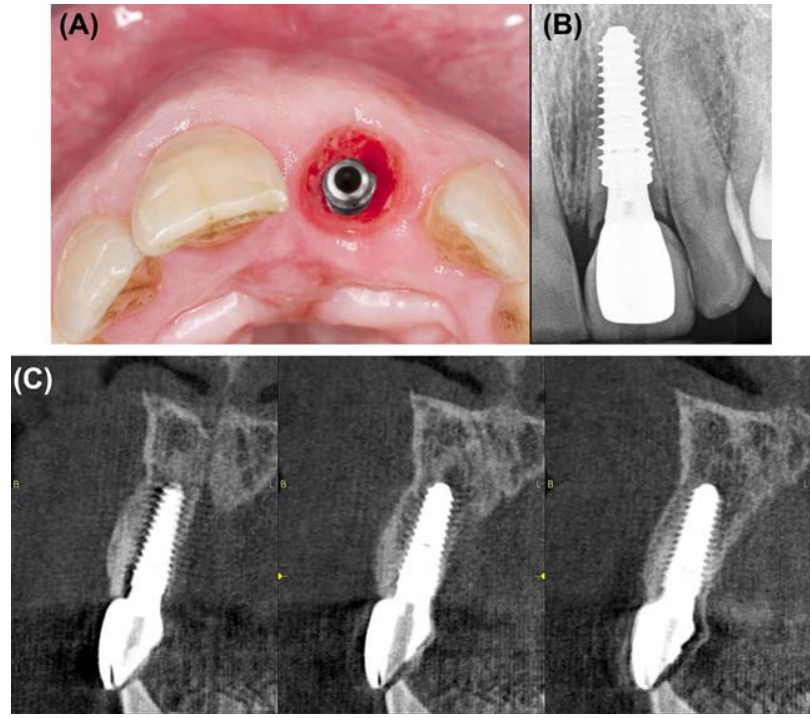

FIGURE 3 A 3-year follow-up of immediate implant at socketshield site 21. (a) Note the bulk of tissue facial to the implant. (b) maintenance of interproximal bone peak, periapical radiograph. (c): CBCT slices demonstrate the hard tissue facial to the implant

- Signs of peri-implantitis

- Other complications (socket-shield exposure, infection)

Data were compiled into a Microsoft Excel spreadsheet for analyses.

\section{3 | RESULTS}

The patient database was searched for all records of socket-shield with immediate implant placement. Of the totaled results returned, 128 cases met the selection criteria. 70 immediate implants with socketshield were placed in female patients and 58 in males. The data comprised examination records from previous follow-up visits $\geq 12$ months, or subsequent patient recall for additional follow-up, thus with an inclusion of all 128 patients and zero loss to follow-up. Period of follow-up and the number of patients respectively are demonstrated in Figure 4.

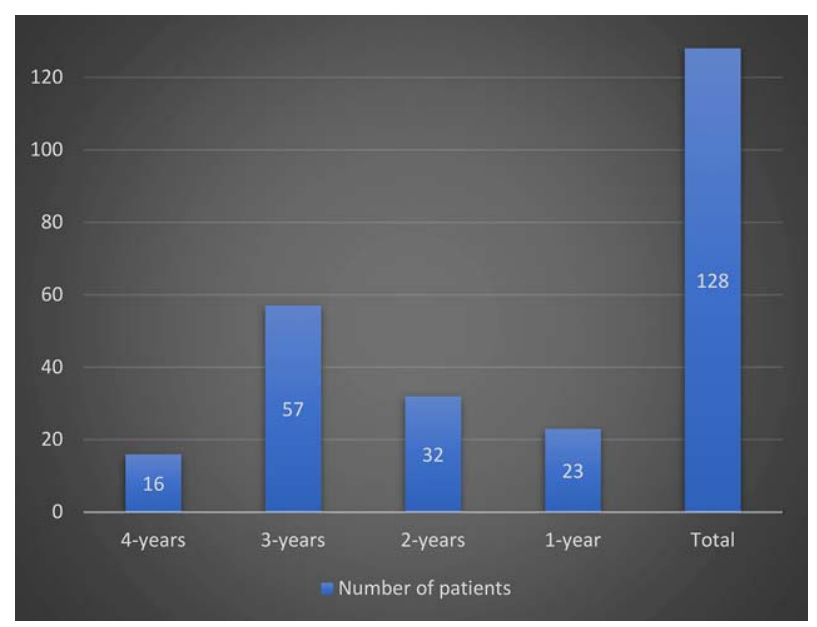

FIGURE 4 The number of patients followed up per years of follow-up ( $y$-axis: number of patients, $x$-axis: time in year intervals)

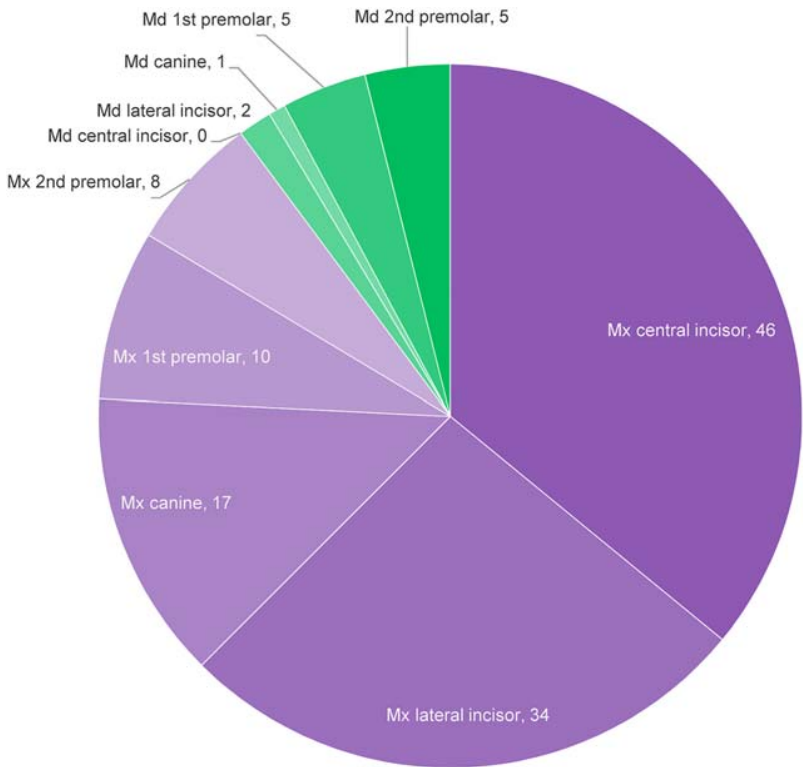

FIGURE 5 Distribution of socket-shields per tooth sites, per jaw

Patient age ranged 24-71 (mean 39 years). Maxillary incisors were treated most often (64\%), premolars second most often (22\%), and canines least often (14\%) (Figure 5). Maxillary sites were treated far more often the mandible (89.9\% vs $10.1 \%$ ). A total of 25 complications occurred (19.5\% complication rate). Five of these implants failed during the initial osseointegration/healing period. Sixteen socket-shields encountered exposure. Three sites developed an infection. One socket-shield migrated/overerupted (Table 1).

\section{1 | Complications and management}

\subsection{1 | Implant failure}

It is not possible to determine with certainty whether the five implants failed to osseointegrate as a result of the additional socket-shield procedure. All five implants were removed and the sites managed. Three of these socket-shields were still intact and uninfected. The sites were cleaned and the failed implant replaced in two of the cases (Figures 6 and 7). Both implants osseointegrated and were restored. In one case, the implant was removed, the site converted to a pontic shield. In the two other failures, both socket-shield and implant were removed, and the patients opted for a fixed partial denture (FPD) and removable partial denture respectively.

\subsection{2 | Infection}

Three Socket shields were mobile and developed an infection (Figure 8). In one case, the socket shield was mobile and removed, the site exposed and cleared, the exposed surface of the implant decontaminated, grafted with a GBR procedure, and later restored. In another two cases the socket-shield and implant were both removed. In one scenario the site healed, another implant placed, osseointegrated, and restored. In the other scenario, the site was grafted as a ridge preservation and later restored with a FPD. 
TABLE 1 The totaled complications and management of each

\begin{tabular}{|c|c|c|c|c|c|c|c|c|}
\hline & Tooth & $\begin{array}{l}\text { Exposure } \\
\text { (internal) }\end{array}$ & $\begin{array}{l}\text { Exposure } \\
\text { (external) }\end{array}$ & Infection & $\begin{array}{l}\text { Implant } \\
\text { failure }\end{array}$ & Migration & $\begin{array}{l}\text { Timing of } \\
\text { complication }\end{array}$ & Management \\
\hline 1 & 21 & & & & 1 & & $\begin{array}{l}\text { At integration check, } \\
3 \text { months }\end{array}$ & $\begin{array}{l}\text { SS intact, implant replaced, } \\
\text { osseointegrated, } \\
\text { restored }\end{array}$ \\
\hline 2 & 11 & 1 & & & & & $\begin{array}{l}\text { At integration check, } \\
3 \text { months }\end{array}$ & $\begin{array}{l}\text { SS reduced, soft tissue } \\
\text { healed, restored }\end{array}$ \\
\hline 3 & 21 & 1 & & & & & $\begin{array}{l}\text { At integration check, } \\
3 \text { months }\end{array}$ & $\begin{array}{l}\text { No treatment, no additional } \\
\text { complications }\end{array}$ \\
\hline 4 & 33 & & 1 & & & & 1-year postop & $\begin{array}{l}\text { Reduced, CTG, soft tissue } \\
\text { healed, restored }\end{array}$ \\
\hline 5 & 21 & & & 1 & & & $\begin{array}{l}2 \text { months postop, prior to } \\
\text { integration check }\end{array}$ & $\begin{array}{l}\text { SS removed, implant } \\
\text { decontaminated, GBR, } \\
\text { restored }\end{array}$ \\
\hline 6 & 13 & & & & 1 & & $\begin{array}{l}\text { At integration check, } \\
3 \text { months }\end{array}$ & $\begin{array}{l}\text { implant replaced, restored, } \\
\text { shield intact }\end{array}$ \\
\hline 7 & 12,11 & & 2 & & & & $\begin{array}{l}\text { 1-month postop, prior to } \\
3 \text { months integration } \\
\text { check }\end{array}$ & $\begin{array}{l}\text { SS reduced, soft tissue } \\
\text { healed, midfacial reces- } \\
\text { sion }\end{array}$ \\
\hline 8 & 12 & 1 & & & & & $\begin{array}{l}\text { At integration check, } \\
3 \text { months }\end{array}$ & SS reduced, restored \\
\hline 9 & 21 & & 1 & & & & $\begin{array}{l}2 \text { months, at exposure } \\
\text { of adjacent implant }\end{array}$ & $\begin{array}{l}\text { SS reduced, CTG, soft } \\
\text { tissue healed, restored }\end{array}$ \\
\hline 10 & 12 & & & 1 & 1 & & 1-month postop & $\begin{array}{l}\text { SS and implant removed, } \\
\text { healed, new implant and } \\
\text { GBR, restored }\end{array}$ \\
\hline 11 & 11 & & & 1 & 1 & & 1-month postop & $\begin{array}{l}\text { SS and implant removed, } \\
\text { ridge preservation graft, } \\
\text { FPD }\end{array}$ \\
\hline 12 & 21 & 1 & & & & & $\begin{array}{l}9 \text { months, at delivery of } \\
\text { definitive crown }\end{array}$ & $\begin{array}{l}\text { No treatment, no additional } \\
\text { complications }\end{array}$ \\
\hline 13 & 11 & 1 & & & & & $\begin{array}{l}\text { At integration check, } \\
3 \text { months }\end{array}$ & SS reduced, restored \\
\hline 14 & 11 & 1 & & & & & $\begin{array}{l}\text { At integration check, } \\
3 \text { months }\end{array}$ & $\begin{array}{l}\text { No treatment, no additional } \\
\text { complications }\end{array}$ \\
\hline 15 & 21 & 1 & & & & & $\begin{array}{l}9 \text { months later at final } \\
\text { check before final crown } \\
\text { placed }\end{array}$ & $\begin{array}{l}\text { No treatment, no additional } \\
\text { complications }\end{array}$ \\
\hline 16 & 21 & 1 & & & & & $\begin{array}{l}\text { At integration check, } \\
3 \text { months }\end{array}$ & $\begin{array}{l}\text { No treatment, no additional } \\
\text { complications }\end{array}$ \\
\hline 17 & 23 & 1 & & & & & $\begin{array}{l}\text { At integration check, } \\
3 \text { months }\end{array}$ & $\begin{array}{l}\text { No treatment, no additional } \\
\text { complications }\end{array}$ \\
\hline 18 & 22 & & & & 1 & & $\begin{array}{l}4 \text { months, at time of } \\
\text { exposure of adjacent } \\
\text { implant }\end{array}$ & Implant removed, RPD \\
\hline 19 & 11,21 & 2 & & & & 1 & $\begin{array}{l}\text { Exposure at } 9 \text { months, be- } \\
\text { fore delivery of definitive } \\
\text { crowns. Migration noted } \\
\text { at 3-years. }\end{array}$ & $\begin{array}{l}\text { No treatment, no additional } \\
\text { complications }\end{array}$ \\
\hline 20 & 34 & 1 & & & & & $\begin{array}{l}\text { At integration check, } \\
3 \text { months }\end{array}$ & $\begin{array}{l}\text { SS reduced twice, soft } \\
\text { tissue healed, restored }\end{array}$ \\
\hline Total & & 12 & 4 & 3 & 5 & 1 & Mean 4 months & $\begin{array}{l}25 \text { sites in total, } 17 \\
\text { managed and } 8 \\
\text { monitored }\end{array}$ \\
\hline
\end{tabular}

SS, socket-shield. 


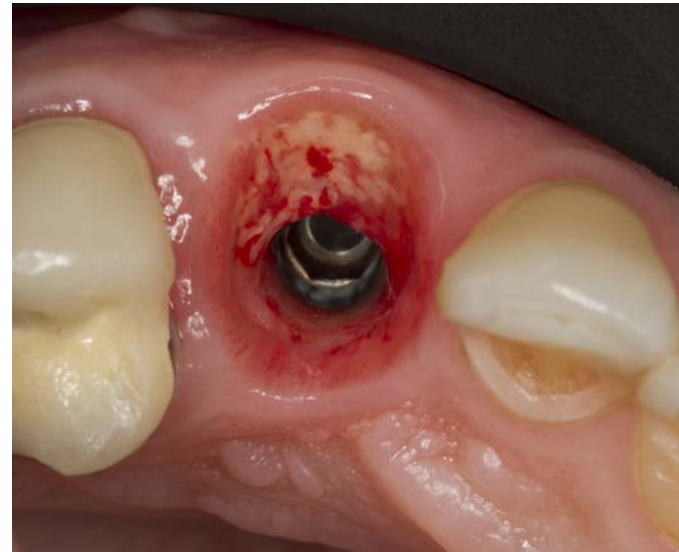

FIGURE 6 Infection and failed implant at socket-shield site

\subsection{3 | Socket-shield exposure}

Exposure (coronal portion of the socket-shield perforating the soft tissue) was the most common complication encountered, and may be denoted as internal exposure (toward the restoration) (Figures 9 and 10) or external (toward the oral cavity) (Figure 11). The incidence of internal exposures (12/128) exceeded external (4/128), 9.4\% of all cases vs $3.1 \%)$ respectively. All internal exposures were managed by either no treatment and observation, or by reduction of the exposed root portion with a diamond bur coupled to a high-speed handpiece. Four external exposures occurred, all of which were managed by reducing the coronal aspect for soft tissue closure. 2/4 external exposures had an additional connective tissue graft (CTG) augmentation to assist soft tissue healing. All healed satisfactorily and were restored. In a case of external exposures in the same patient of sites 12 and 11, the SS were reduced allowing for soft tissue to heal over. Both healed and the midfacial tissues receded $2 \mathrm{~mm}$.

\subsection{4 | Migration}

$1 / 128$ socket-shields migrated. In this patient, both sites 8 and 9 also had socket-shields and both demonstrated internal exposure when the provisional restorations were removed for impression taking. One socket-shield had migrated (confirmed on CBCT scan). The

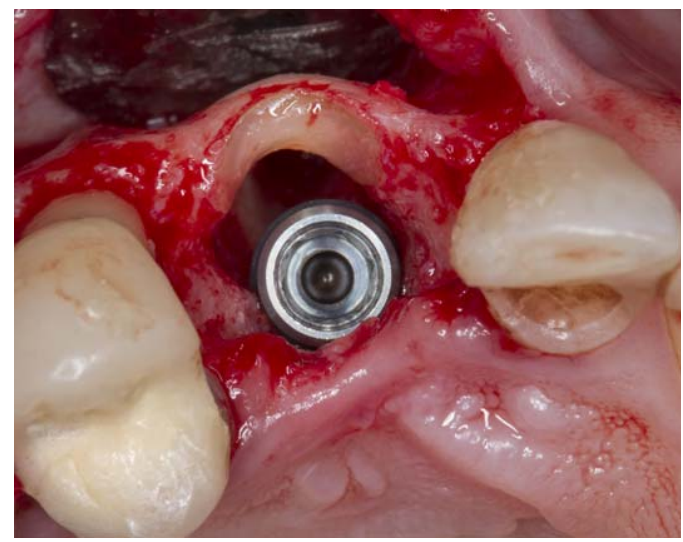

FIGURE 7 Implant removed. Socket-shield checked, immobile, intact, site cleaned, rinsed with saline, and new implant placed

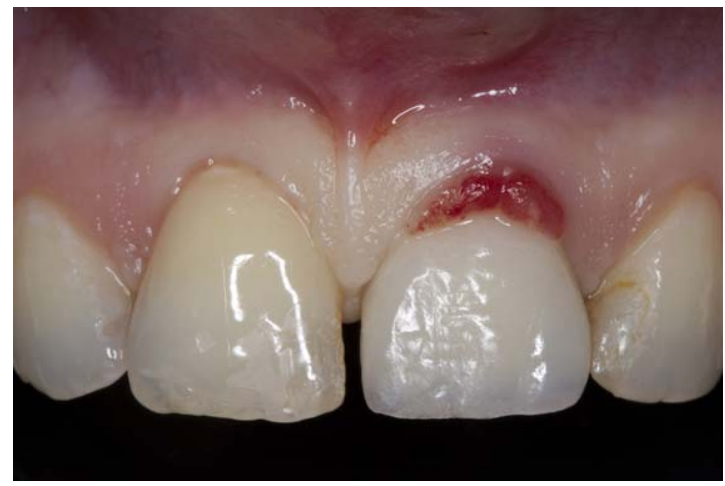

FIGURE 8 Infection at site 21. Restoration removed, socket-shield was mobile and thus removed. GBR procedure was done, implant restored and in function 4-years

prosthodontist restored both implants without reduction of the socketshields and both have been monitored without additional complication.

123/128 implants osseointegrated and survived 1-4 years following restoration (survival rate $96.1 \%$ ). Five implants failed to osseointegrate and were removed. The remaining 17 complications were all managed or monitored without management and definitively restored, all surviving at mid-term follow-up. Subjective evaluation of the definitive restorations at follow-up identified $2 \mathrm{~mm}$ tissue recession at adjacent socket-shields after reduction in the same patient. No other situations of recession sufficient to expose the implant-abutment interface or implant to the oral cavity were noted. Blue-gray hue as a sign of implant translucency through the gingival tissue was not noted in any cases. Signs of peri-implantitis, clinically or radiographically, was not noted in any of the cases followed-up. All 128 cases evaluated may be viewed online. ${ }^{11}$

This study is STROBE compliant.

\section{4 | DISCUSSION}

The submergence of tooth root portions is not a new concept. Malmgren and coworkers in the 1980s as well as Casey and Lauciello were the pioneers of this ridge preservation concept. ${ }^{12,13}$ The outcomes of

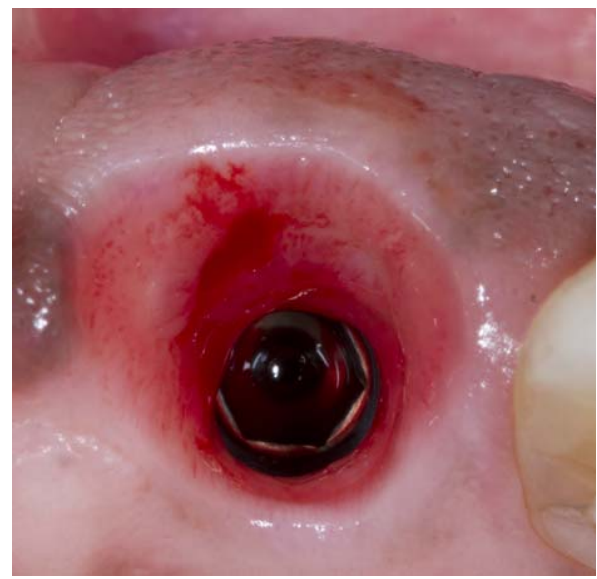

FIGURE 9 Internal exposure with inflammation 


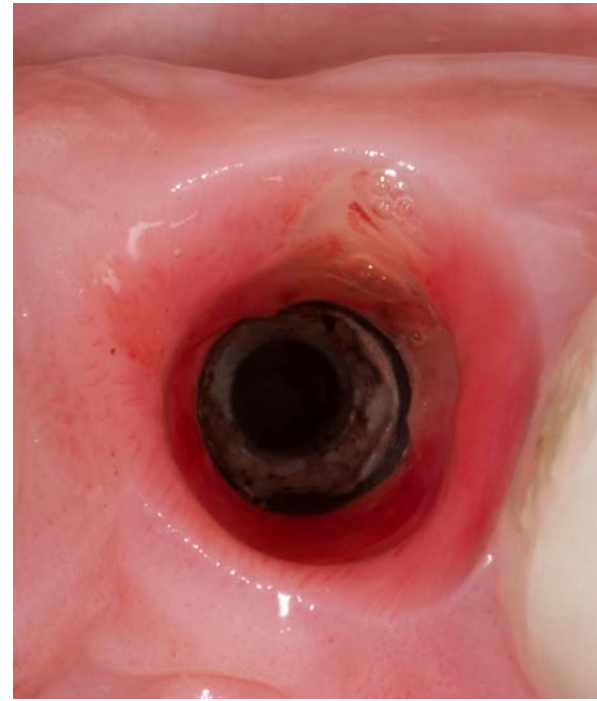

FIGURE 10 Internal exposure without inflammation

root fracture during extraction have undoubtedly been experienced by clinicians the world over. These may be one of several-migration, promulgation of pre-existing infected root canal system, with or without symptoms, root resorption, ankylosis, or no response. ${ }^{14}$ All the partial extraction therapies require complete removal of infection. ${ }^{1-3}$ The socket-shield case series reported here required preparation of the buccofacial root portion such that the canal contents (root canal filling material or neurovascular tissue) with the apex be removed. The purpose of retaining this carefully designed and prepared facial root section is to maintain the root's periodontal attachment to the facial bundle bone that is prone to collapse post-extraction. ${ }^{2,3,14-16}$ The technique is not without failure, yet the survival rate of using the socket-shield technique is consistent with implants placed into extraction sockets as well as healed ridges (97\%). Conventional implant treatment also incurs a degree of complication and failure. Augmentation itself has drawbacks. It is an invaluable addition to implant dentistry with sound long-term data. Though, cost, morbidity, technique sensitivity, failure, infection, and so on. similarly beset this technique. ${ }^{17,18}$ One technique does not supersede another. Patients are not to be treated epidemiologically. The main duty of the clinician is to practice evidence-based treatment, and when appropriate, properly inform the patient that a said treatment may still be under evaluation. It is also the duty of the responsible clinician and scientist to pioneer ever improving treatment modalities for patients and the profession. Partial extraction therapies endeavor such an aim. The "extract-and-augment" emphasis on surgical acumen may well be replaced by improved conservative dentistry and endodontic therapy skill as the socket-shield technique and partial extraction therapies evolve. This underpins a conservative approach to implant dentistry, the profession recognizing that an artifact is of less biological value than the original healthy tissue. ${ }^{8}$ It may also facilitate patients from the dentate to partially and fully edentulous state, preserving in part their dental tissues. When supported by a healthy tooth/tooth either side, an implant-supported restoration may perform excellently. However, multiple tooth loss or loss of the complete dentition, even if the treatment milestones are accomplished (osseointegration, healthy

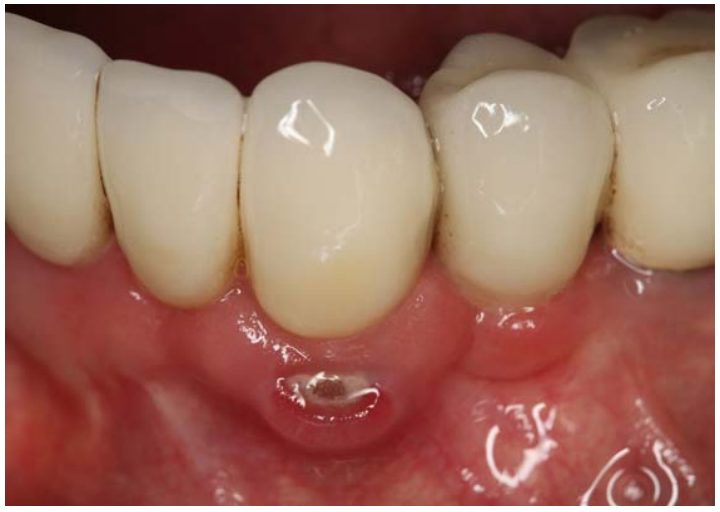

FIGURE 11 External exposure, site 33

and healed tissues, then fully restored) these may at day of restoration appear as a total success. But what about 10, 15, 20 years later? This is a concept emphasized at implant dentistry symposia. ${ }^{9}$ It is a contemporary reality that patients are retaining their dentition for longer and living longer, and as a result, the projected treatment outcomes may currently not apply. ${ }^{19}$ Implant therapy provided to a patient in their fourth decade of life may have to endure 3,4 , or more decades.

This study would be remiss without mention of its limitations and potential bias, namely a single practitioner highly experienced in the technique who carried out treatment in all cases. A multicenter prospective or retrospective study could address this. Data are now ever increasing reports on the potential for partial extraction therapies with long-term clinical performance at 5 years in two studies, ${ }^{15,20}$ histological evidence of the tissue healed at the socket-shield-implant-interface, ${ }^{14,16}$ indications/technique/risks/guidelines, ${ }^{1-3}$ numerous case reports, and this study of 128 cases with mid-term follow-up.

Like all techniques there is the possibility of complications. The most common complication seen in this study was internal exposure of the socket-shield (Figures 9-11). The likely cause is a lack of adequate space between the coronal edge of the shield and the subgingival contour of the crown. The potential for tissue inflammation is not ideal and as yet the long-term effects are not known. This complication was left untreated in some cases but as our technique has developed, these authors have strived for the complete and healthy coverage of the shield with soft tissue (Figures 12 and 13). These authors consider this

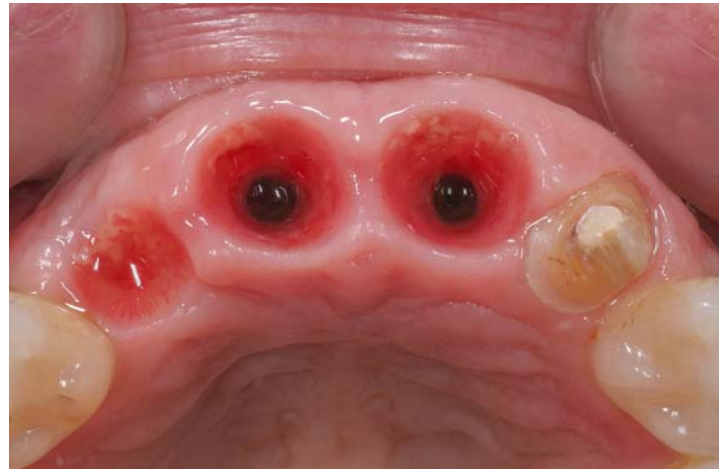

FIGURE 12 Ideal soft tissue presentation at adjacent sites 11, 21, at time of provisional removal and osseointegration check 


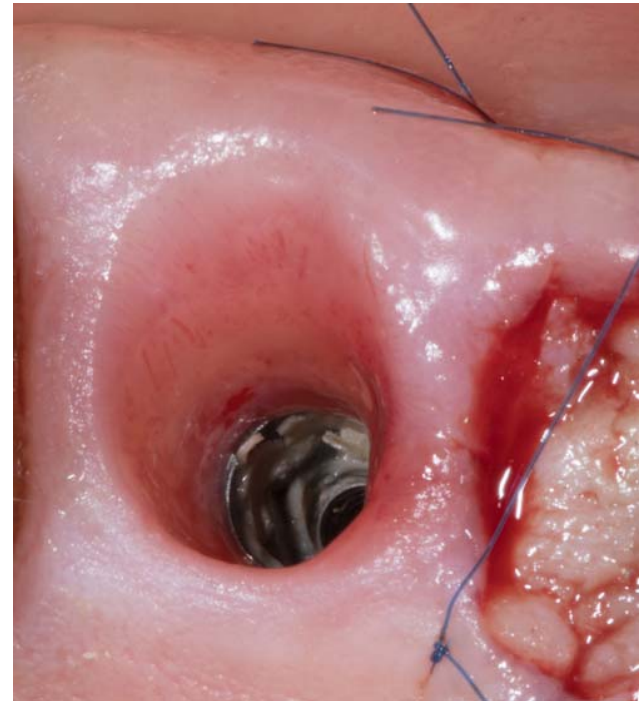

FIGURE 13 Ideal soft tissue emergence profile and health at time of placing adjacent implant

the only acceptable way to perform a socket shield. Internal exposures are usually noted at the time of removing the provisional restoration and it is advisable to correct this before restoring definitively. At that stage, a micro-flap is raised and the shield is reduced to the bone level and all sharp edges smoothed. It is advised to add a small connective tissue graft into the sulcus to assist soft tissue closure. Although this is not always necessary, these authors have found this to be the most predictable way of achieving complete coverage and soft tissue health. The second most common complication is the external exposure (Figure 11). This also is likely due to an over extension of the shield's coronal aspect, or the sharp coronal aspect that perforates the overlying soft tissue, and more likely at sites inherently deficient in facial bone (lower anterior, cuspids, previous orthodontic treatment). From these authors' experience, this complication is also easily managed with a micro flap, reduction of the perforating shield, and in most cases a soft tissue graft to close the exposure.

The occurrence of these complications has lead to a change in the way these authors perform the technique. We originally described preparing the shield to $1 \mathrm{~mm}$ above bone crest. ${ }^{3}$ The rationale behind this was the maintenance of the periodontal fibers. ${ }^{16}$ The possibility of this occurring as well as the need is overstated. As a result of the experience gained since the technique's inception these authors now reduce the socket-shield to bone crest level, and observed best results when a chamfer is created in the crestal $2 \mathrm{~mm}$ of the shield, thinning it slightly and providing additional and critical prosthetic space of 2-3 mm between the subgingival crown contour and the shield for soft tissue infill (Figure 14). These modifications of the technique has lead to an almost total elimination of either of these complications.
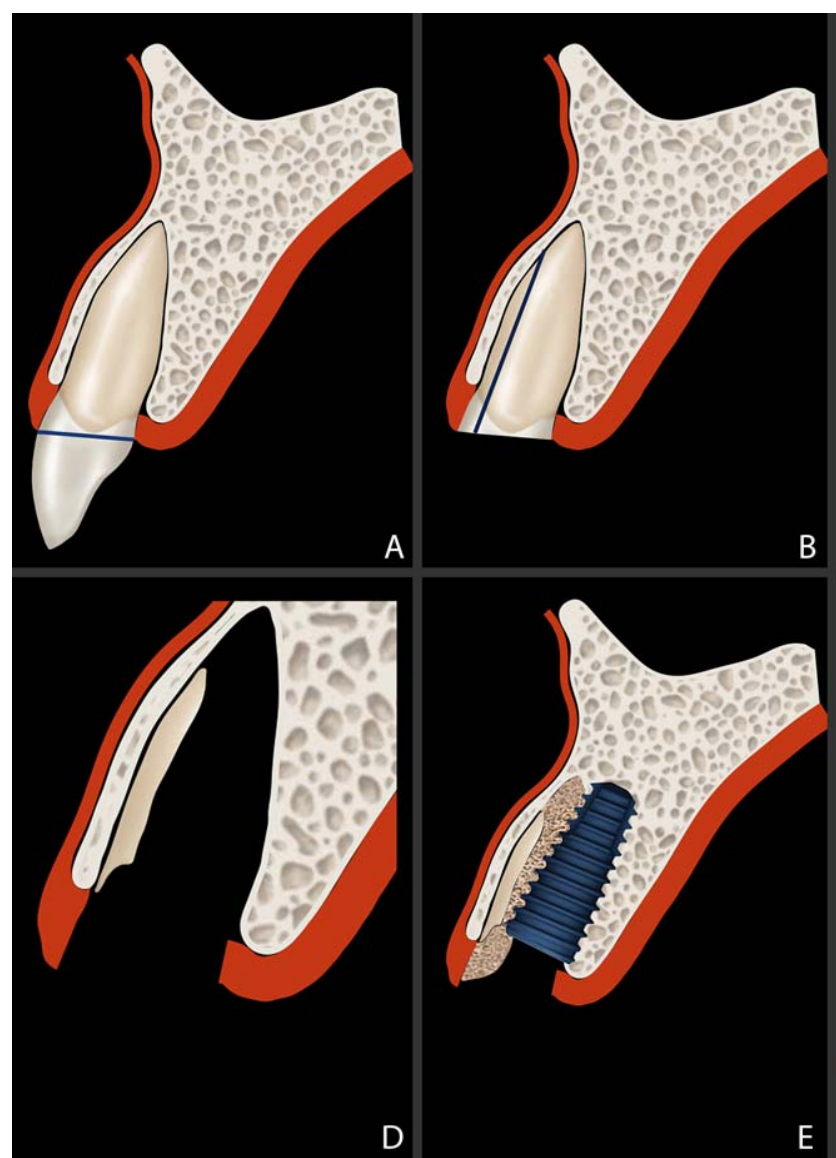
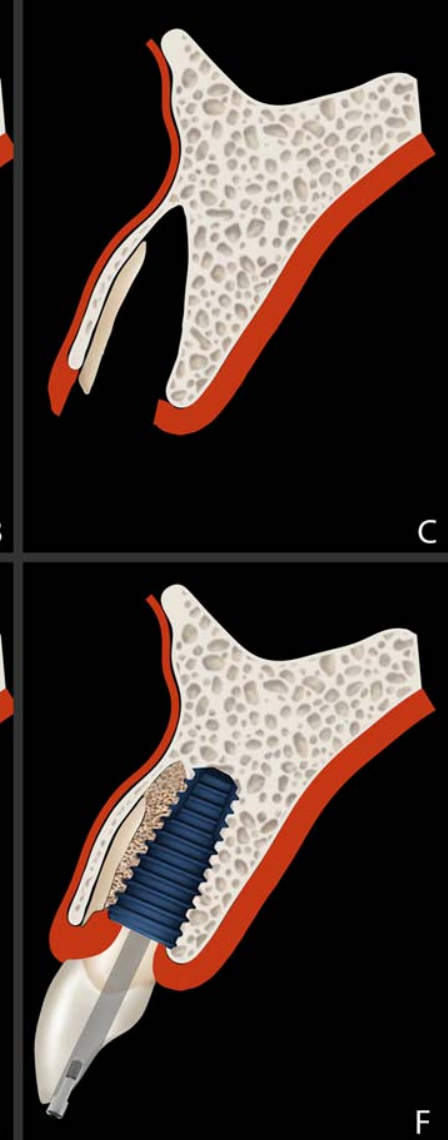

FIGURE 14 Preparation steps of the socket-shield. Note panel D, the final steps of creating a chamfer bevel 
In conclusion, methods to manage the ridge collapse must be explored. Emphasis on commercial products to augment ridge deficit may better be replaced by improved techniques to preserve the patient's own tissues. This is the first $>100$ patient case series reporting on implant survival with the socket-shield technique at mid-term follow-up. The results support this paradigm change toward tooth root tissue preservation. The technique performs comparably to conventional delayed and immediate implant placement in terms of implant survival and complication rate. These results warrant further extensive inquiry and research.

\section{CONFLICT OF INTEREST}

The authors declare no conflict of interest.

\section{ORCID}

Jonathan Du Toit BChD, MSc (iD http://orcid.org/0000-0001-5427-2659

\section{REFERENCES}

[1] Gluckman H, Du Toit J, Salama M. The Pontic-shield: partial extraction therapy for ridge preservation and Pontic site development. Int J Periodontics Restorative Dent. 2016;36(3):417-423.

[2] Gluckman H, Salama M, Du Toit J. Partial Extraction Therapies (PET) part 1: maintaining alveolar ridge contour at pontic and immediate implant sites. Int J Periodontics Restorative Dent. 2016;36(5): 681-687.

[3] Gluckman H, Salama M, Du Toit J. Partial Extraction Therapies (PET) part 2: procedures and technical aspects. Int J Periodontics Restorative Dent. 2017;37(3):377-385.

[4] Hansson S, Halldin A. Alveolar ridge resorption after tooth extraction: a consequence of a fundamental principle of bone physiology. J Dent Biomech. 2012;3:1758736012456543.

[5] Chappuis V, Buser R, Brägger U, Bornstein MM, Salvi GE, Buser D. Long-term outcomes of dental implants with a titanium plasmasprayed surface: a 20 -year prospective case series study in partially edentulous patients. Clin Implant Dent Relat Res. 2013;15(6): 780-790.

[6] Annibali S, Bignozzi I, La Monaca G, Cristalli MP. Usefulness of the aesthetic result as a success criterion for implant therapy: a review. Clin Implant Dent Relat Res. 2012;14(1):3-40.

[7] Setzer FC, Kim S. Comparison of long-term survival of implants and endodontically treated teeth. J Dent Res. 2013;93(1):19-26.

[8] Devigus A. Minimally invasive dentistry. Eur J Esthet Dent. 2011;6 (2):123.
[9] Gallucci G. Factors for long-term treatment outcomes. In: ITI World Symposium; May 4, 2017; Basel: Switzerland.

[10] Heitz-Mayfield L. Supportive care of implant patients. In: ITI World Symposium; May 4, 2017; Basel: Switzerland.

[11] A retrospective long-term evaluation of 128 socket-shield cases in the esthetic zone and posterior sites. [Internet]: Partial Extraction Therapies; 2017 Available from: http://www.partialextractiontherapies.org. Accessed February 17, 2017.

[12] Casey DM, Lauciello FR. A review of the submerged-root concept. J Prosthet Dent. 1980;43(2):128-132.

[13] Malmgren B, Cvek M, Lundberg M, Frykholm A. Surgical treatment of ankylosed and infrapositioned reimplanted incisors in adolescents. Scand J Dent Res. 1984;92(5):391-399.

[14] Bäumer D, Zuhr O, Rebele S, Schneider D, Schupbach $P$, Hürzeler M. The socket-shield technique: first histological, clinical, and volumetrical observations after separation of the buccal tooth segment-a pilot study. J Esthet Restor Dent. 2015;17(1): 71-82.

[15] Baumer D, Zuhr O, Rebele S, Hurzeler M. Socket Shield Technique for immediate implant placement-clinical, radiographic and volumetric data after 5 years. Clin Oral Implants Res. 2017 Mar 23. doi: 10.1111/clr.13012. [Epub ahead of print].

[16] Hurzeler MB, Zuhr O, Schupbach P, Rebele SF, Emmanouilidis N, Fickl S. The socket-shield technique: a proof-of-principle report. J Clin Periodontol. 2010;37(9):855-862.

[17] Esposito M, Grusovin MG, Coulthard P, Worthington HV. The efficacy of various bone augmentation procedures for dental implants: a Cochrane systematic review of randomized controlled clinical trials. Int J Oral Maxillofac Implants. 2006;21(5):696-710.

[18] Esposito M, Grusovin MG, Felice P, Karatzopoulos G, Worthington $\mathrm{HV}$, Coulthard P. Interventions for replacing missing teeth: horizontal and vertical bone augmentation techniques for dental implant treatment. Cochrane Database Syst Rev. 2009;(4):Cd003607.

[19] Schimmel M, Muller F, Suter V, Buser D. Implants for elderly patients. Periodontol 2000. 2017;73(1):228-240.

[20] Siormpas KD, Mitsias ME, Kontsiotou-Siormpa E, Garber D, Kotsakis GA. Immediate implant placement in the esthetic zone utilizing the "root-membrane" technique: clinical results up to 5 years postloading. Int J Oral Maxillofac Implants. 2014;29(6):1397-1405.

How to cite this article: Gluckman H, Salama M, Du Toit J. A retrospective evaluation of 128 socket-shield cases in the esthetic zone and posterior sites: Partial extraction therapy with up to 4 years follow-up. Clin Implant Dent Relat Res. 2017;00:18. https://doi.org/10.1111/cid.12554 


\section{The Pontic-Shield: Partial Extraction Therapy for Ridge Preservation and Pontic Site Development}

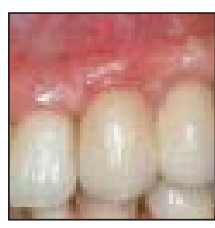

Howard Gluckman, BDS, MChD (OMP)

Jonathan Du Toit, BChD, Dipl Implantol, Dipl Oral Surg, MSc Dent ${ }^{2}$

Maurice Salama, DDS ${ }^{3}$
Augmentive ridge preservation techniques aim to manage the postextraction ridge. The partial extraction of teeth may better preserve the ridge form by maintaining the bundle bone-periodontal ligament apparatus. Root submergence has been demonstrated to retain the periodontal tissues and preserve the ridge beneath dentures or fixed prostheses. The socket-shield technique entails preparing a tooth root section simultaneous to immediate implant placement and has demonstrated histologic and clinical results contributory to esthetic implant treatment. A retrospective 10-patient case series treating 14 partial extraction sites demonstrates how a modification of the socket-shield technique can successfully develop pontic sites and preserve the ridge. Int J Periodontics Restorative Dent 2016;36:417-423. doi: 10.11607/prd.2651
${ }^{1}$ Specialist in Periodontics and Oral Medicine, Director of the Implant and Aesthetic Academy, Cape Town, South Africa.

2Department of Periodontics and Oral Medicine, School of Dentistry, Faculty of Health Sciences, University of Pretoria, Pretoria, South Africa.

${ }^{3}$ Clinical Assistant Professor of Periodontics, University of Pennsylvania, Philadelphia, Pennsylvania, USA; Medical College of Georgia, Augusta, Georgia, USA; Private Practice, Atlanta, Georgia, USA.

Correspondence to: Howard Gluckman, The Implant and Aesthetic Academy, 39 Kloot Street, Cape Town, South Africa. Fax: +2721 4263053.

Email: docg@theimplantclinic.co.za

C2016 by Quintessence Publishing Co Inc.
Resorption of the alveolar ridge commences immediately postextraction, is more pronounced on the buccal aspect, plateaus after 3 months of healing, and may result in as much as $56 \%$ loss of the residual ridge. ${ }^{1}$ This loss occurs as a result of the destruction of the bundle bone-periodontal ligament (BB-PDL) complex following the removal of a tooth and leads to resorption of the buccofacial ridge contour. ${ }^{2}$ Positioning a pontic restoration at a missing tooth site requires residual ridge tissue bulk and a positive contour to create esthetic harmony between the restoration and the alveolar ridge. It is a wellestablished concept that to ideally or even adequately restore an edentulous or partially dentate patient in most instances requires management of these extraction sites either to prevent tissue loss or to augment the already collapsed tissues.3,4 These may be divided into preridge collapse interventions, namely ridge preservation techniques, and post-ridge collapse interventions, namely bone augmentation, soft tissue augmentation, or a combination thereof. ${ }^{3-6}$

To maintain this tissue complex the tooth root, its ligament fibers, its vascular supply, and its attachment to bone need to be retained.? The root submergence concept has been demonstrated with success in the development of pontic sites. ${ }^{8}$ 


\begin{tabular}{|c|c|c|c|c|c|}
\hline $\begin{array}{l}\text { Patients } \\
\text { (no.) }\end{array}$ & $\begin{array}{c}\text { Socket- } \\
\text { shield(s) (no.) }\end{array}$ & $\begin{array}{c}\text { Socket-closure } \\
\text { technique }\end{array}$ & Healing & Complications & $\begin{array}{c}\text { Further treatment } \\
\text { needed }\end{array}$ \\
\hline 4 & 5 & Buccal flap advancement & Complete & - & - \\
\hline 1 & 3 & No flap closure & $\begin{array}{l}\text { Incomplete healing in } \\
\text { all } 3 \text { sockets }\end{array}$ & $\begin{array}{l}\text { Exposure of } \\
\text { the shield }\end{array}$ & $\begin{array}{l}\text { Exposure of the shields } \\
\text { requiring surgical closure }\end{array}$ \\
\hline 1 & 1 & $\begin{array}{l}\text { Placement of cytoplast } \\
\text { membrane }\end{array}$ & $\begin{array}{l}\text { Complete with wider } \\
\text { band of attached gingiva }\end{array}$ & - & - \\
\hline 2 & 3 & Socket-seal technique & $\begin{array}{l}\text { Complete healing, } \\
\text { took longer }\end{array}$ & - & - \\
\hline 2 & 2 & $\begin{array}{l}\text { Zuchelli free gingival } \\
\text { graft closure with buccal } \\
\text { and palatal pouch }\end{array}$ & $\begin{array}{l}\text { Complete healing with } \\
\text { excellent soft tissue } \\
\text { contours }\end{array}$ & - & - \\
\hline
\end{tabular}

An infection-free tooth root, whether endodontically treated or with a vital pulp, may when submerged support the ridge architecture to develop a pontic site. 'The technique, however, is contraindicated by endodontic apical pathology. Successful endodontic treatment would first be needed, or the root would need extraction and an alternative ridge management applied.

The socket-shield technique, in addition to its application as a buccofacial ridge preservation technique at immediate implant placement, overcomes this limitation and provides the clinician with an alternative method to submerge the buccofacial tooth root section, retain the vital periodontal tissues buccofacial to the root, and develop a pontic site with little or no collapse in a buccopalatal dimension. ${ }^{7}$ This report presents a case series of 14 sites in 10 patients treated with a modification of the technique, the pontic-shield.

\section{Materials and methods}

Ten adult patients of either gender, free of contributory medical condi- tions, presented for restorative implant therapy. Neither smoking nor apical pathology contraindicated treatment. Pontic sites $(n=14)$ were developed in each patient by preparing a pontic-shield with adjunct augmentation materials within the extraction sockets. The sites were left to heal for a minimum of 90 days and the ridge at the pontic sites developed by moderate pontic pressure of an interim fixed partial denture (FPD) for an additional 90 days. Final restorations were placed once the sockets had fully healed without clinical evidence of ponticshield exposure.

\section{Socket-shield technique}

The first step was to prepare a socket-shield. The preparation of the socket-shields was standardized in its methodology and its instrumentation and was carried out by the same clinician. The tooth roots at desired pontic sites were sectioned along their long axes as far apical as possible in a mesiodistal direction with a long shank root resection bur (Komet Dental). This was intended to preserve the buccofacial half of the tooth root intact and undamaged. Periotomes were inserted between the palatal root section and alveolar socket wall to sever the PDL, and this section of root was then carefully delivered (with attached apical pathology, if present) so as not to disturb the facial root section. The remaining root section was then shaped and reduced coronally to 1 $\mathrm{mm}$ above the alveolar crest as well as thinned slightly and concaved by careful application in an apicocoronal direction using a long-shanked, large, round diamond bur (Komet Dental). The tooth socket apex was then curetted to remove any remnant of infection, and each facial root section was checked for immobility by applying a sharp probe to its surface. Once they were fully prepared, these root sections were thus the socket-shields.

Modifying the technique as a pontic-shield

All sockets were additionally grafted with a xenogeneic bone particulate (Gen-Os, Osteobiol). Closure of the 
Fig 1 (left) Socket-shields prepared at sites $12,11,21$, and 23, with implants inserted immediately at 12, 21, and 23 . The socketshield at 11 with socket grafting and soft tissue closure thereafter completes preparation of the site as a pontic-shield.

Fig 2 (right) Immediate grafting of the postextraction socket at site 11 with xenogeneic bone particulate.

Fig 3 (left) CTG at the entrance to site 11.

Fig 4 (right) 90 days of healing with an additional 90 days of pontic pressure developed an anatomical soft tissue frame to receive the final prosthesis. Note the total absence of buccopalatal collapse at site 11 due to the pontic-shield.

sockets was achieved by buccal flap advancement (five socket sites), Zucchelli connective tissue graft (CTG) inserted into buccal and palatal pouches (two sites), cytoplast membrane (one site), and socket-seal technique (three sites). Three sites were initially managed without closure (Table 1). The following three cases are representative.

\section{Case report 1}

An adult male patient presented for treatment of a failing five-unit FPD. The prosthodontic treatment had been carried out several years prior and following several recementations the abutment teeth lacked adequate ferrules and proved unsuitable to support the restoration. The patient had lost tooth 22 (FDI) and the ridge collapse was evident (Fig 1). The abutment teeth were deemed nonrestorable and an implant-supported FPD was planned at sites 12, 21, and 23 .

Use of the pontic-shield procedure was planned for sites 11 and 22. Apical pathology at site 11 pre-
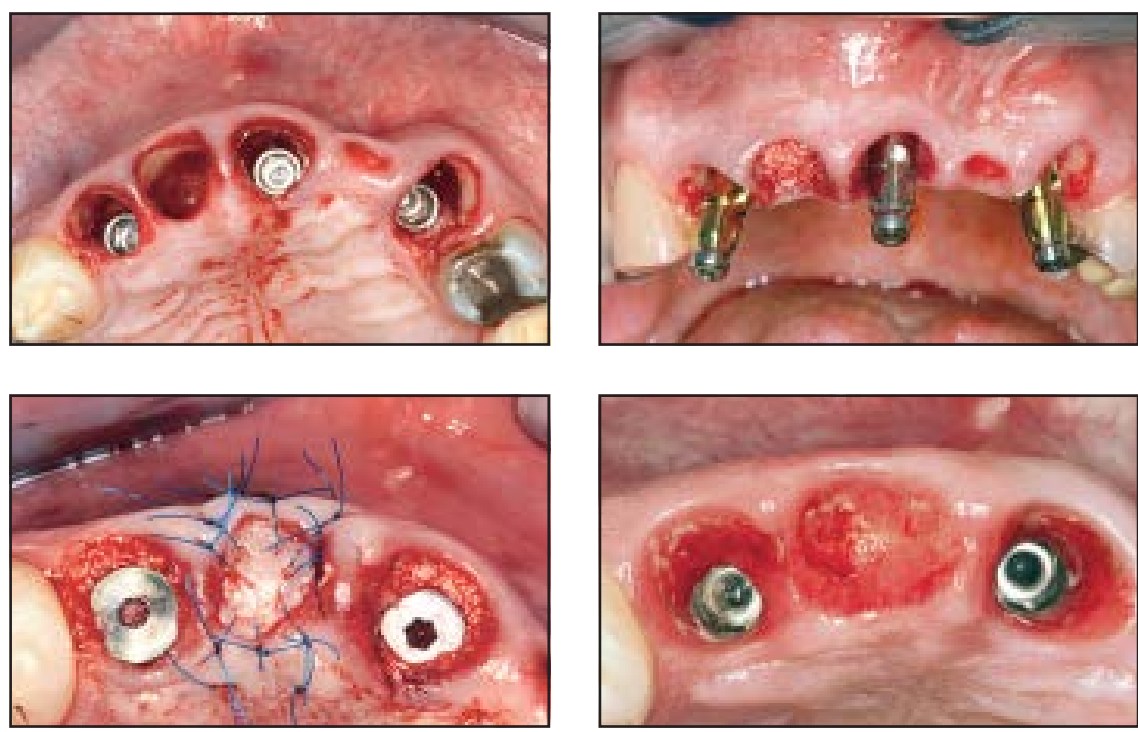

cluded the use of the root-submergence technique. Tooth root 11 was then prepared as a pontic-shield. The socket was filled with a xenograft bone particulate and the entrance sealed by CTG placed within a buccal and palatal pouch (Figs 2 and 3). After 90 days of healing, an interim prosthesis was fixed to the neighboring implants and a pontic applied prolonged pressure for an additional 90 days to the ridge crest at site 11. The absence of buccopalatal collapse was evident, and an esthetic pontic site with pseudopapillae was successfully developed (Fig 4). At the 18-month follow up, the results had been maintained (Figs 5 and 6).

\section{Case report 2}

An adult male patient presented for treatment with a partially edentulous anterior maxilla. The patient was a smoker, though the medical history was noncontributory. A FPD restored the edentulous space in the anterior maxilla with teeth 13, 11, and 22 as abutments. An implant- supported FPD was planned. However, the ridge at sites 12 and 21 had resorbed greatly and would require augmentation prior to implant placement. To prevent further collapse at site 11, ridge preservation was planned with the pontic-shield technique. Since an apical endodontic infection contraindicated the use of root submergence, the tooth was sectioned and a pontic-shield prepared. The socket was filled with a xenograft bone particulate and the socket entrance closed by the socket-seal technique as described by Landsberg. ${ }^{10}$ A 2- to 3-mm-thick, circular free gingival graft was harvested from the palatal mucosa and transferred to the de-epithelialized socket entrance. Healing of the socket was, however, prolonged in comparison with the other cases (Table 1) to ensure complete resolution of the apical pathology at site 11. After 4 months of healing, the ridge preserved at site 11 allowed for bone augmentation at sites 12 and 21 that did not extend outside of the bony envelope. 

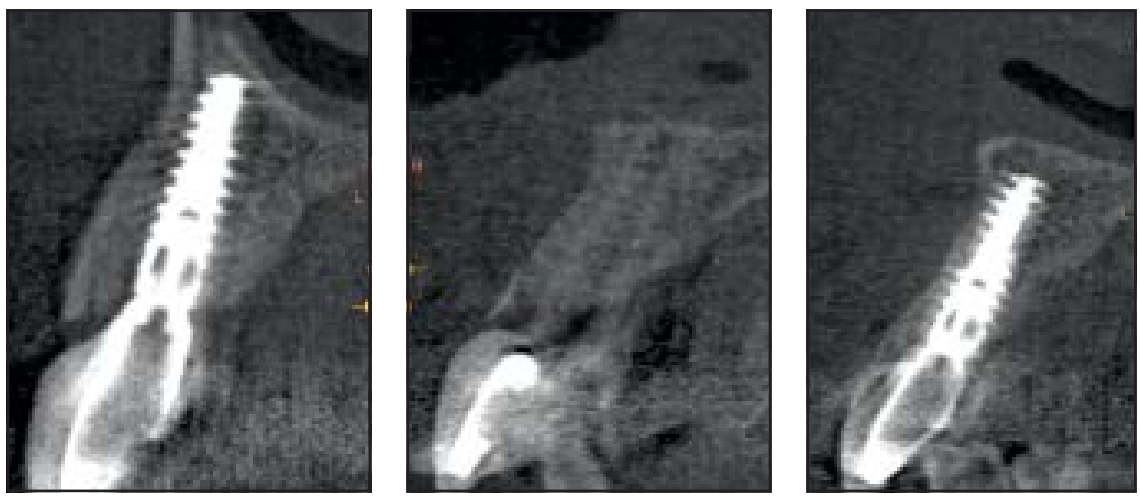

Fig 5 Postoperative CBCT, sliced at site 11 of the healed pontic-shield.

Fig 6 (right) Oblique view of the anterior maxilla illustrating the lack of collapse at the 1-year follow-up.

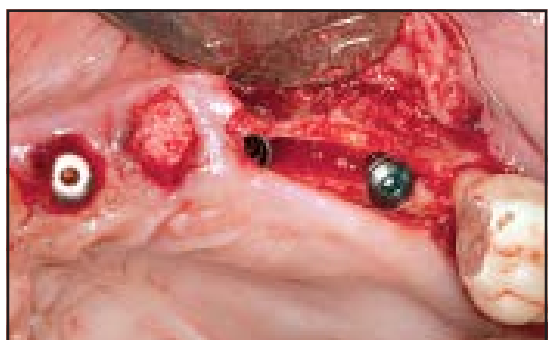

Fig 7 Xenograft particulate placed within socket 23 (with sinus augmentation and ridge-split carried out in 24 to 26).

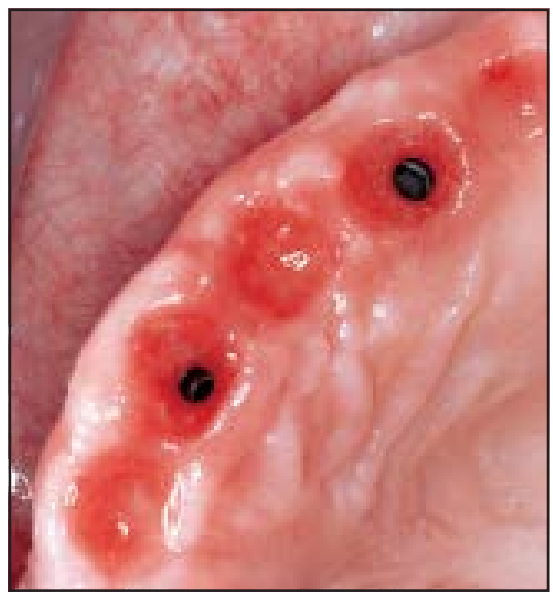

Fig 10 Note the absence of buccopalatal collapse at the pontic-shield site at 23, comparable with the adjacent partial extraction treatments.

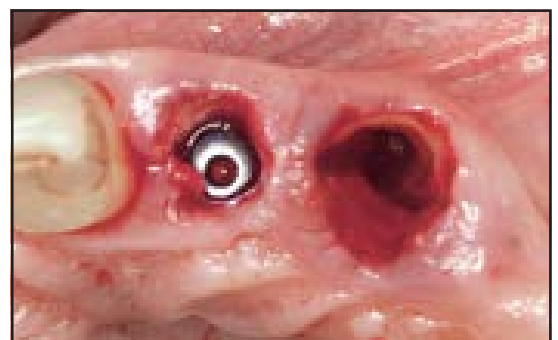

Fig 8 Tooth 21 was planned for root submergence, 22 was immediately placed with a socket-shield, and tooth 23 was planned as a pontic-shield.

\section{Case report 3}

An adult female patient presented with a failing dentition in the left maxilla. An implant-supported FPD was planned with strategic implant placement and pontic sites to be developed. A ridge split procedure with sinus augmentation was planned at sites 24 to 26 (Fig 7). Tooth 22 was prepared as a socketshield at implant placement. Tooth 11, however, had a horizontal fracture contraindicating a socket-shield technique at placement. The tooth was removed and an implant immediately placed. Tooth 21 was free of apical pathology, and a pontic site was prepared by a root submergence technique, sealing the
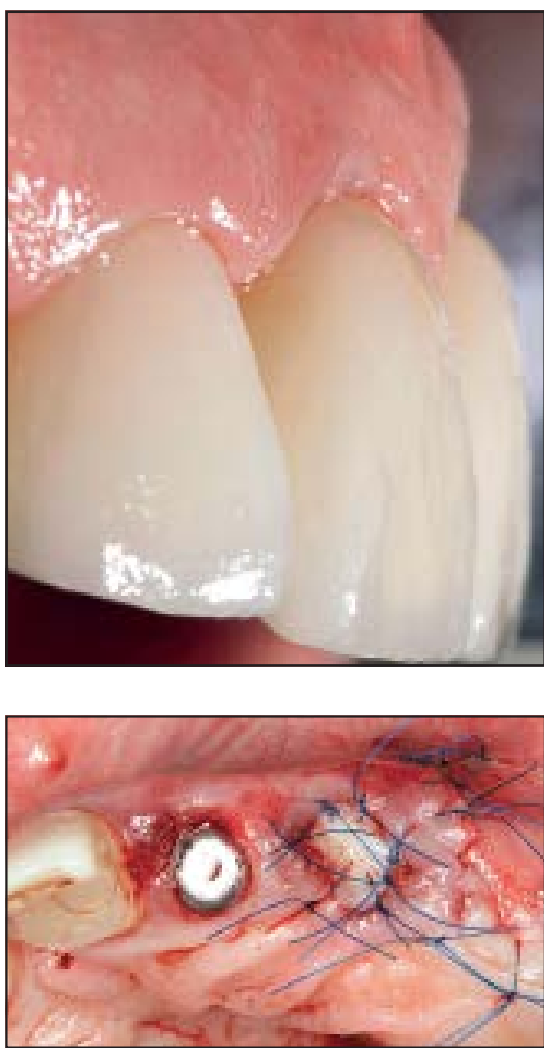

Fig 9 Final closure of the pontic-shield at site 23 with CTG.

socket entrance by rotated palatal flap. Tooth 23 was prepared as a pontic-shield (Fig 8), the socket was filled with a xenograft bone particulate, and the site was closed (Fig 9). All sites were left to heal and the implants to osseointegrate for a minimum of 90 days, after which an interim FPD was fitted to the implants and the soft tissue developed with gradual pontic pressure for an additional 90 days. Both pontic sites at 21 and 23 were successfully sculpted to accommodate the final restoration, the ridge width was maintained, and the tissues were prevented from collapsing (Fig 10). There was no evidence of pathology or exposure of the pontic-shield. 


\section{Results}

Of the 14 sites treated using the pontic-shield technique, noticeable ridge preservation quantified by subjective observation was achieved in all cases at the 12- and 18-month follow-ups. Assessment of the treatment outcomes as viewed from the occlusal and facial aspects demonstrated ridge preservation at all 14 sites using this partial extraction technique. In one patient, treatment was complicated by exposure of all 3 pontic-shields as a result of omitting soft tissue closure of the sites. Healing in this patient was prolonged and required buccal flap advancement for closure of the sites. An eventual positive outcome and ridge preservation was achieved. Healing was uneventful in all other patients (see Table 1). Results remained stable, and the pontic sites' tissues were healthy at the 18-month follow-up (Figs 5, 6, 11, and 12).

\section{Discussion}

Following tooth extraction, the tissues resorb as a direct result of the destruction of the BB-PDL-tooth complex. ${ }^{2} \mathrm{BB}$ arises from a functionally loaded PDL and is lost following extraction, which results in an almost certain collapse of residual buccofacial tissues. ${ }^{11} \mathrm{~A}$ healed ridge defect following tooth extraction may require extensive surgical intervention prior to definitive restorative treatment. This may involve guided bone regeneration (GBR) techniques using bone and/or bone substitute materials with a barrier membrane,
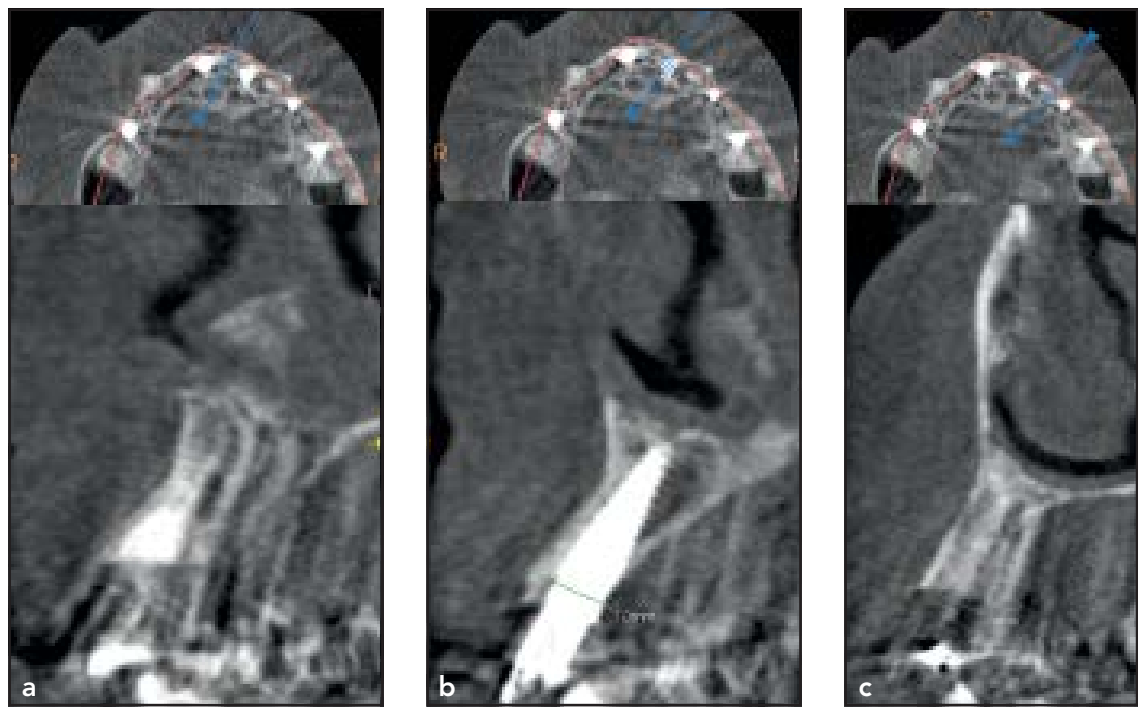

Fig 11 CBCT slices of sites (a) 21, (b) 22, and (c) 23 at the 1-year follow-up.

Fig 12 (right) The healed pontic-shield at site 23 at the 1-year follow-up.

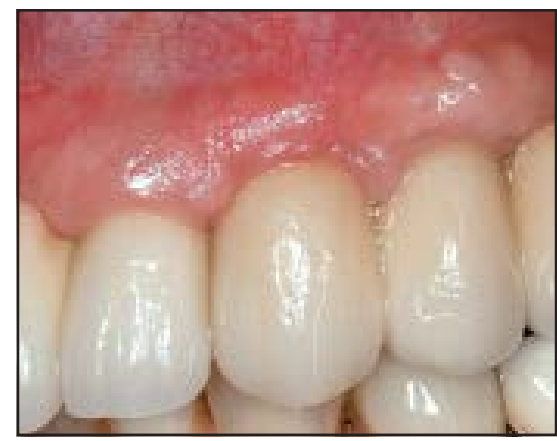

bone block GBR procedures, ridgesplit techniques, and so forth. All of these may provide hard tissue gains, though with limitations, and with the drawbacks of increased morbidity, technique sensitivity, increased costs, and difficulty of access to materials. ${ }^{3}$ The soft tissue alterations are also a challenge, with loss of papillae, scarring from the ridge augmentation procedure, and so forth. ${ }^{6}$ Root submergence was originally introduced as a technique to preserve alveolar ridge volume beneath removable full prostheses.12,13 More than three decades ago, Malmgren et al reported successful bone regeneration around submerged tooth roots, that bone forms coronal to such submerged teeth, and that even new cementum and connective tissue may form coronally over submerged teeth. ${ }^{8}$ Preserving the entire attachment apparatus for complete preservation of the alveolar ridge for pontic site development has been demonstrated.? This technique involves decoronation of the tooth at the bone crest or, preferably, 1 to $2 \mathrm{~mm}$ above the crest to 


\section{Table 2 Available case reports and literature reporting on the socket-shield technique}

\begin{tabular}{|c|c|c|}
\hline Year & Author(s) & Study \\
\hline 2015 & Bäumer et al ${ }^{14}$ & Animal histology of three cases of socket-shield with vertical fractures \\
\hline $2014^{a}$ & Siormpas et al ${ }^{17}$ & 46 case series of the root-membrane technique with follow up from 2 to 5 years \\
\hline 2014 & Holbrook ${ }^{20}$ & Case report: Guided implant placement with socket-shield \\
\hline $2014^{a}$ & Glocker et al ${ }^{16}$ & 3 case series of a modified socket-shield for delayed placement \\
\hline $2014^{a}$ & Cherel and Etienne ${ }^{19}$ & 1 case report of modified socket-shield for papillae preservation \\
\hline $2013^{a}$ & Kan and Rungcharassaeng ${ }^{18}$ & 1 case report of proximal socket-shield for papillae preservation \\
\hline 2013 & Chen and $\operatorname{Pan}^{15}$ & 1 case report of socket-shield with immediate implant placement \\
\hline 2010 & Hürzeler et $\mathrm{al}^{7}$ & $\begin{array}{l}\text { Original proof of principle report of animal histology following socket-shield and } \\
1 \text { clinical case report }\end{array}$ \\
\hline
\end{tabular}

${ }^{\text {aNot }}$ the actual socket-shield technique, but a version thereof.

preserve the supracrestal fibers with epithelial and connective tissue attachment.

Preservation of supracrestal fibers can better develop pontic sites by papillae preservation. ${ }^{7,9}$ Root submergence can achieve this and is indicated in vital and nonvital tooth roots alike. However, periapical pathology contraindicates the use of submerged roots for developing pontic sites. Hürzeler et al were the first to report the socketshield technique. Initially the procedure was applied to an immediate implant placement protocol, but its use in a far wider variety of applications and even in managing complications can be expected.? The histology from Hürzeler et al's first report of the socket-shield technique confirmed a retained attachment of the socket-shield to the buccal plate via a physiologic PDL free of any inflammatory response. The buccal plate crest showed an absence of osteoclastic activity-an absence of active remodeling. The coronal soft tissue demonstrated a physiologic junctional epithe- lium free of any inflammatory response that formed an attachment and junction at the newly formed cementum on the internal surface of the socket-shield. The working group of the original protocol later reported bone fill between the socket-shield and the implant. ${ }^{14}$

The pontic-shield should not be overprepared, since overthinning of the root may leave it unstable and flexure could lead to failure. Salama et al reported that root submergence for pontic site development may be left open to heal by secondary intention, but the pontic-shield must heal by surgical closure of the soft tissue. ${ }^{9}$ The complications seen in this case series may be attributed to the sites not surgically receiving soft tissue closure. The best results were seen when the Zucchelli CTG was inserted into buccal and palatal pouches to close the socket entrance. It is thus recommended that these steps be reproduced in carrying out the pontic-shield technique.

A discussion on the topic of the socket-shield and pontic-shield would be incomplete without men- tion of the limitations. These partial extraction treatments are still very early in their application, and a review of the literature returns only eight publications to date of the socket-shield (Table 2). Also worth noting is an inconsistency in nomenclature. For clarification, Siormpas et al published a 5-year retrospective case series of immediate implant placement simultaneous to the root-membrane technique. ${ }^{17}$ This publication came 4 years after the first histologic and clinical data on the socket-shield technique were reported in the literature. However, Siormpas et al were the first to provide significant long-term data on this partial extraction methodology, as well as on a significant number of implant sites and patients $(n=$ 46). Their results showed $100 \%$ osseointegration in all cases. Their case series measured crestal bone height, mesial and distal, at the extraction sites, and showed crestal bone loss as little as $0.18 \pm 0.09$ and $0.21 \pm 0.09 \mathrm{~mm}$, respectively. Data to demonstrate a lack of buccopalatal collapse would have been useful. 
The difference in methodology is important. Siormpas et al prepared the implant osteotomy site by drilling through the existing and intact tooth root. After preparation of the osteotomy, buccal and lingual root sections were separated. This differs from the original socket-shield methodology, as used in the present case series. Drilling through the tooth root may be detrimental to the implant drills and may damage the attachment of the socket-shield to the buccal BB. Siormpas et al report no complication in this regard..$^{17}$ The present authors suggest fully preparing the socket-shield prior to preparation of the pontic site or even implant placement.

Absolute preservation has not been demonstrated with the socket-shield technique. Bäumer et al found a mean loss of $1 \mathrm{~mm}$ in a labial direction after the placement of the final restorations. ${ }^{14}$ Chen et al in their case report measured $0.72 \mathrm{~mm}$ of buccal resorption. ${ }^{15}$ The present case series lacked objective methodology to measure any potential loss in ridge width and height following healing of the pontic sites. The results were measured subjectively to ascertain esthetic outcomes in development of the ridge to accommodate a pontic restoration. It is advised that future clinical studies be carried out that include digital ridge scans to compare preservation of the tissues from this technique to a control, possibly established socket/ridge preservation techniques, and sites healing without intervention.

\section{Conclusions}

This case series demonstrates the pontic-shield technique as a partial extraction therapy for development of pontic sites. Additional research, documentation, and scientific scrutiny are needed to validate application of the technique in daily clinical practice.

\section{Acknowledgments}

The authors reported no conflicts of interest related to this study.

\section{References}

1. Araújo MG, Lindhe J. Dimensional ridge alterations following tooth extraction. An experimental study in the dog. J Clin Periodontol 2005;32:212-218.

2. Gluckman H, Du Toit J. The management of recession midfacial to immediately placed implants in the aesthetic zone. International Dentistry African Edition 2015;5:6-15.

3. Kuchler U, von Arx T. Horizontal ridge augmentation in conjunction with or prior to implant placement in the anterior maxilla: A systematic review. Int J Oral Maxillofac Implants 2014;29(suppl): 14-24.

4. Horváth A, Mardas N, Mezzomo LA, Needleman IG, Donos N. Alveolar ridge preservation. A systematic review. Clin Oral Investig 2013;17:341-363.

5. Vignoletti $F$, Matesanz $P$, Rodrigo $D$, Figuero E, Martin C, Sanz M. Surgical protocols for ridge preservation after tooth extraction. A systematic review. Clin Oral Implants Res 2012;23(suppl 5): 22-38.

6. Levine RA, Huynh-Ba G, Cochran DL. Soft tissue augmentation procedures for mucogingival defects in esthetic sites. Int J Oral Maxillofac Implants 2014; 29(suppl):155-185.

7. Hürzeler MB, Zuhr O, Schupbach P, Rebele SF, Emmanouilidis N, Fickl S. The socket-shield technique: A proof-ofprinciple report. J Clin Periodontol 2010; 37:855-862
8. Malmgren $B$, Cvek $M$, Lundberg $M$, Frykholm A. Surgical treatment of ankylosed and infrapositioned reimplanted incisors in adolescents. Scand J Dent Res 1984:92:391-399.

9. Salama M, Ishikawa T, Salama H, Funato A, Garber D. Advantages of the root submergence technique for pontic site development in esthetic implant therapy. Int J Periodontics Restorative Dent 2007; 27:521-527.

10. Landsberg CJ. Implementing socket seal surgery as a socket preservation technique for pontic site development: Surgical steps revisited-A report of two cases. J Periodontol 2008;79:945-954.

11. Ho SP, Kurylo MP, Grandfield K, et al. The plastic nature of the human boneperiodontal ligament-tooth fibrous joint. Bone 2013;57:455-467.

12. Miller PA. Complete dentures supported by natural teeth. J Prosthet Dent 1959;8:924-928.

13. Morrow RM, Feldmann EE, Rudd KD, Trovillion HM. Tooth-supported complete dentures: An approach to preventive prosthodontics. J Prosthet Dent 1969;21: 513-522.

14. Bäumer D, Zuhr O, Rebele S, Schneider $D$, Schupbach $P$, Hürzeler M. The socket-shield technique: First histological, clinical, and volumetrical observations after separation of the buccal tooth segment-A pilot study. Clin Implant Dent Relat Res 2015;17:71-82.

15. Chen $\mathrm{CL}$, Pan $\mathrm{YH}$. Socket shield technique for ridge preservation: A case report. J Prosthondontics Implantology 2013;2:16-21.

16. Glocker M, Attin T, Schmidlin PR. Ridge preservation with modified "socketshield" technique: A methodological case series. Dent J 2014;2:11-21.

17. Siormpas KD, Mitsias $M E$, KontsiotouSiormpa E, Garber D, Kotsakis GA. Immediate implant placement in the esthetic zone utilizing the "root-membrane" technique: Clinical results up to 5 years postloading. Int J Oral Maxillofac Implants 2014;29:1397-1405.

18. Kan JY, Rungcharassaeng K. Proximal socket shield for interimplant papilla preservation in the esthetic zone. Int $J$ Periodontics Restorative Dent 2013;33: e24-e31.

19. Cherel F, Etienne D. Papilla preservation between two implants: A modified socket-shield technique to maintain the scalloped anatomy? A case report. Quintessence Int 2014;45:23-30.

20. Holbrook SE. Model guided immediate implant placement and provisionalization in the esthetic zone utilizing a nanostructured titanium implant. J Oral Implantol 2014 [Epub ahead of print]. 


\title{
Human Histologic Evidence of New Bone Formation and Osseointegration Between Root Dentin (Unplanned Socket-Shield) and Dental Implant: Case Report
}

\author{
Charles Schwimer, DMD, BS 1 /Gregory A. Pette, DMD, MS²/Howard Gluckman, BDS, MChD (OMP) ${ }^{3}$ \\ Maurice Salama, $\mathrm{DMD}^{4} /$ Jonathan Du Toit, BChD, MSc(Dent $)^{5}$
}

\begin{abstract}
The socket-shield technique described 7 years ago has since grown in its reporting in the literature as a valid method of ridge preservation at immediate implant placement. To date, large clinical cohorts with up-to-4-year follow-up have been reported. Additionally, evidence of tissue histology at the dental implant and socket-shield has been demonstrated in the animal model. However, human histologic evidence has not yet been available, and the clinician's uncertainty regarding the tissues that may form between the socket-shield and dental implant may remain unanswered until now. This case report presents the first human histologic evidence that bone may entirely fill the space between root dentin and an osseointegrated implant surface. INT J ORAL MaXILlofac ImPLANTS 2018;33:e19-e23. doi: 10.11607/jomi.6215
\end{abstract}

Keywords: dental implant, implantology, partial extraction therapies, ridge preservation, socket-shield

\begin{abstract}
iterature reporting on the retention of the tooth Lroot or part of the tooth root to maintain alveolar ridge volume and offset postextraction collapse has been growing in recent years. ${ }^{1}$ The socket-shield technique has been proposed as such a method, sectioning the facial root portion for it to remain submerged in situ with its physiologic attachment to bundle bone intact. $^{2}$ The hypothesis asserts that this root portion, when retained, circumvents the destruction of Sharpey's fibers inserted into bundle bone and "shields" the facial alveolar ridge from collapsing adjacent to the implant. ${ }^{2,3}$ The literature to support this theory is growing. ${ }^{1-14}$ As yet, the technique requires additional data to advocate in everyday practice, especially data ranking higher in the hierarchy of scientific evidence.
\end{abstract}

\footnotetext{
1 Private Practice, Pittsburgh, Pennsylvania, USA.

${ }^{2}$ Private Practice, Naples, Florida, USA.

${ }^{3}$ Director, Implant and Aesthetic Academy, Specialist in

Periodontics and Oral Medicine, The Implant Clinic, Cape Town, South Africa.

${ }^{4}$ Clinical Assistant Professor of Periodontics, University of Pennsylvania, Philadelphia, Pennsylvania; Medical College of Georgia, Augusta, Georgia; Private Practice, Atlanta, Georgia, USA.

${ }^{5}$ Resident, Department of Periodontics and Oral Medicine, University of Pretoria, Faculty of Health Sciences, School of Dentistry, South Africa.
}

Correspondence to: Dr Charles Schwimer, 6201 Steubenville Pike, Mckees Rocks, PA, 15136, USA. Email: F40chuck@aol.com

C2018 by Quintessence Publishing Co Inc.
Hürzeler and coworkers ${ }^{2}$ as well as Bäumer and coworkers $^{3}$ have provided valuable histologic evidence of the healed socket-shield and implant sectioned from the alveolar ridge. Yet, these have been presented in the canine model. The clinician may still be uncertain as to what tissue grows between the socket-shield and dental implant in a human. Is it periodontal ligament, new cementum, or partial or full periodontal regeneration? Will the identification of this tissue architecture affect the decision-making when selecting the socket-shield technique to offset resorptive complications at immediate implant placement? The objective of this case report was to present the first human histologic evidence that demonstrates the healing possibility of new bone and osseointegration between root dentin and dental implant.

\section{CASE REPORT}

A woman aged 45 years presented to the offices of her periodontist for a routine check-up, and provided a history that included among others discomfort and vague sensation associated with her implant crown at the left maxillary first premolar site. The patient's medical history was noncontributory. The dental history entailed loss of the premolar tooth 2 years prior and an immediate implant being placed. A period of submerged healing followed, with subsequent implant exposure and definitive restoration with a cement-retained crown. Intraoral examination noted no overt inflammation, peri-implant mucositis, or tissue 


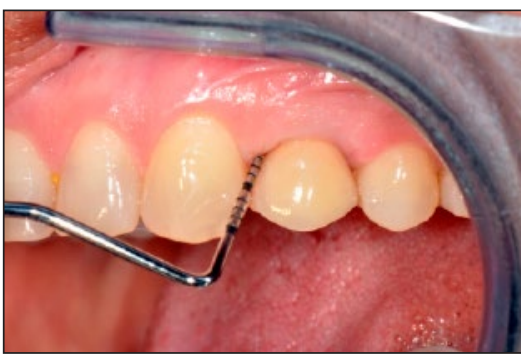

Fig 1 At first presentation, the peri-implant tissues displayed no signs of disease or inflammation. The probe was able to be inserted to a depth of $6 \mathrm{~mm}$ at the mesiobuccal site.
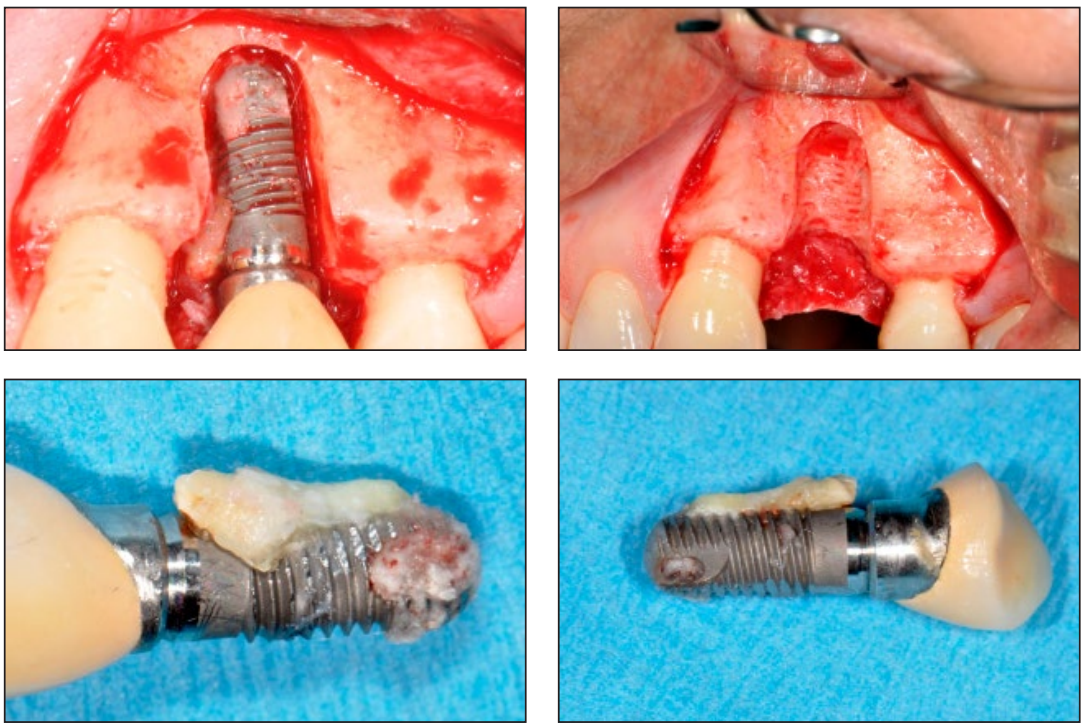

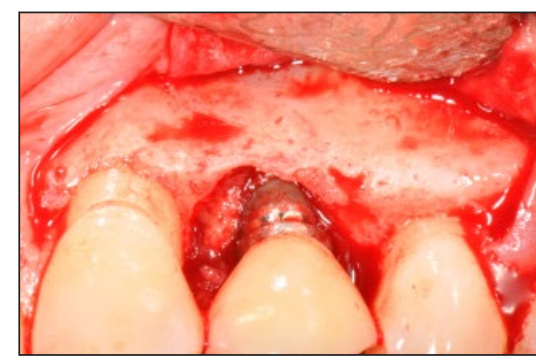

Fig 3 Full-thickness flap was elevated to expose the ridge buccal to the implant; the coronal bone loss is evident. nal bone loss at the implant-abutment terface, and a root fragment at its mesial/ mesiopalatal aspect.

Fig 4 (Left) After preparation of a lateral window for removal of the implant.

Fig 5 (Right) The cleaned site after implant removal.

Fig 6 (Left) The mesial aspect of the implant and restoration affixed, with the root fragment adhering to its surface. Bone adhered to the implant apex, with an absence of fibrous soft tissue on the implant.

Fig 7 (Right) The distal aspect of the implant and restoration affixed, with the root fragment adhering to its surface. recession. Circumferential probing at the implant crown was warranted to investigate further, and increased probing depths were noted, deepest at the mesiobuccal location: $6 \mathrm{~mm}$ (Fig 1). A periapical radiograph was taken, noting crestal peri-implant bone in a "saucerization" presentation, and what appeared to be a foreign object mesial at the implant (Fig 2). The clinical features of crestal loss and bleeding on probing supported the diagnosis of peri-implantitis, yet with a surviving implant. The radiographic diagnosis of a retained root fragment in proximation to the implant, coupled with the peri-implantitis diagnosis, merited presenting the patient with the option of implant removal and rehabilitation of the site. Alternative treatment options, including no additional treatment, were offered to the patient, among which removal and retreatment with an implant-supported restoration was selected by the patient.

Following local anesthesia of the site, a full-thickness mucoperiosteal flap was raised to expose the facial alveolar ridge at the implant (Fig 3). A window was prepared, and the implant with its restoration was torqued and removed laterally via the preparation (Figs 4 and 5). At removal, the longitudinal root section could be noted adherent to the implant surface (Figs 6 and 7). The implant with any attached tissue as is was photographed and then placed into $10 \%$ buffered formalin to be sent for histologic examination. The site was debrided, rinsed with saline, and grafted with an allograft particulate bone (Puros, Zimmer Biomet) hydrated in recombinant human platelet-derived growth factor-BB (rhPDGF-BB) (Fig 8). The graft was covered by a layer of nonresorbable, titanium-reinforced dense polytetrafluoroethylene (dPTFE) membrane (Cytoplast, Osteogenics Biomedical) covered by a resorbable collagen membrane (Bio-Gide, Geistlich). The flap was closed (Fig 9) and the site left to heal for a period of 3 months, whereafter a second implant was placed and subsequently restored following osseointegration (Fig 10).

\section{HISTOLOGIC ANALYSIS}

The implant with adherent tissue was fixed in $10 \%$ neutral buffered formalin, dehydrated, infiltrated, 
Fig 8 (Left) Site grafted with allograft particulate bone hydrated in rhPDGF-BB, covered by dPTFE and collagen membrane layering.

Fig 9 (Right) Final closure of the GBR procedure.
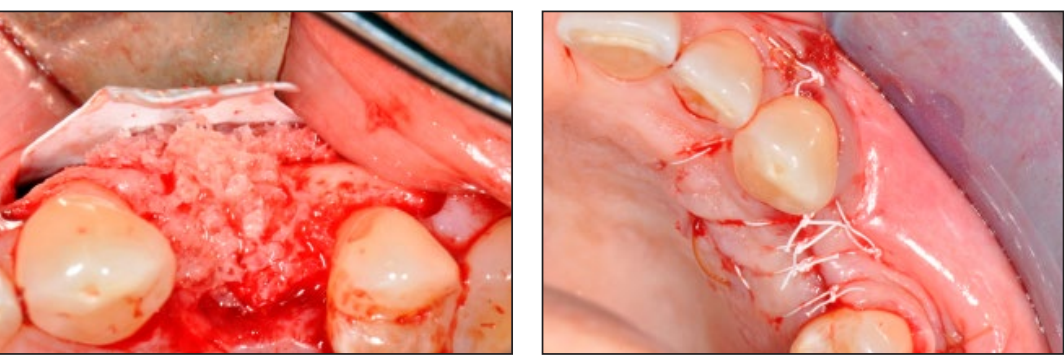

Fig 10 (a) Re-entry of the augmented site at 3 months, with (b) reinsertion of a dental implant.

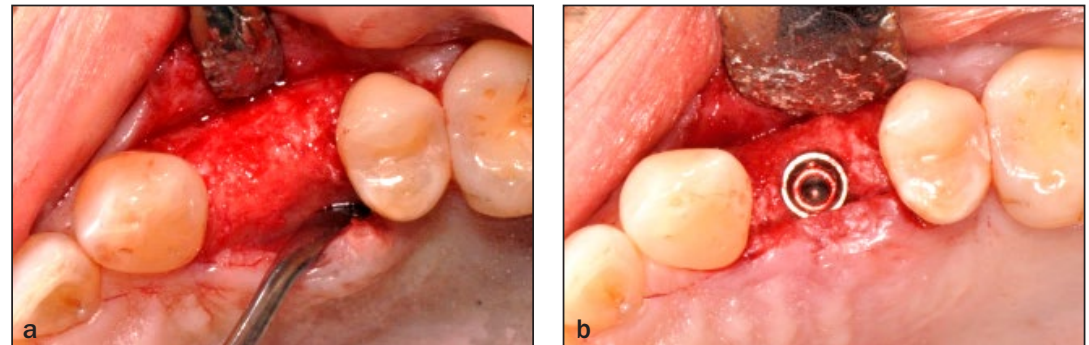

then slowly embedded in a glycol methacrylate-based polymer resin block, and cut by microtome into undecalcified sections (Exakt Apparatebau). The sections were then polished to within 10 microns and stained with Stevenel's blue and van Gieson picro fuchsin. Viewed at low power $(25 \times)$ under a light microscope, an adherent root section was observed extending the vertical extent of the implant approximately 3 $\mathrm{mm}$ coronally beyond the first thread and polished implant collar (Fig 11a). The fragment was verified as tooth root, displaying dentinal tubules that span the dentin layer that interfaces with an outer cementum layer. At medium power magnification $(40 \times)$, the dentinal tubules were distinct (Fig 11b). A lateral canal was also observed at about the apical third of the implant. Tissue was present within the implant apical chamber and between the implant threads (Figs $11 \mathrm{a}$ to $11 \mathrm{~d}$ ). The tissue contained in the apical chamber and that filled the implant's interthread spaces was confirmed as bone, displaying a marbled appearance-the resting and creeping reversal lines typical of alveolar bone's histologic presentation (Fig 11c). This tissue was intimately apposed to the implant surface with continuation to the root section. The bone that filled the thread spaces was confirmed to be vital, displaying osteocytes housed in lacunae, with large atypical vacuolar spaces, which themselves contained bone tissue in areas (Fig 11c). These circular vacuoles were first thought to be vascular lumens of Volkmann canals or Haversian systems. The current hypothesis explaining this presentation is that fragments of dentin dislodged during implant insertion were contained within these in the interthread bone. There appeared to be an absence of fibrovascular tissue at the interfaces between bone and dentin, and bone and implant. The bone that occupied the interthread spaces, when viewed by polarized microscopy, exhibited mineralization with concentric lamellae, evident of mature, remodeled bone (Fig 11d). The space between the implant surface and bone was a separation artifact that likely resulted from the microtome preparation of the sample.

\section{DISCUSSION}

New treatments not yet supported by strong scientific evidence may be unsound and even controversial. Alas, all health care innovations have their starting point. Typically, in vitro precedes in vivo application, with testing in the animal model before human subjects. ${ }^{15}$ The socket-shield technique has progressed to the current stage, where the literature reports on case cohorts as large as 128 patients in a single study, with follow-up at 4 years. Additionally, histologic reports in the canine model have provided insight into the healing of tissues at an implant placed adjacent and in contact with a root fragment. ${ }^{2,3,16}$ However, the clinician contemplating this technique may still have unanswered questions; paramount among these: What tissues grow between the implant and socket-shield? Since several studies over the last two decades have investigated the probability of forming a periodontal ligament and periodontal tissues onto the implant surface and failed to achieve osseointegration, the clinician would be wary to suspect similar of the socket-shield technique. The distinction, though, is to be made regarding the root section configuration, and the origin of the mesenchymal cells that have osteoblastic differentiation potential. Buser et al had experimented with implantation into retained primate teeth. ${ }^{17}$ This novel study demonstrated that a cementum layer 

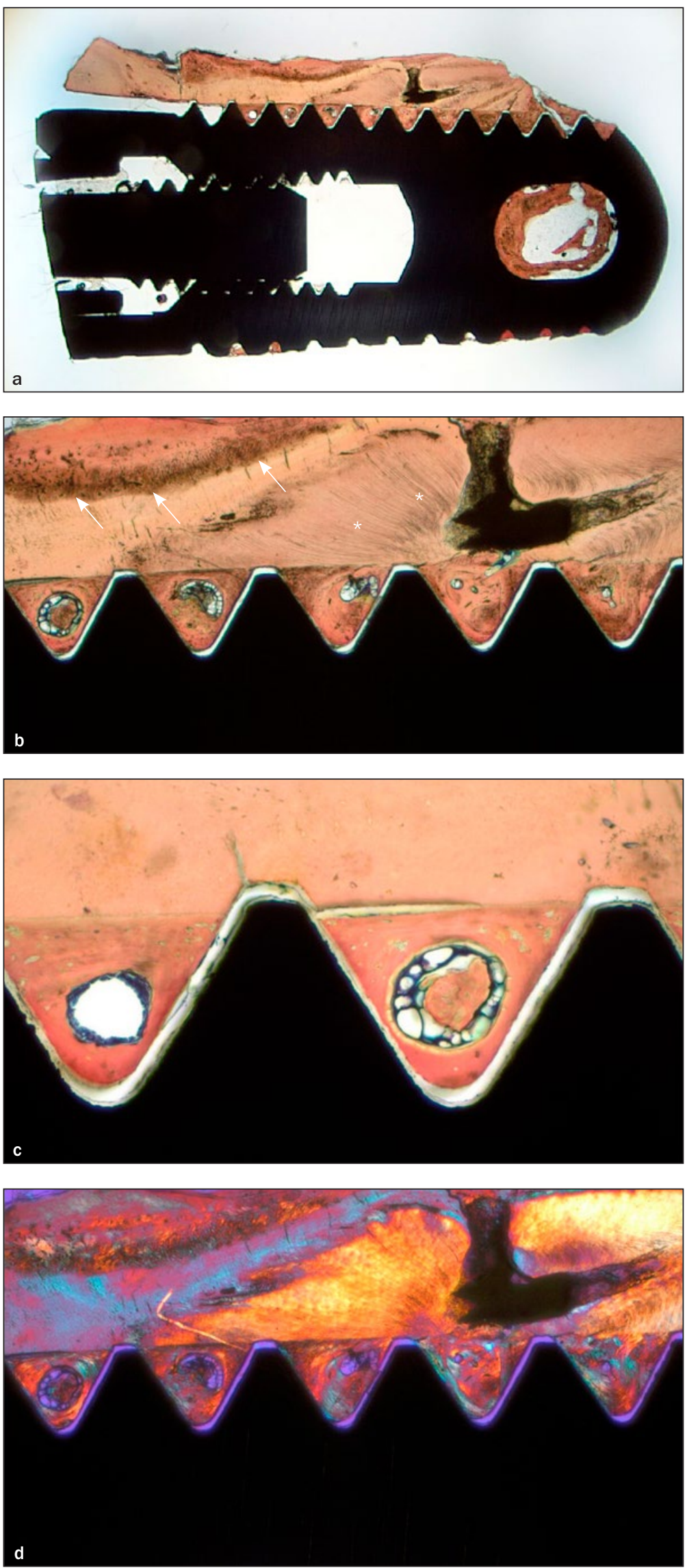

Fig 11a Undecalcified section of the implant with the root fragment closely adherent to its surface, spanning from apex well beyond the implant's polished collar. Tissue is visible filling each thread space, as well as within the apical chamber. Light microscopy, 25×, Stevenel's blue and Van Gieson's picro fuchsin.

Fig 11b The dentinal tubules of the root fragment are prominent (asterisks), as the root fragment interfaces with root cementum (arrows). Note that each thread space is wholly occupied by bone, which intimately interfaces with the root dentin. The interthread bone displays circular, vacuolar structures. Bone tissue obliterates, partly infiltrates, or centrally occupies these vacuoles. Light microscopy, $40 \times$, Stevenel's blue and Van Gieson's picro fuchsin.

Fig 11c High-power magnification verified mature, living bone, organized in concentric lamellae, containing osteocytes within lacunae. Vacuolar structures central to the interthread bone themselves contain bone tissue. Light microscopy, 200×, Stevenel's blue and Van Gieson's picro fuchsin.

Fig 11d Bone filled each thread space intimately interfacing between the root fragment and implant surface. Note the Haversian systems containing vessels. Polarized light microscopy, 40×, Stevenel's blue and Van Gieson's picro fuchsin. 
formed on the implant surfaces and that a periodontal ligament consistently was present, inserting fibers from implant cementum into adjacent bone. Fifteen years later, Parlar and coworkers similarly aimed to investigate the potential of periodontal tissues to form around dental implants placed into canine teeth. ${ }^{18}$ The teeth were hollowed, and implants were inserted wholly inside the teeth. Slits in the teeth were prepared to allow passage to the periodontal ligament. The results of this study also failed to demonstrate successful osseointegration. These root configurations, however, differed vastly from the socket-shield. The socket-shield is prepared as a vertical root portion, facial to the implant, shaped to a concave and thinned slightly, with its physiologic attachment to bundle bone maintained. ${ }^{19} \mathrm{An}$ implant is inserted palatal/lingual to the socket-shield and derives its primary stability from apical bone, as is routine for immediate implant placement. The socket-shield in its orientation does not obstruct the passage of peri-vascular pleuripotent cells and trabecular bone-lining mesenchymal cells to the implant surface. It may be inferred that the socket-shield does not interfere with adequate osseointegration, and merely serves to support the tissues facial to the implant. After submission of this histologic evidence for peer-review, authors Mitsias and coworkers had reported histology of a similar technique-the root membrane. While differing from the socket-shield by preparing the implant osteotomy through the tooth root, the authors similarly reported the presentation of bone between implant and root dentin. ${ }^{20}$ In this case presentation, a vertical root segment that spanned implant apex to collar was observed and living, ordered bone that interfaced between inner dentin and implant threads. It appeared from the radiograph that the root fragment extended beyond the bone crest, and it is now known today from Gluckman and coworkers that that is not a desirable preparation. ${ }^{14,19} \mathrm{Had}$ the root fragment in the case presented here been reduced with a diamond bur and high-speed handpiece, the peri-implant tissues may have returned to optimal health. It is debatable whether the root contributed to the peri-implant bone loss, since bone loss can also be noted farthest from the root at the implant's distal aspect. Literature reporting 5-year follow-up has demonstrated the contrary, that crestal bone is maintained by the socket-shield. ${ }^{21}$ Thus, possibly, were this root fragment prepared strictly according to steps described previously, the peri-implant bone level may have been maintained.

\section{CONCLUSIONS}

Bone can occupy the space between an implant surface and a socket-shield, as is the desired outcome of an osseointegrated implant.

\section{ACKNOWLEDGMENTS}

The authors wish to acknowledge Hari Prasad for the expert preparation of the histologic specimens. The authors reported no conflicts of interest related to this study.

\section{REFERENCES}

1. Gluckman H, Salama M, Du Toit J. Partial Extraction Therapies (PET) Part 1: Maintaining alveolar ridge contour at pontic and immediate implant sites. Int J Periodontics Restorative Dent 2016;36:681-687.

2. Hürzeler MB, Zuhr O, Schupbach $P$, Rebele SF, Emmanouilidis N, Fickl $\mathrm{S}$. The socket-shield technique: A proof-of-principle report. J Clin Periodontol 2010;37:855-862.

3. Bäumer D, Zuhr O, Rebele S, Schneider D, Schupbach P, Hürzeler M. The socket-shield technique: First histological, clinical, and volumetrical observations after separation of the buccal tooth segment-A pilot study. Clin Implant Dent Relat Res 2015;17:71-82.

4. Abadzhiev M, Nenkov P, Velcheva P. Conventional immediate implant placement and immediate placement with socket-shield technique Which is better. Int J Clin Med Res 2014;1:176-180.

5. Chen C, Pan Y. Socket shield technique for ridge preservation: A case report. J Prosthodont Implantol 2013;2:16-21.

6. Cherel F, Etienne D. Papilla preservation between two implants: A modified socket-shield technique to maintain the scalloped anatomy? A case report. Quintessence Int 2014;45:23-30.

7. Glocker M, Attin T, Schmidlin PR. Ridge preservation with modified "socket-shield" technique: A methodological case series. Dent J 2014;2:11-21.

8. Gluckman H, Du Toit J, Salama M. The pontic-shield: Partial extraction therapy for ridge preservation and pontic site development. Int J Periodontics Restorative Dent 2016;36:417-423.

9. Holbrook SE. Model-guided flapless immediate implant placement and provisionalization in the esthetic zone utilizing a nanostructured titanium implant: A case report. J Oral Implantol 2016;42:98-103.

10. Huang $H$, Shu L, Liu Y, Wang L, Li J, Fu G. Immediate implant combined with modified socket-shield technique: A case letter. J Oral Implantol 2017;43:139-143.

11. Kan JY, Rungcharassaeng K. Proximal socket shield for interimplant papilla preservation in the esthetic zone. Int J Periodontics Restorative Dent 2013;33:e24-e31.

12. Mitsias ME, Siormpas KD, Kontsiotou-Siormpa E, Prasad H, Garber D, Kotsakis GA. A step-by-step description of PDL-mediated ridge preservation for immediate implant rehabilitation in the esthetic region. Int J Periodontics Restorative Dent 2015;35:835-841.

13. Saeidi Pour R, Zuhr O, Hürzeler M, et al. Clinical benefits of the immediate implant socket shield technique. J Esthet Restor Dent 2017;29:93-101.

14. Gluckman H, Salama M, Du Toit J. A retrospective evaluation of 128 socket-shield cases in the esthetic zone and posterior sites: Partial extraction therapy with up to 4 years follow-up. Clin Implant Dent Relat Res 2017. [Epub ahead of print]

15. U.S. Food and Drug Administration. FDA Case Study. Bringing an Innovative Device to Market: Premarket Approval (PMA) of Medica Devices. https://www.fda.gov/downloads/Training/CourseMaterialsforEducators/NationalMedicalDeviceCurriculum/UCM404249.pdf. Accessed 31 October 2017.

16. Guirado JL, Troiano M, López-López PJ, et al. Different configuration of socket shield technique in peri-implant bone preservation: An experimental study in dog mandible. Ann Anat 2016;208:109-115.

17. Buser D, Warrer K, Karring T. Formation of a periodontal ligament around titanium implants. J Periodontol 1990;61:597-601.

18. Parlar A, Bosshardt DD, Unsal B, Cetiner D, Haytaç C, Lang NP. New formation of periodontal tissues around titanium implants in a novel dentin chamber model. Clin Oral Implants Res 2005;16:259-267.

19. Gluckman H, Salama M, Du Toit J. Partial Extraction Therapies (PET) Part 2: Procedures and technical aspects. Int J Periodontics Restorative Dent 2017;37:377-385.

20. Mitsias ME, Siormpas KD, Kotsakis GA, Ganz SD, Mangano C, lezzi G. The root membrane technique: Human histologic evidence after five years of function. Biomed Res Int 2017;2017:7269467

21. Bäumer D, Zuhr O, Rebele S, Hürzeler M. Socket shield technique for immediate implant placement-Clinical, radiographic and volumetric data after 5 years. Clin Oral Implants Res 2017;28:1450-1458. 


\title{
The socket-shield technique to support the buccofacial tissues at immediate implant placement
}

\author{
Howard Gluckman, ${ }^{1}$ Jonathan Du Toit, ${ }^{2}$ Maurice Salama ${ }^{3}$
}

\begin{abstract}
Aim: Tooth loss and subsequent ridge collapse continue to burden restorative implant treament. Careful management of the post-extraction tissues is needed to preserve the alveolar ridge. In-lieu of surgical augmentation to correct a ridge defect, the socket-shield technique offers a promising solution. As the root submergence technique retains the periodontal attachment and maintains the alveolar ridge for pontic site development, this case report demonstrates the hypothesis that retention of a prepared tooth root section as a socket-shield prevents the recession of tissues buccofacial to an immediately placed implant. Materials and Methods: An adult male patient had a ferrule-less central maxillary incisor sectioned to prepare a socket-shield at implant placement. The implant was provisionalized and immediately loaded until definitive restoration at 4 months of healing. Results: The implant osseointegrated successfully and without complication. Immediate postoperative as well as the 1 year follow up demonstrated a functional and aesthetic outcome of the treatment. The socket-shield technique in conjunction with immediate placement and provisionalization positively supported the ridge facial to the implant. Conclusions: The socket-shield technique is a highly promising addition to clinical implant dentistry and this case report is among the first to demonstrate the procedure in clinical practice with a 1-year follow up.
\end{abstract}

Keywords: Socket-shield technique, dental implant, ridge preservation, immediate placement

\section{' Howard Gluckman BDS, MChD (OMP). \\ Specialist in periodontics and oral medicine, director of the Implant and Aesthetic Academy, Cape Town, South Africa 2 Jonathan Du Toit BChD, Dipl. Implantol., Dip Oral Surg, MSc Dent. The Implant and Aesthetic Academy, Cape Town, South Africa \\ ${ }^{3}$ Maurice Salama DMD. Clinical Assistant Professor of Periodontics, University of Pennsylvania, Philadelphia, Pennsylvania; Medical College of Georgia, Augusta, Georgia; Private Practice, Atlanta, Georgia}

\section{Corresponding Author Howard Gluckman BDS, MChD (OMP) \\ Contact email:docg@mweb.co.za Telephone: 2721-426-2300}

\section{Introduction}

Immediate implant placement is a well-recognized and successful treatment option following tooth removal. ' Although the success rates for both immediate and delayed implant techniques are comparable, the literature reports that one can expect there to be recession of the buccal / facial gingiva of at least $1 \mathrm{~mm}$ following immediate implant placement, with the recession to possibly worsen in thin gingival biotypes. ${ }^{2}$ Low aesthetic value areas may be of less concern, however this recession and ridge collapse can pose an aesthetic disaster in areas such as the anterior maxilla. Compromised aesthetics may be masked to some degree by a low lip-line, thick gingival biotype, when treating single tooth cases, and so forth, but when implant therapy is carried out in patients with high lip-lines, patients with high aesthetic demands, with a very thin gingival biotype or multiple missing teeth where there is more extensive tissue deficit, then the risk for an aesthetic failure is far greater. ${ }^{3}$

The socket-shield (SS) technique provides a promising treatment adjunct to better manage these risks and preserve the post-extraction tissues in aesthetically challenging cases. ${ }^{4}$ The principle is to prepare the root of a tooth indicated for extraction in such a manner that the buccal / facial root section remains in-situ with its physiologic relation to the buccal plate intact. The tooth root section's periodontal attachment apparatus (periodontal ligament (PDL), attachment fibers, vascularization, root cementum, bundle bone, alveolar bone) is intended to remain vital and undamaged so as to prevent the expected post-extraction socket remodeling and to support the buccal / facial tissues. Hereafter a case is presented where the SS technique was carried out at implant placement and the results from the case followed up at 1 year post-treatment demonstrate the degree of facial ridge tissue preservation achieved. 


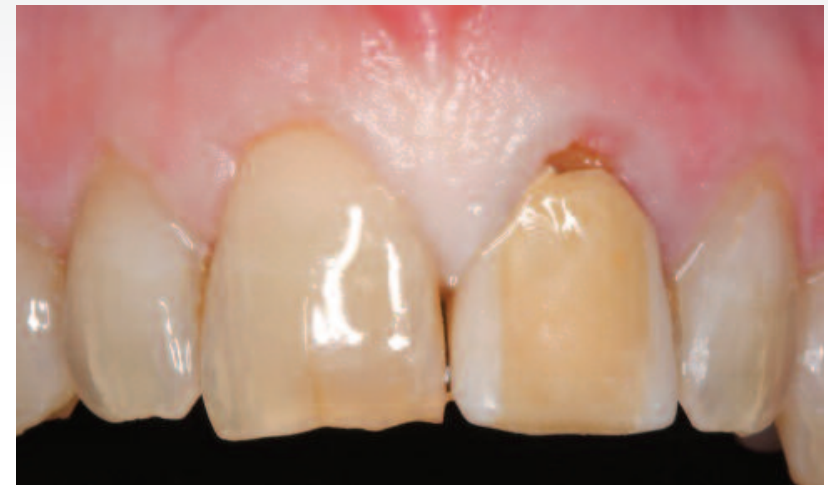

Figure 1: The preoperative view with an interim restoration at 21.

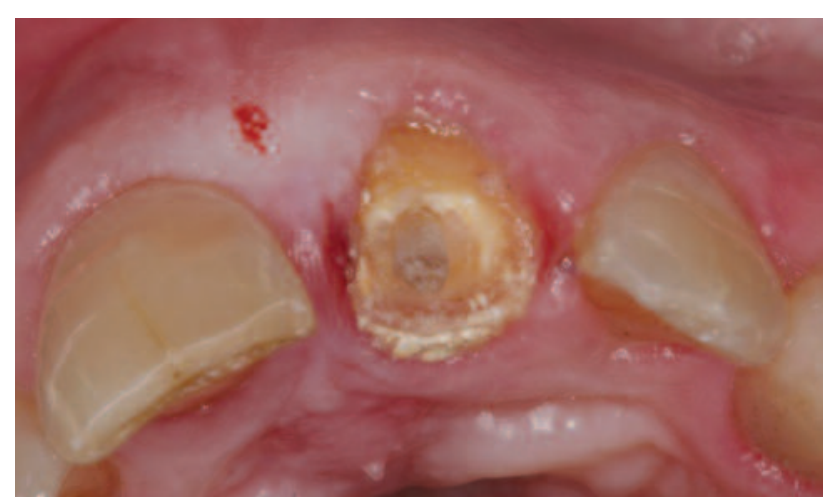

Figure 3: The lack of ferrule and coronal dentine was evident.

\section{Case report}

A 43 year old male patient presented for definitive treatment of a heavily restored left maxillary central incisor. The patient was a non-smoker with a non-contributory medical history. The tooth had been root treated and after several years required frequent recementation of a post-core crown restoration. The patient had high functional demands and moderate aesthetic expectation. At the first visit the patient presented with an interim restoration fixed to the remaining tooth root (Figure 1). Treatment options included A) root submergence of tooth 21 with a fixed partial denture (FPD) or removable prosthesis, B) crown lengthening of tooth 21 with lengthening also of 11 for symmetry, followed by reconstruction of the post-core and crown, C) orthodontic extrusion of tooth 21 and reconstruction of the restoration, D) implant therapy with a crown restoration. In consultation with the patient considering costs, duration of treatment and prognoses, implant therapy was opted for. To offset the expected post-extraction ridge

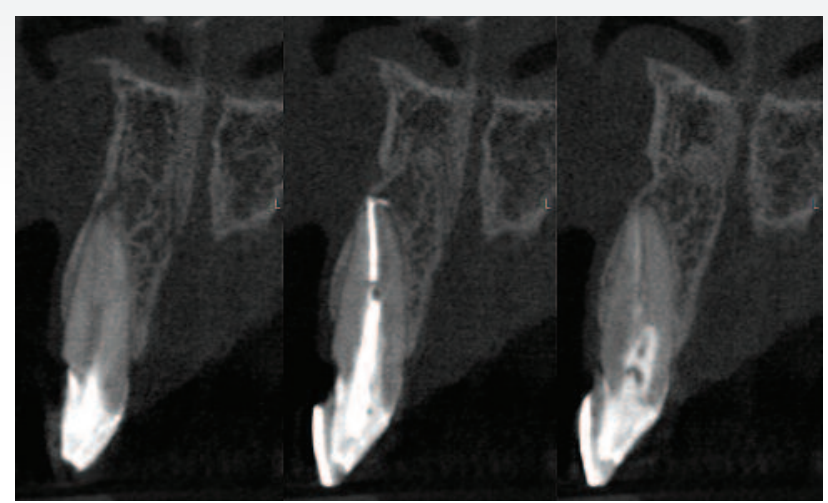

Figure 2: Preoperative CBCT scans of tooth 21.

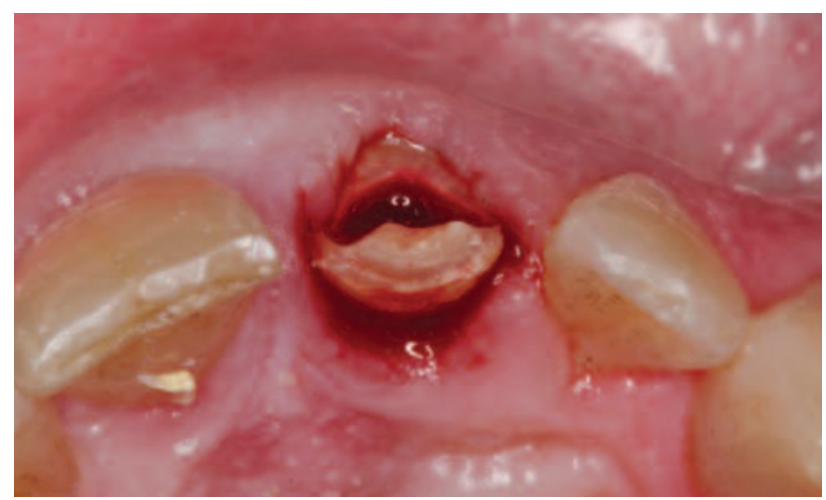

Figure 4: The tooth root sectioned mesiodistally.

resorption the SS technique was planned for simultaneous to immediate placement and provisionalization. Preoperative cone beam computed tomography (CBCT) indicated sufficient width palatal to the planned facial root section to accommodate a $4 \times 13 \mathrm{~mm}$ implant with the option for screw-retention (Figure 2).

Following local anaesthesia of the treatment site the crown restoration of tooth 21 was removed and the lack of ferrule and supporting coronal tooth tissue could be appreciated (Figure 3). The root was then sectioned in a mesiodistal direction along its long axis as far apical as was possible using a long shank root resection bur (Komet Dental, Germanyl coupled to a hydrated high-speed handpiece. Sectioning divided the tooth root into facial and palatal halves with the intention of preserving the facial root section unmanipulated and attached to the tooth socket (Figure 4). Periotomes were then inserted between the palatal root section and the alveolar socket wall to sever the PDL and 
this section of root was then carefully delivered with so as not to disturb the facial root section. The remaining root section was then reduced coronally to $1 \mathrm{~mm}$ above the alveolar crest, and thinned slightly to a concave contour by careful application in an apico-coronal and mesiodistal direction with a long shanked round diamond bur (Komet Dental, Germany). The tooth socket's palatal wall and apex were then curetted to remove any tissue or infective remnants and the root section was checked for immobility with a sharp probe. With the preparation steps complete, the tooth root hereafter was known as the socket-shield (SS) (Figure 5). An osteotomy was then sequentially prepared and a $4 \times 13 \mathrm{~mm}$ internal conical connection implant (AnyRidge, MegaGen) was inserted palatal to the SS via a prosthodontically planned surgical guide with the implant table $2 \mathrm{~mm}$ below the facial crest. The jump gap was grafted with a xenogeneic bone particulate (Osteobiol, Tecnoss) (Figure 6). The implant gained primary stability from bone apical and palatal sufficient to immediately restore with a provisional restoration, and confirmed by implant stability quotient (ISQ) readings in the 70s. A provisional crown was then constructed chairside with an emergence profile to support the coronal tissues whilst ensuring adequate space between the SS and the provisional, thus creating an "S-shaped" emergence (Figure 7). This is essential to allow the soft tissue to grow between the provisional and the SS. Failure to do this would lead to a SS that is not covered with soft tissue.

Healing was uneventful with no signs of infection or other complication at the 1 week and 1 month follow up visits (Figures 8, 9). After 3 months of healing the patient returned for confirmation of osseointegration and to continue with the restorative phase of the treatment (Figures 10, 11). ISQ readings were $73 \mathrm{M}, 73 \mathrm{D}$ and objectively demonstrated successful osseointegration. The implant was then restored by a screw-retained metal-porcelain crown restoration (Figure 12). The patient was satisfied with the aesthetic and functional outcomes achieved. At the 1 year follow up visit

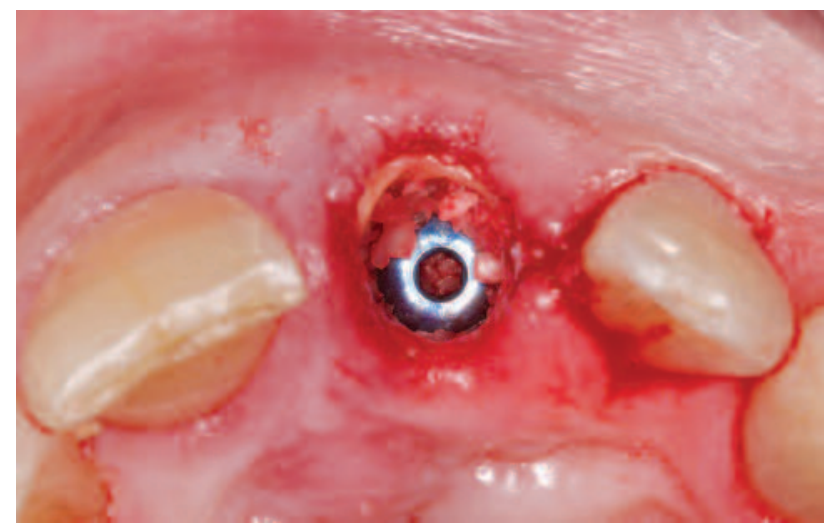

Figure 6: The jump gap between socket-shield \& implant grafted.
Figure 5: The prepared socket-shield.
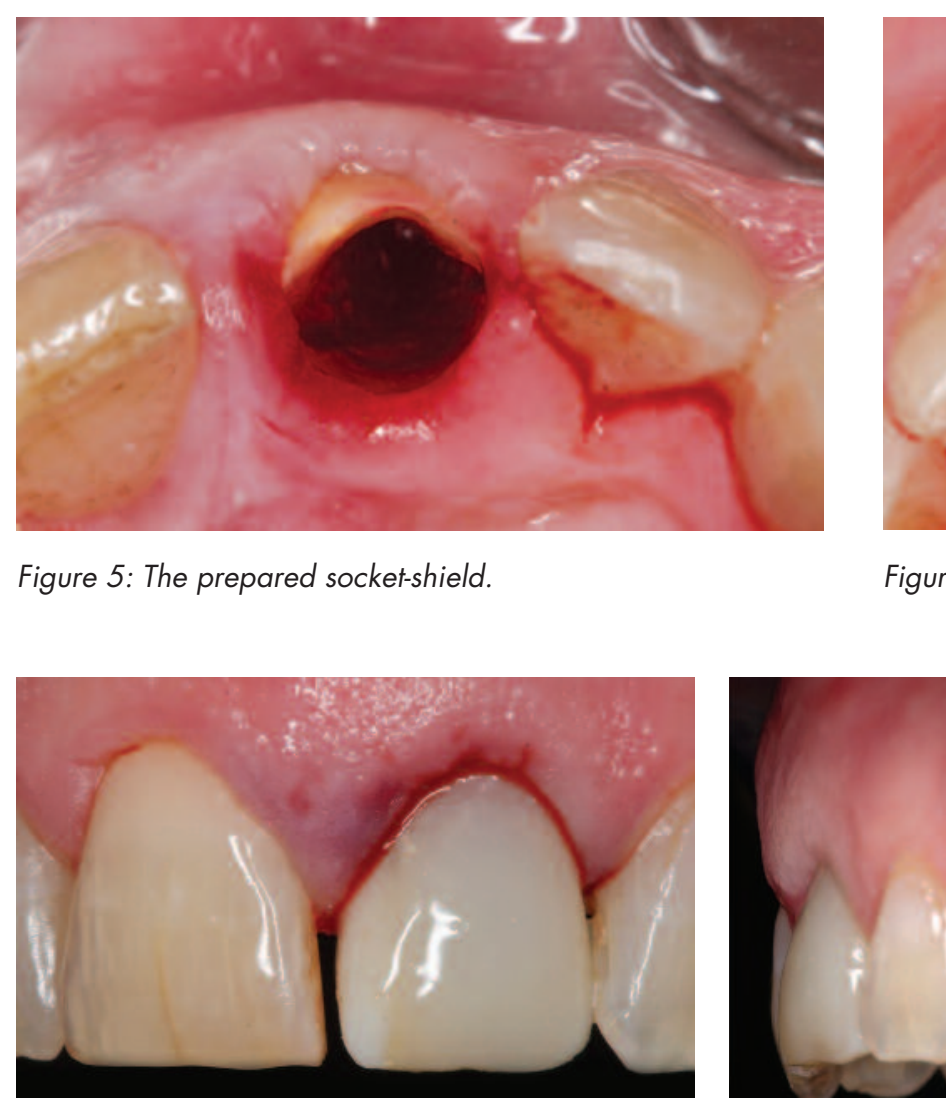

Figure 7: The provisional being tried in.
Figure 8: The 1 week follow up.

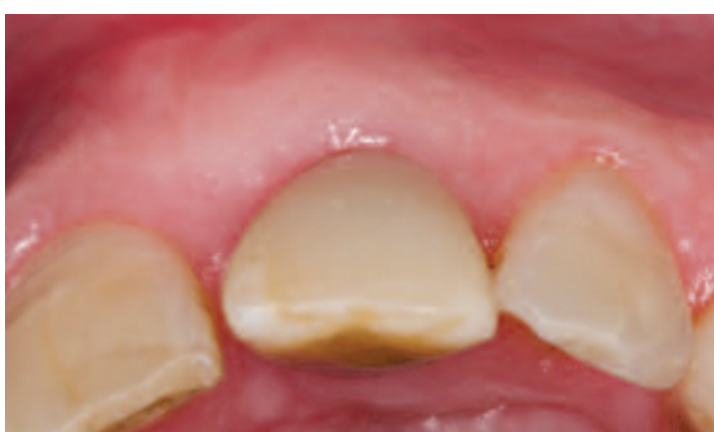

Figure 9: The 1 month follow up visit, occlusal view. 


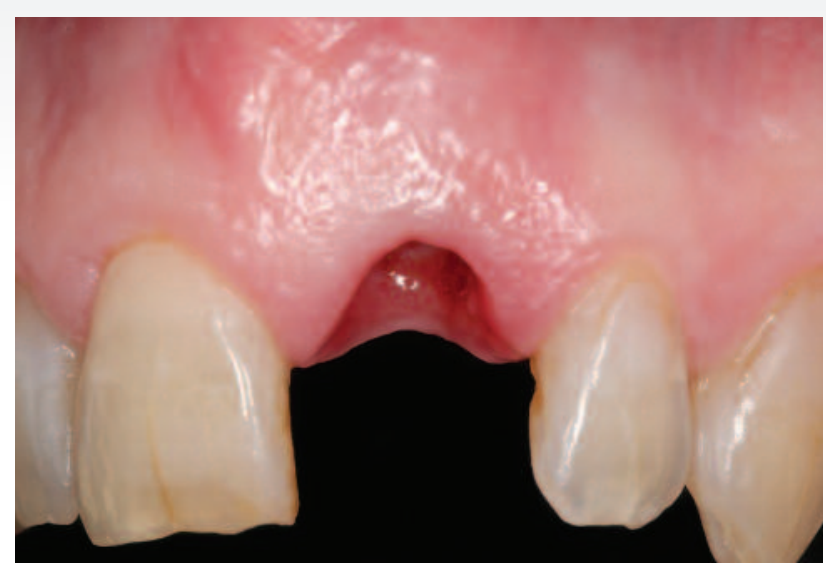

Figure 10: 3 Months postop at the start of restorative treatment.

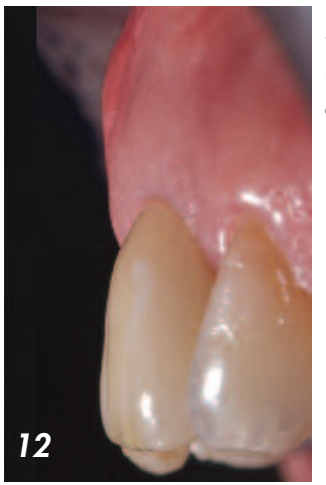

Figure 12: Maintenance of the facial tissues with the final crown in place.

Figure 13: Soft tissue contours comparable to tooth 11 .

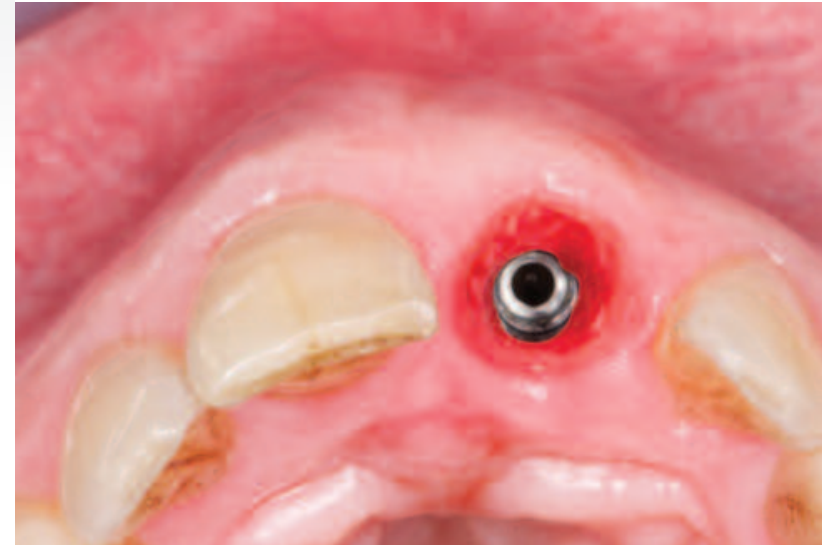

Figure 11: 3 Months postop with the facial ridge very well maintained.

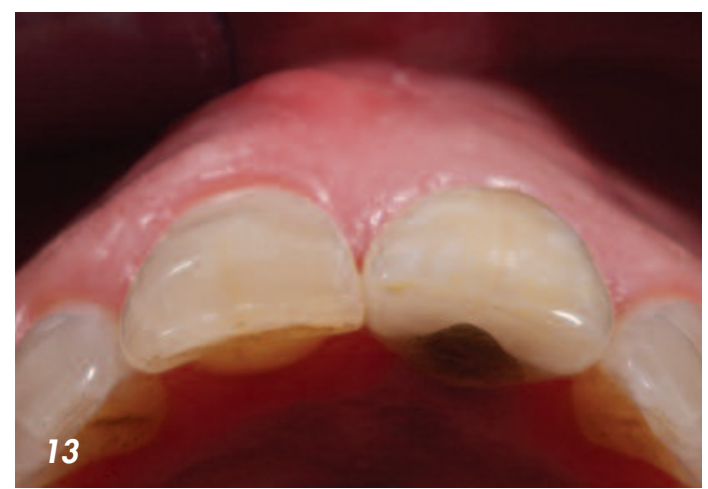

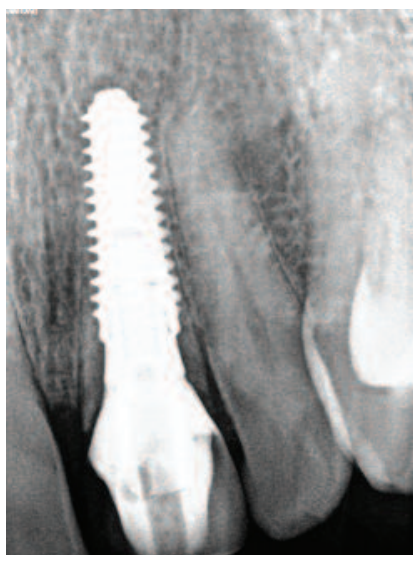

Figure 14: Periapical view of the implant \& crown 21

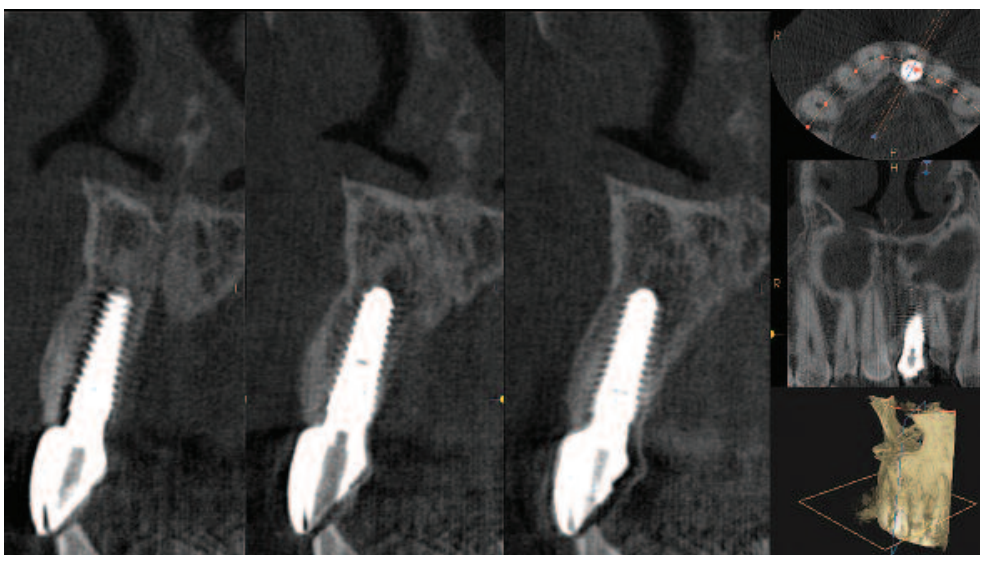

Figure 15: CBCT at the 1 year follow up. Note the bulk of tissue facial to the implant. the soft tissue contours at the implant restoration remained comparable to the neighbouring central incisor and no noticeable tissue recession nor other complication could be observed (Figure 13). The periapical radiograph illustrated the bone height interproximal to the implant and tooth 11 , and the relationship between the SS and the implant (Figure 14). The postoperative CBCT scan illustrated clearly the bulk of tissues facial to the implant (Figure 15). 
Table 1: Comparative tabulation of procedures to manage the effects of post-extraction resorption adjunct to implant therapy

\begin{tabular}{|c|c|}
\hline Advantages & Disadvantages \\
\hline \multicolumn{2}{|c|}{ GBR } \\
\hline Tissues gains & Surgically invasive (autogenous) \\
\hline \multirow[t]{6}{*}{ Well supported in the literature } & Technique sensitive \\
\hline & Additional healing time \\
\hline & Additional co-morbidity \\
\hline & Additional expense (xeno / allograft) \\
\hline & Additional risk of infection / complication \\
\hline & Vertical gains are challenging \\
\hline \multicolumn{2}{|c|}{ Sub-epithelial connective tissue graft } \\
\hline Reliable, predictable & Surgically invasive (autogenous) \\
\hline Well supported in the literature & Technique sensitive \\
\hline \multirow[t]{2}{*}{ No additional material cost } & Additional healing time \\
\hline & Additional co-morbidity \\
\hline \multicolumn{2}{|c|}{ Socket-shield technique } \\
\hline No additional material cost & Not yet reliable or predictable \\
\hline No co-morbidity & No long-term data yet \\
\hline Single surgery & Technique sensitive \\
\hline $\begin{array}{l}\text { Applicable in sites with endodontic apical } \\
\text { pathology }\end{array}$ & \\
\hline
\end{tabular}

\section{Discussion}

The results from the case reported here are consistent with the original report by Hürzeler and coworkers, that retention of the buccofacial root section at immediate implant placement achieved osseointegration without resorptive response of the ridge buccofacial to the implant. ${ }^{4}$ The technique offers a viable solution when managing the postextraction ridge and its complications associated with immediately placed implants. Prior to the SS technique, the implant surgeon conventionally was to select between an immediate placement protocol with an augmentation of the jump gap, with or without bulking of the buccofacial soft tissues, or a delayed approach with additional surgical intervention to correct an existing ridge defect. ${ }^{5}$ Overbuilding the ridge buccal / facial to the implant by guided bone regeneration and soft tissue augmentation can only partly compensate. A wealth of literature supports these ridge management techniques but an amount of shrinkage with healing is to be expected. Moreover, healing is not without complication by infection and complete failure with a worse outcome is possible. Alternatives are thus desired and the benefits of the SS technique can be appreciated (Table 1).

First reported in 2010 the SS technique had progressed from concepts introduced in the 1950s that the retention of a tooth limits tissue alterations following extraction. The submergence of tooth roots was introduced originally to preserve alveolar ridge volume beneath removable full prostheses.6,7 Malmgren and coworkers had also more than 3 decades ago reported successful tissue regeneration around submerged tooth roots. ${ }^{8}$ Thereafter, submerging a tooth root for pontic site development has become a welldocumented treatment. Salama and coworkers reported on preserving the entirety of the attachment apparatus as well as complete preservation of the alveolar ridge when developing pontic sites beneath FPD. ${ }^{9}$ This technique typically decoronates the tooth at the bone crest or preferably 


\section{Table 2: Review of the available literature on the socket-shield technique}

\begin{tabular}{|c|c|c|}
\hline Year & Author(s) & Study \\
\hline $2015^{*}$ & Bäumer et al. ${ }^{5}$ & Animal histology of 3 cases of socket-shield with vertical fractures \\
\hline $2014^{*}$ & Siormpas et al. ${ }^{13}$ & 46 Case series of the "root-membrane technique" with follow up varying 2-5 years \\
\hline 2014 & Holbrook $^{29}$ & Case report: Guided implant placement with socket-shield \\
\hline $2014^{*}$ & Cherel \& Etienne ${ }^{15}$ & Case report: Modified socket-shield for papillae preservation \\
\hline $2014^{*}$ & Glocker et al. ${ }^{16}$ & Case series: Modified socket-shield for ridge preservation, delayed placement \\
\hline $2013^{*}$ & Kan \& Rungcharassaeng ${ }^{14}$ & Case report: Proximal socket shield for papillae preservation \\
\hline 2013 & Chen \& $\operatorname{Pan}^{12}$ & Case report: Socket-shield with immediate implant placement \\
\hline 2010 & Hürzeler et al. ${ }^{4}$ & $\begin{array}{l}\text { Animal histology of } 1 \text { case of socket-shield technique, \& } 1 \text { human clinical case of implant } \\
\text { restoration with socket-shield }\end{array}$ \\
\hline
\end{tabular}

* Not the actual socket-shield technique, but a version thereof

$1 \mathrm{~mm}$ above it so as to preserve the supracrestal fibers with epithelial and connective tissue attachment. By comparison, ridge preservation techniques may reduce the amount of ridge resorption but cannot prevent the loss of interdental bone and papillae. Preservation of supracrestal fibers however can better develop pontic sites by in turn preserving the papillae. And thus it has been shown that the retention of part of the tooth contiguous with the PDL, its fibers and reticulate vascularity interconnected with bundle bone, eludes the physiological remodeling of an extraction socket and the alveolar crest. These delicate tissues can be preserved - PDL, bundle bone, buccofacial plate, and overlying keratinized mucosa. ${ }^{10}$ It can be postulated that retention of part of the tooth as a SS eludes the body from realizing the tooth has been extracted and circumvents the normal events of physiological healing that would resorb the alveolar socket.

The resorption of a post-extraction socket is the direct result of trauma to the bone-PDL-tooth complex. Bundle bone born from a functionally loaded PDL is lost following extraction and sees an almost certain recession of residual buccofacial tissues. ${ }^{11}$ Complete maintenance of ridge volume after tooth extraction with preservation techniques utilizing currently available materials as a primary prevention is not yet possible. ${ }^{5}$ However, as stated before, the retention of tooth roots in the alveolar process can preserve the ridge tissues. Histologically this was demonstrated by Hürzeler and coworkers. ${ }^{4}$ Their report confirmed the retained attachment of the SS to the buccal plate via a physiologic PDL free of any inflammatory response. The buccal plate crest showed an absence of osteoclastic activity - an absence of active remodeling. The coronal soft tissue demonstrated a physiologic junctional epithelium also free of any inflammatory response. The clinical outcome of Hürzeler and coworkers' report presented the successful osseointegration of an implant placed simultaneous to the SS technique and a restoration with aesthetics indistinguishable from the adjacent maxillary central incisor. Whilst the authors reported preservation of the buccofacial tissues, it should be noted that absolute preservation has not yet been shown. The authors later reported a mean of $1 \mathrm{~mm}$ horizontal loss after final restoration, Chen and coworkers reported $0.72 \mathrm{~mm}$ of buccal resorption. 5,12

In spite of the histological and clinical findings to date and the prospects of the SS technique, to safely apply a newly introduced treatment in everyday practice data from longterm clinical studies are required and at present this data is not yet available. Only one case series with a 2 year or more follow up of a significant number cases exists in the literature. ${ }^{13}$ However, that technique differed significantly. The authors had prepared the implant osteotomy directly through the intact tooth root and thereafter prepared what they termed the "root-membrane". That said, the study is a significant contribution to literature on these techniques. Very few case reports currently exist and this case reported here to the authors' knowledge is the ninth (Table 2). Of the reports currently available most have also deviated from the original protocol. The modified / proximal socket shield reported by Kan \& Rungcharassaeng had the jump gap grafted with a xenograft material, the facial soft tissues augmented. ${ }^{14}$ In their report the methodology further differs by sectioning the 
SS into mesial and distal sections for the purpose of papillae preservation. Cherel \& Etienne also reported papillae preservation by a modified SS sectioned in a similar manner..$^{15}$ The methodology of this case report replicated the orginal technique's working groups' revision to graft the jump gap, whilst omitting the application of an enamel matrix protein derivative.

\section{Concluding remarks}

The SS technique offers a promising solution to the difficulties encountered when managing the postextraction tissues. This case report of immediate placement simultaneous to the SS technique is among the first to demonstrate with a 1 year follow up successful preservation of post-extraction tissues coinciding with successful restorative implant treatment. The void in the literature reporting on the technique's long-term success requires prudent participation of clinicians to contribute to the knowledge base before the procedure can be routinely prescribed for ridge preservation simultaneous to immediate implant placement. At present the technique is highly promising and holds significant potential for the field of aesthetic and restorative implant dentistry.

\section{Declaration}

The authors declare no conflict of interest.

\section{References}

1. Lang NP, Pun L, Lau KY, Li KY, Wong MC. A systematic review on survival and success rates of implants placed immediately into fresh extraction sockets after at least 1 year. Clin Oral Implants Res. 2012;23 Suppl 5:39-66.

2. Chen ST, Buser D. Esthetic outcomes following immediate and early implant placement in the anterior maxilla-a systematic review. Int J Oral Maxillofac Implants. 2014;29 Suppl: 186-215.

3. Schropp L, Wenzel A, Kostopoulos L, Karring T. Bone healing and soft tissue contour changes following singletooth extraction: a clinical and radiographic 12-month prospective study. Int J Periodontics Restorative Dent. 2003;23(4):313-23.

4. Hürzeler MB, Zuhr O, Schupbach P, Rebele SF, Emmanouilidis $N$, Fickl $S$. The socket-shield technique: a proof-of-principle report. J Clin Periodontol.
2010;37(9):855-62.

5. Bäumer D, Zuhr O, Rebele S, Schneider D, Schupbach P, Hürzeler M. The socket-shield technique: first histological, clinical, and volumetrical observations after separation of the buccal tooth segment - a pilot study. Clin Implant Dent Relat Res. 2015;17(1):71-82.

6. Miller PA. Complete dentures supported by natural teeth. J Prosthet Dent. 1958;8:924-8.

7. Morrow RM, Feldman EE, Rudd KD, Trovillion HM. Tooth-supported complete dentures: an approach to preventive prosthodontics. I Prosthet Dent. 1969;21:513-22

8. Malmgren B, Crek M, Lundberg M, Frykholm A. Surgical treatment of ankylosed and infrapositioned reimplanted incisors in adolescents. Scand J Dent Res. 1984;92(5):391-9.

9. Salama M, Ishikawa T, Salama H, Funato A, Garber D. Advantages of the root submergence technique for pontic site development in esthetic implant therapy. Int J Periodontics Restorative Dent. 2007;27(6):521-7.

10. Filippi A, Pohl Y, von Arx T. Decoronation of an ankylosed tooth for preservation of alveolar bone prior to implant placement. Dent Traumatol. 200 1;17(2):93-5.

1 1. Gluckman H, Du Toit J. The management of recession midfacial to immediately placed implants in the aesthetic zone. Int Dent Africa Ed. 2015; 10 (1):6-9.

12. Chen CL, Pan YH. Socket Shield Technique for Ridge Preservation: A Case Report. J Prosthondontics Implantology. 2013;2(2): 16-21.

13. Siormpas KD, Mitsias ME, Kontsiotou-Siormpa $E$, Garber D, Kotsakis GA, Immediate Implant Placement in the Esthetic Zone Utilizing the "Root-Membrane" Technique: Clinical Results up to 5 Years Postloading.

14. Kan JY, Rungcharassaeng K. Proximal socket shield for interimplant papilla preservation in the esthetic zone. Int J Periodontics Restorative Dent. 2013;33(1):e24-31.

15. Cherel F, Etienne D. Papilla preservation between two implants: a modified socket-shield technique to maintain the scalloped anatomy? A case report. Quintessence Int. 2014;45(1):23.

16. Glocker M, Attin T, Schmidlin P. Ridge Preservation with Modified "Socket-Shield" Technique: A Methodological Case Series. Dent. J. 2014, 2, 11-21. 


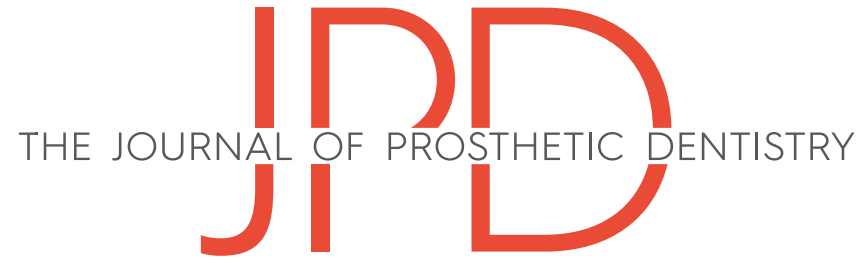

DENTAL TECHNIQUE

\section{Prosthetic management of implants placed with the socket-shield technique}

\author{
Howard Gluckman, BDS, MChD (OMP), ${ }^{a}$ Katalin Nagy, DDS, PhD, ${ }^{\mathrm{b}}$ and \\ Jonathan Du Toit, BChD, Dip Oral Surg, Dipl Implantol, MSc (Dent) ${ }^{c}$
}

Root submergence to preserve the alveolar ridge was first reported about 50 years ago. ${ }^{1}$ In 2010, Hurzeler et $\mathrm{al}^{2}$ published a method of preserving the facial ridge at immediate implant placement with part of a submerged root. These authors sectioned the submerged tooth root such that its facial root portion remained attached to a healthy and intact periodontium adjacent to an immediate implant. This technique has been described in several reports ${ }^{3-10}$ and has been somewhat modified by Gluckman et al. ${ }^{11-15}$ The original technique proposed applying enamel matrix derivative to the inner dentin surface of the socket-shield to promote cementum formation. ${ }^{2}$ However, the technique may not require this step. Not only are these materials exceedingly costly but also human histology has demonstrated that bone can grow between root dentin adjacent to an implant surface without enamel matrix derivative. ${ }^{16}$ Baumer et $\mathrm{al}^{15}$ also omitted this step in their follow-up study. The original technique by Hurzeler et $\mathrm{al}^{2}$ also advocated drilling through the root with the implant drills and preparing the initial osteotomy somewhat inside the tooth root, with the socket-shield 1-mm coronal to the facial bone crest. A similar treatment, the root membrane technique, also advocated these steps ${ }^{17}$ although the modified technique reported by Gluckman et $\mathrm{al}^{18}$ did not. In the largest cohort reported to date of 128 socket-shields followed up to 4 years, the authors reported the most common complication encountered to be internal exposure. This means that the coronal portion of the socket-shield facing the implant crown and abutment penetrated the soft tissue (in $9.4 \%$ of the treatments), and in some instances, inflammation was noted. Regardless, the authors stated this as a complication requiring management. The peri-implant mucosa should be healthy and not ulcerated. This technique report will provide step-by-step management of the coronal socketshield and prosthetics in an effort to limit this complication.

\section{TECHNIQUE}

The clinician providing immediate implant treatment and the socket-shield technique should be experienced with advanced training. For all treatments, comprehensive planning must be carried out, including planning the prosthetic outcomes with digital smile design and/or with trial restorations. Data are typically obtained with 3dimensional cone-beam computed tomography scan of

Funding: This research did not receive any specific grant from funding agencies in the public, commercial, or not-for-profit sectors.

aSpecialist in Periodontics, Implantology and Oral medicine, Private practice, Cape Town, South Africa; and Director, The Implant Clinic, The Implant \& Aesthetics Academy, Cape Town, South Africa.

bProfessor and Head of Oral Surgery, Faculty of Dentistry, University of Szeged, Szeged, Hungary.

${ }^{\mathrm{c}}$ Resident, Department of Periodontics and Oral Medicine, School of Dentistry, Faculty of Health Sciences, University of Pretoria, Pretoria, South Africa. 


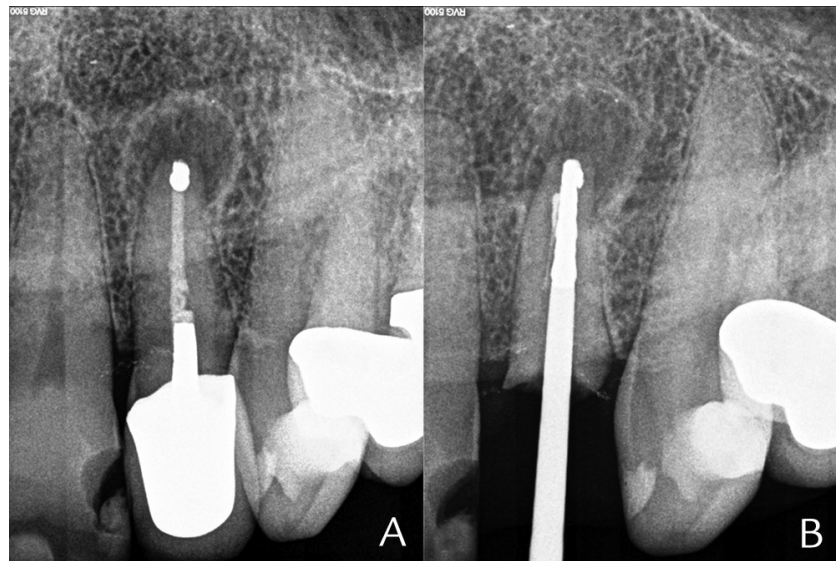

Figure 1. A, Preoperative periapical radiograph of maxillary left lateral incisor. B, Decoronated tooth with long-shank rotary instrument inserted to root length.

the treatment site. The following steps outline the clinical procedures once the treatment has been thoroughly planned and indications for the socket-shield met. ${ }^{13}$

As described previously, ${ }^{18}$ the socket-shield for single-rooted teeth is prepared as follows:

1. Achieve adequate local anesthesia of the working site and decoronate the tooth planned for partial extraction. At all times, take care not to cut or damage the adjacent structures (gingiva, adjacent teeth, or restorations). Cut the crown with a conventionally irrigated high-speed handpiece coupled to a straight diamond rotary instrument (Bur H254LE; Komet Dental) to approximately the level of the gingiva (Figs. 1, 2). Complete the preparation of the socket-shield with the same handpiece with sequential rotary instruments under copious irrigation.

2. Once decoronated, section the tooth root vertically in a mesiodistal direction, creating a facial and a palatal root portion. Aid sectioning of the root by making sequential periapical radiographs (Fig. 1). Use an endodontic file or a Gates-Glidden rotary instrument inserted to the apex to orient and measure on the radiographs. If previously endodontically treated, these may aid in removing the root canal obturation materials (Figs. 1-3).

3. Use periotomes and microelevators to carefully dislodge the palatal root portion into the buccal space created when sectioning the root. Be sure to handle the tissues with care at all times. Do not ever lever against the facial root portion but instead apply finger pressure to support and sense movement. Once loose, remove the palatal root portion with microforceps (Fig. 3).

4. Refine the facial root portion with a long-shank diamond rotary instrument (Bur 801; Komet

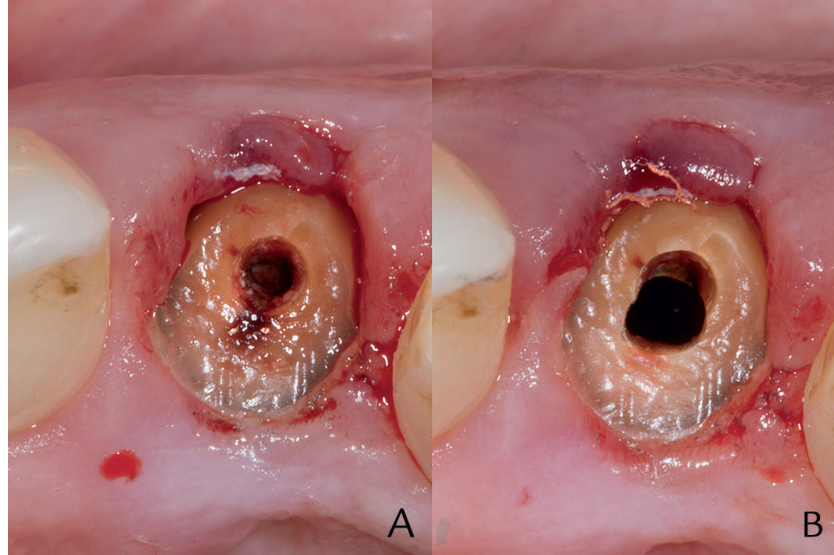

Figure 2. A, Occlusal view after decoronation. B, Root canal widened to apex with long-shank root resection rotary instrument.

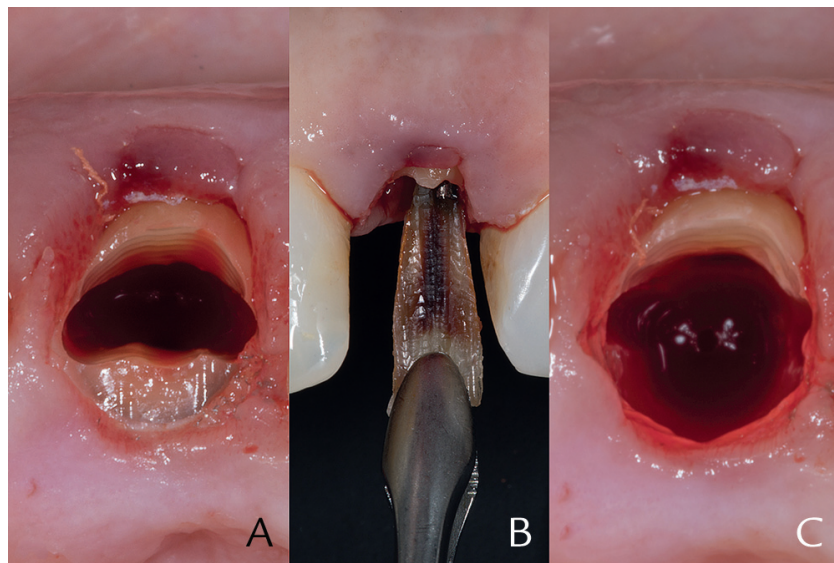

Figure 3. A, Root sectioned vertically and cut mesiodistally into facial and palatal portions. B, C, Palatal root portion removed.

Dental) and gingival protector (Wound Retractor 24158-00; Ustomed), orienting the rotary instrument toward the tooth apex in a triangular movement. As much as possible, avoid cutting excessively into adjacent alveolar bone. Reduce the socket-shield to approximately half the thickness from the canal to the root's facial limit, creating a concave structure extending from the mesial to the distal of the socket.

5. Curette the apex and rinse repeatedly. Make sequential periapical radiographs to ensure all root canal obturation materials are fully removed and that the root apex with all its contents and any pathologic tissues are removed. If an apical periodontal ligament space can be seen on the radiograph, or any other radiopaque dental materials, then repeat this step carefully until all are removed. Do not proceed without ensuring complete removal of pathologic tissues.

6. Reflect and protect the gingiva and complete the definitive coronal reduction with a large round diamond rotary instrument (Bur 801; Komet 


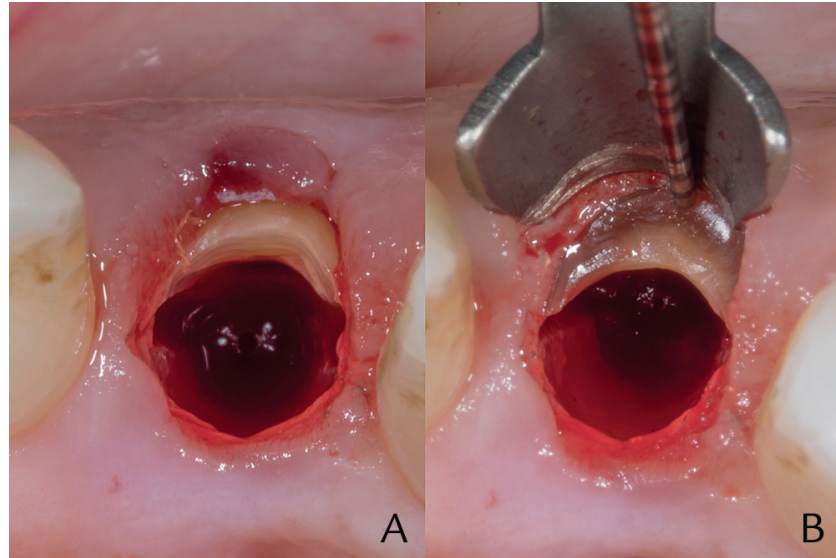

Figure 4. A, Apical and root canal contents removed, socket rinsed. $B$, Under magnification, gingiva protected, socket-shield reduced to crestal bone.

Dental) (Fig. 4). Cut the coronal socket-shield to the alveolar crest but do not leave a 1 - to $2-\mathrm{mm}$ coronal portion as previously described. Then, cut an internal beveled chamfer in the socket-shield to create the required prosthetic space to accommodate an S-shaped prosthesis emergence profile (Figs. 4B, 5A).

7. Prepare the implant osteotomy apical/palatal to the fully prepared socket-shield. Follow conventional immediate implant placement protocol and insert the implant (Fig. 5). Seal the implant with its cover screw and graft the facial gap if accessible with a bone material (NovaBone Putty; NovaBone) (Fig. 6A). Omit this step if the space between the implant and socket-shield is small.

8. Verify the implant's primary stability. If adequate implant stability quotient (ISQ; >70), attach an interim crown immediately. If less than adequate $(<60$ ISQ), attach a custom transgingival abutment to the implant that mimics the intended emergence profile (Fig. 6B, C). Ensure ample space for soft tissue by designing a narrow but expanding $\mathrm{S}$-shape curve in the transgingival, prosthetic component. Observe the facial gingiva and ensure that minimal to no blanching of the tissue occurs. Reduce the prosthetic component if needed while maintaining an emergence that seals the socket entrance.

9. Ensure the interim crown has no contact in maximum intercuspation or excursive moments, or if a custom abutment is used, ensure no contact with the subsequent interim prosthesis.

10. Make a postoperative radiograph.

\section{DISCUSSION}

The socket-shield technique is potentially one of the most significant contributions to implant and restorative

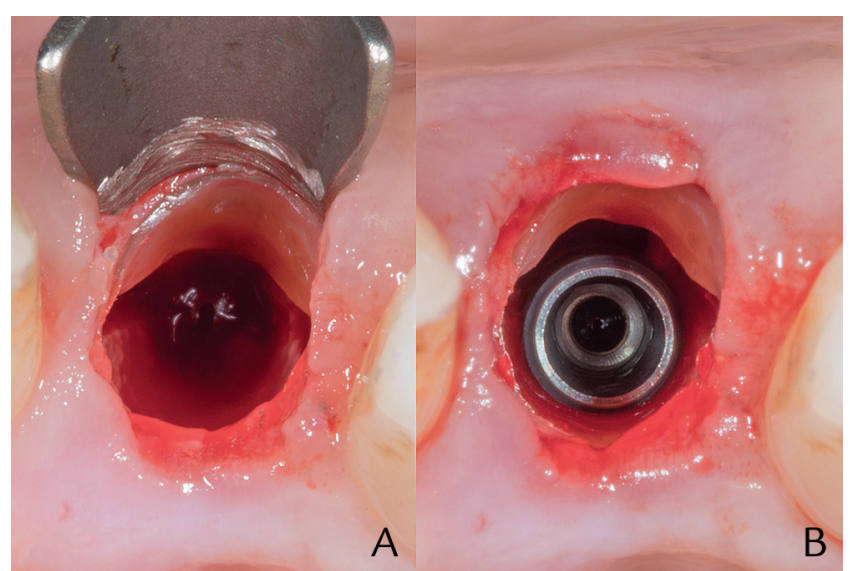

Figure 5. A, Internal, coronal portion reduced, creating beveled chamfer. B, Immediate implant placement, palatal to socket-shield.

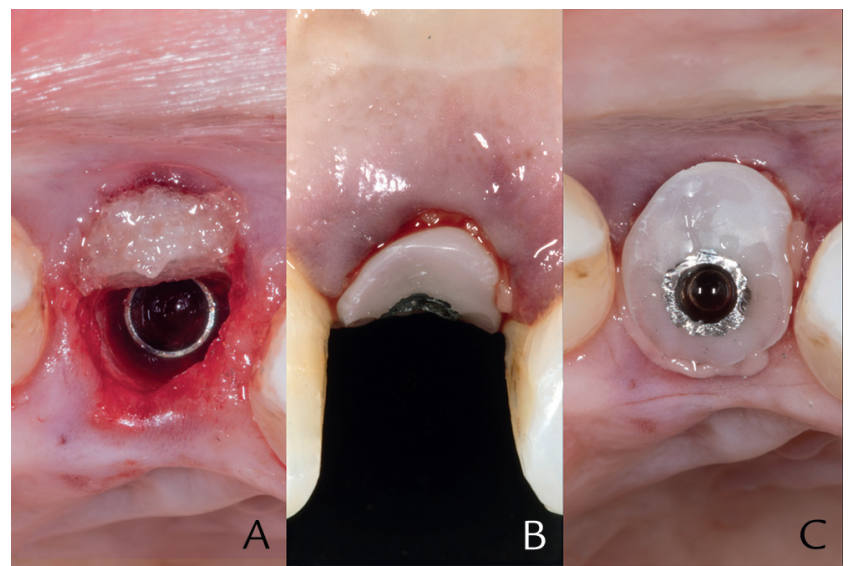

Figure 6. A, Facial gap grafted with bone particulate. B, C, Custom healing abutment attached to implant, with platelet-rich fibrin membranes beneath.

dentistry, managing the resorptive sequalae of tooth extraction. The technique, part of a collective concept known as partial extraction therapies, challenges the extract-and-augment mindset. ${ }^{12}$ Although clinical reports, case series, and trial studies have been published, ${ }^{3-10,14,15}$ a consistent approach to the technique is essential.

The technique as it is known today requires preparation of the socket-shield to bone level as previously reported..$^{18}$ Many aspects of the socket-shield technique and other partial extraction therapies remain to be researched. These include factors such as vertical length of the socket-shield, its thickness, grafting the gap, materials and instrumentation, and their impact on overall treatment. However, what is known from the current literature is that the original socket-shield preparation as recommended by Hurzeler et $\mathrm{al}^{2}$ at $1 \mathrm{~mm}$ or more above the socket crest may result in perforation of the shield through the overlying healed/healing soft tissue, known as exposure. ${ }^{18}$ When this occurs facing the implant 


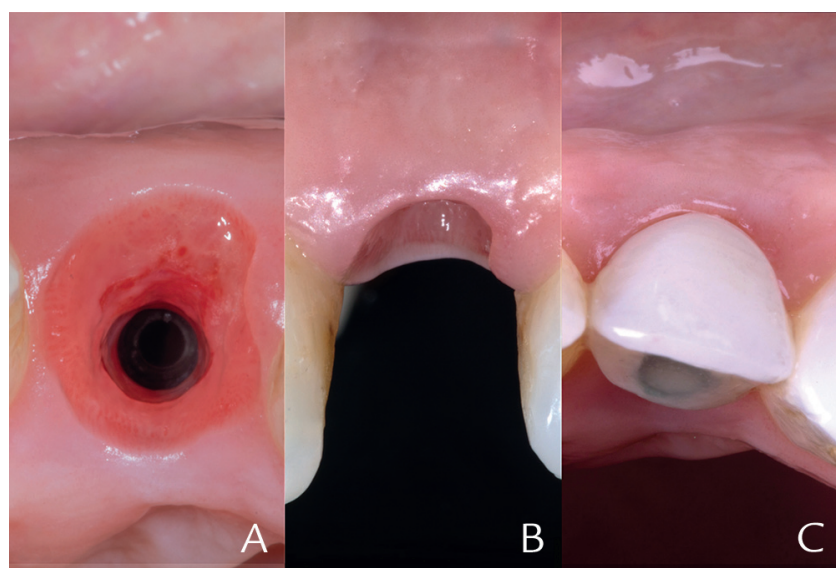

Figure 7. A, B, 3 months of healing. C, Definitive metal-ceramic, screw-retained crown.

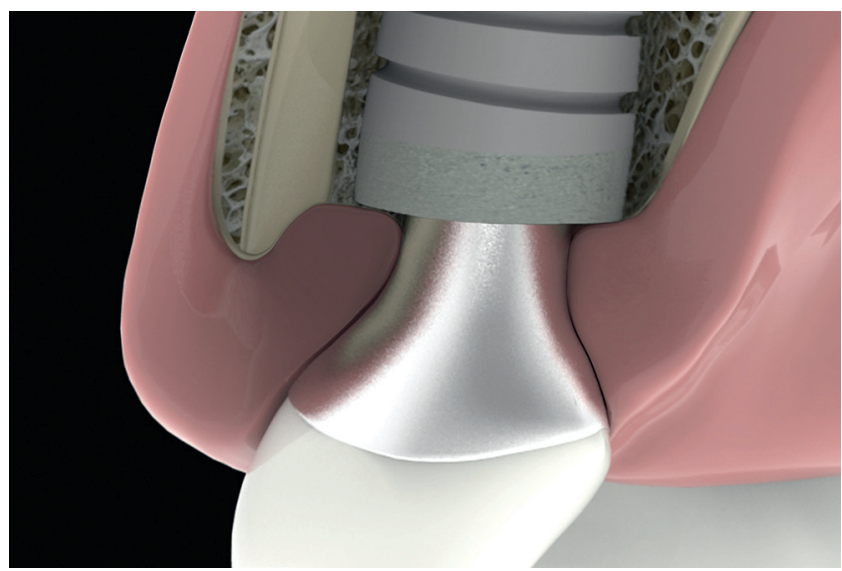

Figure 9. Diagram of socket-shield, reduced to crestal bone with internal beveled chamfer. Note S-shape contour of transgingival prosthetic portion.

prosthesis, it is termed an internal exposure, and this type has been reported to be the most common complication of the technique ( $9.4 \%$ of the treatments). ${ }^{18}$ This could also be expected of the root membrane technique of Siormpas et $\mathrm{al}_{1}{ }^{17}$ one that is similar to the original method by Hurzeler et al, that also proposes a 1-mm or more supracrestal preparation of the tooth root portion. For this reason, the current authors strongly recommend meticulous reduction of the socket-shield to the bone crest, achievable almost exclusively with reflection of the coronal gingiva under magnification.

Because of the risk of tissue loss, a full-thickness flap is not recommended in most patients, especially in single-tooth and esthetic zone sites. Instead, a gingival protector should reflect the soft tissue away during preparation of the coronal socket-shield (Fig. 4B). However, multiple partial extraction therapies, multiple submerged root sites, and socket-shields adjacent to each other may better be prepared by raising a flap.

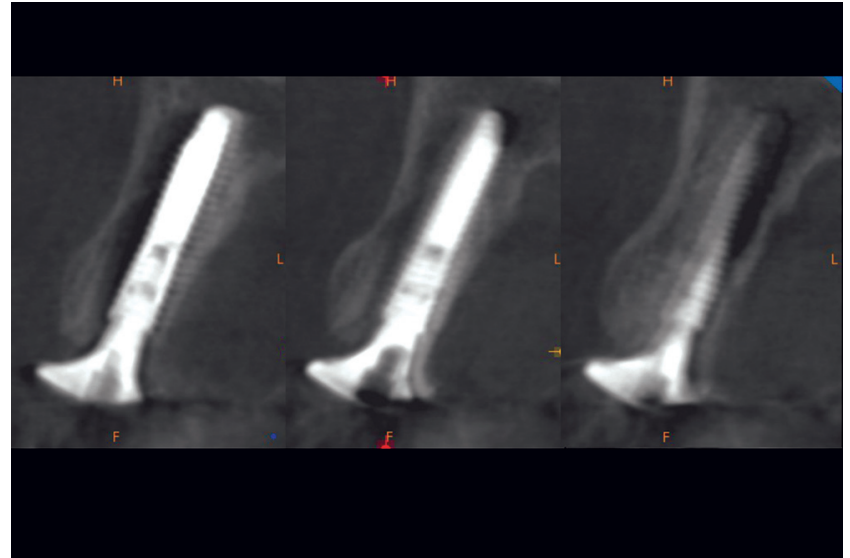

Figure 8. Postoperative cone beam computed tomography at integration check, before proceeding to definitive restoration.

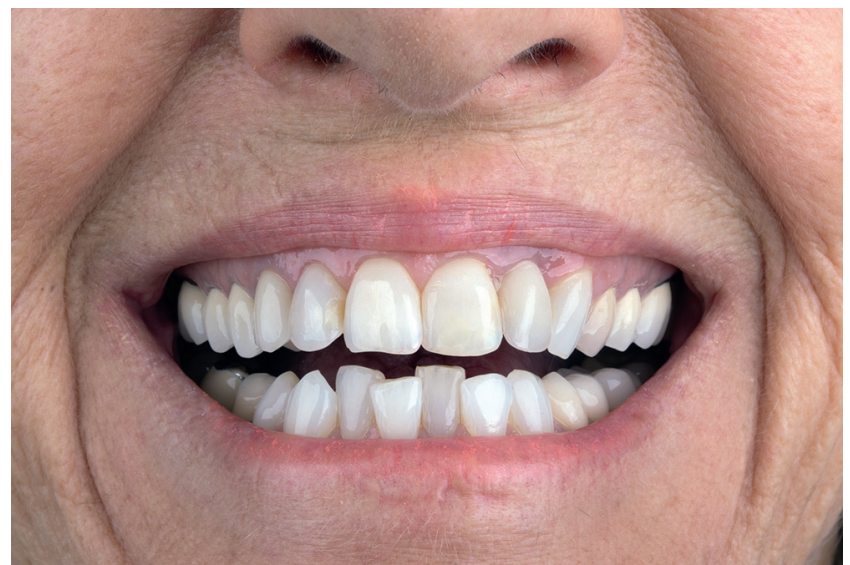

Figure 10. Definitive outcome.

The second important aspect of this technique report is the preparation of an internal beveled chamfer (Fig. 5A). After the socket-shield has been reduced to crestal bone, it needs to be cut in an oblique direction, reducing its most coronal and internal aspect facing the socket. A large round diamond rotary instrument coupled to a high-speed handpiece cuts away this area, providing more prosthetic space for soft tissue infill between the implant prosthesis' emerging transgingival portion (Fig. 7). The socket-shield in situ, healed and prepared as described, can be seen on the cone-beam computed tomography at an integration check before the definitive restoration (Fig. 8). The third important aspect of this technique is the preparation of the prosthetic emergence profile. This should reflect an S-shape (Fig. 9). The connecting abutment at the implant needs to emerge as narrow as possible, then curve wider, and then back toward the implant's long axis. This prosthetic design provides maximal soft tissue infill and avoids excessive pressure on the socket-shield's coronal portion that previously resulted in internal exposure. The intended esthetic outcomes (Fig. 10) with a bulk of tissue 
supported facial to the immediate implant was achieved for the patient described (Figs. 7, 8).

\section{SUMMARY}

With each addition of the socket-shield technique to the literature, more is learned about the treatment's potential and how to minimize its complications. Internal exposure of the socket-shield is a known complication and can be adequately managed by reducing the coronal portion. Conversely, this technique report emphasizes the prosthetic management of this area to prevent the complication. The restoration and/or interim restoration/ customized transgingival healing abutment must be prepared in an S-shape to allow for maximal infill of the coronal soft tissue.

\section{REFERENCES}

1. O'Neal RB, Gound T, Levin MP, del Rio CE. Submergence of roots for alveolar bone preservation. I. Endodontically treated roots. Oral Surg Oral Med Oral Pathol 1978;45:803-10.

2. Hurzeler MB, Zuhr O, Schupbach P, Rebele SF, Emmanouilidis N, Fickl S. The socket-shield technique: a proof-of-principle report. J Clin Periodonto 2010;37:855-62.

3. Chen C, Pan Y. Socket shield technique for ridge preservation: a case report J Prosthodontics Implantology 2013;2:16-21.

4. Cherel F, Etienne D. Papilla preservation between two implants: a modified socket-shield technique to maintain the scalloped anatomy? A case report. Quintessence Int 2014;45:23-30.

5. Glocker M, Attin T, Schmidlin PR. Ridge preservation with modified "socket-shield" technique: a methodological case series. Dent J 2014;2 $11-21$.

6. Kan JY, Rungcharassaeng K. Proximal socket shield for interimplant papilla preservation in the esthetic zone. Int J Periodontics Restorative Dent 2013;33: e24-31.

7. Saeidi Pour R, Zuhr O, Hurzeler M, Prandtner O, Rafael CF. Clinical benefits of the immediate implant socket-shield technique. J Esthet Restor Dent 2017:2:93-101.
8. Bramanti E, Norcia A, Cicciu M, Matacena G, Cervino G, Troiano G, et al. Postextraction dental implant in the aesthetic zone, socket shield technique versus conventional protocol. J Craniofac Surg 2018. [Ahead of print].

9. Tan Z, Kang J, Liu W, Wang H. The effect of the heights and thicknesses of the remaining root segments on buccal bone resorption in the socket-shield technique: an experimental study in dogs. Clin Implant Dent Relat Res 2018. [Ahead of print].

10. Roe P, Kan JYK, Rungcharassaeng K. Residual root preparation for socketshield procedures: a facial window approach. Int J Esthet Dent 2017;12:324-35.

11. Gluckman H, Du Toit J, Salama M. The pontic-shield: partial extraction therapy for ridge preservation and pontic site development. Int J Periodontics Restorative Dent 2016;36:417-23.

12. Gluckman H, Salama M, Du Toit J. Partial extraction therapies (PET) Part 1: maintaining alveolar ridge contour at pontic and immediate implant sites. Int J Periodontics Restorative Dent 2016;36:681-7.

13. Gluckman H, Salama M, Du Toit J. Partial extraction therapies (PET) Part 2: procedures and technical aspects. Int J Periodontics Restorative Dent 2017;37: 377-85.

14. Baumer D, Zuhr O, Rebele S, Hurzeler M. Socket-shield technique for immediate implant placement - clinical, radiographic and volumetric data after 5 years. Clin Oral Implants Res 2017;28:1450-8.

15. Baumer D, Zuhr O, Rebele S, Schneider D, Schupbach P, Hurzeler M. The socket-shield technique: first histological, clinical, and volumetrical observations after separation of the buccal tooth segment - a pilot study. J Esthet Restor Dent 2015:17:71-82.

16. Schwimer C, Pette GA, Gluckman H, Salama M, Du Toit J. Human histologic evidence of new bone formation and osseointegration between root dentin (unplanned socket-shield) and sental implant: case Report. Int J Oral Maxillofac Implants 2018:33:e19-23.

17. Siormpas KD, Mitsias ME, Kontsiotou-Siormpa E, Garber D, Kotsakis GA. Immediate implant placement in the esthetic zone utilizing the "rootmembrane" technique: clinical results up to 5 years postloading. Int J Oral Maxillofac Implants 2014;29:1397-405

18. Gluckman H, Salama M, Du Toit J. A retrospective evaluation of 128 socketshield cases in the esthetic zone and posterior sites: partial extraction therapy with up to 4 years follow-up. Clin Implant Dent Relat Res 2017;20:122-9.

\section{Corresponding author:}

Dr Howard Gluckman

The Implant Clinic

39 Kloof St, Gardens

8001 Cape Town

SOUTH AFRICA

Email: docg@mweb.co.za

Copyright () 2018 by the Editorial Council for The Journal of Prosthetic Dentistry. https://doi.org/10.1016/j.prosdent.2018.06.009 


\section{Partial Extraction Therapies (PET) Part 1: Maintaining Alveolar Ridge Contour at Pontic and Immediate Implant Sites}

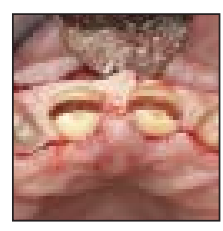

Howard Gluckman, BDS, MChD (OMP)

Maurice Salama, DDS²

Jonathan Du Toit, BChD, Dipl Implantol, Dip Oral Surg, MSc Dent ${ }^{3}$

Buccopalatal collapse of the postextraction ridge is a significant challenge in restorative and implant dentistry. A variety of ridge preservation techniques using tissue and augmentative materials have been proposed in the literature. A slightly different approach is to use the tooth itself. Root submergence has been reported in the literature for more than 4 decades, and it has been demonstrated that the submerged tooth root retains the periodontal tissues and preserves the bone in pontic sites or below dentures to retain the ridge. The socket-shield technique entails preparing a tooth root section simultaneous to immediate implant placement and has demonstrated histologic and clinical results that are highly promising to esthetic implant treatment. The pontic shield technique preserves the alveolar ridge at sites intended for pontic development where the root submergence technique is not possible. The aforementioned techniques collectively may be termed partial extraction therapies (PET), a term newly introduced into the literature and clinical environment. This article is a review of these ridge preservation therapies, providing a classification and a guide to their application. Int J Periodontics Restorative Dent 2016;36:681-687. doi: 10.11607/prd.2783

1Specialist in Periodontics and Oral Medicine, Director of the Implant and Aesthetic Academy, Cape Town, South Africa.

${ }^{2}$ Clinical Assistant Professor of Periodontics, University of Pennsylvania, Philadelphia, Pennsylvania, USA; Medical College of Georgia, Augusta, Georgia, USA; Private Practice, Atlanta, Georgia, USA.

3Postgraduate, Department of Periodontics and Oral Medicine, School of Dentistry, Faculty of Health Sciences, University of Pretoria, South Africa.

Correspondence to: Dr Howard Gluckman, The Implant and Aesthetics Academy, 39 Kloof Street, Cape Town, South Africa. Fax: +2721 4263053.

Email: docg@theimplantclinic.co.za

(C2016 by Quintessence Publishing Co Inc.
Ridge resorption as a result of tooth loss is well reported in the literature. ${ }^{1}$ This loss of alveolar bone and change in ridge contour is the result of the bundle bone-periodontal ligament (BB-PDL) complex lost following the removal of a tooth. ${ }^{2,3}$ To restore an edentulous or partially dentate patient in many instances requires management of these resorbed sites by careful surgical intervention. The literature is abundant with guidelines to limit tissue loss (ridge preservation techniques) or restore the ridge architecture (bone and soft tissue augmentation). ${ }^{4,5}$ However, none of these circumvent the primary cause of resorption, ultimately resulting in partial or total ridge collapse. ${ }^{3}$ Partial extraction therapies (PET) represent a subgroup of precollapse interventions that collectively use the tooth itself to offset the loss of alveolar tissue. By retaining the tooth root and its attachment to bone, the BB-PDL complex with its vascular supply may be maintained. Root submergence has been demonstrated with success in the preservation of the postextraction ridge and development of pontic sites. ${ }^{6,7}$ However, the technique is limited by apical pathology and endodontic treatment requiring an alternative partial extraction therapy.

The socket-shield technique introduced by Hürzeler et al uses the 


\section{Table 1 Partial extraction therapies (PET) and their indications}

\section{PET}

\section{Clinical situation(s) indicated}

Root

submergence $^{7}$

Unrestorable tooth crown or tooth indicated for extraction

Absence of apical pathology

Healthy amputated pulp or endodontic therapy completed

Intention to preserve the alveolar ridge

Planned removable full or partial prosthesis

Planned pontic site beneath fixed prosthesis

Cantilever pontic site as an alternative to two adjacent implants

Actively growing young patient planned for implant

treatment later

Ridge preservation in conjunction with other PET

Socket-shield ${ }^{8}$ Unrestorable tooth crown or tooth indicated for extraction

Tooth root with or without apical pathology

Intention to preserve the alveolar ridge, specifically to

prevent buccopalatal collapse

Immediate implant placement

Ridge preservation in conjunction with other PET

Pontic shield ${ }^{9} \quad$ Unrestorable tooth crown or tooth indicated for extraction

Tooth root with or without apical pathology

Intention to preserve the alveolar ridge

Planned pontic site(s) beneath fixed prosthesis

Cantilever pontic site as an alternative to two adjacent implants

Ridge preservation in conjunction with other PET

Proximal Unrestorable tooth crown or tooth indicated for extraction

socket-shield ${ }^{23}$ Tooth root with or without apical pathology

Intention to preserve interdental papillae

Planned immediate implant placement sites of two or

more adjacent implants

Papillae preservation in conjunction with other PET facial or buccal root section alone to maintain the tissues at immediate implant placement. 8 A tooth planned for extraction with immediate placement is sectioned mesiodistally such that the facial and palatal root halves may be separated. The palatal root section is removed, leaving the facial root section to remain in situ. The root section is further refined and prepared while its attachment to the socket remains undisturbed. With an implant placed palatal to it this prepared socket-shield maintains the attachment to bundle bone and its vascularity, thus maintaining the support of the ridge facial to the implant and the restoration.

An additional PET that borrows from both the aforementioned techniques is the pontic shield. ${ }^{9}$ This technique develops a pontic site and preserves the alveolar ridge by retaining the buccal or facial root section, applying ridge preservation materials to the site, and sealing the tooth socket. The root submergence technique for pontic site development is limited to sites with a healthy tooth pulp or sites at which endodontic treatment of the tooth root is complete. The pontic shield, however, provides the clinician with an alternative method when apical pathology contraindicates root submergence. The vital periodontal tissues buccofacial to the root may be maintained to develop a pontic site with little or no collapse in the buccopalatal dimension.

\section{PET classification}

At present the concept of PET as a collective group of treatments to manage the postextraction ridge and its subsequent resorption does not exist. As a result, it may be difficult for a clinician to discern between the clinical indications for each therapy to select a treatment option. Root submergence has long been available in restorative and implant dentistry. The other PET treatments, however, are relatively new. Their indications overlap, but each therapy is suited to the final intention for the site. Two or more therapies can successfully be used simultaneously in the same patient, as each extraction site may be managed specific to the planned restoration, pontic, or implant. Combining several therapies when treating an arch or quadrant affords the clinician additional options to consider alternative treatment plans and placement strategies, restoration designs, placement sites, and so forth. A classification to guide the clinician is proposed and indicates the clinical scenarios suitable to each therapy (Table 1). 


\section{Clinical techniques}

Common to all PET treatments is the decoronation of a tooth that is no longer restorable or that is indicated for extraction, and the preservation whole or in part of its root such that the periodontal tissues associated with it are preserved. Simplified outlines of each therapy are presented here as a step-bystep guide to their application. The reader is directed to additional literature on these therapies for a greater understanding..$^{10}$

\section{Root submergence}

Root submergence when planning a pontic site beneath a conventional fixed partial denture (FPD) or implant-supported FPD (or any other indication) requires that the root be free of apical pathology, or that endodontic treatment first successfully be carried out. The tooth is decoronated at the level of the bone crest and the coronal root hollowed to mimic the future ovate pontic. Soft tissue closure is then achieved to ensure healing by primary intention. The attached gingiva may be advanced and sutured or, preferably, a soft tissue graft, connective tissue alone or epithelialized, is placed atop the submerged root for soft tissue closure and a bulk of tissue to later develop a pontic site. The site is to heal for a minimum of 3 months prior to any pontic pressure of the tissue overlying the tooth root.

\section{Socket-shield}

The socket-shield is created by preparation of a tooth indicated for extraction at an immediate implant placement site, typically in the anterior maxilla. The tooth is decoronated at $1 \mathrm{~mm}$ above the bone crest, and the root is thereafter sectioned longitudinally into facial and palatal halves. The palatal root section is delivered and any pathology present is cleared from the tooth apex. The facial root section is then concaved slightly with a long shank dental bur. The implant is then immediately placed palatal to the socket shield (and the buccal gap preferably grafted with a slow-resorbing bone substitute material).

\section{Pontic shield}

The pontic shield involves identical preparation of the socket-shield and the extraction socket grafted with a slow-resorbing bone substitute material (or bone material of the clinician's choice). The socket must be sealed, preferably with a soft tissue graft. The site is left to heal for a minimum of 3 months, and thereafter pontic pressure may gradually be applied to develop the site.

\section{Discussion}

Postextraction ridge collapse with degrees of alveolar resorption has been extensively documented in the literature. These hard and soft tissue defects can negatively affect ideal planned implant placement with a potential for esthetic failure. ${ }^{11}$ The clinician needs to be knowledgeable of the physiologic healing processes to best manage the resorbing ridge. Following tooth extraction, the tissues resorb as a direct result of the destruction of the BB-PDL-tooth complex. ${ }^{2}$ Bundle bone arises from a functionally loaded PDL and is lost following extraction, resulting in an almost certain collapse of the buccofacial tissues. ${ }^{12} \mathrm{~A}$ healed ridge defect following tooth extraction may require extensive surgical intervention prior to definitive restorative treatment. These may involve guided bone regeneration (GBR) techniques by bone and/or bone substitute materials with a barrier membrane, bone block GBR procedures, ridgesplit techniques, and so forth-all of which may provide hard tissue gains, though with limitations and with drawbacks such as increased morbidity, technique sensitivity, increased costs, and limited access to materials. ${ }^{13}$ Most notable are the soft tissue alterations that present with loss of papillae, scarring from the ridge augmentation procedure, and so on. The clinician should note that these techniques provide limited gains and will demonstrate protracted healing with shrinkage, and overcompensation is needed. Preventing ridge collapse before it occurs or limiting collapse as far as possible are beneficial to both patient and clinician. ${ }^{14}$

A multitude of ridge preservation techniques have been proposed in the literature with a large variety of materials and methods, leaving the clinician unclear as to which is best suited for ridge management. Not all of these, however, are able to treat the underlying cause of the resorption-the loss 


\begin{tabular}{|c|c|c|}
\hline Table 2 & $\begin{array}{l}\text { Available litera } \\
\text { technique or } \mathbf{m}\end{array}$ & $\begin{array}{l}\text { ure reporting on the socket-shield } \\
\text { difications thereof }\end{array}$ \\
\hline Year & Author(s) & Study \\
\hline 2016 & Gluckman et al ${ }^{9}$ & 10 case series of the pontic shield \\
\hline 2016 & Mitsias $^{25}$ & Case report: The root membrane technique \\
\hline 2015 & Bäumer et al17 & $\begin{array}{l}\text { Animal histology of } 3 \text { cases of socket-shield } \\
\text { with vertical fractures }\end{array}$ \\
\hline 2015 & Gluckman et al ${ }^{18}$ & $\begin{array}{l}\text { Case report: Socket-shield at immediate } \\
\text { placement, 1-year follow-up }\end{array}$ \\
\hline 2014 & Siormpas et al ${ }^{19}$ & $\begin{array}{l}46 \text { case series of the root-membrane technique } \\
\text { with follow-up varying } 2 \text { to } 5 \text { years }\end{array}$ \\
\hline 2014 & Holbrook $^{20}$ & $\begin{array}{l}\text { Case report: Guided implant placement with } \\
\text { socket-shield }\end{array}$ \\
\hline 2014 & Cherel and Etienne ${ }^{21}$ & $\begin{array}{l}\text { Case report: Modified socket-shield for } \\
\text { papillae preservation }\end{array}$ \\
\hline 2014 & Glocker et $\mathrm{al}^{22}$ & $\begin{array}{l}3 \text { case series: Modified socket-shield for } \\
\text { ridge preservation, delayed placement }\end{array}$ \\
\hline 2013 & $\begin{array}{l}\text { Kan and } \\
\text { Rungcharassaeng }\end{array}$ & $\begin{array}{l}\text { Case report: Proximal socket-shield for } \\
\text { papillae preservation }\end{array}$ \\
\hline 2013 & Chen and $\operatorname{Pan}^{24}$ & $\begin{array}{l}\text { Case report: Socket-shield with immediate } \\
\text { implant placement }\end{array}$ \\
\hline 2010 & Hürzeler et al ${ }^{8}$ & $\begin{array}{l}\text { Animal histology of } 1 \text { case of socket-shield } \\
\text { technique, and } 1 \text { human clinical case of } \\
\text { implant restoration with socket-shield }\end{array}$ \\
\hline
\end{tabular}
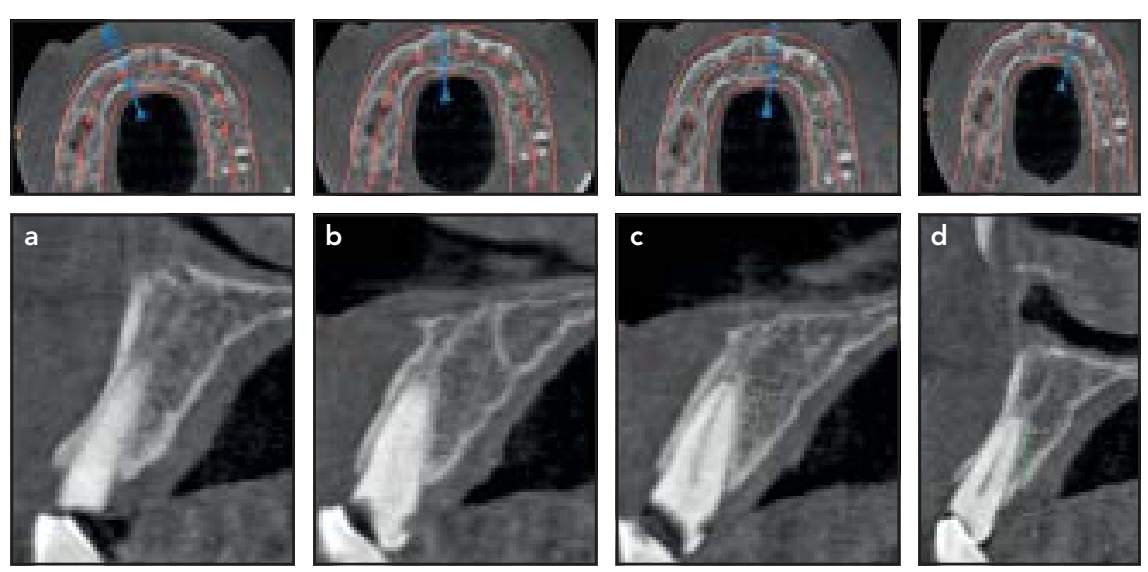

Fig 1 Case 1. Preoperative CBCT scan of the maxillary (a) right lateral incisor, (b) right central incisor, (c) left central incisor, and (d) left lateral incisor.

of the tooth. Root submergence was originally introduced as a technique to preserve alveolar ridge volume beneath removable full prostheses..$^{15}$ Malmgren et al, more than 3 decades ago, reported successful bone regeneration around submerged tooth roots, that bone forms coronal to such submerged teeth, and that new cementum and connective tissue may form coronally over submerged teeth. ${ }^{16}$ Later, the concept of submerging a tooth root for the development of pontic sites beneath FPDs was reported. Preserving the entire attachment apparatus for complete preservation of the alveolar ridge for pontic site development has been demonstrated.? This concept has evolved and has been applied to the socket-shield technique and the pontic shield, with root submergence collectively known as PET. Current literature to support some of these approaches is very poor. Six case reports, three case series (one with follow-up of 2 to 5 years), and two animal histology reports represent the only current studies (Table 2). Obviously, a randomized controlled study is highly recommended to support the use of these techniques. While literature reporting on these is lacking, PET treatments are hugely promising in the improved management of the postextraction ridge. These techniques preserve the supracrestal fibers and support the peri-implant tissues, as Hürzeler et al demonstrated histologically. ${ }^{8}$ The BB-PDL-tooth complex remains undisturbed, and the soft tissue frame for a pontic site or implant placement site can better be supported. In no way do the PET treatments yet supersede established ridge preservation techniques. It is, however, this working group's intention to demonstrate the techniques carried out and the results that have been gained (Figs 1 to 16) and inspire prudent scientific inquiry that may produce the long-term data required to confirm their validity. 


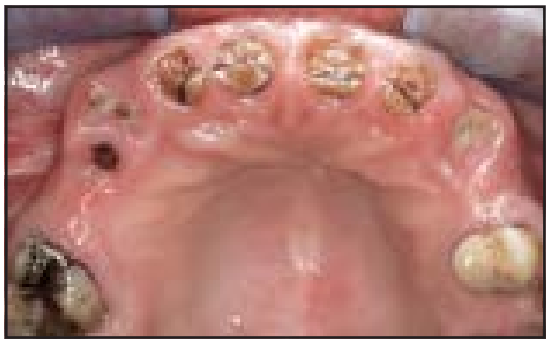

Fig 2 Case 1. Patient with rampant caries lesions that required multiple extractions in the maxilla.

Fig 5 Case 1. The final restoration at the 1-year recall. Note the bulk of tissue preserved, negating the need for disguising with pink restorative materials.

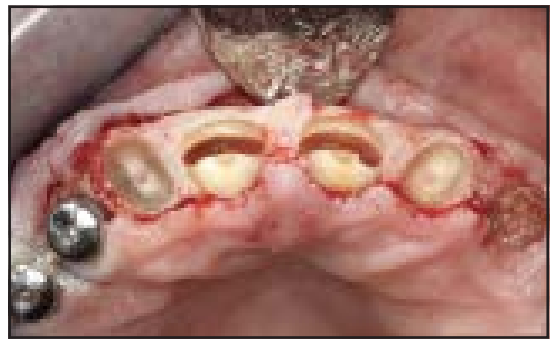

Fig 3 Case 1. Root submergence technique of the maxillary lateral incisors, and socket-shield technique at the central incisors.

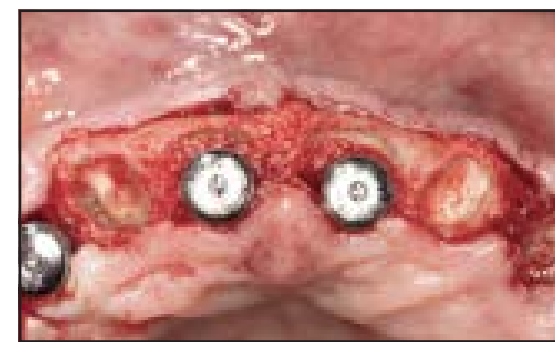

Fig 4 Case 1. Implants were inserted as per immediate placement protocol, as far palatal as possible, and the buccal gap was grafted with xenograft particulate bone.

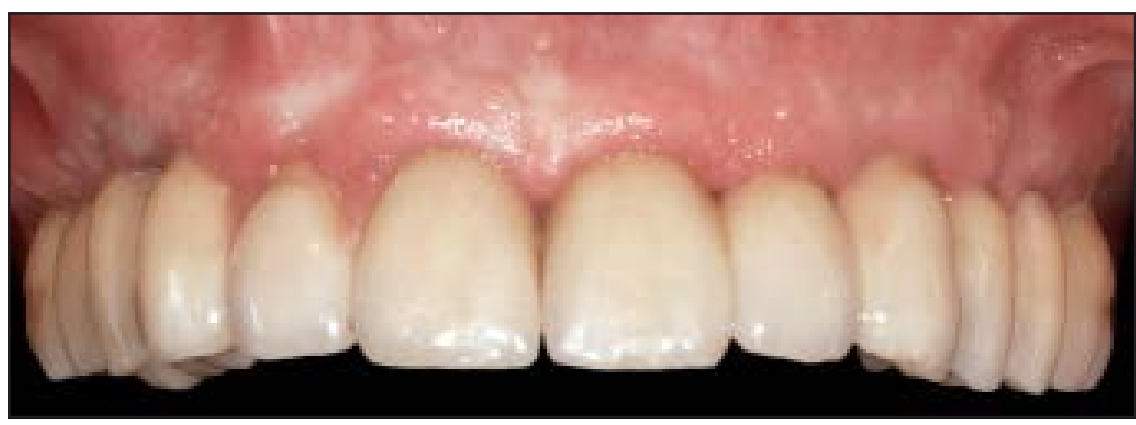

Fig 6 Case 1. CBCT scans at the 1-year recall of the partial extraction therapies at the maxillary (a) right lateral incisor, (b) right central incisor, (c) left central incisor, and (d) left lateral incisor.
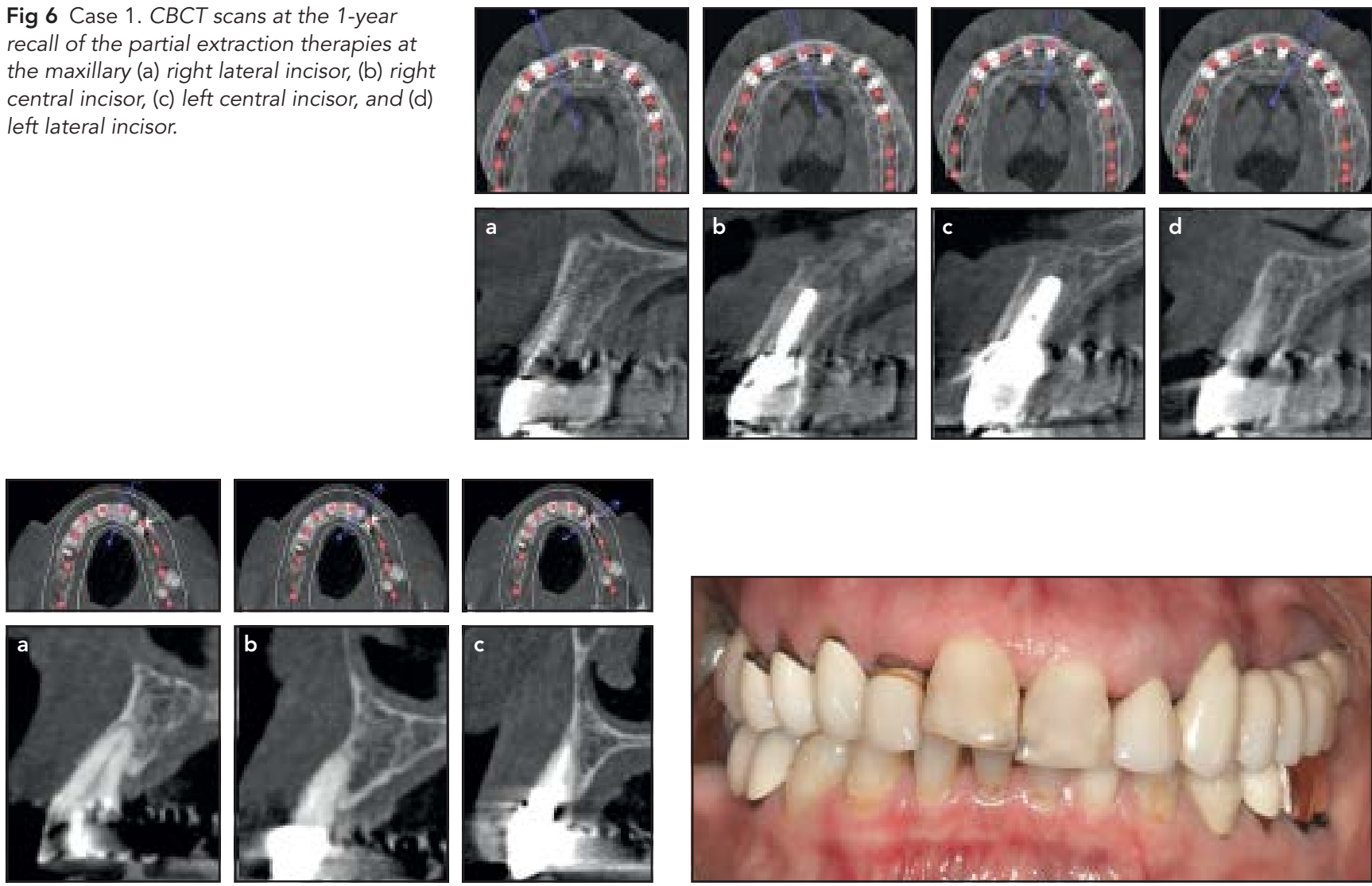

Fig 7 Case 2. Preoperative CBCT scan of the maxillary (a) left central incisor, (b) left lateral incisor, and (c) left canine.

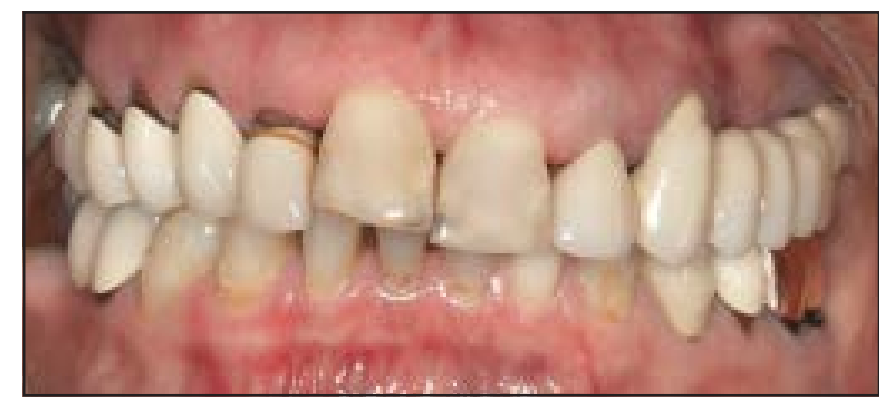

Fig 8 Case 2. Preoperative clinical view. 

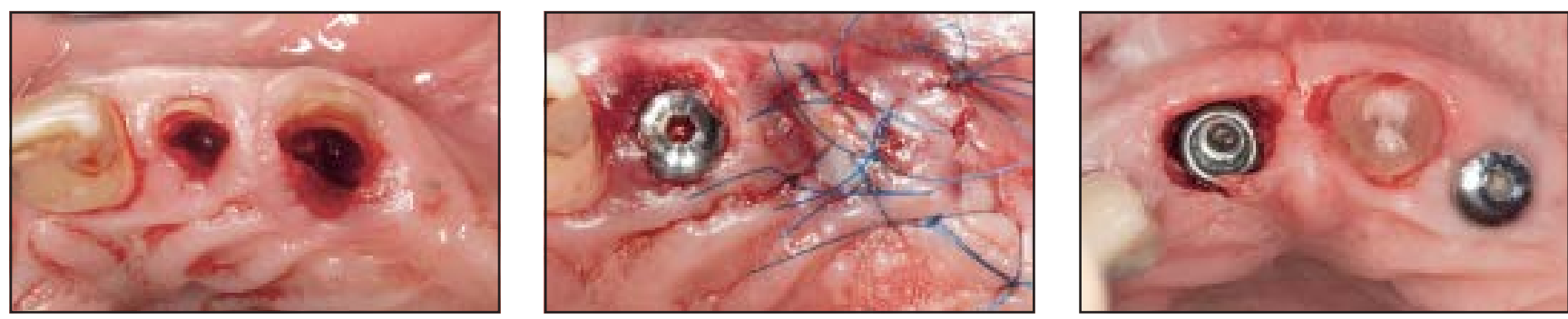

Fig 9 Case 2. At stage 1, the socket-shield technique was carried out at the site of the maxillary left lateral incisor (left). The pontic shield was carried out at the maxillary left canine, the healing abutment was fixed in place at the maxillary left lateral incisor, and connective tissue graft closure of the site of the maxillary left canine was performed (middle). At stage 2, immediate implant placement was done at the site of the right central incisor (right) and root submergence was performed at the left central incisor.
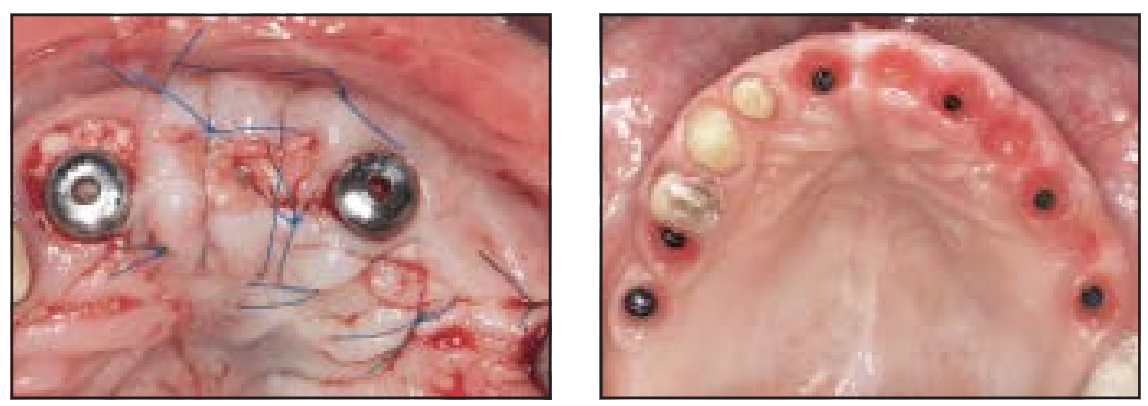

Fig 10 (left) Case 2. Grafting of the buccal gap at the maxillary right central incisor, connective tissue graft coverage of root submergence at the left central incisor, healed socket-shield at the left lateral incisor, and healed pontic shield at the left canine.

Fig 11 (right) Case 2. Day of delivery of the final prostheses. Note the symmetry between the left and right sides of the arch from the premolars anteriorly with excellent health and bulk of the soft tissue.

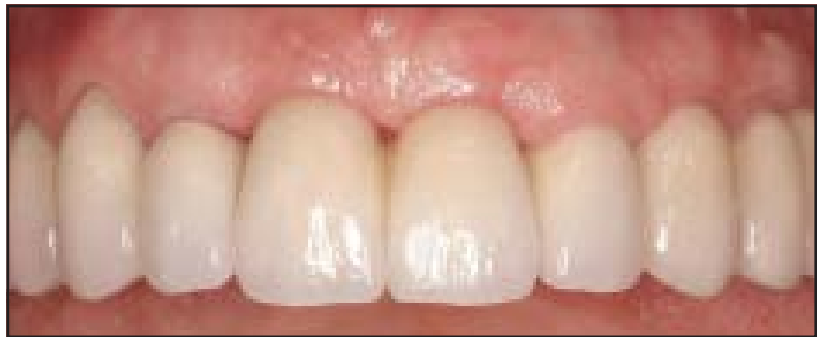

Fig 12 Case 2. Final prostheses at the 1-year recall.
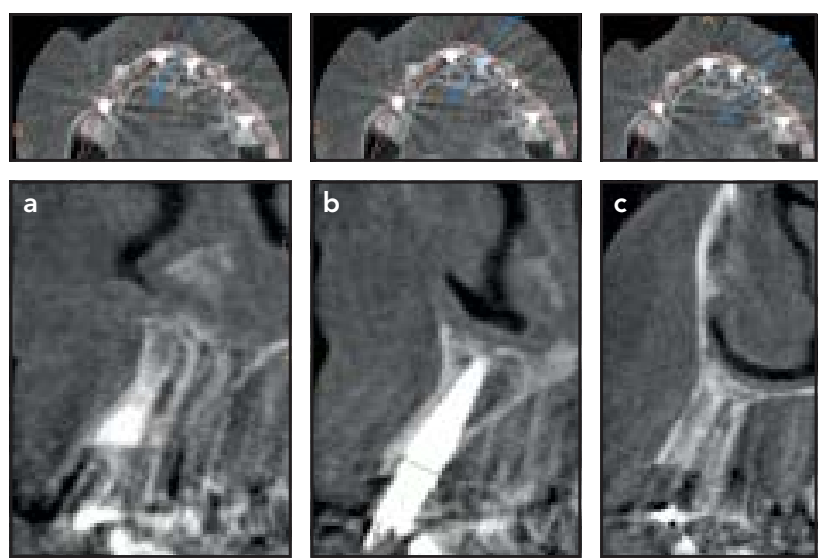

Fig 14 Case 2. CBCT scans at the 1-year recall at the maxillary (a) left central incisor, (b) left lateral incisor, and (c) left canine.

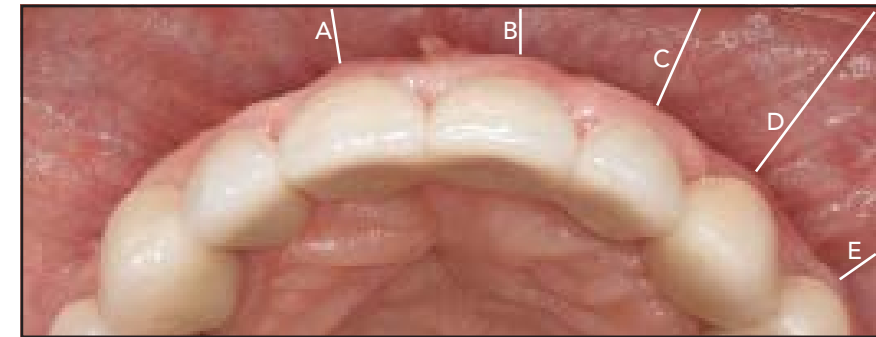

Fig 13 Case 2. Occlusal view at 2-year follow-up. Immediate implant placement (a), root submergence and pontic (b), socket-shield (c), pontic shield (d), and implant with ridge split (e). Note the maintenance of soft tissue profile and lack of collapse.

\section{Conclusions}

PET may be considered a more conservative ridge preservation strategy for teeth slated for extraction. Retention of all or part of a tooth for the enhancement of a pontic site or preservation of papillae or labial tissues at immediate or delayed implant placement has demonstrated promising results. It is the opinion of the authors and the reviewers of this article that before the socket-shield and PET are further advocated in daily clinical practice, more abundant histologic evidence and proof of long-term clinical success need to be presented. This article is the first proposition of a collective term and classification of these techniques. 

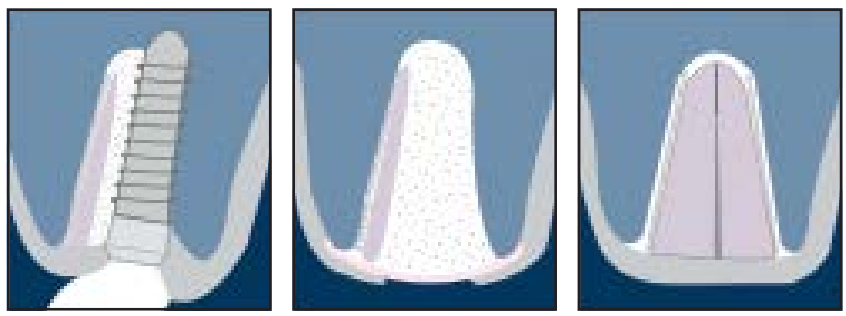

Fig 15 Diagrammatic representation of the partial extraction therapies (buccopalatal axial view): socket-shield (left), pontic shield (middle), and root submergence (right).
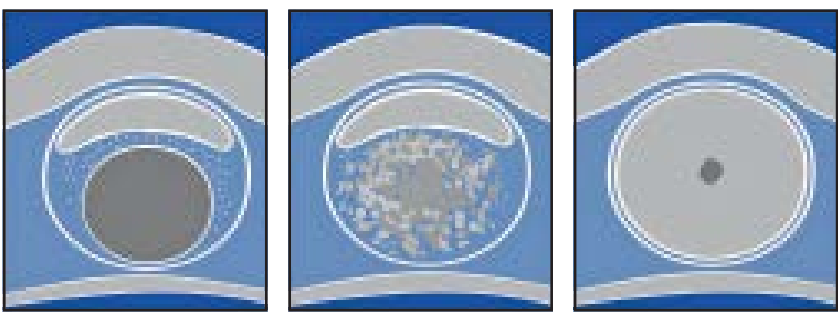

Fig 16 Horizontal cross-section midway through the sockets of partial extraction therapies; socket-shield (left), pontic shield (middle), and root submergence (right).

\section{Acknowledgments}

The authors reported no conflicts of interest related to this study.

\section{References}

1. Van der Weijden F, Dell'Acqua F, Slot DE. Alveolar bone dimensional changes of post-extraction sockets in humans: A systematic review. J Clin Periodontol 2009; 36:1048-1058.

2. Araújo MG, Sukekava F, Wennström JL, Lindhe J. Ridge alterations following implant placement in fresh extraction sockets: An experimental study in the dog. J Clin Periodontol 2005;32:645-652.

3. Cardaropoli G, Araújo M, Lindhe J. Dynamics of bone tissue formation in tooth extraction sites. An experimental study in dogs. J Clin Periodontol 2003;30: 809-818.

4. Kuchler U, von Arx T. Horizontal ridge augmentation in conjunction with or prior to implant placement in the anterior maxilla: A systematic review. Int J Oral Maxillofac Implants 2014;29:S14-S24.

5. Chen ST, Buser D. Esthetic outcomes following immediate and early implant placement in the anterior maxillaA systematic review. Int J Oral Maxillofac Implants 2014;29:186-215.

6. Malmgren B, Cvek M, Lundberg M, Frykholm A. Surgical treatment of ankylosed and infrapositioned reimplanted incisors in adolescents. Scand J Dent Res 1984;92:391-399.

7. Salama $M$, Ishikawa $T$, Salama $H$, Funato A, Garber D. Advantages of the root submergence technique for pontic site development in esthetic implant therapy. Int J Periodontics Restorative Dent 2007;27: 521-527.
8. Hürzeler MB, Zuhr O, Schupbach P, Rebele SF, Emmanouilidis N, Fickl S. The socketshield technique: A proof-of-principle report. J Clin Periodontol 2010;37:855-862.

9. Gluckman H, Du Toit J, Salama M. The pontic shield: Partial extraction therapy for ridge preservation and pontic site development. Int J Periodontics Restorative Dent 2016:36;417-423.

10. The Implant \& Aesthetic Academy. Partial Extraction Therapies. http://www. implantacademy.co.za/PET Accessed 19 May 2013.

11. Comut A, Mehra M, Saito H. Pontic site development with a root submergence technique for a screw-retained prosthesis in the anterior maxilla. J Prosthet Dent 2013;110:337-343.

12. Ho SP, Kurylo MP, Grandfield K, et al. The plastic nature of the human boneperiodontal ligament-tooth fibrous joint. Bone 2013;57:455-467.

13. Levine RA, Huynh-Ba G, Cochran DL. Soft tissue augmentation procedures for mucogingival defects in esthetic sites. Int J Oral Maxillofac Implants 2014;29: S155-S185.

14. De Risi V, Clementini M, Vittorini G, Mannocci $A$, De Sanctis M. Alveolar ridge preservation techniques: A systematic review and meta-analysis of histological and histomorphometrical data. Clin Oral Implants Res 2015;26:50-68.

15. Miller PA. Complete dentures supported by natural teeth. J Prosthet Dent 1959;8:924-928.

16. Malmgren $B$, Cvek $M$, Lundberg $M$, Frykholm A. Surgical treatment of ankylosed and infrapositioned reimplanted incisors in adolescents. Scand J Dent Res 1984;92:391-399.

17. Bäumer $D$, Zuhr $O$, Rebele $S$, Schneider $D$, Schupbach P, Hürzeler M. The socketshield technique: First histological, clinical, and volumetrical observations after separation of the buccal tooth segmentA pilot study. Clin Implant Dent Relat Res 2015;17:71-82.
18. Gluckman H, Du Toit J, Salama M. The socket-shield technique to support buccofacial tissues at immediate implant placement: A case report and review of the literature. Int Dent Africa Ed 2015;5:1-7.

19. Siormpas KD, Mitsias ME, KontsiotouSiormpa E, Garber D, Kotsakis GA. Immediate implant placement in the esthetic zone utilizing the "root-membrane" technique: Clinical results up to 5 years postloading. Int J Oral Maxillofac Implants 2014:29:1397-1405.

20 Holbrook SE. Model-guided flapless immediate implant placement and provisionalization in the esthetic zone utilizing a nanostructured titanium implant: A case Report. J Oral Implantol 2016;42:98-103.

21. Cherel F, Etienne D. Papilla preservation between two implants: A modified socket-shield technique to maintain the scalloped anatomy? A case report. Quintessence Int 2014;45:23-30.

22. Glocker M, Attin T, Schmidlin PR. Ridge Preservation with Modified "SocketShield" Technique: A Methodological Case Series. Dent J 2014;2:11-21.

23. Kan JY, Rungcharassaeng K. Proximal socket shield for interimplant papilla preservation in the esthetic zone. Int J Periodontics Restorative Dent 2013; 33:e24-e31.

24. Chen CL, Pan YH. Socket shield technique for ridge preservation: A case report. J Prosthondontics Implantology 2013; 2:16-21.

25. Mitsias $M E$, Siormpas KD, Prasad $H$, Garber D, Kotsakis GA. A step-by-step description of PDL-mediated ridge preservation for immediate implant rehabilitation in the esthetic region. Int $\mathrm{J}$ Periodontics Restorative Dent 2015;35: 835-841. 


\section{Partial Extraction Therapies (PET) Part 2: Procedures and Technical Aspects}

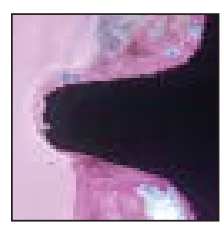

Howard Gluckman, BDS, MChD (OMP)

Maurice Salama, DDS²

Jonathan Du Toit, BChD, Dipl Implantol, Dipl Oral Surg, MSc Dent ${ }^{3}$

Part 1 of this series introduced the partial extraction therapies as a group of techniques for ridge preservation at immediate implant placement and beneath pontic sites. The concept proposes a paradigm shift away from extract and augment toward partly retaining the tooth root to preserve the ridge and prevent buccopalatal collapse. The revolutionary socket-shield technique was introduced in 2010; however, there has been no follow-up literature to guide the clinician in terms of procedural steps. While root submergence is well established, the socket-shield and pontic shield are still in their clinical infancy and require longterm clinical data before they can be proposed as routine in everyday implant dentistry. Yet without sound knowledge on how to carry out the partial extraction therapies, a global dental community cannot participate in their application or contribute to the growing knowledge base. In this, the second part of the series, the procedures for root submergence, socket-shield, and pontic shield are addressed, step by step, supplemented with applicable guidelines as the first such publication guiding the clinician to apply these root- and ridge-preservation techniques. Technical aspects and complication management are also addressed. Int J Periodontics Restorative Dent 2017;37:377-385. doi: 10.11607/prd.3111

${ }^{1}$ Specialist in Periodontics and Oral Medicine, Director of The Implant and Aesthetic Academy, Cape Town, South Africa.

${ }^{2}$ Clinical Assistant Professor of Periodontics, University of Pennsylvania, Philadelphia, Pennsylvania; Medical College of Georgia, Augusta, Georgia; Private Practice, Atlanta, Georgia.

${ }^{3}$ Department of Periodontics and Oral Medicine, School of Dentistry, Faculty of Health Sciences, University of Pretoria, Pretoria, South Africa.

Correspondence to: Dr Howard Gluckman, The Implant and Aesthetic Academy, 39 Kloof Street, Cape Town, South Africa. Fax: +2721 426 3053. Email: docg@theimplantclinic.co.za

(C)2017 by Quintessence Publishing Co Inc.
Successful implant therapy as we know it today is not merely a pursuit of osseointegration, but a full integration of healthy and esthetic peri-implant tissues framing the prosthesis. ${ }^{1}$ Akin to ensuring healthy periodontium around a tooth, establishing healthy peri-implant tissues is of paramount importance. The health, stability, and volume of bone has been the focus of the implant-restorative treatment dilemma for some time, yet the entire peri-implant tissue complex requires careful management. ${ }^{2}$ Healthy bone maintained at the coronal implant supports the establishment of the biologic width, namely connective tissue and the long junctional epithelium. ${ }^{3}$ With tooth loss, however, these tissues recede apically, as is evident at immediate implant placement. ${ }^{4}$ An understanding of the periodontium and this loss of tissues postextraction alludes to the underlying process-removal of the tooth severs the rich periodontal ligament $(\mathrm{PDL})$ vasculature that supplies the alveolus bundle bone. ${ }^{5}$ Subsequently, resorption of the postextraction socket is inevitable. At an immediately placed implant site, the resorption may have significant esthetic and functional failure if the supporting tissues recede and when exacerbated by risk factors for recession. ${ }^{6}$

To address this, the partial extraction therapies (PET) propose 


\section{Table 1 Instruments and Materials Required for PET}

\section{Socket-shield}

1. Long shank root resection bur

2. Extra-large round diamond head bur (to reduce inner aspect of shield into concavity)

3. End-cutting diamond head bur (to reduce coronal aspect of shield)

4. Gingival protector

5. Irrigated surgical motor

6. Contra-angled surgical fast handpiece

7. Microperiotomes

8. Microforceps

\section{Pontic shield}

As for socket-shield, plus:

1. Socket grafting instruments: plugger, particulate graft spoon, crucible

2. SM 69 blade (or other suitable microblade, mandatory for split thickness dissection of facial and palatal pouches to tuck CTG into)

3. $6 / 0$ nylon sutures

Root submergence

1. Irrigated surgical motor

2. Contra-angled surgical fast handpiece

3. Extra-large round diamond head bur (for reducing coronal aspect root into concavity)

4. SM 69 blade (or other suitable microblade, mandatory for split thickness dissection of facial and palatal pouches to tuck CTG into)

5. $6 / 0$ nylon sutures

the partial retention of the tooth root to maintain the periodontium buccal/labial to it.7 The hypothesis has been that retention of the tooth root or part of it retains the PDL fibers that anchor it to the alveolus and preserve the PDL vasculature that supply the bundle bone, thus preserving all tissue components of the periodontium. Chronologically, root submergence introduced in 1953 proposed retaining decoronated tooth roots beneath full removable dentures to maintain the alveolar ridge. In 2007, the concept evolved to be applied at pontic sites beneath fixed partial dentures. ${ }^{8}$ The socket-shield technique progressed from there, and healed tissue histology has been demonstrated following sectioning of a submerged root at immediate implant place- ment-the labial root section remaining in situ and supporting the periodontal tissues. ${ }^{9}$ In 2015, the socket-shield technique's partial root submergence was combined with socket grafting to preserve the ridge at pontic site developmentviz the pontic shield. ${ }^{10}$ These PET collectively encompass the rootand ridge-preservation techniques as applied in implant and restorative dentistry. They collectively use the tooth itself to offset the loss of ridge tissues by retaining the attachment to the periodontium with its vascular supply, preserving the tooth-PDL-bundle bone complex, and thus challenge the conventional extract and augment approach. ${ }^{7}$ The authors propose that strategically saving part of the tooth is the ultimate preservation technique for retaining soft tissue esthetics at implant and pontic sites.

However, it is pertinent that rigorous testing be applied to newer techniques that long-term data be used to scrutinize.11 This would not be possible if there were vast heterogeneity in the application of PETs with no congruency as to how the treatments are applied and thus no data to accurately inspect. Therefore, step-by-step instructions for these techniques are provided here (Table 1). The aim of this work is to facilitate carrying out and reporting on these techniques and accumulation of significant clinical and research data to allow the techniques to be scrutinized for validity, or lack thereof, in restorative and implant dentistry.

The term buccal denotes the cheek and may be used incorrectly in the literature. For clarification, buccal in this report will refer to outer aspects of the teeth and ridge apposed to the vestibule up to the mesial edge of the first premolar, and labial or facial will refer to the outer aspects of the ridge and teeth apposed to the vestibule of the anterior teeth, distal canine to distal contralateral canine. While the technique may be possible in mandibular anterior tooth sites, for the sake of descriptive purposes the anterior maxilla will be referred to throughout this review.

\section{PET Preparation}

\section{Preparation Aspects:}

\section{The Socket-Shield}

To date, two or more variants of the socket-shield have emerged, notably the root-membrane technique. ${ }^{12}$ 


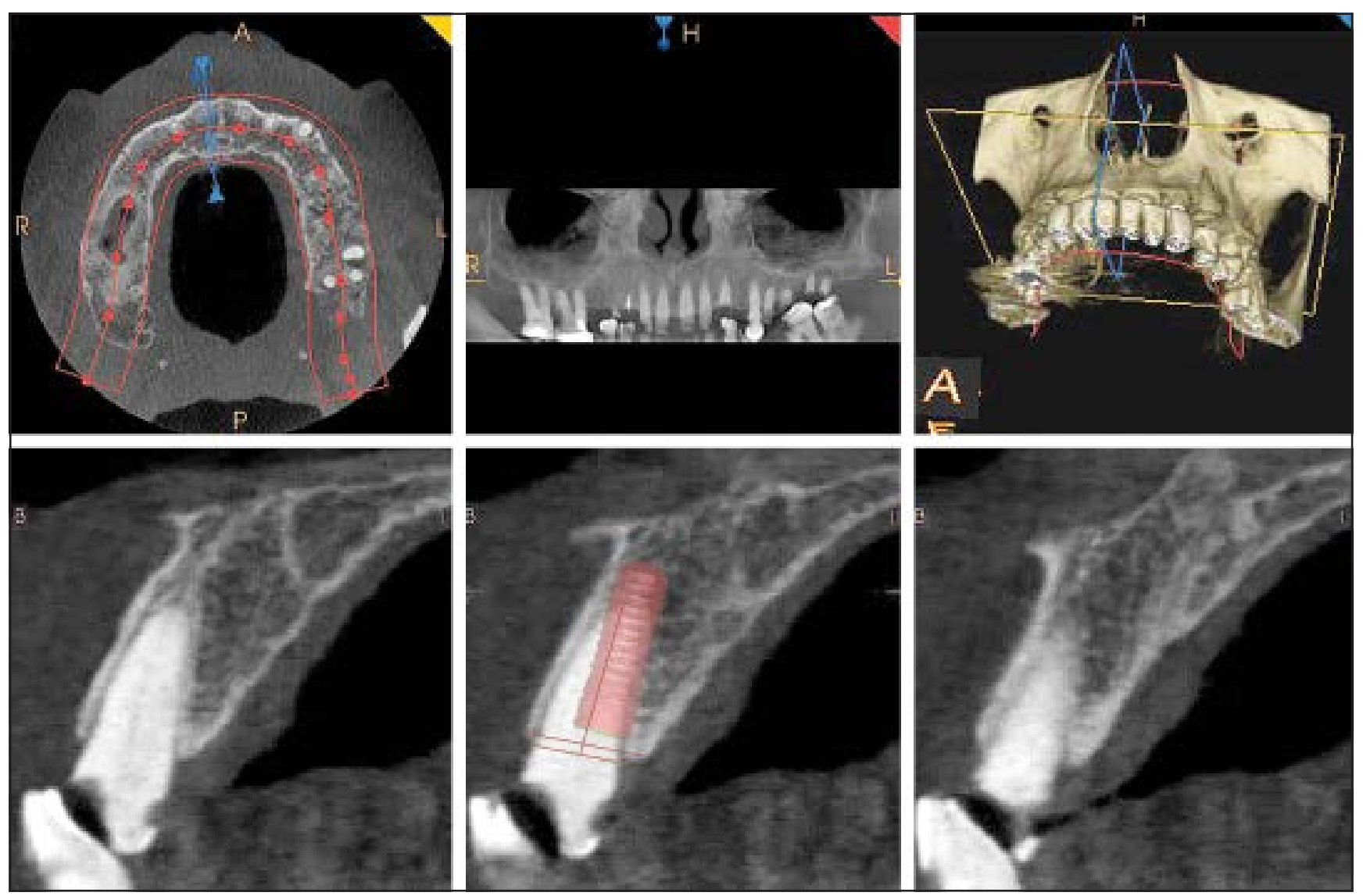

Fig 1 Cone beam computed tomography planning in the maxilla; the clinician can note any pathology of the root, root's dimensions, and orientation within the ridge.

The socket-shield technique, while similar, is not synonymous with these techniques. The authors here regard the techniques pioneered by Hürzeler et $\mathrm{al}^{9}$ as original and hereafter describe its preparation. The socket-shield as yet has only been demonstrated in the literature at anterior tooth sites planned for immediate implant placement. The sectioning of posterior buccal tooth roots in combination with implant treatment has not yet been described. That said, the technique's application may be intended for all tooth sites. The only limitation is the difficulty in preparing smaller roots, as seen in the lower anterior teeth, and curved roots, as seen in posterior sites. The clinician would need to exercise discretion when attempting to prepare smaller and curved roots.

The tooth itself may provide the best biologic implant, and the decision to extract and replace with an implant-supported restoration should be highly deliberated. A tooth indicated for extraction with apical pathology may be selected for the socket-shield technique. An absolute contraindication, however, is mobility of the tooth root as a result of a previously diseased periodontium, traumatic occlusion, or the like. The prepared tooth root section (hereafter referred to as the socket-shield) must be checked for immobility. The authors also submit that active periodontitis at the tooth is an absolute contraindication to preparing it as a socket-shield.

Thorough planning always precedes any implant therapy. No socket-shield treatment planning can fail to appreciate the tooth root in relation to the labial and palatal ridge unless three-dimensional (3D) imaging is used. Thus, cone beam computed tomography (CBCT) of the preparation site and tooth is an absolute requirement (Fig 1). The 

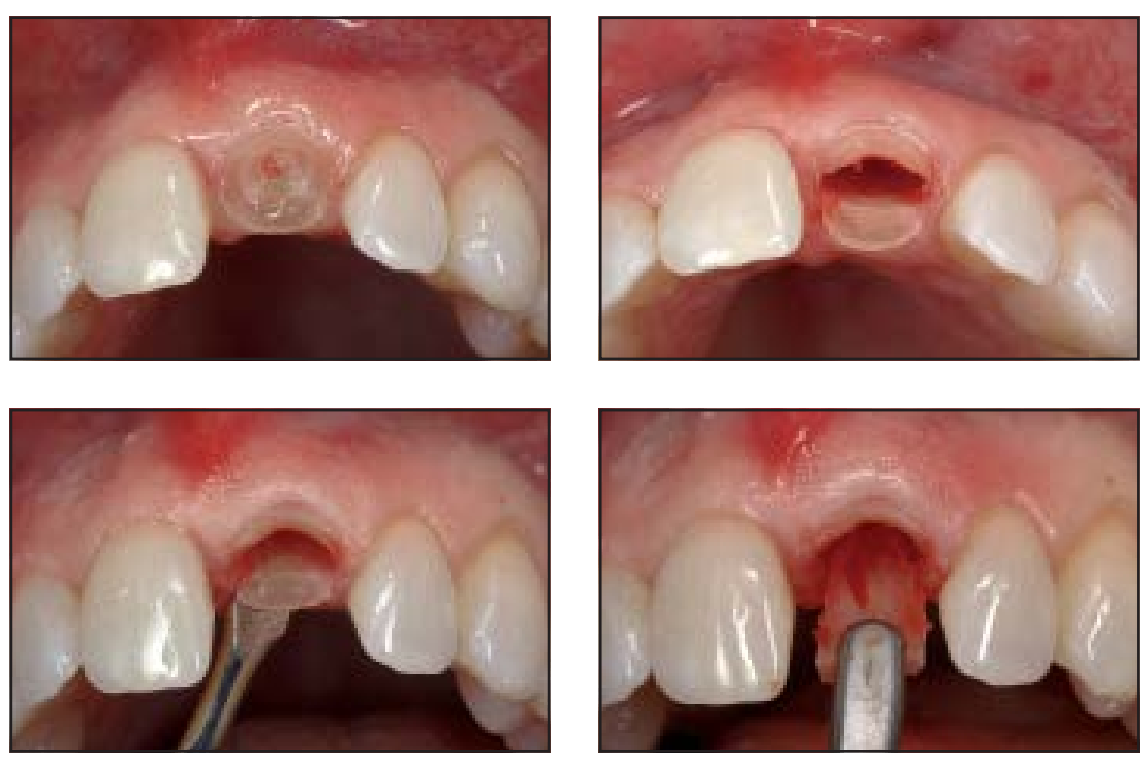

clinician is to visualize possible apical infection, resorption, possible fenestration and dehiscence, and root length and width, measuring the root width in totality as well if sectioned longitudinally. The clinician is to use the same degree of planning required for immediate implant preparation, noting the proximity of adjacent structures, the limits of the bony ridge at various aspects, the volume of soft tissue, and so forth. Additional planning by means of a 3D imaging-prepared surgical guide or conventional analog guide duplicate of an anatomical wax-up are also implicit.

Following adequate anesthesia of the site planned for immediate implant placement, the tooth is decoronated to the gingival level, with care taken at all times not to damage the gingiva (Fig 2). Thereafter, with the use of an irrigated long-shank surgical root resection bur, the tooth root is carefully sectioned mesiodistally and longitudinally midway through the root with the canal as a reference point, such that the labial and palatal halves are separated from each other entirely from the coronal to the apical aspect (Fig 3). The clinician may place an endodontic instrument within the root canal to gauge the orientation of the root, and this orientation is to be followed when sectioning into labial and palatal halves. Absolute care is to be taken not to penetrate bone or neighboring teeth mesial or distally. Periapical radiographs may aid in preparation and may be viewed with the resection bur in situ. Once labial and palatal root halves are adequately separated, a microperiotome instrument is inserted into the palatal PDL space, carefully displacing the palatal root section labially into the recess created by the sectioning bur (Fig 4)
Fig 2 (left) Decoronation of the maxillary left central incisor without damage to the soft tissue.

Fig 3 (right) Mesiodistal sectioning of the tooth root.

Fig 4 (left) Elevation of the palatal root section by microperiotome.

Fig 5 (right) Delivery of the palatal root section by microforceps.

and retrieving it with microforceps (Fig 5). At no time should the labial root, labial bone crest, or labial PDL space be instrumented. It is essential to maintain a finger rest on the buccal/labial ridge. This allows for tactile sensation of the drill position as the apex is reached. When elevating the palatal root section, this tactile sensation from a finger rest may indicate movement of the socket-shield or indicate incomplete root sectioning. Observe for movement-incomplete sectioning may detrimentally dislodge the labial root section. Once it is sufficiently elevated, the palatal root section may be delivered by microforceps (Fig 5). The labial root section that remains in situ is then instrumented on its inner aspect with a sharp probe, inspecting for immobility. If the clinician is absolutely sure the root section is stable, any or all remnants of infection within the socket 


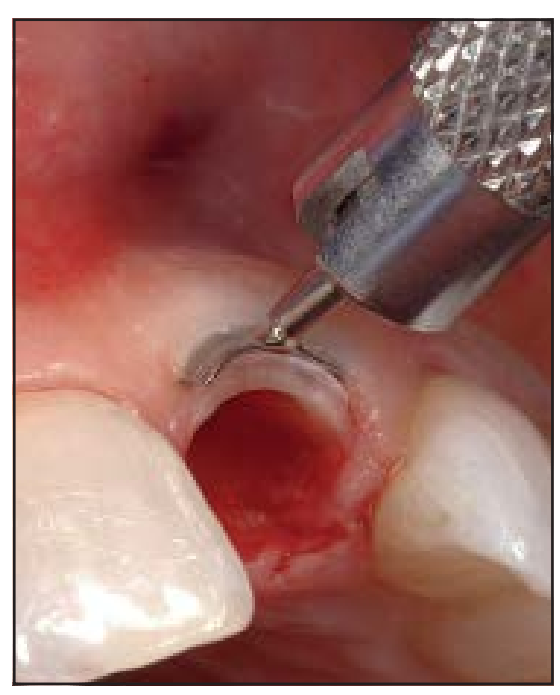

apex are to be thoroughly curetted out, followed by copious saline rinse. Thereafter, the coronal aspect of the root section is reduced and shaped to within $1 \mathrm{~mm}$ above the alveolar socket crest by an irrigated large round diamond bur. It is critical not to damage the gingiva, and the use of a gingival protector is mandatory (Fig 6). Care must be taken not to force the gingival protector into the PDL space but to merely shield the soft tissues from contact with the bur. The clinician is also to beware of metal debris resulting from excessive contact of the gingival protector with a dental bur. These may lead to soft tissue tattooing, though this has not occurred in the authors' experience to date. Thereafter, the root section is reduced and shaped as a crescentshaped concavity conforming to the labial aspect of the alveolus. The clinician here exercises subjec-

Fig 6 (left) Final reduction of the socket-shield with the gingival protector in position.

Fig 7 (center) The socket-shield reduced about midway from the root canal to the root's surface. Note the prepared osteotomy palatal to the socket-shield.

Fig 8 (right) The final socket-shield, reduced $1 \mathrm{~mm}$ above the bone crest, without damage to the overlying gingiva.
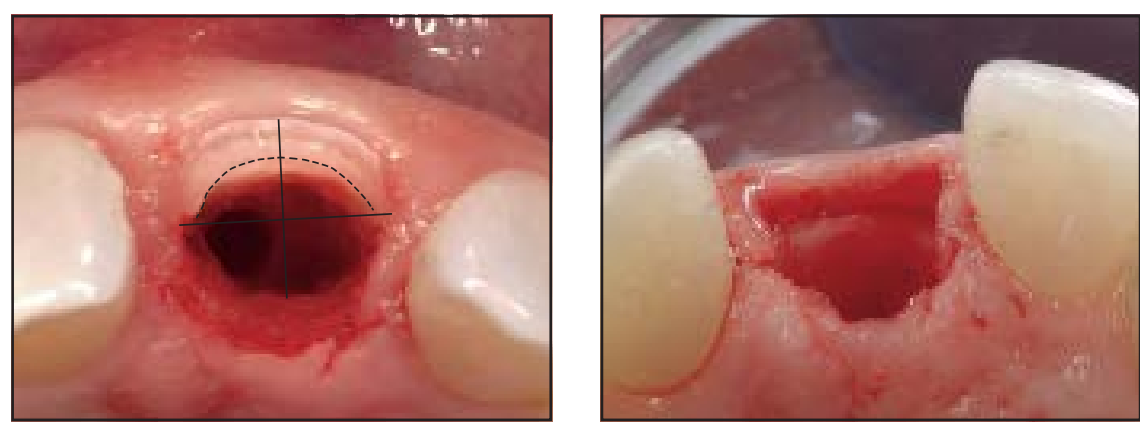

tive discretion. A thick socket-shield is stable but occupies space to accommodate the implant. An overly reduced socket-shield must be avoided and would likely be unstable. The authors' recommendation is to reduce approximately half its thickness from root canal to its labial limit (Fig 7). The coronal portion may be thinner while maintaining a thicker apical root section. Again, the socket is thoroughly rinsed and the root section inspected with a sharp probe for immobility. A periapical radiograph may be used to visualize the completed preparation (that may require adjusting) for sharp edges of the root for orientation $1 \mathrm{~mm}$ above the bony crest, possible bur penetration into neighboring teeth, and so on. The final completed labial tooth section, ready for subsequent implant placement at its palatal aspect, is the socket-shield (Fig 8).
Preparation Aspects: The Pontic Shield

The pontic shield is indicated for sites planned to receive a pontic restoration, be it a removable partial denture or a tooth-supported or implant-supported fixed partial denture, but root submergence has been contraindicated due to apical infection or endodontic treatment failure. $^{10}$ The pontic shield combines the socket-shield technique with established socket grafting treatments. ${ }^{13}$ The socket-shield is prepared first. Note that the treatment planning, the 3D imaging, and the entirety of the steps outlined above are repeated identically. It is essential to ensure that the apex of the root is removed along with all the apical infection. Light and magnification are essential for this procedure. After completing preparation followed by thorough 


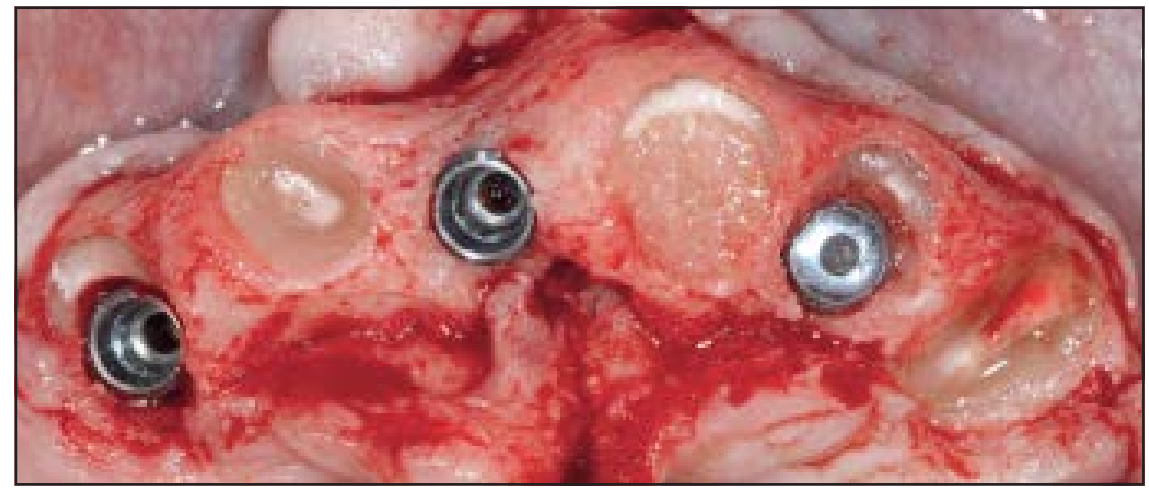

Fig 9 Multiple PET carried out in the same patient. The site of the maxillary left central incisor is prepared as a pontic shield and the socket grafted with xenograft particulate bone. Note the socket-shield at the site of the left lateral incisor allows for grafting of the buccal gap, while the site of the right canine does not.

curettage of the socket with copious saline rinse, the socket may be grafted with bone particulate or a bone substitute material of the clinician's choosing (Fig 9). Established socket grafting principles should be adhered to. The material placed in the socket should not be densely packed with excessive pressure, and care must be taken not to disturb the socket-shield. Once the socket is adequately filled, it must be sealed. In the authors' experience, a lack of closure of the socket by membrane material, autogenous connective tissue graft (CTG), or rotated pedicle flap results in delayed wound healing of the socket with possible complication. ${ }^{10}$ The authors recommend a CTG. A clinician less confident with harvesting and grafting autogenous tissue may use a dense polytetrafluoroethylene (dPTFE) membrane tucked beneath full-thickness pouches atop the ridge. Typically, a provisional restoration with light pontic pressure only is fixed in place for the duration of healing. The prepared labial root section and grafted tooth socket, sealed and secured with sutures, is the completed pontic shield.

\section{Preparation Aspects: Root \\ Submergence}

The indications for each PET were tabulated in Part 1 of this series. Root submergence is indicated for preservation of the alveolar ridge beneath full dentures and fixed or removable partial dentures. ${ }^{8,14}$ Any active infection of the root and the apical area must first be resolved by endodontic treatment. An adequately root-treated tooth or a vital, infection-free tooth root may be submerged. The decision to submerge the whole root or partially submerge it as a pontic shield is based largely on the status of the root and the site. A vertical fracture may contraindicate root submergence, though it may still be prepared as a pontic shield. An apical infection may be mechanically cleared if prepared as a pontic shield and removed entirely with the palatal root section. Preparing the site as a pontic shield requires grafting the socket with particulate bone or substitute and may increase the cost of treatment. The authors regard the pontic shield as slightly more technically challenging than root submergence. Thus, selecting between these two techniques requires consideration of these factors as well as the clinician's level of skill, experience, and preference. That said, root submergence does not necessitate 3D imaging; routine periapical radiographic views suffice. Decoronation of the tooth is identical to that for the other PET methods (Fig 2). The soft tissues are to be protected with a gingival protector instrument, and the root is prepared to slightly below bone level to avoid perforation of the soft tissue. Thereafter, the root is reduced and shaped with an irrigated large diamond bur to form a concavity that will allow soft tissue infill that when healed will frame the pontic. The authors submit that coverage of the coronal root is mandatory: by CTG for a single tooth site, and by primary intention approximation of the flap(s) for multiple tooth sites (Fig 9).

\section{Technical Aspects}

\section{The Socket-Shield}

Prosthetic sealing of the socket by customized transgingival abutment 
or anatomical provisional restoration is mandatory when carrying out a socket-shield procedure coincident to immediate implant placement. The socket cannot be left open. Either of the two prosthetic options mentioned above must conform to the soft tissue periphery of the postextraction socket, with a 2-mm gap between the prosthetic component and the socket-shield to allow for soft tissue infill.

Moreover, the socket-shield has been modified by the inventor of the technique, and the authors regard the first demonstration by Hürzeler et al of the socket-shield preparation as original. 9 The first report by this working group demonstrated the histology of a healed socket-shield in contact with an osseointegrated implant palatal to it. The methodology of the report included the use of an enamel matrix derivative on the root section's aspect facing the implant. The group later omitted this step, and the present authors recommend this omission. The space between the implant and the alveolar socket wall, regularly termed in the literature as the buccal gap, is similarly regarded here as the gap from the implant to the inner surface of the socket-shield facing the implant. The authors recommend grafting this gap with a particulate bone material. The clinician is to gauge necessity. Should the buccal gap be negligible and the coronal aspect of the implant closely apposed to it such that there is no space to accommodate instrumentation and particulate material, this step may be omitted (Fig 9).
The literature reports on improved histologic outcomes following grafting of the buccal gap. ${ }^{15}$ Thus, grafting of the void between implant and socket-shield is a biologically sound recommendation. Bäumer et $\mathrm{a}^{16}$ demonstrated the formation of new bone between the implant and the dentin surface (Fig 10).

The authors of the original technique also described the intimate contact of implant threads to the cementum of the socket-shield and apposition of newly formed cementum on the implant surface. This was later modified by the same working group. For clarification, contact of implant to socket-shield is not a requisite or a recommendation. Contact may occur as a result of space limitation at time of placement and may pose no concern other than displacement of the socket-shield and damage of the PDL attachment. Care should be taken to avoid this.

\section{Root Submergence}

Root submergence has been described without primary closure of the site, resulting in incomplete soft tissue coverage of the root and requiring CTG later. ${ }^{14}$ The authors strongly recommend primary closure, or soft tissue grafting to achieve it. This may present a challenge and require extensive periosteal release, especially in multiple adjacent submerged roots. In cases with removable interim prosthesis, impact to the healing tissues must be monitored for possible exposure complication. The clinician must ensure the absence of sharp edges

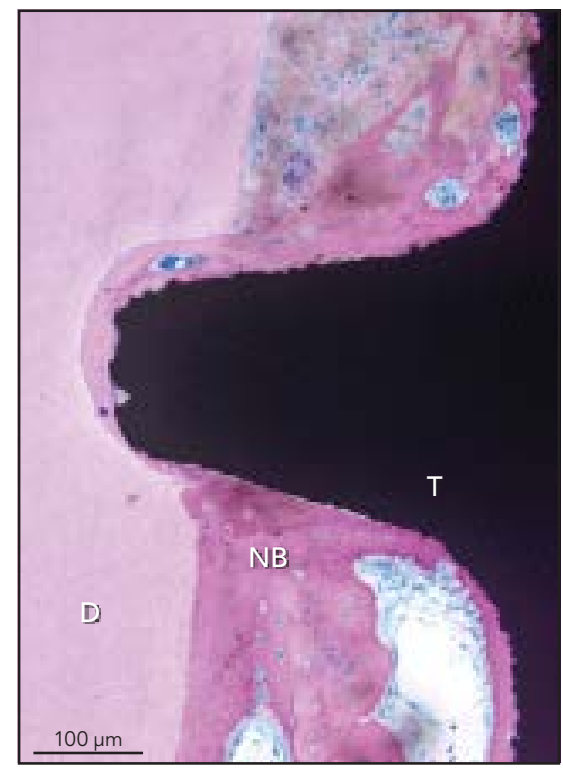

Fig 10 New bone (NB) interposed between implant thread $(T)$ and dentin of socketshield (D) $(100 \mu \mathrm{m})$. Image reprinted by permission of Wiley Periodicals.

at the coronal root periphery that might cause perforation of the overlying soft tissues. Orthodontic tooth movement may also later present a challenge if tooth roots are moved into a submerged root. Alternatively, the root may spontaneously overerupt. In the absence of pathology or infection, the coronal aspect may be reprepared and resubmerged.

\section{Managing Complications}

The totality of possible complications cannot yet be known. The following, however, may guide the clinician toward better application of PET and management of possible complications. With the socketshield as with other PET, the retained tooth root section must be free of 

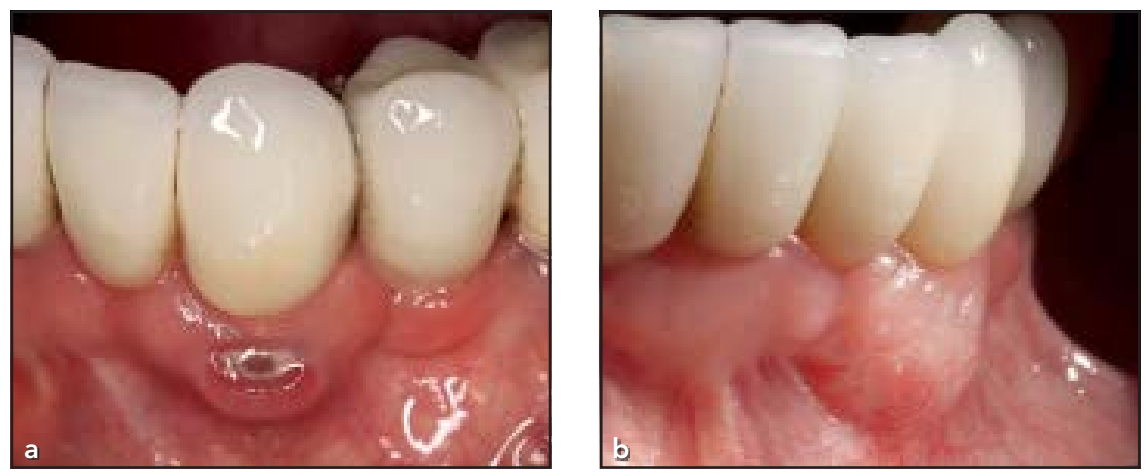

sharp edges. Sharp edges and overextension above the alveolar crest may result in exposure through the soft tissue. The root section may be reduced and reshaped to manage such a complication. Primary closure should again be achieved, or intimate contact between the soft tissue and the restoration ensured. Exposure of the coronal aspect of the root section in the absence of any other pathology should be scrutinized if overextending the 1-mm supracrestal guideline. Reduction of the socket-shield and soft tissue closure may adequately treat this complication without loss of the implant or the socket-shield (Fig 11). Any exposure in the absence of additional pathology may be managed by soft tissue closure-by advancing the overlying soft tissue for primary closure, CTG, rotated flap, or free gingival graft, in accordance with the clinician's preference and skill set.

In PET cases where infection of the root section is coupled with mobility, removal is mandatory. The site may then be managed as for any other recession complication around implants, highlighting the advanced skill and experience required to carry out these techniques. In the unlikely event of endodontic inflammation subsequent to root submergence, the clinician may select a root canal procedure and resubmergence in lieu of extraction, if access to the canal can be achieved. Mobility of a socket-shield adjacent to an implant or of a pontic shield always necessitate its removal. If the implant fails to osseointegrate but the socket-shield is stable, immobile, and free of infection, the implant may be removed and the site closed and left to heal before reevaluation as a pontic shield site, or treatment may be reattempted at implant placement.

\section{Conclusions}

The partial extraction therapies are a highly promising set of techniques that may significantly alter future management of the failing dentition and postextraction ridge, viz a paradigm shift from extract and augment to salvaging the patient's own tissues where possible. Of equal
Fig 11 (a) Overextended socket-shield resulted in perforation that when reduced (b) allowed for healing and closure of the soft tissues. importance are the degree of advanced knowledge and experience required to apply these therapies and the need for more abundant histologic evidence and long-term data to refute or support their use in established clinical practice. The present technical report provides clinicians with the information needed to contribute to the growing literature.

\section{Acknowledgments}

The authors reported no conflicts of interest related to this study.

\section{References}

1. Fürhauser $R$, Florescu $D$, Benesch $T$, Haas R, Mailath G, Watzek G. Evaluation of soft tissue around single-tooth implant crowns: The pink esthetic score. Clin Oral Implants Res 2005;16:639-644.

2. Esposito M, Grusovin MG, Felice $P_{1}$ Karatzopoulos G, Worthington HV, Coulthard P. The efficacy of horizontal and vertical bone augmentation procedures for dental implants-A Cochrane systematic review. Eur J Oral Implantol 2009;2:167-184. 
3. Hermann JS, Buser D, Schenk RK, Higginbottom FL, Cochran DL. Biologic width around titanium implants. A physiologically formed and stable dimension over time. Clin Oral Implants Res 2000;11:1-11.

4. Chen ST, Buser D. Esthetic outcomes following immediate and early implant placement in the anterior maxilla: A systematic review. Int J Oral Maxillofac Implants 2014;29(suppl):s186-s215.

5. Nanci A. Periodontium. In: Nanci A, Ten Cate R (eds). Ten Cate's Oral Histology, ed 8. St Louis: Mosby, 2013;228-229.

6. Chen ST, Buser D. Clinical and esthetic outcomes of implants placed in postextraction sites. Int J Oral Maxillofac Implants 2009;24(suppl):s186-s217.

7. Gluckman H, Salama M, Du Toit J. Partial extraction therapies (PET). Part 1: Maintaining alveolar ridge contour at pontic and immediate implant sites. Int J Periodontics Restorative Dent 2016; 36:681-687.

8. Salama M, Ishikawa T, Salama $H$, Funato A, Garber D. Advantages of the root submergence technique for pontic site development in esthetic implant therapy. Int J Periodontics Restorative Dent 2007; 27:521-527.
9. Hürzeler MB, Zuhr O, Schupbach P, Rebele SF, Emmanouilidis N, Fickl S. The socket-shield technique: A proof-ofprinciple report. J Clin Periodontol 2010; 37:855-862.

10. Gluckman H, Du Toit J, Salama M. The pontic-shield: Partial extraction therapy for ridge preservation and pontic site development. Int J Periodontics Restorative Dent 2016;36:417-423.

11. Kwok V, Caton JG, Polson AM, Hunter PG. Application of evidence-based dentistry: From research to clinical periodontal practice. Periodontol 2000 2012; 59:61-74.

12. Siormpas KD, Mitsias ME, KontsiotouSiormpa E, Garber D, Kotsakis GA. Immediate implant placement in the esthetic zone utilizing the "root-membrane" technique: Clinical results up to 5 years postloading. Int J Oral Maxillofac Implants 2014;29:1397-1405.

13. Darby I, Chen ST, Buser D. Ridge preservation techniques for implant therapy. Int J Oral Maxillofac Implants 2009; 24(suppl):s260-s271.
14. Comut A, Mehra M, Saito H. Pontic site development with a root submergence technique for a screw-retained prosthesis in the anterior maxilla. J Prosthet Dent 2013;110:337-343.

15. Araújo MG, Linder E, Lindhe J. Bio-Oss collagen in the buccal gap at immediate implants: A 6-month study in the dog. Clin Oral Implants Res 2011;22:1-8.

16. Bäumer D, Zuhr O, Rebele S, Schneider $D$, Schupbach $P$, Hürzeler M. The socket-shield technique: First histological, clinical, and volumetrical observations after separation of the buccal tooth segment-A pilot study. Clin Implant Dent Relat Res 2015;17:71-82.

\section{Erratum}

In the article by Sarmiento et al (A Classification System for Peri-implant Diseases and Conditions), in Volume 36, Number 5 (September/ October), 2016, a correction is needed to Table 1. For "Peri-implantitis induced by extrinsic pathology," the correct definition is "Implants that present with bone loss caused by an unrelated pathology, systemic disease, and/or periapical pathology migration to an implant." 
Copyright of International Journal of Periodontics \& Restorative Dentistry is the property of Quintessence Publishing Company Inc. and its content may not be copied or emailed to multiple sites or posted to a listserv without the copyright holder's express written permission. However, users may print, download, or email articles for individual use. 